\title{
II. \\ Herbst 1938 - Herbst 1939: Europas Weg in den Krieg
}

\section{Hitlers Bruch des Münchner Abkommens}

Nichts hätte von den kontinentaleuropäischen Realitäten weiter entfernt sein können als die Erwartung, die Neville Chamberlain mit Erlebnis und Ergebnis der Münchner Konferenz verband. Sein Gegenspieler Adolf Hitler, nach der Annexion Österreichs und der Sudetengebiete „Führer" nicht mehr des Deutschen, sondern des "Großdeutschen“ Reiches, dachte gar nicht daran, einen Part in einem Quartett europäischer Großmächte zu übernehmen und Deutschland dadurch abermals in das Geflecht eines multilateralen internationalen Systems einbinden zu lassen, das ständig Abstimmung mit den Partnern erfordert und mithin bestenfalls nur kleine oder halbe Schritte einer in seinem Sinne aktiven Außenpolitik erlaubt hätte. Die Erfahrung von München war ihm in dieser Hinsicht eine so bittere Lehre, daß er gegen jede multilaterale internationale Konferenz eine unüberwindliche Abneigung faßte, von der Institution häufiger und womöglich mit einer gewissen Regelmäßigkeit stattfindender Konferenzen ganz zu schweigen. Aber Hitler reagierte auf München ohnehin ganz anders als der britische Premier, und zwar reagierte der „Führer" auf eine Weise, die nun in der Tat, wie das Beobachter mit den scharfen Augen eines Harold Nicolson jetzt mit Recht befürchteten, einen erneuten großen europäischen Krieg zur Gewißheit, ja die sogar den baldigen Beginn eines solchen Krieges unausweichlich machte. Neville Chamberlain gehörte einer Familie an, die seit mehr als einem Jahrhundert im Wirtschaftsleben und in der Kommunalpolitik Birminghams eine prominente Rolle spielte, seit Generationen auch im Londoner Unterhaus und in den Regierungen des Landes; Neville war, wie sein Vater Joseph Chamberlain, nicht allein einer der Führer der britischen Konservativen und Minister gewesen, sondern auch, von sieben Jahren als Farmer auf den Bahamas abgesehen, Fabrikant und Bürgermeister von Birmingham. Er lebte in einer Tradition, die, auf dem Boden einer eigentümlich englischen Mischung aus christlicher Religiosität, Geschäftssinn und Engagement für das Gemeinwohl, von Werten geprägt war wie Vernunft und Nüchternheit, wie Redlichkeit und Kompromißbereitschaft, wie Verantwortung und Fairness; die Phantasma- 
gorien, die den „Führer“ im Herbst 1938 bewegten, hătte Chamberlain sicherlich mit fassungs- und ratlosem Entsetzen aufgenommen, wären sie ihm bekannt geworden.

Hitler sah zunächst einmal, daß ihm das Münchner Abkommen ein lediglich „halberledigtes machtpolitisches und strategisches Problem" hinterlassen habe, das er, um dem "geschlossenen Aufmarschraum“ gegen die östlichen Eroberungsziele näher zu kommen, bald endgültig bereinigen zu müssen glaubte119. In dieser Hinsicht verstand er München als überaus lästigen Aufenthalt auf der Bahn zu wahrhaft expansionistischer Politik. Da er sich während der Sudetenkrise und in München mehrmals in den taktischen Zwang manövriert hatte, öffentlich allen Ansprüchen auf Herrschaft über fremde Völker ausdrücklich abzuschwören, empfand er das Münchner Abkommen auch, wie Staatssekretär v. Weizsäcker die Stimmung in der Reichskanzlei beschrieb, als zusätzliche Schwierigkeit beim Übergang von der revisionistischen Politik, die noch irgendwie mit dem Nationalstaatsprinzip und dem Selbstbestimmungsrecht der Völker gerechtfertigt werden konnte, zum schieren und offenen Imperialismus ${ }^{120}$; namentlich der eigenen Nation gegenüber durfte man keinesfalls zum „Gefangenen des Volkstumsprinzips" werden ${ }^{121}$. Andererseits hatte ihm selbst und dem Deutschen Reich doch auch die halbe Lösung von München einen enormen Gewinn an Prestige und einen beträchtlichen Zuwachs an realer Macht und Kraft eingebracht: Frankreichs mitteleuropäischer Bündnispartner war nicht nur als potentieller Feind ausgeschaltet, sondern hatte praktisch bereits die Fähigkeit zu jeglichem eigenständigen außenpolitischen Handeln verloren; nach der Annexion Österreichs und der Sudetengebiete zählte das Reich rund 10 Millionen mehr Einwohner, was eine fühlbare und auch sofort eingeleitete Verstärkung der Armee erlaubte; die agrarische und industrielle Basis der deutschen Produktivkräfte war deutlich breiter geworden. Hitler fand sich so auf einen Punkt gehoben, der ihm einen berauschenden Rundblick bot, und zwar wirkten die diversen Eroberungsziele, die er sich gesetzt hatte, jetzt nicht nur noch verlockender als bisher, sondern auch schon zum Greifen nah. Mehr denn je war er entschlossen, zur „Überwindung der Raumnot“ über die „ethnographischen Grenzen des Deutschtums" hinauszugehen, und klarer denn je dachte er nun an einen baldigen Beginn der Eroberung. Gewiß gab es, so flüsterten sich nach Hitlers Rede vom 10. November die Auguren der Partei zu, „keine festliegende Speisekarte“, deren „erste Gänge Österreich und die Tschechoslowakei waren und auf der nach festliegender Reihenfolge noch andere Gerichte stehen“, aber „die räumliche Tendenz als solche“ lag erkennbar fest ${ }^{122}$. Für

119 Booms, Der Ursprung des 2. Weltkriegs, S. 340.

120 L. Hill (Hrsg.), Die Weizsäcker-Papiere 1933-1950, Frankfurt-Berlin-Wien 1974, S. $150 \mathrm{f}$.

121 H. Booms, Der Ursprung des 2. Weltkriegs, S. 341.

122 Ebenda, S. 341, 353. 
Hitler selbst stellte sich in diesem Zusammenhang vor allem die Frage, ob er bei der Verwirklichung seines imperialistischen Programms die in früheren Jahren für die Stoßrichtung ins Auge gefaßten Prioritäten und die drei Jahre zuvor noch so erreichbar scheinenden alten Bündniskonzepte beibehalten könne oder ob er nicht vielmehr, nach den Eindrücken von der britischen Grundhaltung in deutschen und europäischen Problemen, wie sie während der Sudetenkrise und auf der Münchner Konferenz zu gewinnen waren, zu einer radikalen Korrektur der - um es militärisch auszudrücken - operativen Planung seiner Eroberungspolitik gezwungen sei. Seine Unterschriften auf dem Münchner Abkommen und auf der deutsch-britischen Konsultationsvereinbarung waren noch nicht recht trocken, da traf der „Führer" denn auch bereits Anstalten, das Abkommen möglichst rasch zu überwinden und dabei aus der in seinem Verständnis eigentlichen Lehre von München möglichst rasch die praktische Nutzanwendung zu ziehen.

Daß er die halbe Lösung von München ehebaldigst komplettieren werde, hat Hitler schon in den ersten Tagen und Wochen nach der Unterzeichnung des Abkommens häufig genug und vor den unterschiedlichsten $\mathrm{Zu}$ hörern erklärt. Nach einer Unterredung mit Hitler wußte z.B. General v. Reichenau, Oberbefehlshaber der gerade in die CSR einmarschierten 10. Armee, bereits am 3. Oktober, als er in einem Karlsbader Hotel in abendlicher Runde ein Glas Sekt nach dem anderen leerte und hochgestimmt die Spielerqualitäten des „Führers“ rühmte, zu berichten, daß dieser „entschlossen sei, in absehbarer Zeit die Lösung der Gesamt-Tschechei herbeizuführen. Es sei nur das erste Stadium jetzt erreicht worden."123 Als Voraussetzung mußte zunächst einmal den Westmächten klargemacht werden, daß die CSR nun in einem Hinterhof des Großdeutschen Reiches liege und daß von einem westlichen Mitspracherecht in den Angelegenheiten dieses Hinterhofs, an das man in London und Paris offenbar noch immer glaube, natürlich keine Rede mehr sein könne.

Auf Grund der Münchner Vereinbarung war aus Staatssekretär v. Weizsäcker und den Berliner Botschaftern Italiens, Frankreichs und Großbritanniens ein Internationaler Ausschuß gebildet worden, der, unter Beteiligung Vojtech Mastnys, des Berliner Gesandten der CSR, die neue Grenze zwischen Deutschland und der restlichen Tschechoslowakei festzulegen hatte; ein Unterausschuß, bestehend aus den Berliner Militärattachés der drei Münchner Partner von Deutschland, tschechoslowakischen Offizieren und Vertretern von $\mathrm{OKH}$ und $\mathrm{OKW}$, war für den Transfer und die Besetzung der abgetretenen Zonen zustāndig. Daß sich einige der deutschen Militärs wie "Sieger nach einer gewonnenen Schlacht" - so das tadelnde Urteil Weizsäckers ${ }^{124}$ - benahmen und daß auch Weizsäcker selbst sowohl Mastny wie vor allem den drei Botschaftern mit Schärfe und oft ultimativer Rück- 
sichtslosigkeit entgegentrat, war keineswegs allein - und bei Weizsäcker überhaupt nicht - als Ausbruch teutonischen Siegestaumels zu verstehen, sondern, auf Weisung Hitlers, als ein Akt der Politik ${ }^{125}$ : Den Tschechen wie den Westmächten sollte demonstriert werden, daß in diesem Teil Europas nur noch Deutschland politische Entscheidungen treffe. Tatsächlich ermatteten die drei Botschafter, und die definitive Grenzziehung wurde einem Deutsch-Tschechoslowakischen Ausschuß überlassen, in dem die deutschen Repräsentanten - offenbar ohne sich dabei an die eigenen Klagelieder über das „Diktat von Versailles“ zu erinnern - nahezu ausschließlich mit Ultimaten arbeiteten. Die Tschechen wagten es bereits nicht mehr, offen an die Westmächte oder Italien zu appellieren; „streng vertraulich“ unterrichtete Mastny am 17. November 1938 den britischen Geschäftsträger, Sir George Ogilvie-Forbes, über deutsche Forderungen, die über die Münchener Vereinbarung hinausgingen und eine beträchtliche Anzahl von Tschechen unter deutsche Herrschaft brächten. Am 21. November kam Karl Ritter, früher Botschafter in Rio de Janeiro, jetzt zur besondern Verwendung im Auswärtigen Amt und in Abwesenheit Weizsäckers Vorsitzender des Internationalen Ausschusses, zu Sir George und teilte ihm mit, daß der Ausschuß noch am selben Abend zusammentreten und die „zwischen Tschechen und Deutschen vereinbarte“ - d.h. die den Tschechen ultimativ abgepreßte - Grenze sanktionieren müsse; er fügte hinzu, daß die Sitzung des Ausschusses „kurz und natürlich reine Formsache“ sein werde. Und so geschah es denn auch. Am folgenden Tag charakterisierte selbst Chamberlain das Resultat dieser "direkten deutsch-tschechischen Verständigung“ als einen „Kompromiß, bei dem die Tschechen alles konzediert und nichts gewonnen“ hätten. „Das Resultat ist beklagenswert", setzte er seinen Kabinettskollegen auseinander, „doch konnten wir in der Sache nicht mehr tun." Der Schlußsatz zeigt, wie gut die deutsche Rechnung aufgegangen war.

In ähnlichem Stil und mit gleichem Zweck behandelte Hitler auch die Ansprüche Ungarns an die CSR. In München war vereinbart worden, daß die vier Vertragsmächte die Garantie der neuen deutsch-tschechoslowakischen Grenze aussprechen müßten, sobald die Forderungen befriedigt seien, die neben Deutschland auch Polen und Ungarn an die CSR stellten. Polen, das in den Wochen und Tagen vor München sogar zu einer Beteiligung an einem deutschen Feldzug bereit gewesen war, hatte sich schon selbst bedient und mit einem Ultimatum vom 1. Oktober Prag das Teschener Gebiet abgepreßt. Ungarn hingegen, bis zum Münchner Abkommen doch zu vorsichtig, um sich offen als Verbündeter Deutschlands gegen die CSR zu deklarieren und dadurch womöglich in einen großen europäischen Krieg verwickelt zu werden, verlangte die Erfüllung seiner territorialen Ansprüche an die CSR, nämlich die Karpatho-Ukraine und im Grunde auch 
die Slowakei, erst nach der Münchner Konferenz, jetzt aber um so hartnäkkiger. Hitler, der die weise ungarische Zurückhaltung zu den Faktoren rechnete, die ihn um seine böhmische Kampagne gebracht hatten, und der folglich bei jeder Erwähnung der Magyaren Gift und Galle spuckte, hätte Budapest am liebsten nicht einen Quadratmeter überlassen. Doch erstens war auch von ihm grundsätzlich anerkannt worden, daß Ungarn Forderungen stellen dürfe, und zweitens ließ die Budapester Regierung nicht locker. So nützte Hitler, statt von den Magyaren am Ende wieder die Westmächte ins Spiel ziehen zu lassen, die Gelegenheit, um ganz im Gegenteil abermals die alleinige Zuständigkeit des Großdeutschen Reiches in dieser Region darzutun. Ohne die Westmächte auch nur zu informieren, zwang Hitler im Bunde allein mit Italien, das er jetzt schon praktisch zur Preisgabe seiner traditionellen Rolle als Protektor Ungarns und zur Übernahme einer Rolle als Werkzeug der Berliner Politik nötigen konnte - die ungarische Regierung dazu, auf die Karpatho-Ukraine vorerst zu verzichten und sich mit relativ bescheidenen slowakischen Territorien zu begnügen, die ein deutsch-italienischer Schiedsspruch, am 2. November in Wien gefällt, zuteilte. Wiederum war es Hitler gelungen, die Westmächte zu bloßen $\mathrm{Zu}-$ schauern zu machen. Es versteht sich, daß er sich auch nach dem „Wiener Schiedsspruch", obwohl nun die in München postulierte Voraussetzung für die Garantierung der Rumpf-Tschechoslowakei gegeben war, beharrlich weigerte, öffentlich die Unverletzlichkeit des verstümmelten Staates zu erklären, womit er die Vier-Mächte-Garantie ebenfalls blockierte und so auch in dieser Frage die beiden Westmächte - wie Italien - aus den tschechoslowakischen Angelegenheiten aussperrte.

Daß Hitler den Ungarn die Karpatho-Ukraine und den größten Teil der Slowakei vorenthielt, hatte indes noch andere Gründe. So entschlossen der "Führer“ war, die Rumpf-Tschechoslowakei möglichst bald deutscher Herrschaft zu unterwerfen, so sah er auf der anderen Seite doch ein, daß er das Münchner Abkommen wenigstens etliche Monate alt werden lassen mußte, ehe er zum entscheidenden Coup gegen Prag ausholte. Konnte aber erst in vier oder sechs Monaten wieder gehandelt werden, dann war es doch wohl, wie er dachte, erneut notwendig, dem Überschreiten der tschechoslowakischen Grenze jenen Schein von Plausibilität zu geben, der geeignet sein mochte, die internationale Kritik zu dämpfen und anderen Mächten die Neigung zum Eingreifen zu nehmen, der es also der Welt erleichtern sollte, sich abermals mit einem deutschen Streich abzufinden: Wie 1938 wurde sowohl eine zur Intervention einladende innere Krise der CSR gebraucht wie eine der richtigen „Internationalisierung“ dienende Begleitung der ordnungstiftenden deutschen Aktion durch den einen oder anderen befreundeten Staat. Für diese beiden Zwecke waren die Karpatho-Ukraine und die Slowakei unentbehrlich ${ }^{126}$. Angesichts der veränderten Machtlage 126 G. Weinberg, The Foreign Policy of Hitler's Germany. Starting World War II 1937-1939, Chicago-London 1980, S. $470 \mathrm{ff}$. 
konnte den Ungarn die Mitwirkung an der Liquidierung der CSR jetzt sicherlich einfach befohlen werden, doch natürlich nur dann, wenn bei Gehorsam eine genügend fette Beute winkte, und so hatte die KarpathoUkraine aufgespart zu werden und bis zum endgültigen Schlag gegen Prag im tschechoslowakischen Staatsverband zu verbleiben, dabei seit dem 17. November mit Autonomie ausgestattet. Die Slowakei hingegen - ebenfalls seit dem 17. November autonom, weshalb im deutschen Sprachgebrauch nun statt Tschechoslowakei die Bezeichnung Tschecho-Slowakei benutzt wurde - durfte auch später nicht den Magyaren überlassen werden. Hitler wollte nämlich den slowakischen Nationalismus und die tschechisch-slowakischen Spannungen als Sprengsatz zur Zerstörung der CSR benutzen. Wie Anfang 1938 die österreichische NSDAP und dann Konrad Henleins Sudetendeutsche Partei sollten nun die Führer der slowakischen Autonomiebewegung, die kräftige faschistische Elemente aufwies, dazu gebracht werden, zum gewünschten Zeitpunkt jene innere Krise in dem ins Visier genommenen Staat auszulösen, die zur Begründung der Grenzüberschreitung deutscher - und ungarischer - Truppen für erforderlich gehalten wurde.

So begann schon in den ersten Tagen und Wochen nach der Münchner Konferenz die Arbeit an der Anknüpfung und Festigung engerer Beziehungen zu etlichen slowakischen Politikern, und bereits am 16. Oktober gipfelte die Arbeit in einer Unterhaltung zwischen einem der seit München amtierenden neuen slowakischen Minister, Dr. Ferdinand Durcansky, und Generalfeldmarschall Hermann Göring, dem nach Hitler zweiten Mann des NS-Regimes und in dieser Funktion wie als Oberbefehlshaber der Luftwaffe und als Beauftragter für den Vierjahresplan mit weitreichenden auch außenpolitischen - Exekutivkompetenzen ausgerüstet. Wie sein Begleiter Sano Mach, Propagandachef der jungen slowakischen Regierung, gehörte Durcansky zum faschistischen rechten Flügel der slowakischen Bewegung, und mit großer Geste - doch nur für eine kleine Minderheit sprechend - versicherte er Göring, die Slowaken strebten nach der - natürlich vom Deutschen Reich zu schützenden - vollen Selbständigkeit. Göring gab danach die Parole aus: „Bestrebungen der Slowaken auf Selbständigkeit in geeigneter Weise unterstützen. “127 Tatsächlich fiel in jenen Tagen ein Schwarm deutscher Emissäre in der Slowakei ein, die nun alle, vom Diplomaten über den Vertreter der NSDAP bis zum Agenten des SD, des Sicherheitsdienstes der SS, eifrig daran wirkten, möglichst viele slowakische Politiker gegen Prag „einzustellen“ und für die Politik des Reiches verfügbar zu machen. Gleichzeitig wurde den Magyaren mehrmals bedeutet, daß sie sich die Slowakei aus dem Kopf schlagen sollten, und mehrmals, so vom 18. bis zum 20. November, wurde ihnen auch die beabsichtigte Besetzung der Karpatho-Ukraine als verfrüht strikt untersagt, wobei sich Mussolini von Berlin abermals die wenig ruhmvolle Aufgabe zuteilen ließ, seinen 
ungarischen Schützlingen klarzumachen, daß sie den Willen des „Führers“ nicht ignorieren dürften ${ }^{128}$.

Angesichts der eindeutigen Absichten Hitlers und angesichts des ebenso eindeutigen Charakters der politischen Akte, die schon unmittelbar nach München die Verwirklichung der Absichten vorbereiteten, wirken selbst jene Überlegungen mittlerer deutscher Funktionäre noch rührend, die der reduzierten Tschechoslowakei zwar die absolute Unterordnung unter die politische Vormundschaft des Deutschen Reiches zumuten, ihr aber immerhin auf Dauer die formale staatliche Selbständigkeit belassen wollten. Am 25. November legte Ministerialdirektor Gaus, Leiter der Rechtsabteilung im Auswärtigen Amt, den Entwurf eines "Freundschaftsvertrages“ zwischen Berlin und Prag vor, in dessen Artikel 1 es sogar hieß: „Das Deutsche Reich übernimmt die Garantie für die Integrität und Unverletzlichkeit des tschechoslowakischen Staatsgebiets und wird, falls diese Integrität und Unverletzlichkeit von dritten Mächten gefährdet werden sollte, der Tschechoslowakischen Republik seinen Beistand gewähren." ${ }^{129}$ Am 9. Dezember folgte Karl Ritter, im Auswärtigen Amt jetzt kommissarisch für wirtschaftliche Fragen zuständig, mit dem zum Gaus-Papier passenden Entwurf für eine deutsch-tschechoslowakische "Wirtschaftsunion"130. Hitler hatte für derlei Versuche, den Schein zu wahren und den Geschlagenen auch tatsächlich Atemraum zu lassen, keinen Sinn. Sein Wesen, sein Verständnis von Politik und seine Zielsetzung machten es ihm unmöglich, sich mit Einfluß, und sei er noch so groß, zu begnügen, er mußte nach Herrschaft trachten. Weit davon entfernt, den im Auswärtigen Amt ersonnenen Rezepten für die künftige Behandlung der CSR Beachtung zu schenken, gaben sich der "Führer" und Ribbentrop vielmehr Mühe, noch ein weiteres Element des taktischen Konzepts der Sudetenkrise im Spiel zu halten: die Diskreditierung der CSR, die Stilisierung des in Wahrheit schwachen Opfers zum gefährlichen Feind.

František Chvalkovsky, zuvor tschechoslowakischer Gesandter in Rom und nach München zum Außenminister der CSR ernannt, hatte am 6. Oktober, kurz vor seiner Abreise aus der italienischen Hauptstadt, dem dortigen deutschen Botschafter Hans Georg v. Mackensen gesagt, daß er so bald wie möglich von Hitler und Ribbentrop empfangen werden wolle, um sich von ihnen "gleichsam die Richtschnur seines Handelns" zu holen"131, und als er am 14. Oktober tatsächlich mit Hitler sprechen konnte, hat er in der Tat die vollständige Unterwerfung seiner Republik unter die deutsche Füh-

128 Weinberg, The Foreign Policy of Hitler's Germany, S. 477; J. Hoensch, Der ungarische Revisionismus und die Zerschlagung der Tschechoslowakei, Tübingen 1967.

129 H. Bodensieck, Der Plan eines „Freundschaftsvertrages" $z$ wischen dem Reich und der Tschecho-Slowakei im Jahre 1938, in: Zeitschrift für Ostforschung 10 (1961), S. $464 \mathrm{ff}$.

130 Ebenda.

131 ADAP, D, 4, Nr. 37. 
rung zugesichert, sowohl hinsichtlich der internationalen Orientierung wie hinsichtlich der Wirtschaftspolitik, und gleich auch noch die Anpassung des politischen Systems und der Innenpolitik angekündigt; er gelobte sogar die Übernahme des reichsdeutschen Antisemitismus 132. Andere Prager Politiker äußerten in Gesprächen mit Deutschen die gleiche Kollaborationsbereitschaft, und solchen Worten folgten in der CSR durchaus Taten. Es symbolisierte die Entwicklung, daß Dr. Eduard Beneš, der Staatspräsident, am 5. Oktober von seinem Amt zurücktrat und von Emil Hacha abgelöst wurde, seit 1925 Präsident des Obersten Verwaltungsgerichts in Prag. Beneš hatte zusammen mit T.G. Masaryk zu den Gründervätern der CSR gehört und von 1918 bis 1935, als er an die Stelle des am 14. Dezember 1935 aus dem Amt des Staatspräsidenten geschiedenen Masaryk trat, ununterbrochen als Außenminister fungiert. Nachdem Masaryk am 14. September 1937 gestorben war, durfte Beneš als die Personifizierung der tschechoslowakischen Staatsidee gelten, und abgesehen davon, daß er zeitlebens für den Völkerbundsgedanken und das Prinzip der kollektiven Sicherheit gestanden hatte, war er auch einer der Architekten der Kleinen Entente gewesen. $\mathrm{Daß}$ er das Feld räumen mußte, und zwar einem im Grunde gänzlich unpolitischen Verwaltungsrichter, stellte eine Geste des Abschieds von der tschechoslowakischen Selbständigkeit und einen Akt der Unterwerfung dar.

Die Deutschen, von Hitler angefangen, nahmen aber solche Zeichen und die Gehorsamsschwüre der neuen Vertreter Prags keineswegs mit Befriedigung oder gar Wohlwollen auf, schoben vielmehr derlei Bekundungen und Beteuerungen ungeduldig beiseite, um dann mit großer Eindringlichkeit das Risiko zu beschwören, das die tschechischen Politiker eingingen, wenn sie die Fortdauer oder das Wiederaufleben des „Beneš-Geistes“ zulieBen. Als Chvalkovsky am 21. Januar 1939 erneut nach Berlin kam, machte ihm Hitler bereits recht ominös klingende Vorwürfe: „Es habe in der Tschechoslowakei bis jetzt noch keine gründliche Säuberung der Vertreter der Benesch-Tendenzen stattgefunden. Diese wirkten weiter und hätten ihre Position eigentlich in der letzten Zeit verstärkt." Er benutzte Wendungen wie "Vernichtung der Tschechoslowakei“ und sagte dann, „wenn die Tschechoslowakei immer noch glaube, einmal ein Instrument gegen Deutschland sein zu können, so sei das katastrophal, und zwar nicht für Deutschland, sondern für die Tschechoslowakei“133. Die behauptete Mühelosigkeit der „Vernichtung der Tschechoslowakei“ und die demgemäß behauptete Hilflosigkeit der CSR gegen eine deutsche Aktion stimmten ja wenig zu der ebenfalls stets wiederholten Behauptung, eine ungehorsame und deutschfeindliche Tschechoslowakei sei für das Deutsche Reich eine unerträgliche Gefahr, doch derartige Widersprüche störten Hitler nicht.

132 Ebenda, Nr. 61.

133 Ebenda, Nr. 158, 159. 
Schon in der Unterredung vom 14. Oktober hatte er Chvalkovsky gedroht, falls die CSR wieder zu einer Bedrohung Deutschlands werden sollte, „mache ich in 24 Stunden - nein in 8 Stunden - Schluß “. Dem entsprach exakt seine militärische Planung. Am 21. Oktober befahl er der Wehrmacht, Vorbereitungen zu treffen, um "die Rest-Tschechei jederzeit zerschlagen zu können“, und in dieser „Führer-Weisung“ war festgelegt, daß der Schlag gegen die „Rest-Tschechei „überfallartig“ zu erfolgen und eine „rasche Besetzung" des Landes zu gewährleisten habe ${ }^{134}$. In einem Nachtrag vom 17. Dezember wurde die Verzahnung mit der politischen Taktik noch deutlicher gemacht. Im Auftrag Hitlers untersagte darin der Chef des OKW, General Keitel, jede vorbereitende Mobilmachungsmaßnahme, da „nach auBen klar in Erscheinung treten" müsse, "daß es sich nur um eine Befriedungsaktion und nicht um eine kriegerische Unternehmung handelt" $" 135$.

In Hitlers Augen war die "Rest-Tschechei“" freilich nur ein Randproblem, das nach einer gewissen Anstandsfrist und bei leidlicher politischer Inszenierung des notwendigen Coups ohne sonderliche Schwierigkeiten erledigt werden konnte. $\mathrm{Zu}$ General v. Reichenau hatte er kurz nach München gesagt, er werde auch „an anderen Stellen weiterarbeiten und aktiv sein“, und tatsächlich beschäftigte er sich seit dem bitteren Triumph von München vornehmlich - so wie Staatssekretär v. Weizsäcker dann im Dezember gegenüber Ulrich v. Hassell klagte - mit der Frage, in welche Richtung er den Expansionismus des nationalsozialistischen Deutschland zuerst lenken solle: Nach Osten oder vielleicht doch nach Westen? Mit Recht ging er dabei, ohne an das Problem seiner Autorität einen einzigen Gedanken zu verschwenden, davon aus, daß es allein seine Sache sei, die Antwort auf die gestellte Frage zu finden. Es wäre nun überaus merkwürdig gewesen, hätte er dem Osten, bislang als wichtigeres Angriffsobjekt angesehen, dem auch im zeitlichen Ablauf Priorität zukomme, abrupt den Rücken gekehrt und seinen Blick ganz nach Westen gerichtet. So setzte denn auch im Herbst 1938 eine lebhafte Tätigkeit deutscher Emissäre in der KarpathoUkraine ein, die dort und von dort aus - zur Vorbereitung größerer Operationen im Osten - den ukrainischen Nationalismus zu stimulieren suchten. In etlichen Gesprächen mit polnischen Diplomaten und dem polnischen Außenminister Beck machten Ribbentrop und Göring außerdem klar, daß neben sowjetischen Territorien auch schon die baltischen Länder - weit über das ohnehin bald fällige Memelgebiet hinaus - ins Visier geraten waren ${ }^{136}$.

134 Ebenda, Nr. 81; Documents on British Foreign Policy (DBFP), Serie III, Bd. 3, Nr. 251.

135 ADAP, D, 4, Nr. 152.

136 APA, Poln. Botschaft Berlin, Mappe 18, Lipski-Göring, 10.8.1938, Mappe 19, LipskiRibbentrop, 27.9.1938; Josef Lipski, Diplomat in Berlin 1933-1939, New York-London 1968, S. $453 \mathrm{ff}$. 
Dennoch und obwohl Hitler bis tief ins Jahr 1939 hinein offensichtlich zu keiner rechten Klarheit kam, ergab sich doch zumindest eine andere Präferenz. Aus internen Erklärungen des „Führers“, so am 23. Mai 1939 vor den Spitzen des OKW wie der drei Wehrmachtteile137 und am 22. August 1939 vor einer größeren Anzahl von Generälen und Admirälen ${ }^{138}$, geht zweifelsfrei hervor, daß er zu der Ansicht gekommen war, den Zug nach Osten noch etwas aufschieben und zunächst klare Verhältnisse im Westen schaffen, d.h. das kontinentale Westeuropa deutscher Herrschaft unterwerfen und die politische Mitsprache Großbritanniens in kontinentaleuropäischen Angelegenheiten mit militärischer Gewalt liquidieren zu müssen. Am 22. August sagte er zum Beispiel, daß er noch im Frühjahr geglaubt habe, sich „erst gegen den Westen wenden“ zu sollen, das Reich „zunächst gegen den Westen zu kämpfen" habe. Reichsaußenminister v. Ribbentrop hatte Admiral Wilhelm Canaris, dem Chef der Abwehr, bereits im Dezember 1938 eröffnet, daß der nächste Stoß gegen die Westmächte geführt werde 139 .

Der Grund für eine solche - immerhin doch radikale - Korrektur der operativen Expansionsplanung ist deutlich zu erkennen. Hitler hatte den Glauben daran verloren, den Marsch nach Osten ohne politische und militärische Einmischungsversuche der Westmächte antreten zu können. Vor allem meinte er mit dem Widerstand Großbritanniens rechnen zu müssen. Noch im Sommer 1935 hatte er auf das „ewige Bündnis“ mit England gehofft ${ }^{140}$, worunter er freilich immer nur die beiderseitige temporäre Anerkennung einer Grenze zwischen zwei Machtsphären verstand: dem nationalsozialistischen Deutschland war für eine Weile lang erst der Osten und anschließend der Westen des europäischen Kontinents zuzuschlagen, während Großbritannien für eine Weile lang noch die Weltmeere behalten sollte, dazu Indien, Kanada, Australien usw., Gibraltar, Malta, Ägypten etc. Im Herbst 1936 beklagte er sich aber bereits bitter über England: „Es will und will nicht. Seine Führung hat keinen Instinkt." 141 Immerhin spekulierte er noch einige Zeit darauf, daß er von London „freie Hand“ bekommen werde, wenn er - worauf er ja jahrelang baute - die Ausdehnung deutscher Herrschaft auf dem Kontinent als ordnungstiftende Intervention gegen offene Ausbrüche des Bolschewismus, etwa in Frankreich, deklarieren könne. Während der Sudetenkrise gewann er jedoch ein ganz anderes Bild von der britischen Politik. Von Anfang bis Ende hatte er es weit mehr mit den Briten zu tun gehabt als mit den Tschechen, und die Hartnäckigkeit, mit der ihn Chamberlain gezwungen hatte, Europas Wunsch nach Frieden zu respektieren und sich mit einem relativ bescheidenen territorialen $\mathrm{Ge}$ -

137 ADAP, D, 6, Nr. 433.

138 ADAP, D, 7, Nr. 192, 193.

139 Groscurth, Tagebücher eines Abwehroffiziers, S. 159.

140 Tagebücher von Joseph Goebbels, Bd. 2, S. 504.

141 Ebenda, S. 724. 
winn zu begnügen, ließ für die Zukunft Böses ahnen. Als die Krise ihrem Höhepunkt zuging, am 21. August 1938, erklärte Hitler intern - mit all der naiven und deshalb manchmal fast entwaffnenden Verlogenheit und Realitätsverfälschung, die für ihn typisch waren -, wie "gerne er mit England in ein gutes Verhältnis kommen möchte“ und daß er "auch alles dafür" tue: „Aber England steht unserem expansiven Drang im Wege." ${ }^{142}$ Zehn Tage später notierte Goebbels, seit Ende der zwanziger Jahre in außenpolitischen Dingen ein getreues Echo seines „Führers“: „London steht immer dem deutschen Interessenanspruch im Wege. So auch hier und diesmal. Es ist eine Schande, wie die Engländer immer germanische Interessen verraten und sich deutschem Ausdehnungszwang entgegenstellen. "143

Gewiß: In den Monaten der Krise und in den persönlichen Begegnungen mit Chamberlain und Daladier steigerte Hitler die Geringschätzung der westlichen Politiker, die er seit der schwächlichen Reaktion der Westmächte auf Mussolinis abessinisches Abenteuer empfunden hatte, zu offener Verachtung. „Chamberlain sei ein alter Mann, den er glatt in die Tasche stecke“, höhnte er kurz nach der Münchner Konferenz, und Daladier sei „ein kleiner Bäckermeister"144; gelegentlich nannte er seine Münchner Partner auch „kleine Würmchen"145. Auf der anderen Seite setzte sich bei ihm der Eindruck fest, daß, von der Verwirklichung des Gesamtprogramms ganz zu schweigen, auch schon die Expansion nach Osten auf britisch-französische Gegnerschaft treffen werde; dazu schloß er nicht mehr aus, daß Briten und Franzosen ein kriegerisches Engagement des Reiches im Osten zu einem militärischen Überfall nutzen könnten, um das zu mächtig gewordene Deutschland wieder niederzuwerfen und das verhaßte NS-Regime zu stürzen. Für beide Fälle hatte der Rücken frei zu sein. Ein erzwungener Abschied von Lieblingsideen verdrießt und verärgert. Hitler war daher im Herbst 1938 „auf die Engländer geladen“146, und diese Stimmung hat dann wiederum jene „staatsmännischen“ UUberlegungen plausibler erscheinen lassen und gefestigt, die in seinen Augen dafür sprachen, vor dem Aufbruch nach Osten die Verhältnisse im Westen zu bereinigen; daß dabei gleich auch die im Westen liegenden Ziele zu erreichen waren, die er dem Imperialismus des nationalsozialistischen Deutschland gesteckt hatte, stellte sicherlich einen zusätzlichen Reiz dar.

Im übrigen hat ihn sein Außenminister in seinem antiwestlichen und namentlich antibritischen Denken noch zu bestärken gesucht. Joachim v. Ribbentrop war wohl die unseligste Figur, die je irgendwo in das Amt des Außenministers gelangt ist ${ }^{147}$. Durch die Umstände und die Gunst eines

142 Tagebücher von Joseph Goebbels, Bd. 3, S. 514.

143 Ebenda, S. 524.

144 Groscurth, Tagebücher eines Abwehroffiziers, S. 134.

145 ADAP, D, 7, Nr. 192, 193.

146 Tagebücher von Joseph Goebbels, Bd. 3, S. 536.

147 Vgl. dagegen W. Michalka, Ribbentrop und die deutsche Weltpolitik. 
mit diktatorischer Gewalt ausgestatteten Parteihäuptlings und Regierungschefs im Deutschen Reich an die Spitze des Auswärtigen Amts gestellt, betrachtete Ribbentrop die internationalen Beziehungen insgesamt und die einzelnen Fragen der Außenpolitik im Geiste und mit den Kategorien eines nationalistischen Stammtisch-Philisters. Er glich seinem Herm und Meister auch insofern, als er in der praktischen Außenpolitik selbst auf das bescheidenste Minimum an Geschäftsmoral verzichten zu können glaubte und zu äußerster Brutalität ebenso bereit war wie zu törichtester Treulosigkeit oder zu stupidesten Täuschungsmanövern, falls er sich davon einen momentanen Nutzen versprach. Doch fehlten ihm Hitlers Verstand, Hitlers taktische Talente und erst recht der Charme, den der „Führer“ einschalten konnte, wenn er ihn brauchte. Ohne eine einzige der Eigenschaften, die ein Diplomat haben sollte, auch nur ansatzweise zu besitzen, wurde seine Borniertheit vielmehr noch von einer eisigen und starren Arroganz übertroffen, die ihn sowohl für seine ausländischen Mit- und Gegenspieler wie für seine Gefährten in der Umgebung des „Führers“ zu einer Zielscheibe des Spotts und mehr noch zu einer Quelle ununterbrochener Irritationen machte, die ihm meist dauerhafte Feindschaften eintrugen. Mit Hitler gemeinsam waren ihm wiederum brennender Ehrgeiz, unstillbarer Machthunger und der Drang zum Krieg, dazu der glühende Wunsch, gestaltend an "historischen“ Ereignissen teilzunehmen und so ,in die Geschichte einzugehen"; die Gewißheit, daß sich letzterer Wunsch gerade erfülle, verleitete ihn dann zu allem Überfluß noch zu einem Gefühl der eigenen Bedeutung, das sich unweigerlich in Aufgeblasenheit und Wichtigtuerei äußerte. Als deutscher Botschafter in Großbritannien war er, durch sein humorloses, tölpelhaftes und taktloses Benehmen, ein gesellschaftlicher und politischer Mißerfolg gewesen, wie ihn die englische Hauptstadt seit langem nicht mehr erlebt hatte, und die Stars der gesellschaftlichen und der politischen Bühne Londons, etwa der gebildete, musische, elegante Anthony Eden, der, dekorierter Frontoffizier des Weltkriegs und gleichwohl leidenschaftlicher Anhänger des Völkerbunds, von 1935 bis 1938 AuBenminister gewesen war, haben ihre Geringschätzung dieses Repräsentanten des Deutschen Reiches nicht immer zu verbergen vermocht ${ }^{148}$; die Aufmerksamkeiten etlicher „Appeaser“ glichen das nicht aus.

So brachte Ribbentrop, als ihn der „Führer" am 4. Februar 1938 zum Reichsaußenminister ernannte, aus England keineswegs das von Hitler begehrte deutsch-britische Bündnis mit, sondern tief eingefressene anti-englische Ressentiments und die feste Uerzeugung, daß Großbritannien stets der Feind Deutschlands sei, und zwar der gefährlichste Feind, der sich den deutschen Ambitionen in den Weg stelle ${ }^{149}$. Unermüdlich predigte er seit-

148 R. Rh. James, Anthony Eden, London 1986.

149 W. Michalka, Joachim v. Ribbentrop und die deutsche Englandpolitik 1933-1940, Mannheim 1976. 
her seinem „Führer" schriftlich und mündlich, daß die Versuche, England zu gewinnen, zum Scheitern verurteilt seien, daß sich die Reichspolitik vielmehr darauf konzentrieren müsse, Großbritannien mit allen erreichbaren Mitteln unter Druck zu setzen, damit es wenigstens - in seinem derzeitigen Zustand militärischer Schwäche - einigen der kleineren Forderungen Deutschlands nachgebe, und daß sich die Führung des Reiches im übrigen besser auf die Notwendigkeit einstellen sollte, einen so unversöhnlichen Gegner des deutschen Aufstiegs zur Weltmacht eines Tages gewaltsam auszuschalten. Ob er bei dem Hitler des Jahres 1938 mit seinen Diagnosen und Prognosen nur noch offene Türen einrannte oder ob er, über die verstärkende Wirkung, die mit der Lieferung willkommener Bestätigungen verbunden sein kann, doch auch einen gewissen Einfluß ausübte, ist nicht zu erkennen. Jedenfalls begannen sich die Meinungen Hitlers und Ribbentrops zu decken. Als der „Führer“ am 23. Mai 1939 vor seinen engsten militärischen Mitarbeitern sprach, war seine Rede bereits ein einziger Versuch, die Soldaten auf einen Krieg gegen die Westmächte einzustimmen. Er wußte sehr wohl, wie sehr seine Zuhörer einen solchen Krieg fürchteten. Um so eindringlicher suchte er ihnen einzuhämmern, daß Deutschland „um ihn“ nicht „herum kommen“ könne: „England sieht in unserer Entwicklung die Fundierung einer Hegemonie, die England entkräften würde. England ist daher unser Feind, und die Auseinandersetzung mit England geht auf Leben und Tod." 150

Die diplomatischen Aktivitäten der deutschen Führung galten denn auch seit München weit mehr der Vorbereitung antiwestlicher Züge als der Inszenierung des zweiten Akts auf der tschechoslowakischen Bühne und der Einleitung noch größerer östlicher Unternehmungen. Im Zentrum solcher Vorbereitung standen energische und beharrliche Versuche, den Antikominternpakt zu einem deutsch-italienisch-japanischen Militärpakt auszubauen. In den Beziehungen zwischen den beiden europäischen Großmächten und dem japanischen Kaiserreich hatte der Proklamierung des „weltpolitischen Dreiecks“ bislang ja überhaupt keine Substanz gegeben werden können; ihr war weder eine Abstimmung des politischen Handelns gefolgt noch ein bindendes Versprechen gegenseitigen Beistands im Kriegsfall, und wenn auch die gemeinsame Kriegserklärung an den Status quo nicht ohne Einfluß auf die Politik der Westmächte und der Sowjetunion geblieben war, so gab es in Berlin, Rom und Tokio doch etliche Politiker und Soldaten, die im Hinblick auf die jeweils eigenen Interessen ohnehin nicht bei einer bloßen Solidaritätsadresse der expansionistischen Staaten stehenbleiben wollten. Auch die „Achse Berlin-Rom" war immer noch wenig ansehnlich, war nur Stückwerk. Vom Zusammenwirken in Spanien abgesehen, hatte sich das mit schmetternder Fanfarenbegleitung verkündete Freundschaftsverhältnis zwischen dem nationalsozialistischen Deutschland 
und dem faschistischen Italien in wechselseitiger Tolerierung aggressiver Aktionen erschöpft, des Kriegs in Abessinien, der Remilitarisierung des Rheinlands, der Annexion Österreichs und des Vorgehens gegen die Tschechoslowakei. Bei italienischen Besuchen in Deutschland - wo sich Mussolini vom 25. bis zum 29. September 1937 umjubeln ließ - und bei deutschen Besuchen in Italien - wo sich Hitler vom 3. bis zum 9. Mai 1938 aufhielt - schwelgten beide Seiten stets in flammenden Bekundungen der geistigen und ideologischen Übereinstimmung zwischen den zwei ,totalitären" Staaten und in feierlichen Bekundungen der Identität ihrer Interessen. Aber Rhetorik und Gestik konnten den Mangel an politischem Gehalt nicht verbergen, und wiederum formierten sich in Berlin und Rom Gruppen radikaler Imperialisten, die sich ohnehin für eine politisch noch besser nutzbare Ausgestaltung der Achse einsetzten. In Deutschland verlieh indes die Erfahrung der Sudetenkrise derartigen Tendenzen eine solche Wichtigkeit und Dringlichkeit, daß sie in der politischen Prioritätenskala ganz nach oben stiegen. Wenn vermutlich als nächste die Westmächte zu erledigen waren, mußte ein handfestes Bündnis mit Italien geschlossen werden, um französische und britische Kräfte an der italienisch-französischen Grenze und im Mittelmeerraum zu fesseln, mußte ferner die deutsch-italienische Allianz durch einen Militärpakt mit Japan ergänzt werden, der nicht allein - durch den Druck auf die asiatischen, indischen und pazifischen Glieder und Interessen des Commonwealth - eine zusätzlich schwächende Ablenkung Großbritanniens bewirken, sondern vor allem die USA an einem militärischen Engagement in Europa hindern sollte.

Bereits im Juni 1938 hatte Ribbentrop die Notwendigkeit einer militärischen Dreierallianz erst General Hiroshi Oshima, dem japanischen Militärattaché in Berlin, der dann im November zum Botschafter ernannt wurde, klarzumachen versucht, danach Bernardo Attolico, dem italienischen Botschafter. Die Divergenzen zwischen den „autoritären Staaten“ und den „Demokratien“ würden notwendigerweise ständig wachsen, erklärte er Attolico, und deshalb müßten die autoritären Staaten einen festen Block bilden. Um den Italienern die Furcht zu nehmen, bei einer engeren Verbindung mit Deutschland womöglich schon in wenigen Monaten in einen Krieg mit den Westmächten verwickelt zu werden, versicherte Ribbentrop, daß man, wie er auch vom „Führer" wisse, die CSR „schon im Sack“ habe und daß Deutschland die Liquidierung der CSR ohnehin „allein auf seine Schultern" nehme und auch bei einem größeren Konflikt jetzt noch keine militärische Hilfe von Italien erwarte; falls dies der Duce wünsche, werde sich Deutschland verpflichten, bei Abschluß einer Allianz den „Fall CSR“ ausdrücklich auszunehmen ${ }^{151}$. Die Deutschen dachten also bereits an die Zukunft und wären für den Augenblick offenbar schon mit der Aufnahme

151 Akten des Italienischen Außenministeriums (AIA), Ap Germania, Bericht Attolico, 23.6.1938. 
von Bündnisgesprächen zufrieden gewesen, die den Demokratien wenigstens den Eindruck vermittelt hätten, „daß der Block fest ist“, wie sich Göring einige Wochen später, am 16. Juli, zu General Alberto Pariani äußerte, Stabschef des italienischen Heeres und Staatssekretär im italienischen Kriegsministerium ${ }^{152}$. Göring setzte freilich hinzu, ein deutsch-italienisches Abkommen müsse die gegenseitige Unterstützung auch für den Fall sichern, „daß sich einer der Partner irrt“. Da damit nur eine falsche Einschätzung von Kriegsrisiken gemeint sein konnte, klangen Görings Worte in italienischen Ohren natürlich beunruhigend, und es dürften derartige Beunruhigungen gewesen sein, die Mussolini und Graf Ciano wieder abschreckten, nachdem beide die erste Initiative Ribbentrops positiv aufgenommen hatten und Attolico von Ciano ermächtigt worden war, zu einer „ernsthaften Besprechung der Frage Militärallianz" eine Zusammenkunft der Außenminister zu verabreden ${ }^{153}$. Die Italiener reagierten außerdem mit Skepsis auf Ribbentrops prahlerische Behauptung, er stehe „in Japan mit jenen in Verbindung, die zählen", und das Kaiserreich werde einem Militärpakt ebenso beitreten wie dem Antikominternpakt ${ }^{154}$; sie schätzten die Widerstände, die es in Japan gegen allzu englandfeindliche Liaisons noch gab, realistischer ein, und wie sie über Ribbentrops japanische Freunde dachten, zeigt die boshafte Bemerkung Attolicos, in Japan habe es nicht gerade positiv gewirkt, daß ein Mann wie Oshima für den Dreierpakt eintrete ${ }^{155}$. Jedenfalls kam es bis zum Ende der Sudetenkrise nicht zu einer „ernsthaften Besprechung", obwohl Hitler im Juli auch noch konkrete Vorschläge für den Auszug der Deutschen aus Südtirol ankündigte. Mussolini hat im Gegenteil, obschon er monatelang in Berlin, Paris und London den Eindruck zu erwecken suchte, ein treuer und auch durchaus kriegsbereiter Freund seines Achsenpartners zu sein, am Ende eine Politik gemacht, die wesentlich zum Zustandekommen der Münchener Konferenz beitrug, und er hat dabei mit der Berliner Friedenspartei um Staatssekretär v. Weizsäkker und mit Chamberlain kollaboriert, nicht mit Hitler und Ribbentrop.

$\mathrm{Da}$ das faschistische Italien einem Krieg an der Seite des nationalsozialistischen Deutschland auswich, aller Achsen-Rhetorik und aller imperialistisch-kriegerischen Gestik zum Trotz, ist vom „Führer" und seinem AuBenminister aber nur als ein zusätzlicher Grund empfunden worden, Italien für den künftigen Ernstfall vertraglich fest zu binden, so wunderlich es sich, angesichts ihrer eigenen Vorstellung von Vertragstreue, ausnimmt, daß sie offenbar annahmen, einen Mann wie den Duce mit einem Papier an sich fesseln zu können. Noch in München wurde den italienischen Gästen ein Entwurf für einen Dreierpakt ausgehändigt ${ }^{156}$, und vier Wochen später, am

152 AIA, Ap Germania, Bericht Pariani, 15. u. 16.7.1938.

153 Ebenda, Ciano an Attolico, 27.6.1938.

154 Ebenda, Attolico an Ciano, 23.6.1938.

155 Ebenda, Attolico an Ciano, 2.7.1938.

156 M. Toscano, The Origins of the Pact of Steel, Baltimore 1964. 
27. Oktober, erschien Ribbentrop in Rom, um den Duce und Ciano endlich auf den rechten Weg zum Militärpakt zu bringen. Er trug seinen Gastgebern - als Meinung des „Führers“ - vor, daß der Krieg gegen die Westmächte in einigen Jahren kommen werde und daß es für Deutschland, Italien und Japan nun an der Zeit sei, den politischen und militärischen Aufmarsch gegen die bereits bestehende Kombination England-Frankreich umgesäumt einzuleiten. Habe der „Führer“ bislang geglaubt, ein Militärpakt werde die Aufrüstung der Westmächte beschleunigen, die Stellung der Achsenfreunde in Paris und London erschüttern und die USA zu einer Allianz mit Großbritannien veranlassen, so meine er jetzt, daß die Westmächte ohnehin zu großen Anstrengungen auf dem Felde der Rüstung entschlossen seien, während die Vereinigten Staaten offensichtlich gar nicht daran dächten, sich in einen Konflikt zwischen der „Achse“ und den Demokratien einzumischen, „erst recht nicht, wenn Japan beteiligt ist“. Seit der Münchner Konferenz und ihren Resultaten seien die Achsenmächte unangreifbar und die Herren der Situation; bei ihnen liege die Initiative, und das müsse rücksichtslos ausgenutzt werden, zumal der Rücken im Osten und Südosten frei sei: die Freundschaftspolitik mit Polen werde fortgesetzt und ausgebaut, Staaten wie Rumänien, Jugoslawien und Ungarn lehnten sich mehr und mehr an die „Achse“ an, Rußland sei schwach ${ }^{157}$. Daß Ribbentrop den politischen Überblick mit militärischem Bramarbasieren vermischte, daß er mit den „98 Divisionen“ prahlte, die Deutschland im vergangenen September bei einem allgemeinen Krieg ins Feld geschickt hätte, daß er mit noch größerem Enthusiasmus von der Verbesserung der militärischen Lage schwärmte, die München bewirkt habe, und daß er daran die triumphierende Feststellung knüpfte: ,Jetzt können wir einen großen Krieg mit den Demokratien ins Auge fassen!" war in einer bestimmten Hinsicht freilich höchst verdächtig. Dies konnte als ein Indiz dafür aufgefaßt werden, daß Hitler und Ribbentrop, wenige Wochen zuvor nur mühsam von einem kriegerischen Abenteuer abgehalten, schon wieder unruhig zu werden begannen und den Beginn des militärischen Konflikts mit den Westmächten nicht erst „,in einigen Jahren“, wie der Reichsaußenminister betont hatte, erwarteten, sondern bereits wesentlich früher herbeizuführen gedachten.

Wie sich bald zeigen sollte, waren die Italiener in der Tat sogleich mißtrauisch geworden. Zunächst reagierten Mussolini und Ciano, zum Erstaunen und zur Enttäuschung ihres Gastes, aber ohnehin ausweichend. Zwar schloß sich Mussolini der Meinung Hitlers an, daß Deutschland und Italien „in wenigen Jahren“ gegen die Westmächte Krieg führen müßten; das liege, angesichts des „unheilbaren Bruchs zwischen zwei Welten“, in der „historischen Dynamik“. Aber dann erklärte er, daß es für einen Militärpakt

157 AIA, Ap Germania, Aufzeichnung über Gespräche Ribbentrop-Ciano-Mussolini, 28.10.1938. 
noch zu früh sei. Ein Defensivbündnis, wie es zwischen Großbritannien und Frankreich existiere, sei nicht notwendig, da niemand daran denke oder daran denken könne, die ,totalitären Staaten“ anzugreifen. Bei dem Bündnis, das selbstverständlich in absehbarer Zeit kommen werde, müsse es sich vielmehr um ein Offensivbündnis handeln: „Wir wollen einen Pakt machen, um die Landkarte der Welt zu verändern!" Und abgesehen davon, daß eine derartige Allianz der sorgfältigen Vorbereitung und der genauen Definition und Abstimmung der beiderseitigen Eroberungsziele bedürfe, sei die Zeit noch nicht reif. In Italien sei wohl die Luftwaffe für den Abschluß eines Militärpakts, und auch in der Marine gebe es Zustimmung, doch im Offizierskorps des Heeres, namentlich in den mittleren und höheren Rängen, sei noch breiter Widerstand anzutreffen. Das katholische Bürgertum betrachte das nationalsozialistische Deutschland leider noch mit Kühle, da die Kirchenpolitik des Regimes rundweg abgelehnt werde; bei einer Entspannung zwischen Staat und Kirche könnte das deutsch-italienische Bündnis viel populärer sein. Alles in allem habe das italienische Volk in der Entwicklung seiner politischen Gefühle erst die „Phase der Achse“ erreicht und sei noch nicht bei der "Phase Militärallianz" angekommen. Mussolini suchte Ribbentrop mit dem Hinweis auf die Solidarität der Regime in Deutschland und Italien, die sowieso gegenseitige Hilfe verbürge, zu trösten; auch ohne Militärpakt enthalte doch die „Achse“ bereits „eine Vorstellung militärischer Solidarität" 158.

Ribbentrop hatte sich mit solchen Phrasen, die man ihm auch noch in einer schriftlichen Note zukommen ließ, und mit Mussolinis Versicherung, daß Berlin bis zum unausweichlichen Abschluß einer Militärallianz keine italienischen Techtelmechtel mit den Westmächten zu fürchten brauche, fürs erste zufriedenzugeben. Einige Wochen lang herrschte Stagnation. Indes hatten die Italiener ihre Zurückhaltung nur mit recht oberflächlichen oder sogar bloß vorgeschützten Argumenten begründet. Ihre wahren Motive sahen ganz anders aus. Mussolini war, bei aller Lust an imperialistischer Expansion, ein Mann, der von Ratio und Realismus nie völlig Abschied nahm, und sein Schwiegersohn Graf Galeazzo Ciano besaß, obschon der elegante Genießer auch Politik in einer Art Playboy-Haltung betrieb und von den sozusagen ästhetischen Reizen der imperialistischen Projekte des Faschismus tatsächlich fasziniert war, eine gehörige Portion Vernunft und selbst eine gewisse Portion patriotischen Verantwortungsgefühls. Wenn ihnen nicht gerade imperialistische Phantasien den Verstand verwirrten und wenn ihnen nicht gerade der Rausch faschistischer Rhetorik und Theatralik die Urteilsfähigkeit minderte, wußten beide sehr genau, daß ihr Land aus geographischen und strategischen Gründen zu verwundbar und aus wirtschaftlichen, politischen und militärischen Gründen viel zu schwach war, um gegen die Westmächte Krieg führen zu können. Einen Pakt abzu- 
schließen, der einen solchen Krieg nicht nur zur Eventualität erklärte, sondern zum Vertragsziel erhob, war mithin in den Augen des Duce und seines Außenministers eine sehr bedenkliche Sache. Die von den Deutschen gewünschte Allianz kam durchaus in Frage, aber nur dann, wenn es gelang, den zum Bündniszweck deklarierten Krieg so weit in die Zukunft zu verlagern, daß man über seinen Ausbruch noch nicht ernsthaft nachzudenken brauchte, wenn also die praktische Bedeutung des Pakts in der Gegenwart auf seine Verwendbarkeit als politisches Druckmittel reduziert werden konnte. War das mit Partnern möglich, wie sie in Berlin saßen? Daß hier reiflich überlegt werden mußte, hatte Attolico schon im Juni gemahnt ${ }^{159}$.

Näher noch als die künftigen kriegerischen Möglichkeiten lag zudem eine bei Abschluß des Pakts unmittelbar drohende Gefahr. Seit dem Krieg in Abessinien und der ersten Annäherung an Deutschland war die außenpolitische Handlungsfreiheit Italiens ständig geringer geworden, und die Gesetzmäßigkeit, mit der die Verfolgung eigener imperialistischer Ziele und die Anlehnung an ein laufend stärker werdendes Deutschland die internationalen Optionen des Landes verringerten, ist den italienischen Politikern nicht entgangen; mit dem Blick auf die bevorstehende Annexion Österreichs hatte Graf Ciano schon im Februar 1938 an Dino Grandi, den italienischen Botschafter in London, geschrieben, Italien werde, falls die Annexion tatsächlich komme und dann der solchermaßen erstarkte deutsche Nachbar auf die italienische Grenze drücke, „keine Alternative mehr bleiben und wir werden unsere Politik endgültig auf eine klare, offene und umwandelbare Feindschaft zu den Westmächten ausrichten" 160 . Stand aber jetzt, wenn man die definitive Entscheidung traf und sich durch einen Militärpakt auf Gedeih und Verderb an Deutschland band, nicht zu befürchten, daß ein optionslos gewordenes Italien in eine zumindest äußerst unangenehme Abhängigkeit von dem in jeder Hinsicht überlegenen Deutschen Reich geriet? Außerdem: Wie gedachten es die Deutschen, die fortwährend beteuerten, daß die Ziele ihres Imperialismus im Osten lägen und den Italienern das Mittelmeer gehöre, eigentlich mit den italienischen Interessenzonen in Südosteuropa und an der Adria zu halten? Wie gedachten sie es zum Beispiel, nachdem sie gerade schon im Begriff waren, die italienische Position in Ungarn zu liquidieren, im italienischen Einflußgebiet Jugoslawien mit Kroatien zu halten? Schließlich gab es im Oktober 1938 noch ein weniger grundsätzliches Problem, das ebenfalls ein gewisses Verzögern der Paktfrage geraten erscheinen ließ. Ostern 1938 hatte Mussolini die Appeasement-Neigung Chamberlains noch einmal ausnutzen und mit den Briten ein Abkommen schließen können, das gegen den Abbau des militärischen Engagements Italiens in Spanien die britische Anerkennung des Erwerbs Abessiniens vorsah. Das Abkommen war im Oktober noch nicht

159 Wie Anm. 151.

160 AIA, Ap Germania, Ciano an Grandi, 16.2.1938. 
in Kraft gesetzt, doch stand dies kurz bevor - am 16. November war es dann so weit -, und Mussolini lag doch einiges daran, den offiziellen britischen Segen für das bisher wichtigste imperialistische Unternehmen des faschistischen Italien zu erhalten. Nun mochten die Briten zwei Augen zudrücken, wenn Italien die Verpflichtung zum Rückzug aus Spanien nahezu ignorierte. Ein deutsch-italienischer Militärpakt hingegen, der sich eindeutig gegen die Westmächte richtete, konnte nicht einmal von Chamberlain mit Stillschweigen übergangen werden und mußte das Ostern-Abkommen ernstlich gefährden.

Indes brauchte die Enttäuschung in Berlin nicht lange zu währen. Da der Neid auf den Münchner Erfolg des nationalsozialistischen Deutschland fortwährend an ihrem faschistischen Selbstgefühl fraß, träumten Mussolini und Ciano alsbald von neuen italienischen Beutezügen, und da sie dafür den Militärpakt mit Deutschland nötig zu haben glaubten, leisteten sie sich doch ein weiteres Mal einen ihrer periodischen Verzichte auf Klugheit und Vorsicht und begannen sich einzureden, daß es ihnen sehr wohl gelingen werde, die deutschen Partner zu kontrollieren und einen Militärpakt ausschließlich als politisches Druckmittel zu handhaben. Die nächsten Ziele des italienischen Imperialismus waren französischer Besitz, und der Duce versprach sich von einer deutsch-italienischen Militärallianz in erster Linie die notwendige Einschüchterung Frankreichs, während die Gefahr, die Deutschland auch für Großbritannien darstellte, England daran hindern sollte, Frankreich gegen die italienischen Forderungen den Rücken zu stärken; vielleicht, so spekulierte man in Rom, brachte der Pakt die friedenssüchtigen Briten sogar dazu, in Paris als Fürsprecher der römischen Ansprüche aufzutreten. Nachdem außerdem das italienisch-britische OsternAbkommen am 16. November in Kraft gesetzt worden war und nachdem man wenige Tage später in Rom überdies den Eindruck gewonnen hatte, England und Frankreich seien gerade dabei, ihre Entente in eine Militärallianz umzuwandeln, hielten nun wiederum Mussolini und Ciano Eile für geboten. Am 24. November wurde Attolico von Ciano beauftragt, Ribbentrop - falls sich die Gerüchte über die britisch-französischen Gespräche bestätigen sollten - wissen zu lassen, daß die Formulierungen, die Mussolini während des Ribbentropschen Aufenthalts in Rom gebraucht habe, überholt seien und Italien jetzt auf das militärische Bündnisprojekt eingehen wolle ${ }^{161}$.

Attolico, der am Militärpakt ohnehin noch keine attraktiven Züge fand, konnte keine Bestätigungen der Gerüchte über eine britisch-französische Miliärallianz entdecken und führte daher die Instruktion Cianos zunächst nicht aus ${ }^{162}$. Da die Gerüchte auch danach bloße Gerüchte blieben, wurde man in Rom wieder etwas ruhiger. Doch gab man das Bündnisprojekt nicht 
mehr völlig auf. Daß Ribbentrop, um der deutsch-britischen Konsultationsvereinbarung, die Hitler und Chamberlain noch in München unterzeichnet hatten, eine deutsch-französische Entsprechung zu geben, am 6. Dezember nach Paris kam und dort eine solche Vereinbarung unterschrieb, stimmte die Italiener mißtrauisch. Wohl war die Reise des Reichsaußenministers ohne jede politische Bedeutung, und das galt erst recht, wie Weizsäcker wahrheitsgemäß Attolico mitteilte, für die Konsultationsverpflichtung ${ }^{163}$; tatsächlich hat Ribbentrop seine Pariser Gesprächspartner in souveräner Mißachtung der eben formulierten gemeinsamen Erklärung belehrt, daß die Reichsregierung in osteuropäischen Fragen Frankreich gerade nicht mehr konsultieren werde, weil Frankreich in Osteuropa nichts mehr zu suchen habe ${ }^{164}$. Aber in Rom sah man derartige deutsch-französische Extratouren trotzdem nicht gerne, zumal sich gerade die italienisch-französischen Beziehungen verschlechterten, und der Militärpakt erschien als probates Mittel, die Deutschen auf dem Pfade der Achsen-Tugend zu halten. Die Verschlechterung des Verhältnisses zwischen Rom und Paris war in der Tat dramatisch, allerdings durch die Schuld der Italiener, die den $\mathrm{Au}$ genblick für opportun hielten, ein antifranzösisches Erpressungsmanöver einzuleiten und Frankreich in aller Öffentlichkeit mit der ganzen Skala der italienischen Ansprüche zu konfrontieren. Am 30. November hielt Graf Ciano eine außenpolitische Rede im Faschistischen Großrat, und als er zum Schluß sagte, Italien werde nicht auf die Verfechtung seiner „natürlichen Ansprüche" verzichten, skandierten auf dieses verabredete Signal hin zahlreiche Ratsmitglieder in Anwesenheit des Duce: „Tunis, Korsika, Nizza, Savoyen!" 165 Die französische Reaktion war vernichtend, und Mussolini mußte abermals erfahren, daß zur Einschüchterung und zur Erpressung Frankreichs mehr gehörte als ein italienischer Anspruch. Am 23. Dezember unterrichtete er Ciano, daß er sich entschlossen habe, Ribbentrops Vorschläge anzunehmen ${ }^{166}$, und am 2. Januar 1939 schrieb der italienische AuBenminister an Ribbentrop, der Duce sei jetzt bereit, der Umwandlung des Antikominternpakts in einen Militärpakt zuzustimmen; als Termin für die Unterzeichnung schlage er Ende Januar vor ${ }^{167}$.

Aber mit ihrer antiwestlichen Bündnispolitik hatten die Berliner wenig Glück. Kaum waren die Italiener auf die deutsche Linie eingeschwenkt, da stellte sich nämlich etwas heraus, wofür es in den Monaten zuvor schon zahlreiche Indizien gegeben hatte: Ribbentrop hatte - wohl etwas anders als der in dieser Frage realistischere Hitler - die japanische Bündnisbereitschaft weit überschätzt bzw. in einem entscheidenden Punkt völlig falsch

163 Ebenda, Attolico an Ciano, 8.11.1938.

164 ADAP, D, 4, Nr. 369, 370.

165 F. Siebert, Der deutsch-italienische Stahlpakt, in: VfZ 7 (1959), S. 372-395; M. Toscano, Le origine diplomatiche del patto d'Acciaio, Florenz 1956.

166 Weinberg, The Foreign Policy of Hitler's Germany, S. 509.

167 Ebenda; ADAP, D, 4, Nr. 421. 
eingeschätzt. Energischer noch als bisher und jetzt unmißverständlich machte die Regierung in Tokio wieder klar, daß Japan allenfalls dann für den Ausbau des Antikominternpakts in eine Militärallianz zu haben sei, wenn sich der neue Pakt nach den internen Bekundungen der Partner und nach dem Vertragstext eindeutig gegen die Sowjetunion richte. Da die japanisch-sowjetische Spannung in der Mandschurei, in der Mongolei und in Nordchina immerhin noch andauerte und gelegentlich auch gefährlich wirkende Formen annahm - ab Mai 1939 sollte es in der Mongolei sogar, ohne daß ein Krieg erklärt worden wäre, zu monatelangen größeren Kampfhandlungen kommen -, hätte die japanische Regierung nichts dagegen gehabt, Stalin mit einer militärischen Verbindung $z$ wischen Berlin und Tokio zu beeindrucken und von ernsthafteren Operationen im Fernen Osten abzuhalten. Auf der anderen Seite dominierten in Japan, solange es die Konflikte mit der Sowjetunion gab und solange ein beträchtlicher Teil der militärischen Energie des Landes nach China abgesogen wurde, jene Kräfte Hof, Marine, Teile der Wirtschaft, hohe Bürokratie, liberale Gruppen in den gesellschaftlichen und politischen Eliten -, die sich jeder offenen Herausforderung Großbritanniens und der USA strikt widersetzten. Ihrer Meinung nach wäre aber ein antibritischer Militärpakt mit Deutschland und Italien eine solche Herausforderung gewesen, und so ließ die japanische Regierung keinen Zweifel daran, daß Nippon einer Dreierallianz mit der von Berlin und Rom gewünschten Ausrichtung nicht beitreten werde.

Es ist nun ein schlagender Beweis für die im Augenblick gegebene Westwendung der Hitlerschen Expansions- und Kriegsplanung, daß sich nicht nur die Italiener, sondern auch die Deutschen an einem Vertrag, dessen Spitze auf Moskau zielte, gänzlich desinteressiert zeigten und auf einer eindeutig antiwestlichen Zielsetzung des Militärpakts bestanden.

Da Ribbentrop, bestärkt von General Oshima, die Interessenlage Japans nicht wahrhaben und die Weigerung der japanischen Regierung nicht ernst nehmen wollte, unternahm er eine lange Serie von Versuchen, die Japaner von ihrer, wie er sagte, „lächerlichen“ Haltung abzubringen 168 . Zeitweise kam es dabei zu einem Belauern der Vorgänge in Tokio, das der Komik nicht entbehrte: Schien die Paktpartei in einer Kabinettssizung oder in einer Besprechung zwischen Heer und Marine einen Millimeter gewonnen zu haben, brach in Berlin unmäßiger Optimismus aus, erfuhr man einen Tag später, daß die Paktgegner ihren Kurs doch behauptet hatten, entweder schon gegen Ende der Kabinettssitzung oder kurz danach etwa durch eine Intervention der anglophilen Hofkreise, herrschten Verärgerung und grimmiger Zorn. Gelegentlich schickte Ribbentrop auch General Oshima nach Tokio, damit er die japanische Regierung endlich zur Vernunft bringe, und stellte dem Botschafter für die Reise sogar ein deutsches Flugzeug zur Verfügung. Süffisant bemerkte einmal der italienische Botschafter Attolico, als 
er Graf Ciano über eine derartige Mission Oshimas berichtete, Ribbentrop sei. „so aufgeregt, daß er am liebsten selber fliegen würde“169; die Italiener schätzten die Situation in Tokio richtiger ein und wären ohnehin, da sie den Militärpakt ja nur als diplomatischen Knüppel zu verwenden gedachten, schon früh mit einem Zweiervertrag zwischen Berlin und Rom zufrieden gewesen. Indes blieben alle Bemühungen, die japanische Regierung umzustimmen, notwendigerweise vergeblich. Fürs erste bestand die tatsächliche Wirkung der deutsch-japanischen Verhandlungen darin, daß sie Berlin einen doppelten Nachteil bescherten: Sie blockierten den Abschluß eines deutsch-italienischen Militärpakts und sie gaben den britischen Politikern - die Londoner Regierung war über den Gang der Dinge zwischen Berlin und Tokio ganz gut unterrichtet - die Gewißheit, daß von Japan vorerst nichts Ernstes zu befürchten war und Großbritannien sich auf die in Europa drohenden Gefahren konzentrieren durfte.

Auch ein anderes Manöver im Aufmarsch gegen den Westen kam nicht recht vom Fleck, obgleich Hitler und Ribbentrop eine Weile lang gerade dieses Manöver offensichtlich für ein simples und problemloses Unternehmen hielten. Für den Stoß nach Westen mußte, wie Ribbentrop ja bereits bei seinen Oktobergesprächen mit Mussolini und Ciano zu verstehen gegeben hatte, die Ruhe im Rücken garantiert sein, und zwar durch eine Anbindung der ost- und südosteuropäischen Nachbarstaaten an Deutschland und Italien, die der Unterordnung unter zwei Führungsmächte gleichkam. Bei Ungarn machte das auch nicht die geringsten Schwierigkeiten. Nach etlichen deutschen Winken trug Ungarn, das seit München in außenpolitischen Fragen faktisch zum Befehlsempfänger Berlins geworden war, der veränderten Machtlage auch äußerlich Rechnung, indem es zur Besiegelung der Anerkennung des deutschen Führungsanspruchs am 24. Februar 1939 in den Antikominternpakt ein - und am 11. April aus dem Völkerbund austrat. Wichtiger noch als Ungarn war aber Polen. Am 22. August 1939, als die Dinge schon völlig anders lagen, hat Hitler noch einmal klar ausgesprochen, daß er, um Rückendeckung gegen den Westen zu haben, vom Spätsommer 1938 bis zum Frühjahr 1939 an der Ruhigstellung Polens gearbeitet hatte. Unter anderem sagte er: „Ich wollte zunächst mit Polen ein tragbares Verhältnis herstellen, um zunächst gegen den Westen zu kämpfen." 170 Doch die polnische Regierung verhielt sich nicht so wie die Budapester Politiker, obschon Ribbentrop in Rom den Fall Polen ebenfalls als praktisch bereits erledigt hingestellt hatte. Allerdings gab es auch einen wesentlichen Unterschied im Verfahren. Während Hitler und Ribbentrop den Ungarn wenigstens keine konkreten Opfer zumuteten, den Kotau vor Deutschland vielmehr mit weiteren territorialen Gewinnen zu belohnen verhießen, suchten sie die Polen mit einer Kombination aus Lockung und Forderung ins Lager der Achsenmächte zu ziehen.

169 Ebenda.

170 Vgl. Anm. 138. 
Noch während der Sudetenkrise, am 10. August 1938, hatte Göring dem polnischen Botschafter in Berlin, Jozef Lipski, auseinandergesetzt, daß der Prozeß der deutsch-polnischen Annäherung nicht bei dem bisher erreichten und durch das Zusammenwirken gegen die CSR weiter zu erreichenden Stand stehenbleiben dürfe. Nach dem tschechischen Problem werde die russische Frage aktuell werden, hatte der Generalfeldmarschall hinzugefügt und für diesen Fall deutlich eine gewinnbringende deutsch-polnische Zusammenarbeit angeboten: an der Ukraine etwa sei das Deutsche Reich nicht selbst interessiert ${ }^{171}$. Das war nicht Görings erster Versuch, die „großpolnische" Begehrlichkeit zu wecken, wie sie sich während des polnisch-sowjetischen Krieges von 1919/20 in Marschall Pilsudskis Zug nach Kiew gezeigt hatte. Schon Ende Januar 1935, als er zum ersten Mal nach Polen gekommen war, hatte er bei seinen polnischen Gesprächspartnern sondiert ${ }^{172}$, um im Februar 1937 in einer Unterhaltung mit Marschall Edward Rydz-Smigly, dem Generalinspekteur der polnischen Streitkräfte, bereits offener ${ }^{173}$ und bei einem erneuten Polen-Besuch in der zweiten Februarhälfte 1938 ganz offen zu sprechen ${ }^{174}$. Solche Offerten hatten auch Substanz. Hitler war durchaus bereit, polnische Bundesgenossenschaft bei der deutschen Ostexpansion territorial zu belohnen, zumal der Bundesgenosse im Laufe des gemeinsamen Unternehmens unweigerlich zu einem abhängigen Satellitenstaat werden mußte, über dessen endgültiges Schicksal im deutschen Machtbereich später nach Belieben entschieden werden konnte. Am Vorabend der Münchner Konferenz hatte sich dann Ribbentrop den polnischen Botschafter zu einer nächtlichen Unterredung geholt, und als der Reichsaußenminister seinen Gast bat, über den Beitritt Polens zum Antikominternpakt nachzudenken, verstand Lipski das mit Recht als eine Bestätigung der Göringschen Hinweise vom August ${ }^{175}$.

Nach München erfuhr die deutsche Haltung jedoch eine bezeichnende Veränderung. Am 24. Oktober lud Ribbentrop den polnischen Botschafter nach Berchtesgaden ein, und im Laufe einer dreistündigen Unterhaltung schlug er Lipski eine „Generalbereinigung“ der zwischen Deutschland und Polen schwebenden Fragen vor: Der Freistaat Danzig müsse zum Deutschen Reich zurückkehren und Deutschland eine aus Autobahn und Bahnlinie bestehende exterritoriale Verbindung von Pommern nach Ostpreußen - durch den sog. „Polnischen Korridor“ - bekommen; dazu habe Polen dem Antikominternpakt beizutreten. Unter solchen Voraussetzungen sei

71 APA, Botschaft Berlin, Mappe 18, Lipski an Beck, 11.8.1938.

172 A. Kube, Pour le mérite und Hakenkreuz - Hermann Göring im Dritten Reich, München 1986, S. $105 \mathrm{ff}$.

173 Weißbuch der Polnischen Regierung über die polnisch-deutschen und die polnischsowjetrussischen Beziehungen im Zeitraum von 1933 bis 1939, Basel 1940, Nr. 29.

174 Lipski, Diplomat in Berlin, S. 345ff. -St. Schimitzek, Drogi ibez droźa minioney epoki, Warschau 1976, S. 420.

175 APA, Botschaft Bertin, Mappe 19, Lipski an Beck, 28.9.1939. 
wiederum das Reich bereit, die derzeitige deutsch-polnische Grenze anzuerkennen, Polen eine ebenfalls exterritoriale Verbindung im Danziger Gebiet einzuräumen und den deutsch-polnischen Nichtangriffsvertrag von 1934 - der noch mehr als fünf Jahre Laufzeit hatte - "um zehn bis fünfundzwanzig Jahre“ zu verlängern ${ }^{176}$. Neben den Köder - im Begriff Antikominternpakt steckte noch immer die Verheißung eines gemeinsamen Beutezugs gegen die Sowjetunion - hatte also Ribbentrop nun etliche Forderungen placiert. Abgesehen davon, daß darin auch eine durch den Triumph von München bewirkte Zunahme der nationalsozialistischen Arroganz zum Ausdruck kam, war die Addition indes eine logische Folge der neuen Berliner Prioritätensetzung. Wenn zuerst die Lage im Westen bereinigt und für diesen Fall polnische Passivität gesichert werden sollte, hatte Polen eben ohne und vor einer östlichen Unternehmung diszipliniert zu werden. Als geeignete Mittel erschienen Hitler und Ribbentrop einmal die Durchsetzung einiger Ansprüche des deutschen Revisionismus, die dem Reich überdies eine weitgehende Kontrolle des polnischen Zugangs zur Ostsee und die Festsetzung auf polnischem Territorium bringen würde, vor allem aber der Beitritt Polens zum Antikominternpakt, der - so bedeutungslos die derart bekundete Anerkennung der deutschen Führungsrolle unter Umständen sein mochte - Polen schon jetzt mit der Sowjetunion verfeinden und Warschau außerdem die letzten Reste französisch-britischer Unterstützungsbereitschaft kosten, dem Land mithin jede außenpolitische Möglichkeit außer der Anlehnung an Deutschland nehmen mußte. Fraglos rechneten der „Führer“ und sein Außenminister mit der Annahme ihrer Forderungen. Schließlich war Polen schwächer und durfte sich daher glücklich schätzen, im Moment noch so billig davonzukommen und nach wie vor eine Einladung zur Komplicenschaft gegen Rußland in Händen zu halten. Auch glaubten sie sich Mühe gegeben zu haben, daß die Pille, die sie den Polen reichten, nicht zu bitter schmeckte. Ribbentrop hatte die in mancherlei Hinsicht benachteiligte deutsche Minderheit in Polen mit keiner Silbe erwähnt, und neun Tage vor dem Berchtesgadener Gespräch, am 13. Oktober, hatte Hitler eine Weisung an die deutsche Presse gehen lassen, wie bisher kein Wort der Kritik über die - durchaus kritikwürdige - polnische Minderheitenpolitik zu bringen ${ }^{177}$.

Lipski, in Breslau geboren, zweisprachig aufgewachsen und aus einer prominenten Familie stammend, die in den geographischen und politischen deutsch-polnischen Kontaktzonen seit langem eine hervorragende Rolle spielte - sein Vater hatte in der Opposition gegen die ebenfalls ruppige Polenpolitik des wilhelminischen Deutschland seinen Mann gestanden ${ }^{178}$-, Lipski nahm die Eröffnungen Ribbentrops sogleich todernst; er

176 ADAP, D, 5, S. 87 ff.

177 Politisches Archiv Auswärtiges Amt (PAA), Büro Staatssekretär, Polen, 1, 34468.

178 Lipski, Diplomat in Berlin, S. XIII ff. 
war bestürzt und sah pessimistisch in die Zukunft. Sicherlich könne man die Deutschen, so sagte er am 29. Oktober zum Grafen Jan Szembek, Staatssekretär im polnischen Außenministerium, jetzt noch einmal ,wegschieben“, doch würden sie wiederkommen ${ }^{179}$. In Warschau aber reagierten Außenminister Jozef Beck, sein Kabinettschef Graf Michal Lubienski und Graf Szembek zunächst weder besorgt noch mit leichtherziger oder grimmiger Entschlossenheit, sie reagierten vielmehr mit ungläubigem Erstaunen. Danzig? Hatte der „Führer“ nicht am 6. November 1937 - am Tag zuvor war in Berlin eine freundschaftliche deutsch-polnische Grundsatzerklärung zur künftig wohlwollenden Behandlung der deutschen Minderheit in Polen und zum rücksichtsvollen Umgang mit der gleichfalls arg geplagten polnischen Minderheit in Deutschland unterzeichnet worden - Lipski offiziell versichert, daß „er nicht beabsichtige, das Danziger Statut zu ändern“? Hatte der „Führer" nicht am 14. Januar 1938 Außenminister Beck erneut offiziell versichert, „daß er keine Anderung des Danziger Statuts unterstützen werde" 180 ? Hatte schließlich der „Führer" nicht erst am 20. Februar 1938 - seither war noch kein Dreivierteljahr vergangen - in öffentlicher Rede im Reichstag versichert, daß die polnische Respektierung der nationalen Verhältnisse in Danzig und die deutsche Respektierung der polnischen Rechte in Danzig einen „Weg zur Verständigung“ geebnet hätten, „die, von Danzig ausgehend, trotz der Anstrengungen einiger Friedensstörer die Beziehungen zwischen Polen und Deutschland endgültig zu entgiften und in eine aufrichtige und freundschaftliche Zusammenarbeit zu verwandeln vermochte"? Hatte sich nicht Generalfeldmarschall Göring zur gleichen Zeit im gleichen Sinne geäußert ${ }^{181}$ ? Gewiß waren ab und zu wilde Reden des Danziger Gauleiters Albert Forster und anderer lokaler NSDAP-Funktionäre zu registrieren gewesen, in denen diese Heißsporne den Anschluß Danzigs an das nationalsozialistische Deutschland nicht nur gefordert, sondern - als unausweichlich und bald bevorstehend - auch prophezeit hatten ${ }^{182}$. Derartige Vorfälle hatte man mit den deutschen Freunden in Berlin besprochen, und dabei waren sich beide Seiten stets einig gewesen, daß es sich nur um lokale Entgleisungen handle und auch künftig nur um lokale Entgleisungen handeln werde. Gab es im übrigen zwischen dem Polen Pilsudskis, national, sozial und vor allem autoritär, und dem nationalsozialistischen Deutschland nicht auch Elemente der ideologischen und politischen Verwandtschaft? Hatte man nicht gerade mit den deutschen Freunden gegen die Prager Bauern- und Kleinbürgerrepublik so gut

179 Diariusz i Teki Jana Szembeka (1935-1945),Tom IV 1938/39, hrsg. v. Jozef Zaránsi, London 1972 (Szembek-Tagebuch), S. 334.

180 PAA, Pol. V $7617 / 37$.

181 Zit. im polnischen Memorandum v. 5.5.1939, PAA, Büro Staatssekretār, Polen 1, $34728 \mathrm{ff}$.

182 L. Denne, Das Danzig-Problem in der deutschen Außenpolitik 1934-1939, Bonn 1959. 
zusammengewirkt? War nicht das polnische Ultimatum an die tschechoslowakische Regierung als „Ausdruck großer Tatkraft und selbständigen Handelns" von Göring wärmstens belobigt worden ${ }^{183}$ ? Die deutschen Freunde, so redeten sich die Warschauer Politiker zu, konnten unmöglich Miene machen, das gleiche Spiel wie gegen die CSR jetzt gegen Polen zu inszenieren: „Wir sind doch keine Tschechen!“184

Doch schienen auch handfeste politische Argumente dafür zu sprechen, daß Hitler keine ernstlichen Schwierigkeiten mit Polen wollen konnte. Da Beck und seine Mitarbeiter seit der deutsch-polnischen Annäherung von 1933/34 den Blick für die wahre Natur ihrer Berliner Partner verloren hatten, waren von ihnen die expansionistischen Tendenzen der nationalsozialistischen Führer und der NS-Bewegung - auch in Form der rußlandfeindlichen Winke an die eigene Adresse in Warschau - nicht mehr ernst genug genommen worden; im Grunde vermochten sie sich nicht vorzustellen, daß Hitler wirklich auf Krieg aus war und die europäische Normalität völlig zu überrennen gedachte. Selbst München hatte ihnen nicht die Augen geöffnet, obwohl ihnen nicht verborgen geblieben, ja ihnen in Berlin ausdrücklich gesagt worden war, daß Hitlers Pläne eigentlich auf die Eroberung der ganzen Tschechoslowakei zielten. So waren sie nach wie vor überzeugt davon, daß das nationalsozialistische Deutschland kein Interesse daran haben könne, Polen zu schwächen, das schließlich als Bollwerk Europas und Deutschlands gegen den Bolschewismus und das bolschewistische Rußland fungiere; noch am 20. September 1938 hatte Hitler im Gespräch mit Lipski betont, daß er Polen in dieser Hinsicht als „erstrangigen Faktor" schätze ${ }^{185}$. Sollte es gar zu einem militärischen Konflikt zwischen dem Deutschen Reich und Polen kommen, würde Polen natürlich geschlagen werden, und eine dann vermutlich entstehende gemeinsame deutsch-russische Grenze mußten die Deutschen doch, wie manche Warschauer Politiker und Diplomaten in einer groben Verkennung der Hitlerschen Politik annahmen, fürchten. Die Münchner Konferenz hatte um den Preis einer Stärkung Deutschlands, so glaubten Beck und seine Umgebung, die lange währende Aussperrung der Sowjetunion aus Europa gebracht, und obwohl ihnen ein französischer Freund wie Reně Massigli, Leiter der Politischen Abteilung im Pariser Außenministerium, mehrmals im Lauf des Jahres 1938 vorhergesagt hatte, daß in einem solchen „äußerst gefährlichen“ Fall Polen das nächste Opfer nationalsozialistischer Aggression sein werde, hielten polnische Diplomaten die Verdrängung der UdSSR unbeirrt für „einen besonders glücklichen Aspekt" Münchens ${ }^{186}$. Sicherlich hatten die Deutschen nicht vor, dies teilweise oder ganz auszulöschen, indem sie Polens Boll-

183 APA, Botschaft Berlin, Mappe 19, Lipski an Beck, 1.10.1938.

184 Szembek-Tagebuch, S. 339, 484, 488.

185 APA, Botschaft Berlin, Mappe 18, Lipski an Beck, 20.9.1938.

186 Ebenda, Frankiewski an Beck, 21.9.1938. 
werk-Funktion erschwerten oder gar zerstörten. Daß die Deutschen plötzlich so ominöse Forderungen anmeldeten, schrieben Beck und andere Warschauer Politiker einem temporären Anfall von Übermut zu, der nach dem Erfolg von München verständlich sein mochte und sich bei hinhaltender Behandlung der Ribbentropschen Vorschläge ohne Zweifel bald wieder legen werde. Gewiß habe München, so erklärte Beck am 4. November seinen Kabinettskollegen, die Lage verändert, da nun der Völkerbund definitiv erledigt und das französische System in Osteuropa bis fast zur Bedeutungslosigkeit kompromittiert sei. „Andererseits“, so fuhr er beruhigend fort, „hat sich gezeigt, daß die Löwen, wenn man eng mit ihnen zusammenlebt, gar nicht so gefährlich sind." 187

Als ersten Zug hinhaltender Taktik übermittelte Beck dem ReichsauBenminister eine Antwort, in der er zunächst sagte, daß nach seiner Meinung das deutsch-polnische Verhältnis während der tschechischen Krise seine Bewährungsprobe bestanden habe, und dann daran erinnerte, „daß die geradlinige polnische Politik für Deutschland bei der Gewinnung des Sudetengebietes von Nutzen gewesen sei und wesentlich dazu beigetragen habe, diese Frage einer glatten Lösung im deutschen Sinne zuzuführen". Die polnische Regierung ,habe während dieser kritischen Tage alle Sirenenklänge, die von gewisser Seite ertönt seien, unbeachtet gelassen“. Anschließend ließ er - die Antwort überbrachte am 19. November Botschafter Lipski - darlegen, daß Polen einer Eingliederung Danzigs in das Reich aus wirtschaftlichen und politischen, vor allem auch innenpolitischen, Gründen nicht zustimmen könne, doch sei es wohl angezeigt, das derzeitige Danziger Völkerbundsstatut durch einen deutsch-polnischen Vertrag über Danzig zu ersetzen, in dem „man einmal Danzig als rein deutsche Stadt anerkenne mit allen Rechten, die hieraus resultieren, andererseits aber Polen und der polnischen Minderheit alle wirtschaftlichen Rechte gleichfalls sicherstelle, wobei der Charakter Danzigs als Freistaat und die Zollunion mit Polen erhalten bleibe“. Zur Forderung nach einer exterritorialen Verbindung zwischen Pommern und Ostpreußen vermied Beck eine klare Stellungnahme, doch deutete Lipski, „persönlich“ sprechend, an, daß man bei diesem Problem über Kompromisse nachdenken könne ${ }^{188}$. Die Reaktion Ribbentrops faßte Lipski in einem schwer erklärlichen Mißverständnis als deutschen Rückzieher auf, und er gewann überdies den ganz unberechtigten Eindruck, daß der deutsche Vorstoß allein das Werk Ribbentrops gewesen sei, unternommen ohne Wissen Hitlers ${ }^{189}$. In solchem Sinne berichtete er Beck, und der polnische Außenminister durfte sich in seiner Politik erst recht bestätigt fühlen, als ihm der deutsche Botschafter in Warschau, Adolf v. Moltke, am 22. November vertraulich mitteilte, er, Moltke, habe Ribben- 
trop gleich gewarnt, daß die polnische Haltung in der Danziger Frage negativ sein müsse, und er freue sich, jetzt sagen zu können, daß der ReichsauBenminister das nach dem Gespräch mit Lipski gebührend verstanden habe: „Berlin stand zuvor unter dem Eindruck falscher Informationen." 190

Aber eine gewisse Unruhe brachte Beck doch nicht mehr los. Von Anfang an stand fest, daß die deutschen Forderungen unerfüllbar waren. Beck verfolgte, als getreuer Schüler des von ihm verehrten Marschalls Pilsudski, des „Kommandanten“, eine strikte Politik des "Gleichgewichts“ zwischen den Großmächten Deutschland und Rußland191. Eine engere Anlehnung an einen der beiden Nachbarn, die überdies mit einer politischen Feindschaftserklärung an den anderen Nachbarn verbunden war, hätte Polen zum Vasallen des stärkeren „Freundes“ gemacht und alsbald - zumal bei dem politischen Charakter der Nachbarn - neben der äußeren auch die innere Freiheit gekostet. Beck war nicht bereit, in solche Richtung auch nur einen Schritt zu gehen. Also konnte Polen wohl über eine verkehrstechnisch bessere und auch zollfreie Verbindung zwischen Pommern und Ostpreußen mit sich reden lassen, jedoch nicht über die Exterritorialität der Verbindung, nicht über Danzigs Anschluß an das Deutsche Reich und vor allem nicht über den Beitritt zum Antikominternpakt. Sollten es die Deutschen mit ihren Forderungen doch ernster meinen, mußten mithin zumindest schwierige Zeiten erwartet werden.

Beck, der Anfang November 1937 im Palais Brühl in einer kleinen Rede zur Feier seines ersten Jahrfünfts als Außenminister bekannt hatte, daß er sich auch in jeder konkreten Situation die Frage stelle: „Was hätte der Kommandant in dieser Lage getan?" 192 begann daher immerhin einige Vorkehrungen zu treffen. So sorgte er dafür, daß die Gespräche zwischen Ribbentrop und Lipski vorerst nur einem ganz kleinen Personenkreis im Außenministerium bekannt wurden ${ }^{193}$. Damit sollte vor allem verhindert werden, daß eine dann unweigerlich öffentliche Erörterung in Frankreich und namentlich in Großbritannien, wo das Prestige Polens angesichts der deutsch-polnischen Kollaboration gegen die CSR auf einen Tiefpunkt gesunken war, womöglich Zustimmung für die eine oder andere deutsche Forderung und vielleicht sogar ähnlichen Druck auf Warschau wie zuvor auf Prag provozierte ${ }^{194}$. Ferner bemühte sich Beck um eine Verbesserung der Beziehungen zur Sowjetunion. Gleich nach München hatte er den polnischen Botschafter in Moskau, Waclaw Grzybowski, beauftragt, in diesem Sinne mit Vladimir Potemkin zu sprechen, dem Stellvertreter des sowjetischen Außenministers Maxim Litwinow ${ }^{195}$. War es dabei noch einfach um

190 APA, Botschaft Berlin, Mappe 804, Aufzeichnung Beck-Moltke, 22.11.1938.

191 Wojciechowski, Die polnisch-deutschen Beziehungen.

192 Schimitzek, S. 414.

193 Ebenda, S. 441, 443.

194 Weinberg, The Foreign Policy of Hitler's Germany, S. 500.

195 H. Batowski, Europa zmierz ku przepaści, Posen 1977, S. 125 ff. 
Normalisierung gegangen, nachdem Polens Vorgehen gegen die CSR das polnisch-sowjetische Verhältnis ziemlich belastet hatte, so bekamen die polnischen Initiativen nach dem 24. Oktober noch einen zusätzlichen Sinn. Als nach etlichen Unterhaltungen zwischen Grzybowski und Litwinow am 27. November 1938 ein polnisch-sowjetisches Kommuniqué veröffentlicht wurde, in dem beide Seiten, von sonstigen Freundlichkeiten abgesehen, bekräftigten, daß der zwischen ihnen am 25. Juli 1932 abgeschlossene und am 5. Mai 1934 bis zum 31. Dezember 1945 verlängerte Nichtangriffspakt nach wie vor die Grundlage ihrer Beziehungen darstelle, hatte Beck damit Moskau versichert und Berlin signalisiert, daß sich Polen keiner antirussischen Kombination anschließen werde. Wie Graf Szembek notierte, handelte es sich bei dem Kommuniqué nur um eine Geste ${ }^{196}$; mehr wollte und konnte Beck den Sowjets nicht geben, wenn er nicht wiederum den Zorn der Deutschen - der nun gefährlicher war, als er noch ein Jahr zuvor gewesen wäre - auf sich ziehen wollte. Doch mochte die Geste genügend Entlastung im Osten bringen, um die Konzentration auf die im Westen aufgetauchten Probleme zu erlauben.

Vor allem aber verfolgte Beck mit vermehrtem Eifer eine Lieblingsidee, die ihm so ans Herz gewachsen war, daß er die bei ihrer Verwirklichung gegebene praktische Bedeutung maßlos überschätzte, zumal in der jetzt entstandenen Situation, in der er etwas im Gesicht gespürt hatte, das vielleicht die erste Bö eines gegen Warschau heranziehenden Wirbelsturms war. Von der Ostsee bis zur Adria sollte, so träumte er seit langem, durch einen engeren Zusammenschluß Polens, Ungarns und Jugoslawiens - unter Beteiligung Italiens - zwischen den Großmächten ein „Drittes Europa“ entstehen und sich gegen die wirtschaftlich und politisch Stärkeren unabhängiger halten können als jedes einzelne Land allein ${ }^{197}$. Von der Rolle als Organisator und Lenker, nach der er dabei trachtete, versprach er sich für Polen eine Konsolidierung des sowieso beanspruchten Großmachtstatus und in erster Linie mehr Sicherheit. Im Rahmen seiner Konzeption schrieb er der Schaffung einer gemeinsamen polnisch-ungarischen Grenze große Bedeutung zu, und daher setzte er sich nach dem Münchner Abkommen sowohl in Budapest wie in Berlin energisch für den Erwerb der Karpatho-Ukraine durch Ungarn ein; zugleich erhoffte er sich davon, daß die notorisch harte Minderheitenpolitik der Magyaren mit der für Polen - wo ja eine stattliche Anzahl Ukrainer lebte - nicht ungefährlichen großukrainischen Agitation kurzen Prozeß machen werde, die in der Karpatho-Ukraine von deutschen Agenten - worüber sich Beck in Berlin denn auch lebhaft beklagte - seit München entfaltet wurde. Noch Ende Februar 1939, als sich Graf Ciano für einige Tage in Polen aufhielt, suchte Beck den Außenminister des südlichen Achsenpartners für seine Pläne zu erwärmen. Ciano hütete sich frei-

196 Ebenda.

197 Weinberg, The Foreign Policy of Hitler's Germany, S. 193, 204 f., 323, 405, 499. 
lich, sich auf osteuropäische Manöver einzulassen, die deutsches Stirnrunzeln hervorrufen konnten; „dieser Mensch“, spottete Beck wenig später voll Ingrimm in einem Brief an einen Freund, „fürchtet sich vor seinem eigenen Schatten, wenn er von Deutschlandpolitik in Osteuropa spricht" ${ }^{198}$. Auch sonst zeitigten Becks Anstrengungen kaum Resultate, doch hätte der von ihm erstrebte Verbund relativ schwacher Länder für die erhoffte Funktion als Block ohnehin nie die notwendige Stärke gewonnen.

Die Hilfsmittel, die Polen gegen eine etwaige Bedrohung zu Gebote standen, konnten also, alles in allem, wenig Vertrauen erwecken. Kein Wunder, daß Becks Unruhe nicht verschwand, sondern zunahm. Im Laufe des Dezember 1938 verriet er zwar noch nicht gerade Furcht oder Nervosität, aber doch eine gewisse Beunruhigung. Intern sprach er nun davon, daß die deutsch-polnischen Beziehungen einen „toten Punkt“ erreicht hätten, wofür er jedoch noch nicht Hitler verantwortlich machte, sondern den schrecklichen Ribbentrop ${ }^{199}$; es war erst zehn Monate her, daß Beck den Wechsel von Baron Neurath zu Ribbentrop begrüßt hatte, weil er annahm, daß die Ablösung eines polenfeindlichen Deutschnationalen durch einen unbefangenen Nationalsozialisten für Polen vorteilhaft sei200, doch waren ihm inzwischen die gefährlichen Eigenschaften und die bedenklichen politischen Tendenzen des neuen Reichsaußenministers von Lipski sehr deutlich geschildert worden. An Ribbentrop war nicht zuletzt zu fürchten, daß er, wie Lipski darlegte, antibritisch empfand und daher in einer grotesken Unterschätzung Großbritanniens daran arbeitete, Hitler und das Deutsche Reich in einen Krieg mit den Westmächten zu hetzen ${ }^{201}$. Für Polen mußte das in jedem Falle bedrohlich sein: Selbst wenn die Deutschen nicht verleitet wurden, vor der Wendung gegen den Westen Polen in einem raschen Feldzug niederzuwerfen, war dann die Unterwerfung des Landes durch Deutschland kaum mehr abzuwenden, da die polnische öffentliche Meinung ein Eingreifen auf der Seite Deutschlands niemals dulden und ein siegreiches Deutschland die Neutralität Polens nicht ungerächt lassen würde 202. Das Bedürfnis Becks nach einer Klärung der Lage wurde immer dringlicher, d.h. sein Bedürfnis, mit den maßgebenden Leuten in Berlin persönlich zu reden. Am 14. Dezember bat er den deutschen Botschafter zu sich, und nachdem er von „einer gewissen Spannung“ im deutsch-polnischen Verhältnis gesprochen hatte, die doch eine „Absurdität“ sei, teilte er Moltke mit, daß er Lipski angewiesen habe, ein Gespräch Becks mit Ribbentrop vorzuschlagen ${ }^{203}$. Beck hätte die Unterredung gerne nach War-

199 Szembek-Tagebuch, S. 376.

200 Schimetzki, S. 419.

201 Szembek-Tagebuch, S. 359.

202 Ebenda, S. $367 \mathrm{f}$.

203 Moltke an AA, 15.12.1938, PAA, Büro Staatssekretär, Polen 1, $34498 \mathrm{ff}$. 
schau gelegt, doch wurde schließlich vereinbart, daß er Anfang Januar 1939 mit Hitler und Ribbentrop in Deutschland zusammentreffen werde.

Von einem Aufenthalt an der Riviera zurückkehrend, machte also Beck am 5. und 6. Januar in Bayern Station, wo er in Berchtesgaden zuerst mit Hitler und dann in München mit Ribbentrop konferierte ${ }^{204}$. Beide Gespräche verliefen alles andere als beruhigend. Zwar schlugen sowohl der „Führer" wie sein Außenminister einen durchaus freundschaftlichen Ton an, und beide versicherten ihrem polnischen Gast, daß sie gewillt seien, das bestehende gute Verhältnis zwischen dem Reich und Polen zu konsolidieren und weiter zu verbessern. Auch Beck tat so, als sei in den deutsch-polnischen Beziehungen grundsätzlich alles in bester Ordnung, als gebe es lediglich etliche kleinere Schwierigkeiten, die gewiß leicht ausgeräumt werden könnten. Aber Becks Hoffnung, er werde eine Bestätigung der positiven Eindrücke mit nach Warschau nehmen dürfen, die Lipski am 19. November gehabt hatte, wurde bitter enttäuscht. Wie sich die beiden Deutschen die „Konsolidierung“ vorstellten und was sie zu den „kleinen Schwierigkeiten" zu sagen hatten, ließ nicht den mindesten $Z$ weifel daran, daß aus dem Katalog, den Ribbentrop am 24. Oktober präsentiert hatte, nicht eine einzige Forderung herausgenommen oder wenigstens abgeschwächt worden war und daß es sich bei dem Katalog selbst keineswegs nur um ein Werk Ribbentrops, sondern sehr wohl um das Werk des „Führers“ handelte. Tatsächlich hörte sich der Anspruch auf Danzig noch bestimmter an als zuvor, und auch im Hinblick auf Rußland wurden die Deutschen drängender. Ribbentrop kam auf den Beitritt Polens zum Antikominternpakt zurück, und nachdem er für die Zukunft die lockendsten Bilder deutsch-polnischer Partnerschaft gegen die Sowjetunion und speziell in der ukrainischen Frage gemalt hatte, erklärte er, dies setze natürlich „eine immer klarere antirussische Einstellung Polens voraus".

Becks Beunruhigung wandelte sich zu tiefer Besorgnis. Er hatte sich genötigt gefühlt, Hitler und Ribbentrop auseinanderzusetzen, daß Polen der Annexion Danzigs durch das Reich nicht zustimmen könne. Dabei hatte er Hitler klarzumachen versucht, daß er in der Danziger Frage nicht auf jene nationalistischen Oppositionellen Rücksicht nehme, die in Warschauer Kaffeehäusern politisierten; um diese Leute habe er sich noch nie gekümmert und sei trotzdem noch immer im Amt. Vielmehr sei in der Danziger Frage die ganze polnische Gesellschaft äußerst reizbar, und zwar in den tiefsten Schichten ihrer Gefühle ${ }^{205}$. Als am 18. Februar der ReichsführerSS Heinrich Himmler Warschau besuchte, bekam er von einem der Stellvertreter Becks, Mieroslaw Arcziszewski, Ähnliches zu hören, und als Himmler auf der Eingliederung Danzigs beharrte, sagte Arcziszewski, Polen werde sich mit der "Gleichschaltung" des ja ohnehin nationalsozialistisch 
regierten Freistaats abfinden, aber nicht mit dessen Anschluß ${ }^{206}$. Zweitens war Beck erst recht gezwungen gewesen, die deutschen Avancen im Hinblick auf Rußland deutlich zurückzuweisen. Wohl hatte er auf Ribbentrops Frage, ob man denn in Polen die Aspirationen Pilsudskis auf die Ukraine tatsächlich völlig aufgegeben habe, lachend geantwortet, er sei schließlich selber mit dem Marschall in Kiew gewesen, und die Aspirationen von damals gebe es zweifellos auch noch heute. Auf der anderen Seite hatte er jedoch den Beitritt zum Antikominternpakt glatt abgelehnt, da ein derartiger politischer Vertrag mit Deutschland jene „friedliche Nachbarschaft mit Rußland, die Polen zu seiner Ruhe brauche“, unmöglich mache. Angesichts einer so tiefen und bereits unüberbrückbar scheinenden Diskrepanz der Standpunkte war es kein Wunder, daß Beck am Ende der Unterhaltung mit Ribbentrop sagte, wenn er bisher nach Gesprächen mit Deutschen immer optimistisch gewesen sei, so sehe er jetzt zum ersten Mal pessimistisch in die Zukunft - er bitte Ribbentrop, dies auch dem „Führer" mitzuteilen ${ }^{207}$.

Nach Warschau zurückgekehrt, berichtete Beck am 8. Januar Staatspräsident Ignacy Moscicki, Marschall Smigly-Rydz, Ministerpräsident Skladkowski und dessen Stellvertreter Eugeniusz Kwiatkowski, daß er nun doch „beunruhigende Erscheinungen“ konstatieren müsse, „die zum Krieg führen können"208. Und man gab sich in Warschau durchaus Rechenschaft darüber, daß, von Danzig und der Korridorfrage ganz abgesehen, allein schon die Weigerung Polens, an einem deutschen Eroberungszug gegen Rußland teilzunehmen, Hitler veranlassen mochte, Polen militärisch anzugreifen. Wie sollten die Deutschen denn, falls sie in der Tat Ziele in der Sowjetunion im Visier hatten, zu diesen Zielen gelangen - so fragten sich z.B. am 3. Januar Lipski und Graf Szembek -, ohne in der einen oder anderen Form Polen zur Verfügung zu haben ${ }^{209}$ ? Vereinzelt meldeten sich auch Stimmen, die sagten, daß es wohl nicht möglich sei, bei der Weigerung zu bleiben. Anatol Mühlstein etwa, bis 1936, zuletzt als Botschaftsrat in Paris, Diplomat und in den politischen Kreisen der polnischen Hauptstadt nicht ohne Einfluß, wenn er auch gerade eben gänzlich erfolglos - und ganz allein - die Tschechenpolitik der polnischen Regierung scharf kritisiert hatte, Mühlstein prophezeite ein großes deutsches Ausgreifen nach Osten, das die Hemisphäre vom Rhein bis zum Pazifik in eine Katastrophe stürzen und von der Ausrottung der Juden begleitet sein werde, und er meinte, Polen werde gezwungen sein, an der Seite Deutschlands zu gehen210. Doch Mühlstein stand, wie einige Monate zuvor im Falle der CSR, allein. In der Besprechung vom 8. Januar waren sich alle Anwesenden nach Becks Bericht einig: Hielten die Deutschen ihren Druck in Fragen aufrecht, die für

206 APA, Botschaft Berlin, Mappe 804, Aufzeichnung Graf Potocki, 20.2.1939.

207 Szembek-Tagebuch, S. 467.

208 J. Krasuski, Miedzy Wojnami, Warschau 1985, S. 183.

209 Szembek-Tagebuch, S. 458.

210 Ebenda, S. 400. 
sie so zweitrangig waren wie Danzig und die Autobahn von Pommern nach Ostpreußen, dann drohte, da waren keine Illusionen erlaubt, ein Konflikt großen Ausmaßes, dann mußten die Forderungen als bloße Vorwände verstanden werden. Jedenfalls kam aber, wie dem auch sein mochte, eine schwankende Haltung Polens nicht in Frage; sie konnte nur auf „eine schiefe Ebene führen“ und bei dem Verlust der Unabhängigkeit des Landes enden ${ }^{211}$.

Indes fiel Beck rasch wieder auf die Überzeugung zurück, daß Festigkeit ohne irgendeine Änderung der Grundlinie der polnischen Politik aus der Krise herausführen werde, weil Hitler lediglich ein Erpressungsmanöver eingeleitet habe, das er bei härterem Widerstand abbrechen werde ${ }^{212}$. Nach wie vor redeten sowohl er wie andere polnische Politiker und Diplomaten sich ein, daß sie es doch unmöglich mit einem grundlegenden Wandel der deutschen Polenpolitik zu tun haben könnten, zumal sich vom 25. bis zum 27. Januar, als Ribbentrop in Erwiderung der Besuche Becks in Deutschland zu zweitägigen Besprechungen nach Warschau kam, einfach die Gesprächsabläufe vom 5. und 6. Januar wiederholten. Ribbentrop zählte abermals die deutschen Vorschläge auf, dabei sowohl die Forderungen wie die Lockungen nur eine Spur schärfer und drängender formulierend, während Beck erneut die Forderungen ablehnte und die Lockungen - als allzu große Gefährdungen Polens - nicht annahm ${ }^{213}$; zu den Forderungen durfte er unwidersprochen anmerken: „Wir sind doch keine Tschechen!"214 Beide Seiten behielten einen freundlichen Ton bei, und am Schluß waren die Gastgeber wohl nicht beruhigter, doch auch nicht sonderlich besorgter gestimmt. Noch ein paar Wochen später, am 17. Februar, konnte Graf Szembek in Rom zu Pater Ledochowski, dem General der Jesuiten, sagen, daß es in den deutsch-polnischen Beziehungen gewiß Probleme gebe, die Schwierigkeiten verursachten, aber diese Schwierigkeiten seien noch keine Beweise für unredliche Absichten der deutschen Regierung; Hitler wolle sicherlich noch immer die deutsch-polnische Entspannung 215 .

Wollten die Polen nicht wahrhaben, daß nach Ansicht Hitlers nun für sie das Stündlein geschlagen hatte, so vermochten andererseits die Deutschen nicht zu begreifen, wieso man in Warschau den deutschen Signalen nicht einfach Folge leistete. Vor dem Gespräch Beck-Ribbentrop in München hatte das Auswärtige Amt für den Reichsaußenminister Unterlagen zusammengestellt, in denen Fürst Bismarck, stellvertretender Leiter der Politischen Abteilung, Ribbentrop empfahl, „Herrn Beck darauf hinzuweisen, daß die Deutsche Regierung erwarten dürfe, daß die Polnische Regierung der durch die Wiedererstarkung Deutschlands, insbesondere aber durch die

211 Krasuski, S. 183.

212 Schimetzki, S. 444.

213 ADAP, D, 5, S. $139 \mathrm{f}$.

214 Szembek-Tagebuch, S. 484.

215 Ebenda, S. 500. 
Ereignisse des Jahres 1938 völlig veränderten europäischen Lage Rechnung trage. Polen werde sich gewiß darüber klar sein, daß Deutschland heute die einzige Macht in Europa sei, an die es sich anlehnen könne... Die deutsche Regierung habe mit Interesse die kürzlichen Bemühungen Polnischer Regierung, das polnisch-russische Verhältnis zu verbessern, verfolgt. Deutscherseits sei gegen eine Normalisierung russisch-polnischer Beziehungen nichts einzuwenden, wobei wir allerdings der Meinung seien, daß die Sowjet-Union zurzeit weder als Freund von besonderem Wert noch als Feind besonders zu fürchten sei. Auch bezüglich des polnisch-französischen Verhăltnisses sei sich Polen gewiß darüber klar, daß Frankreichs Freundschaft eine platonische sei, seitdem der westdeutsche Limes stehe und Frankreich die für ihr europäisches Bündnissystem wesentlich wichtigere TschechoSlowakei kurzerhand ihrem Schicksal überlassen habe." 216 Wenn schon Beamte des Auswärtigen Amts das deutsch-polnische Verhältnis nur mehr in solch machtpolitischen Kategorien sahen und von der polnischen Regierung mit Selbstverständlichkeit den Wechsel ins deutsche Lager - samt der daraus entstehenden Pflicht zu loyalem Gehorsam - erwarteten, so erst recht und noch gröber Hitler und Ribbentrop. Auch Führer der deutschen Minderheit in Polen rechneten, nachdem sie von den bislang gegen die Öffentlichkeit ja streng abgeschirmten deutsch-polnischen Gesprächen vage gehört hatten, bezeichnenderweise sofort damit, daß sich Polen an einer deutschen Rußland-Kampagne beteiligen werde. So beeilten sie sich, in Berlin vorsorglich gegen eine Honorierung der polnischen Waffenbrüderschaft mit der Anerkennung der deutsch-polnischen Grenzen zu protestieren, es sei denn, daß zuvor Danzig und der „Korridor“ zum Reich geschlagen werden könnten; andernfalls müßten sich die dort lebenden Deutschen zwischen Polonisierung und Auswanderung entscheiden ${ }^{217}$. Ebenso bezeichnend war, daß angesichts der unvermeidlichen Gerüchte über deutsche Forderungen an Polen viele Deutsche im Lande und naturgemäß nicht zuletzt in Danzig bereits den Marschtritt deutscher Regimenter zu ahnen und ein entsprechend herausforderndes Benehmen an den Tag zu legen begannen. Studenten, wie so oft in der Geschichte zu politischer Radikalität nur allzu geneigt, zeichneten sich besonders aus. In Danzig, wo an der Technischen Hochschule seit 1922 ein Beschluß der deutschen Studentenschaft existierte, demzufolge polnische Studenten beleidigt werden durften, ohne Anspruch auf Entschuldigung zu haben ${ }^{218}$, erschienen jetzt z.B. an deutschen Studentenkneipen Tafeln, auf denen so geschmackvolle Inschriften zu lesen waren wie: „Hunden und Polen Zutritt verboten!“219

Auch solche deutsche Herausforderungen weckten, wie die auf höherer politischer Ebene, polnische Widerstände, wobei allerdings in diesen Fällen

216 Aufzeichnung Bismarck, 2.1.1939. PAA, Büro Staatssekretär, Polen 1, $34505 \mathrm{f}$.

217 Aufzeichnung Schliep, 30.12.1938, PAA, Büro Staatssekretär, Polen 1, $34517 \mathrm{f}$.

218 PAA, Büro Staatssekretär, Polen 1, $34547 \mathrm{ff}$.

219 Ebenda. 
die polnischen Reaktionen, anders als auf dem Feld der Regierungspolitik, den deutschen Provokationen weder an Dummheit noch an Grobheit nachstanden. Die polnische Gesellschaft und zumal die polnische Studentenschaft besaßen, da gab es durchaus Parallelen zu deutschen Zuständen, ihr gerüttelt $\mathrm{Ma} ß$ an Rechtsradikalen. Vornehmlich diese Rechtsradikalen fühlten sich nun zur Beantwortung der deutschen Aktionen berufen, und wieder einmal bestätigte sich ein politisches Naturgesetz, wonach die Interessen eines Landes von niemand so eifrig und kräftig mit Füßen getreten werden wie von nationalistischen Rechtsradikalen, die das Land besonders zu lieben behaupten. In Anbetracht der Umstände war es gewiß unvermeidlich, daß polnische Studenten in Danzig ihr Recht auf Zutritt zu allen Lokalen und zur Hochschule demonstrieren und durchsetzen wollten, woraus sich am 22. und 23. Februar wüste Massenschlägereien zwischen deutschen Studenten und ihren polnischen Kommilitonen entwickelten. Während der Demonstrationen tauchten jedoch auch Redner und Plakate auf, die nicht allein zur Annexion Danzigs aufriefen, sondern gleich auch noch Ostpreußen und in einigen Fällen sogar ganz Ostdeutschland bis zur Elbe für Polen verlangten. Dazu wurden entsprechend wilde Resolutionen verabschiedet ${ }^{220}$. Am 24. Februar kam es zu ähnlichen Schauspielen in Posen und Warschau, wobei in Posen Fensterscheiben der deutschen „Evangelischen Vereinsbuchhandlung" und der deutschen „Kosmos“ - Buchhandlung zu Bruch gingen, in Warschau auch Fenster der deutschen Botschaft ${ }^{221}$. Die Demonstranten in der Hauptstadt, ebenfalls jugendliche Rechtsextremisten, brüllten auch Parolen wie „Nieder mit Hitler“, „Es lebe das polnische Danzig“, „Nieder mit der deutschfreundlichen Politik“, „Fort mit den deutschen Hunden", und rund hundert zogen vor das Palais des Marschalls Smigly-Rydz und riefen: „Marschall, führe uns nach Danzig!'222

Mit dem offiziellen Polen und mit der Mehrheitsstimmung in der polnischen Bevölkerung hatten derartige Vorfälle indes nicht das geringste zu tun. Auch von der deutschen Propaganda wurden sie erst später verwendet, dann aber, noch aufgebauscht und vor allem als repräsentativ für die ganze polnische Nation ausgegeben, nicht ohne Wirkung. Im Augenblick herrschte jedoch auf beiden Seiten die Überzeugung, daß man sich doch noch verständigen werde. Die polnische Regierung entschuldigte sich beim deutschen Botschafter feierlich und aufrichtig für die Danziger, Posener und Warschauer Zwischenfälle223. Aus Deutschland war z.B. eine Frontkämpfer-Delegation nach Polen gekommen, die allenthalben von polnischen Frontkämpfer-Organisationen und den Spitzen der Armee wie der regionalen Verwaltung herzlich aufgenommen wurde. Am Tag der War-

223 Moltke an AA, 25.2.1939, PAA, Büro Staatssekretär, Polen 1, 34557, 34559. 
schauer Krawalle wechselten die Mitglieder der deutschen Delegation bei einem Frühstück in Krakau kameradschaftliche Trinksprüche mit polnischen Generälen und dem Krakauer Wojewoden Dr. Tyminski; nachdem der Leiter der deutschen Delegation, der Herzog v. Coburg, General der Infanterie und NSKK-Obergruppenführer, am Grab Pilsudskis einen Kranz niedergelegt hatte, wurden die deutschen Gäste mit allen militärischen Ehren verabschiedet ${ }^{224}$. Hitler und Ribbentrop nahmen die antideutschen Kundgebungen noch kaum wahr, geschweige denn ernst. Seit Anfang Januar fragten sie sich, wie das polnische Zögern zu erklären und wie es zu beenden sei. Vielleicht war es nützlich, unterhalb der Spitzengespräche Stimmung für die deutsch-polnische Partnerschaft zu machen. So schickte Ribbentrop den Gesandten Gottfried Aschmann, den Leiter der Nachrichten- und Presseabteilung im Auswärtigen Amt, nach Warschau, der dort mit dem Leiter der Westabteilung im polnischen Außenministerium, mit dem Starosten von Warschau und mit einem der einflußreichsten polnischen Journalisten sprach, um ihren Appetit auf die Ukraine anzustacheln. Als er am 30. Januar Ribbentrop über das Ergebnis seiner Reise unterrichtete, mußte er freilich resignierend schreiben: „Die Idee, die sowjetrussische Ukraine für Polen zu gewinnen, sagte allen Dreien nichts.“ Allerdings hatte er noch tiefe Verehrung für Marschall Pilsudski angetroffen, und das brachte ihn auf eine Idee: „Ich habe das Institut Berber gebeten, alle Äußerungen Pilsudskis zur ukrainischen Frage zusammenzustellen. Vielleicht findet man dabei Argumente, mit denen die laue Haltung der Polen mobilisiert werden kann." 225

Hitlers Denken kreiste in jenen Tagen und Wochen fast ausschließlich um seine nächsten außenpolitischen Schritte. Am 3. Februar 1939 notierte Goebbels nach einem Mittagessen beim „Führer“: „Er wälzt wieder neue Pläne." Und die Pläne veranlaßten den Reichspropagandaminister zu dem Kommentar: „Eine napoleonische Natur.“226 Allerdings konnte sich Hitler, wenn er aus dem Reich der großen Entwürfe zur Erde zurückkehrte und die politischen Realitäten in Europa ins Auge faßte, nicht verhehlen, daß er im Morast der Verhältnisse stecken zu bleiben drohte, daß er jedenfalls keineswegs so schnell vom Fleck kam, wie er das in den ersten Monaten nach München gehofft hatte. Mit besonderem Mißmut blickte er nach England. Noch Anfang Oktober hatten er und Ribbentrop eine Taktik zur Beeinflussung der Meinungsbildung in Großbritannien ausgeheckt, die für beider Wesensart sehr charakteristisch war. Statt eine Kampagne zum Lobe und zur Stützung Chamberlains zu führen, sollten die deutschen Medien, Presse und Rundfunk, britische Kritiker von München wie Churchill, Eden, Duff Cooper und Archibald Sinclair, den Führer der Liberalen, unter Dauerbeschuß nehmen. Hitler gab selbst das Startsignal, als er am 9. Oktober in

224 DNB, 24.2.1939.

225 Aufzeichnung Aschmann, 30.1.1939, PAA, Büro Staatssekretār, Polen 1, $34537 \mathrm{f}$.

226 Tagebücher von Joseph Goebbels, Bd. 3, S. 567. 
Saarbrücken eine Rede hielt, die von Beschimpfungen der britischen Opposition nur so strotzte ${ }^{227}$. Den speziellen Sinn dieser "nach genauen Instruktionen des Herrn Reichsministers" eröffneten Kampagne erläuterte Staatssekretär v. Weizsäcker am 17. Oktober, nachdem der deutsche Botschafter in London, Herbert v. Dirksen, lauthals protestiert hatte228: Ziel sei, „die öffentliche Meinung in England zu spalten, d.h. zu erreichen, daß sich das Lager, das keinesfalls einen Krieg mit Deutschland will, von demjenigen trennt, das von dem Standpunkt ausgehend, England sei in München vor Deutschland zurückgewichen, eine Steigerung und Beschleunigung der Rüstung wünscht, um Deutschland 'das nächste Mal' energisch und ohne Rücksicht auf die Konsequenzen entgegenzutreten“. Weizsäcker fügte vielsagend hinzu: „Die Entwicklung geht hier weiter in einem schnellen Tempo. Einer deutsch-englischen Annäherung wendet sie sich aber z.Zt. nicht zu." 229 Trotz weiteren Widerspruchs aus der Londoner Botschaft waren Hitler und Ribbentrop bei ihrem Rezept geblieben, und fünf Monate später mußte konstatiert werden, daß die Kampagne ihren Zweck völlig verfehlt hatte: sie wirkte in England - weil einfach als antibritisch und als böses Entgelt für das Entgegenkommen von München empfunden - als Zeichen fortdauernder Aggressionslust und stärkte mithin die Position der Angegriffenen, die mit ihrer Einschätzung der deutschen Führer offenbar recht hatten; schon gar nicht war die britische Rüstung, so schwerfällig sie sich auch noch immer entwickelte, von Attacken auf Politiker gebremst worden, die allesamt kein Amt hatten.

War es schon ägerlich genug, daß sich das künftige Opfer weigerte, auf Zuwachs an Stärke zu verzichten oder gar schwächer zu werden, so war noch frustrierender, daß die eigene Rüstungsanstrengung fortwährend auf Schwierigkeiten stieß und hinter den Erwartungen zurückblieb. Allerdings wurden die Erwartungen in schwindelnde Höhen geschraubt. Zwei Wochen nach München, als viele Menschen innerhalb und außerhalb Deutschlands glaubten, der Friede sei durch die Erfüllung der deutschen Ansprüche für lange Zeit gesichert, eröffnete Göring einer Versammlung von Wirtschaftlern, daß er vom „Führer“ den Auftrag erhalten habe, „die Rüstung abnorm zu steigern". An erster Stelle stehe die Luftwaffe, die „schnellstens zu verfünffachen“ sei. Doch „auch die Marine müsse schneller rüsten, und das Heer müsse schneller große Mengen von Angriffswaffen schaffen, in Sonderheit schwere Artillerie und schwere Tanks". Ferner sei die „fabrikatorische Rüstung“ weiterzutreiben, ,wobei in Sonderheit Treibstoffe, Gummi, Pulver- und Sprengstoffe in den Vordergrund zu rücken“" seien. „Daneben muß gehen der beschleunigte Straßenbau, Kanalausbau und in Sonderheit der Eisenbahnausbau."230 Görings Darlegungen, die er

\footnotetext{
227 Monatshefte für Auswärtige Politik 5 (1938), S. $1106 \mathrm{ff}$.

228 ADAP, D, 4, Nr. 253.

229 Ebenda.

230 IMT, Bd. XXVII, S. $160 \mathrm{ff}$.
} 
dem Sinne nach am 19. November auf einer Sitzung des sog. Reichsverteidigungsrates wiederholte ${ }^{231}$, liefen darauf hinaus, Gesellschaft und Wirtschaft noch im Frieden auf Kriegsfuß zu bringen, und Göring sagte denn auch, die Schwierigkeiten, die diesem Vorhaben entgegenstünden, seien fast unüberwindlich. Doch werde er, um das Ziel zu erreichen, die Wirtschaft notfalls „mit brutalen Mitteln umdrehen“. Sogar mit Sozialisierung drohte er: „Es sei jetzt der Moment da, wo die Privatwirtschaft zeigen könne, ob sie noch eine Daseinsberechtigung hätte. Wenn sie versagt, ginge er rücksichtslos zur Staatswirtschaft über.“

Am 1. November wies Hitler das Oberkommando der Marine an, die Flottenrüstung erheblich zu steigern ${ }^{232}$, und bereits am 17. Januar 1939 konnte der „Z-Plan“ verabschiedet werden, der eine beträchtliche Vermehrung der deutschen Hochseeflotte vorsah ${ }^{233}$. Schon am 10. Dezember 1938 hatte aber Botschafter v. Dirksen dem britischen Außenminister Lord Halifax ein Schreiben der Reichsregierung überreicht, in dem mitgeteilt wurde, daß Deutschland seine U-Boot-Waffe von 45 Prozent auf 100 Prozent der U-Boot-Waffe des britischen Commonwealth bringen werde234. Das deutsch-britische Flottenabkommen beschränkte an sich die deutsche UBoot-Waffe auf 45 Prozent der britischen, doch erlaubte eine Klausel die jetzt angekündigte Steigerung, falls eine Situation entstand, in der sich die deutsche Regierung zu einem solchen Schritt gezwungen glaubte. In der deutschen Note war denn auch - noch kein Vierteljahr nach München gesagt, daß es notwendig geworden sei, für den Fall kriegerischer Verwicklungen die deutschen Seeverbindungen besser zu schützen. Abgesehen davon, daß die gegebene Begründung militärisch unsinnig war, weil mit UBooten nur die britischen Verbindungen gefährdet, doch keine deutschen Verbindungen geschützt werden konnten, brachte die deutsche Mitteilung die britischen Empfänger auch deshalb in Harnisch, weil das deutsche Vorhaben - als handfest antibritisch wirkend - geeignet war, Chamberlains Verständigungspolitik lächerlich zu machen, und weil der Bau von deutschen U-Booten zum Bau britischer Zerstörer nötigte. In deutsch-britischen Marinegesprächen suchte Admiral Cunningham zunächst eine geringere Vermehrung der deutschen U-Boote zu erreichen, und als das an der Berufung der deutschen Offiziere auf einen „Führer-Befehl“ scheiterte, bat er - zur Schonung der öffentlichen Meinung in England - darum, bei der öffentlichen Verkündung des doch ohnehin mehrere Jahre beanspruchenden deutschen Plans wenigstens nur die vorgesehenen jährlichen Zuwachsraten - und nicht gleich die angestrebten 100 Prozent - zu nennen. Auch

231 IMT, Bd. XXXII, S. $411 \mathrm{ff}$.

232 Vgl. Taylor, Munich, S. 940 f.; Weinberg, The Foreign Policy of Hitler's Germany, S. 514.

233 Ebenda.

234 Taylor, Munich, S. 940. 
das hatte die deutsche Delegation unter Admiral Otto Schniewind abzulehnen 235 .

Auf der anderen Seite mußten sich Hitler, Göring und Ribbentrop eingestehen, daß ihr Rüstungsprogramm - mit den Schwerpunkten auf Luftwaffe und Marine eine unmittelbare Konsequenz des Wandels in der auBenpolitischen Prioritätensetzung - zwar auf dem Papier „gigantisch“ aussah, doch in der Realität zahlreichen Hindernissen begegnen und sich durch etliche bremsende Engpässe zu quälen haben werde. Rhetorische Peitschenhiebe und Drohungen mit der Sozialisierung, wie sie Göring so liebte, behoben weder den Mangel an Arbeitskräften noch den Mangel an Rohstoffen und Devisen. Hielt sich Hitler außerdem vor Augen, daß sich die Verhandlungen über einen deutsch-italienisch-japanischen Militärpakt vorerst im Tokioter Gestrüpp verfangen hatten und daß sich Polen in einer Weise zierte, die nicht nur unverständlich, sondern geradezu unschicklich zu nennen war, wenn man bedachte, wer da den Warschauern die Hand zum Bunde bot, dann fand der „Führer" in der Tat genügend Anlaß, mit der Entwicklung oder doch mit ihrem Tempo unzufrieden zu sein. Nicht deshalb, weil er den Abschluß der bündnispolitischen Bemühungen und einen Höchststand der Rüstungsanstrengung unbedingt schon im Jahr 1939 zu brauchen geglaubt hätte. Im Februar 1939 war ihm keineswegs klar, daß er noch im Laufe dieses Jahres Krieg führen werde, ob einen großen oder einen kleinen Krieg. $\mathrm{Zu}$ jenem Zeitpunkt sah er dafür weder außenpolitische noch militärisch-strategische oder gar wirtschaftliche Gründe, die ihm als zwingend erschienen wären. Die antiwestliche Bündnispolitik und notwendigerweise erst recht die antiwestliche Rüstungspolitik mußten ohnehin so kalkuliert werden, daß der Termin zum Losschlagen erst in zwei bis drei Jahren zu erwarten stand; wenn die Deutschen seit November 1938 ihre italienischen Freunde mehrmals davor warnten, durch eine allzu hitzige Verfechtung ihrer antifranzösischen Ziele einen verfrühten Krieg mit den Westmächten vom Zaun zu brechen, so war das noch nicht unaufrichtig236. Die krisenhaften Erscheinungen, die sich, als Folge der wahrhaft wahnwitzigen Ausweitung und Beschleunigung der Rüstung, in der Wirtschaft des Großdeutschen Reiches tatsāchlich zeigten, wären schon durch eine gewisse Drosselung oder doch durch den Verzicht auf ständige Forcierung der Rüstung zu dämpfen gewesen. Aber Hitler nahm sie ja überhaupt nicht als Störungen des Wirtschaftslebens wahr, sondern als die unvermeidlichen Reibungen der bisherigen wirtschaftlichen Mobilmachung und als die irgendwie auszuschaltenden Hindernisse der noch zu leistenden Rüstung. Jedenfalls entdeckte er hier keine $Z$ wänge für außenpolitische oder militärische Aktionen, auch nicht für deren zeitliche Festsetzung. Es war ihm durchaus bewußt, daß die Konzentration der personellen, finanziellen

236 AIA, Ap Germania, Pariani an Ciano, 17.4.1939, mit Aufzeichnung Maras für Pariani. 
und materiellen Ressourcen auf den geplanten Krieg, die wohl für eine Weile Vollbeschäftigung garantierte, doch die normalen Handelsbeziehungen des Landes ebenso ruinierte wie die Währung und mit einschneidenden Konsumverzichten verbunden war, Deutschland und der deutschen Bevölkerung nicht auf unbegrenzte Zeit zugemutet werden konnte. Da ihn aber die Belastung des Volkskörpers für eine Frist, nach deren Ablauf er sowieso losschlagen wollte, zumutbar dünkte, hat er jener Einsicht, die er des öfteren als Argument anführte, um darzutun, daß der große Krieg nicht später als 1942/43 begonnen werden dürfe, nicht schon im Jahr 1939 irgendeinen Einfluß auf seine Kalkulationen und Entschlüsse eingeräumt.

$\mathrm{Daß}$ seine Ungeduld wuchs, als er in den ersten Monaten des Jahres 1939 über die Grundfragen und die nächsten Züge seiner Expansionspolitik grübelte, lag auch nicht an Pressionen, die aus der NS-Bewegung gekommen wären oder sich aus der Struktur von Bewegung und Herrschaftssystem ergeben hätten; der Triumph von München reichte aus, um hier jahrelang für Zufriedenheit und Ruhe zu sorgen. Erst recht gab es keinen Druck von Interessentengruppen, etwa aus Wirtschaftskreisen; Industrielle und Bankiers hatten längst jeden eigenständigen politischen Einfluß verloren, und während sie sich in Anpassung an das Regime und seine Politik übten, hätten sie sich nur allzu gern mit gewinnbringenden Aktivitäten im jetzt erreichten Rahmen begnügt. Hitler war der Souverän und in seinen Entscheidungen frei von situationsbedingten oder systemimmanenten Zwängen. Die Unruhe kam allein aus ihm selbst. Wie 1937 und 1938 begann er außenpolitische und kriegerische Expansionsmöglichkeiten, die er mit rationalen Gründen in eine noch etwas weiter entfernte Zukunft placiert hatte, näher heranzuziehen und sich wie seiner engsten Umgebung als unter Umständen viel früher - vielleicht schon demnächst - erreichbar hinzustellen. Die Unfähigkeit, über längere Fristen passiv zu bleiben - die Ulrich v. Hassell, damals noch Botschafter in Rom, bereits bei der Remilitarisierung des Rheinlands als einen der mächtigsten Antriebe der praktischen Politik Hitlers diagnostiziert hatte -237 , machte sich von Woche zu Woche stärker bemerkbar, und so empfand er mehr und mehr das Bedürfnis, ein Mittel zur Beschleunigung der diversen Manöver zu finden, die zur Vorbereitung der größeren Unternehmungen eingeleitet worden waren. Bei seiner Sinnesart lag der Gedanke nahe, daß dazu eine weitere Demonstration deutscher Kraft und ein erneuter Machtzuwachs des Reiches am besten taugten, und danach war es nur logisch, sich zunächst einmal zur ohnehin anstehenden definitiven Bewältigung des von München hinterlassenen „halberledigten machtpolitischen Problems“ CSR zu entschließen. Die Ausdehnung offener deutscher Herrschaft auf Böhmen, Mähren und die Slowakei, ein international völlig gefahrloser Akt, wie er meinte, erschien

237 E. M. Robertson, Zur Wiederbesetzung des Rheinlandes 1936, in: VfZ 10 (1962), S. $204 \mathrm{f}$. 
ihm als geeignet, Freund und Feind gebührend zu beeindrucken. So konnte es nicht ausbleiben, daß dadurch der Militärpakt-Partei in Tokio der Rücken gestärkt wurde, und noch wichtiger war, jedenfalls im Augenblick, daß es die störrischen Polen zur Räson bringen mußte, wenn deutsche Regimenter plötzlich an der bisherigen tschechisch-polnischen Grenze und sogar an der slowakisch-polnischen Grenze aufmarschierten; dies brachte für Polen eine ähnlich einschüchternde Verschlechterung der strategischen Lage wie im Frühjahr 1938 die Annexion Österreichs für die Tschechoslowakei. Als Hitler dann in der ersten Februarhälfte noch bemerkte, daß auch die monatelang gelungene Abschottung der CSR gegen nichtdeutsche Einflüsse ernstlich in Frage gestellt zu werden drohte, weil Großbritannien, Frankreich und selbst Italien - von der Prager Regierung zu schweigen die in München vereinbarte Garantierung der Rumpf-Tschechoslowakei anmahnten 238 , fiel die Entscheidung. Mitte Februar beschloß Hitler, in etwa vier Wochen der Tschechoslowakei „den Todesstoß" zu versetzen ${ }^{239}$.

Am 12. Februar leitete er die Inszenierung der inneren Krise ein, die der deutschen Intervention den Vorwand zu liefern hatte, indem er Professor Vojtěch Tuka, einen der radikalen Slowakenführer, kommen ließ und ihm klar machte, daß die Slowaken von Prag nicht bloß Autonomie, sondern die volle Selbständigkeit fordern müßten ${ }^{240}$. Die seit Herbst 1938 in der Slowakei tätigen Agenten des SD arbeiteten in den folgenden Wochen energisch daran, auch die anderen Preßburger Politiker auf Separationskurs zu drängen. Parallel dazu setzten in den deutschen Medien - fortlaufend massiver werdende - Angriffe auf Prag ein, weil angeblich in der tschechischen Hälfte der Republik ein unerträgliches „Wiederaufleben des Beneš-Geistes“ zu verzeichnen sei; Emissäre des SD bemühten sich zugleich eifrig - wenn auch erfolglos - darum, in Böhmen und Mähren wenigstens ein paar ausschlachtbare deutschfeindliche Kundgebungen zu provozieren. Nach einigen Tagen aufs höchste alarmiert, schickte Außenminister Chvalkovsky seinen Kabinettschef, den Gesandten Hubert Masařik, nach Berlin, um dort, vom Verzicht auf die formale staatliche Souveränität abgesehen, die vollständige Unterwerfung unter deutsche Vormundschaft anzubieten; doch drang Masařik nur bis zum Vortragenden Legationsrat Günther Altenburg vor, dem Referenten des Auswärtigen Amts für die „Tschecho-Slowakei“, der ihm versprach, den Wunsch nach einer Unterredung mit dem Staatssekretär „höheren Orts weiterzuleiten“241. Daneben begann Berlin Ungarn auf eine baldige Aktion gegen die Karpatho-Ukraine hinzulenken.

In der hegemonialen Position, die er jetzt einnahm, gelang es Hitler tatsächlich, eine halbwegs brauchbare innere Krise der Republik zu provozie-

238 ADAP, D, 4, Nr. 164.

239 L. Hill, Weizsäcker-Papiere, S. 150.

240 ADAP, D, 4, Nr. 168.

241 Ebenda, Nr. 177. 
ren und diese Krise bis zu einem gewissen Grade zu internationalisieren. Zwar blieb die Aufstachelung des slowakischen Nationalismus gerade bei den seriöseren und einflußreicheren slowakischen Politikern ohne rechte Wirkung; sie hätten eine weitgehende Autonomie im Rahmen des bestehenden Staates allemal einer von Deutschland kontrollierten Pseudo-Unabhängigkeit vorgezogen. Die Ungarn wiederum hätten sich nur allzu gern auch die Slowakei genommen. Aber Hitler war nun stark genug, widerspenstigen Gehilfen seinen Willen aufzuzwingen. Als selbst ein ernstes Zerwürfnis zwischen Prag und Preßburg, das in der Nacht vom 9. zum 10. März die Regierung der CSR zur Absetzung des slowakischen Kabinetts Tiso veranlaßte, keine Lossagung der Slowaken vom tschechoslowakischen Staat brachte, obwohl die Agenten Berlins, die schon am Zerwürfnis gewichtigen Anteil gehabt hatten, große Anstrengungen unternahmen, Tiso zur Proklamierung der slowakischen Selbständigkeit und zur Anforderung deutscher Hilfe zu bewegen, da griff Hitler mit harter Hand ein. Am 13. März wurde Josef Tiso nach Berlin zitiert, und Hitler eröffnete ihm, daß er nur die Wahl habe zwischen der sofortigen Verkündung eines unabhängigen slowakischen Staates und der Annexion der Slowakei durch Ungarn ${ }^{242}$. Tiso fügte sich, und auf Grund seines Berichts proklamierte der slowakische Landtag am 14. März die slowakische Selbständigkeit. Am gleichen Tag marschierten ungarische Truppen in die Karpatho-Ukraine ein, nachdem Hitler am 13. März Ungarn den „Rat“ gegeben hatte, „blitzartig“ dort einzufallen; der Rat war mit der strikten Weisung verbunden, die Finger von der Slowakei zu lassen 243 .

Unter Berufung auf diese Ereignisse und auf einen mit Tiso verabredeten telegrafischen Hilferuf, der in Berlin allerdings erst am 16. März eintraf die Handhabung derart bestellter Appelle scheint nur selten zu funktionieren -, setzte Hitler am 14. März die ersten deutschen Truppen gegen die „Tschechei“ in Bewegung. Der tschechoslowakische Staatspräsident Emil Hacha und der Prager Außenminister Chvalkovsky, die dem deutschen Gesandten in Prag bereits ihre Bereitschaft mitgeteilt hatten, auch noch der Abtrennung der Slowakei zuzustimmen ${ }^{244}$, unternahmen jetzt einen letzten verzweifelten Versuch, durch eine Reise nach Berlin und eine Aussprache mit Hitler vielleicht doch noch einen Rest tschechischer Unabhängigkeit zu retten. Indes spielten sie damit Hitler nur die Möglichkeit zu, seinen Gewaltakt völkerrechtlich etwas zu verbrämen. Hacha traf Hitler am 15. März um 1.15 Uhr morgens. Drei Stunden später war der Präsident, der zwischendurch einen Schwächeanfall erlitt, durch brutale Drohungen - z.B. durch Görings Androhung vernichtender Bombenangriffe auf Prag - so eingeschüchtert, daß er ein Schriftstück unterschrieb, in dem es hieß, er

242 Ebenda, Nr. 202.

$243 \mathrm{Vgl}$. Hoensch, Der ungarische Revisionismus.

244 Graml, Europa, S. 382. 
lege „das Schicksal des tschechischen Volkes und Landes vertrauensvoll in die Hände des Führers des Deutschen Reiches"245. Am Vormittag des 15. besetzten deutsche Truppen Prag, und am 16. März wurde die Öffentlichkeit über die Errichtung eines „Protektorats Böhmen und Mähren“ unterrichtet. Die Slowakei stellte sich am 23. März unter den Schutz Hitlers, und Deutschland erhielt das Recht, dort Militär zu stationieren. „Göring teilt schon die Slowakei auf", notierte Goebbels leicht übertreibend am 20. März: „Er ist prachtvoll.“246. Hitler selbst war am 15. März um $19 \mathrm{Uhr}$ abends auf dem Prager Hradschin eingetroffen. Der „Führer“ hatte - vor aller Welt und ohne der Welt einen plausiblen Grund weisen zu können das Münchner Abkommen zerrissen und überdies, seine eindeutigsten Versprechen als Lügen entlarvend, mit dem nationalsozialistischen Deutschland den Übergang zum nackten Imperialismus vollzogen.

\section{Europas Abkehr vom Appeasement Deutschlands}

Nachdem Hacha in den frühen Morgenstunden des 15. März unterschrieben hatte, war Hitler zu seinen Sekretärinnen gelaufen, um Gratulationsküsse zu verlangen; er gehe als "der größte Deutsche“ in die Geschichte ein, rief er ihnen strahlend $\mathrm{zu}^{247}$. Als die Regierungen Großbritanniens und Frankreichs gegen die unverfrorene Liquidierung des Münchner Abkommens protestierten, als ebenso empörte wie für die Zukunft besorgte Politiker der Westmächte kritische und mit warnenden Untertönen vermischte Reden hielten, erntete das bei den nationalsozialistischen Herren Deutschlands lediglich Hohn. „Chamberlain hält in Birmingham eine ziemlich madige Rede“, schrieb Goebbels am 19. März in sein Tagebuch. „Dieser good old man wird frech, wie eben die Engländer frech sind. Quatscht von Bruch von Versprechungen u.a. ... Am Nachmittag kommt eine scharfe amtliche Erklärung aus London. Das Münchner Abkommen sei gebrochen. England erkenne die Neuordnung in Böhmen und Mähren nicht an. Aber das ist wohl nur Theaterdonner. Was wollen denn diese Demokraten noch außer protestieren. Das ist nur hysterisches Geschrei post festum, das uns ganz kalt läßt ... Verachtung ist hier am Platze.“248 Einen Tag später notierte er: „Der Führer nimmt die Proteste in Paris und London mit Recht garnicht ernst." 249

So übermütig war nun die Stimmung in Berlin, daß man der Erledigung des tschechoslowakischen Staates ungeniert sogleich zwei weitere Akte fol-

245 ADAP, D, 4, Nr. 228.

246 Tagebücher von Joseph Goebbels, Bd. 3, S. 557.

247 H. G. Rönnefahrt, Die Sudetenkrise in der internationalen Politik, Teil I, Wiesbaden 1961, S. 746.

248 Tagebücher von Joseph Goebbels, Bd. 3, S. 576.

249 Ebenda, S. 577. 
gen ließ, die ebenfalls die Gewichte zugunsten des Deutschen Reiches verschoben und bei den Nachbarn zusätzliche Ängste provozierten. Am 20. März bestellte Ribbentrop den litauischen Außenminister Juozas Urbsys nach Berlin, und in einer amtlichen litauischen Erklärung, die in der Nacht vom 22. zum 23. März veröffentlicht wurde, nachdem der zurückgekehrte Urbsys in Kowno Bericht erstattet hatte, hieß es zu diesem Besuch, „daß der Reichsaußenminister im Namen der Reichsregierung der litauischen Regierung den Vorschlag der Rückgabe des Memelgebiets an Deutschland gemacht und dies als für die Befriedung einzig zweckmäßige Lösung bezeichnet hat"250. Der Ministerrat diskutierte den deutschen „Vorschlag“, gab seine Zustimmung, und noch am 22. März traf eine litauische Delegation in Berlin ein, die um 23 Uhr nachts ein entsprechendes Dokument unterschrieb. Hitler war bereits am Nachmittag des 22. nach Swinemünde gefahren und dort an Bord des Panzerkreuzers „Deutschland“ gegangen. Auf der Fahrt nach Memel - begleitet von zwei weiteren Panzerkreuzern, drei Kreuzern, zwei Zerstörerdivisionen und drei Torpedobootsflottillen bekam er um Mitternacht ein Telegramm Ribbentrops: „Mein Führer! Ich melde die vollzogene Unterzeichnung des Vertrages mit Litauen über die Wiedervereinigung des Memellandes mit dem Reich." Noch an Bord der "Deutschland“ erließ Hitler ein Gesetz über die Wiedervereinigung, das verfassungswidrig war, da weder der Reichsinnenminister Wilhelm Frick und Ribbentrop noch Göring und der Chef der Reichskanzlei Hans Heinrich Lammers, allesamt im Reichsgesetzblatt als Gegenzeichner aufgeführt, Hitler begleiteten und folglich auch nicht gegenzeichnen konnten 251 . Unterdessen war am 22. März als erster Reichsdeutscher bezeichnenderweise der ReichsführerSS und Chef der deutschen Polizei Heinrich Himmler, gefolgt von Polizei- und SS-Kommandos, nach Memel gekommen. Infanterie- und Panzereinheiten des I. Armeekorps rückten am Morgen des 23. März ins Memelgebiet ein, gleichzeitig landeten Staffeln der Luftwaffe, und am Nachmittag, kurz nach $14 \mathrm{Uhr}$, rief Hitler den Memelern, die sich auf dem Theaterplatz versammelt hatten, vom Balkon des Stadttheaters aus zu, sie seien in ein "gewaltiges, neues Deutschland“ zurückgekehrt, das „bereit und entschlossen ist, sein Schicksal selbst zu meistern und zu gestalten, auch wenn dies einer anderen Welt nicht gefällt" 252 . Während aber im nördlichen Europa die deutsche Wehrmacht mit weithin hallendem Gelärme 2658 Quadratkilometer in Besitz nahm, hatte im südöstlichen Europa am 23. Mārz die Bukarester Regierung einen Wirtschaftsvertrag mit Deutschland zu unterzeichnen, der Rumänien in ökonomische Abhängigkeit vom Reich und damit Deutschland der wirtschaftlich-politischen Vorherrschaft auf dem Balkan einen großen Schritt näher brachte.

250 Völkischer Beobachter, 23.3.1939.

251 M. Domarus, Hitler. Reden und Proklamationen 1932-1945, II, Würzburg 1963, S. $1109 \mathrm{ff}$.

252 Ebenda, S. $1112 \mathrm{f}$. 
Zugleich machten sich Hitler und Ribbentrop daran, ungesäumt eine jener politischen Früchte zu pflücken, die nach der Aktion gegen die CSR, wie man sich ja vorher ausgerechnet hatte, leichter zu ernten sein mußten. Sie hielten die Zeit für reif, den Druck auf Polen wieder aufzunehmen, und zwar in stärkerer Dosierung als bisher. Eine Woche nach Hachas fatalem Besuch in Berlin und eine knappe Woche nach Hitlers Reise zum Prager Hradschin ließ Ribbentrop am 21. März den polnischen Botschafter kommen ${ }^{253}$. Der Reichsaußenminister setzte Lipski zunächst die Berliner Propagandaversion von den Gründen der deutschen Operation gegen die CSR vor. Ribbentrop hatte tatsächlich die Stirn, einem ausgezeichnet informierten Diplomaten, der zudem einen noch als befreundet geltenden Staat in Deutschland vertrat, zu sagen, daß ,sich in der Rest-Tschecho-Slowakei der Benesch-Geist wieder geregt habe. Alle Warnungen des Führers an Chvalkovsky seien ungehört verhallt." Mit Empörung konstatierte der Repräsentant einer üblen Diktatur, daß die Prager Regierung ,in der letzten Zeit“ versucht habe, „diktatorisch in der Karpatho-Ukraine und in der TschechoSlowakei vorzugehen“. Selbst die „Drangsalierung der Deutschen in den Sprachinseln“, die erneut begonnen habe, fehlte nicht. Anschließend aber servierte Ribbentrop seinem polnischen Gast Vorwürfe an die Adresse Warschaus, die eine beunruhigende Ähnlichkeit mit der gerade gegebenen Begründung des Handstreichs gegen Prag hatten. So sprach er davon, daß Polen in der "Minoritätenkommission“ - einer aus deutschen und polnischen Beamten bestehenden Kommission zur Erörterung der beiderseitigen Minderheitenpolitik, die vom 27. Februar bis zum 3. März ergebnislos in Berlin konferiert hatte - eine "merkwürdige Haltung eingenommen" habe. Er beschwerte sich über die Danziger, Posener und Warschauer Studentenkrawalle, und er beklagte sich über Kritik der polnischen Presse an den Verhältnissen in Deutschland und an deutscher Politik. In Berlin mißfiel es naturgemäß, daß im katholischen Polen bestimmte Zeitungen, die von der Regierung nicht kontrolliert wurden, immer wieder die nationalsozialistische Kirchenpolitik und die antichristlichen Elemente der NS-Ideologie angegriffen, die totalitären Züge des NS-Regimes und die brutale Verfolgung der Juden angeprangert, die Behandlung der polnischen Minderheit in Deutschland gegeißelt und eben jetzt die Schaffung eines unter deutschem Schutz stehenden slowakischen Staates als Bedrohung Polens charakterisiert hatten. Doch waren derlei Dinge bislang großzügig behandelt worden. Daß sie von Ribbentrop nun in ernsthaften politischen Gesprächen auf so hoher Ebene aufgetischt wurden, mußte als böses Zeichen erscheinen. Aber es kam noch schlimmer. Der Minister klärte Lipski darüber auf, daß Deutschland 1917/18 an der Entstehung eines polnischen Staates „nicht unbeteiligt“ gewesen sei und auch seither als Protektor der staatlichen Existenz Polens fungiert habe. Während er dann offensichtlich 
zu implizieren suchte, daß Deutschland seine Beschützerrolle ja auch aufgeben könne, falls sich Polen nicht vernünftig verhalte, erklomm er einen Höhepunkt konfuser Argumentation: „Auch während der Schleicher-Regierung", so bemerkte Ribbentrop dem deutschen Protokoll der Unterredung zufolge, ,habe die Möglichkeit bestanden, daß sich ein marxistisches Deutschland mit der Sowjetunion verbündet hätte. Auch dann würde Polen heute kaum mehr existieren."

Nach solchen politischen und historischen Tiraden legte der ReichsauBenminister erneut - und wieder mit dem Vorschlag eines gemeinsamen Zuges gegen die Sowjetunion verbunden - die deutschen Forderungen vom Oktober 1938 und vom Januar 1939 auf den Tisch. Mit jener Mischung aus Stumpfheit und Chuzpe, die zu einer der hervorstechendsten Eigenschaften der nationalsozialistischen Führer geworden war, lud Ribbentrop dabei - eine Woche nach der nächtlichen Erpressung Hachas in Berlin - den polnischen Außenminister Beck zur Erörterung, d.h. zur Annahme, der deutschen Forderungen in die Reichshauptstadt ein. Lipski solle sofort nach Warschau fahren, um Beck die Einladung zu überbringen. Während der Unterredung hatte Ribbentrop einmal gesagt, der „Führer“ strebe noch immer einen Ausgleich mit Polen an, „sei aber in zunehmendem Maße ... über die polnische Haltung verwundert". Am Ende des Gesprächs gab er Lipski den Satz mit auf den Weg, bisher sei der „Führer“ über „die merkwürdige Haltung Polens in einer Reihe von Fragen nur verwundert; es käme darauf an, daß er nicht den Eindruck erhalte, daß Polen einfach nicht wolle“.

In Wahrheit hatten die Schläge zur Zertrümmerung der Tschechoslowakei - dazu die Annexion des Memelgebiets und der deutsch-rumänische Wirtschaftsvertrag - auf die europäische Situation ganz anders eingewirkt, als der triumphierende Hitler und seine Umgebung glaubten. Um ein - lediglich lästiges und auch auf mildere Weise zu lösendes - diplomatisches Detailproblem zu eliminieren, nämlich das Verlangen nach Garantierung der im Anschluß an München gezogenen tschechoslowakischen Grenzen, und um die Entschärfung eines - lediglich potentiellen - taktischen Gefahrenmoments seiner operativen Expansionsplanung zu erleichtern, nämlich durch die Beseitigung der Gefahr im Rücken, die ein noch nicht diszipliniertes Polen darstellen mochte, hatte der "Führer“ einen Schritt getan, der das politische Klima in Europa radikal und unkorrigierbar zu seinen Ungunsten veränderte. Es kennzeichnet nicht allein die Brutalität und die Amoralität, sondern vor allem auch den Dilettantismus Hitlers und seiner Gefolgschaft, daß sie die Veränderung zunächst überhaupt nicht bemerkten. Tatsächlich war die Fortsetzung der Appeasement-Politik, wie sie Chamberlain bislang praktiziert hatte, unmöglich geworden. Indem er der Tschechoslowakei „den Todesstoß“ versetzte, hatte Hitler zugleich die Appeasement-Politik tödlich getroffen: Die Wertlosigkeit seines Wortes und seiner Unterschrift, der expansionistische Charakter der nationalsozialisti- 
schen Politik und die Uferlosigkeit des Berliner Imperialismus waren nun vollständig demaskiert und auch für diejenigen in den Staaten Europas sichtbar geworden, die sich bisher - aus Mangel an Vorstellungskraft, aus Friedensliebe, aus Furchtsamkeit - geweigert hatten, die wahre Natur des NS-Regimes und seines Führers zur Kenntnis zu nehmen und den bei richtiger Diagnose unabweisbaren Gedanken an Krieg zu fassen. Jetzt war es soweit. Ohne jede Spur von Enthusiasmus, doch mit fatalistischer Entschlossenheit begannen sich in den von Deutschland und Italien noch unabhängigen europäischen Regionen Politiker, Militärs und die breiten Massen der Bevölkerung - faschistische und bald auch kommunistische Randgruppen ausgenommen - darauf einzurichten, daß Hitler gestoppt werden mußte, unter Umständen mit den Waffen.

Doch stand nach der Prager Erfahrung nicht nur fest, daß es Krieg geben werde, falls deutsche Regimenter erneut die Grenzen eines europäischen Staates überschreiten sollten. Die Appeasement-Politik war auch in dem Sinne tot, daß sich allenthalben die Bereitschaft verflüchtigt hatte, ein weiteres Mal die Kombination von Methoden hinzunehmen, mit der Hitler 1938 so erfolgreich operiert hatte: Larmoyante Klagen über deutsche Leiden - Diskriminierung und Isolierung des gewählten Opfers - Androhung von Waffengewalt - Versprechungen künftigen Wohlverhaltens. Daher hatte sich Hitler durch die Unterwerfung der Tschechoslowakei gerade auch die Bewältigung jener kleinen taktischen Schwierigkeit endgültig unmöglich gemacht, deren leichtere Bewältigung ja zu den Zielen seines Unternehmens gehört hatte. $Z$ war verfügte er nun in der Tat über die „strategische Zange" gegen Polen, die er mit der Eingliederung der Slowakei in den deutschen Aufmarschraum hatte schmieden wollen ${ }^{254}$. Doch taugten solche Positionsgewinne nicht länger zu Mitteln politischer Erpressungsmanöver. In Polen sah man nicht mehr die kleinste Möglichkeit, bei deutschem Druck dem Land durch eine Politik der Nachgiebigkeit zu nutzen, wie immer die Konsequenzen von Widerstand ausfallen mochten, und nirgends in Europa gab es noch jemand, der auf den Gedanken kommen konnte, den Polen eine andere Haltung anzuraten. Gerade in Frankreich und Großbritannien war die Bereitschaft geschwunden, irgendwelche weitere Opfer deutscher Pressionen zum Nachgeben zu bewegen.

In den Westmächten, namentlich in Großbritannien, wirkten die Ereignisse vom März 1939 allerdings auch deshalb so stark und so nachhaltig, weil die Fundamente der Appeasement-Politik dort schon vor Hitlers Fahrt auf den Hradschin recht mürbe geworden waren. Noch während die meisten Briten, von der Kriegsfurcht befreit, Chamberlain begeistert Beifall zollten, setzte gerade in den Reihen der Londoner Regierungsparteien doch auch Kritik an einer Politik ein, die Großbritannien zur Mitwirkung am Münchner Abkommen und also zu einer Kapitulation vor Hitler ge-

${ }^{254}$ H. Booms, Der Ursprung des 2.Weltkriegs, S. 347. 
führt hatte, der man sogar den Charakter der Komplicenschaft mit den $\mathrm{Na}$ tionalsozialisten zuschreiben konnte, und wer die Richtigkeit von Appeasement bereits vor München bezweifelt oder bestritten hatte, verschärfte jetzt noch sein Urteil. Nachdem die Erleichterung über die Vermeidung des Krieges wieder etwas abgeklungen und Nüchternheit eingekehrt war, fand die Fronde gegen Appeasement und München allmählich auch mehr Gehör, zumal sie über formidable Führer und Sprecher verfügte. Duff Cooper, ein geistvoller Redner und glänzender Schriftsteller, der 1932 eine zum Kunstwerk geratene Biographie Talleyrands veröffentlicht hatte, war aus Protest gegen die Kapitulation von München als Marineminister zurückgetreten. Er stand jetzt neben so angesehenen und einflußreichen Mitgliedern des Unterhauses wie Harold Nicolson, wie Anthony Eden - der Anfang 1938 das Foreign Office verlassen hatte, nachdem vom Premier einer der periodischen Versuche zum Appeasement Mussolinis unternommen und außerdem ein Angebot des amerikanischen Präsidenten Roosevelt zur politischen Unterstützung der europäischen Westmächte ignoriert worden war - und wie Winston Churchill.

Wenn auch zu diesem Zeitpunkt viele Kritiker der Appeasement-Politik noch eher in Anthony Eden, nüchterner und weniger der Kandidatur für das Amt des Regierungschefs verdächtig, ihre Zentralfigur sahen, so war doch Churchill der charakteristischste, der potentiell wichtigste und gewiß der bedeutendste Gegenspieler Chamberlains. Ein Sproß des englischen Hochadels - sein Vater, Lord Randolph Churchill, war ein jüngerer Sohn des 7. Herzogs von Marlborough - und der Tochter eines amerikanischen Unternehmers, wie er für das New York des späteren 19. Jahrhunderts typisch war, konnte der 1874 geborene Winston Churchill 1938/39 bereits auf eine lange Karriere als Politiker, Journalist und Historiker zurückblikken, wobei sich seine politische Laufbahn freilich auch durch eine ungewöhnliche Wechselhaftigkeit auszeichnete ${ }^{255}$. Zwar gab es niemand, der ihm seinen Rang als Parlamentarier bestritten hätte. Ein ehrgeiziger Mann, war Churchill doch stets weit mehr an den jeweils umkämpften politischen oder militärischen Fragen interessiert als an seiner eigenen Person; auch fehlten ihm sowohl Neigung wie Begabung zur Intrige. Mit einem scharfen Verstand und einer zuweilen allzu lebhaften Vorstellungskraft ausgerüstet, verband er die Fähigkeit zu logischem und selbständigem Denken mit $\mathrm{Hu}-$ mor und Witz, mit einer brillanten Formulierungskunst und einer legendären Schlagfertigkeit. So war er in Jahrzehnten zu einer der ganz großen Gestalten der britischen Parlamentsgeschichte geworden.

Der Minister Churchill hatte eine weniger glückhafte Fahrt.gehabt. Auf der einen Seite standen große Erfolge und Verdienste: So zwischen 1906 und 1914 in den liberalen Kabinetten Campbell-Bannerman und Asquith als einer der wichtigsten Kampfgefährten Lloyd Georges bei bedeutenden

255 Vgl. R. Rh. James, Churchill: A Study in Failure 1900-1939, London 1970. 
innen- und sozialpolitischen Reformen; in den letzten Friedensjahren als Marineminister bei der Vorbereitung der britischen Flotte auf den Krieg mit dem wilhelminischen Deutschland; 1917/18 als Rüstungsminister vor allem bei der Einleitung einer Tankproduktion größeren Stils; in den ersten Jahren nach dem Weltkrieg als Kriegs-, Luftfahrt- und Kolonialminister bei der Demobilisierung der britischen Armee, bei der Entschärfung der irischen Frage und bei dem vorübergehend durchaus gelungenen Versuch, die Erschließung Palästinas für jüdische Einwanderung im Rahmen einer gemeinsamen britisch-zionistisch-arabischen Politik zu bewältigen. Auf der Sollseite fanden sich jedoch auch bittere Niederlagen: So 1915/16, als man den Marineminister Churchill für die Erfolglosigkeit des Gallipoli-Unternehmens gegen die mit Deutschland verbündete Türkei verantwortlich machte, obschon die politisch und militärisch sehr wohl richtig angesetzte Operation, die in der Tat zu Churchills Lieblingsprojekten zählte, von den militärischen Befehlshabern an Ort und Stelle verpfuscht worden war; im Grunde war der Marineminister auch weniger einem Fehler zum Opfer gefallen - er ging für einige Zeit als Bataillonskommandeur an die Front in Frankreich - als der Koalitionsbildung zwischen Liberalen und Konservativen, weil ihm letztere damals weder seinen 1905 erfolgten Wechsel von ihnen zu den Liberalen noch seine anschließende Aktivität als Reformpolitiker verziehen hatten. Ähnlich erging es ihm zwischen 1918 und 1920, als in erster Linie er es war, der die Alliierten dazu bewog, in den russischen Bürgerkrieg militärisch gegen die Bolschewiki einzugreifen, die Interventionspolitik jedoch völlig Schiffbruch erlitt. Derartige Fehlschläge hatten ihm den Ruf eingebracht, als Kabinettsmitglied auch seine gefährlichen Seiten zu haben, vornehmlich die Eigenschaft, sich das Urteilsvermögen gelegentlich durch hitziges Temperament und Wunschdenken trüben zu lassen. Daneben galt er manchen seiner Kollegen als allzu rastlos, allzu umtriebig und allzu sorglos im Umgang mit Ressortgrenzen. Wenn auch ein gut Teil der Kritik einfach darauf zurückgeführt werden durfte, daß sich die selbstzufriedene Bequemlichkeit, die vielen konservativen und liberalen Politikern eignete, von Churchills Einfallsreichtum, Energie und Tatendrang belästigt fühlte, so steckte in den Vorwürfen schon auch ein wahrer Kern.

In den Jahren vor München hatte er sogar seine Stellung im Unterhaus geschwächt und die Distanz zu einem Sitz im Kabinett erheblich vergröBert; seit 1929, seit dem Wechsel von der konservativen Regierung Baldwin, der er als Schatzkanzler angehört hatte, zur Labour-Regierung MacDonald, war er ja ohne Amt. Das lag einmal daran, daß er, als altmodischer Empire-Anhänger, der sein Berufsleben als Kavallerieoffizier in Indien begonnen hatte, ohne Zögern gegen eine von der Unterhaus-Mehrheit gestützte Reformpolitik auftrat, die Indien auf den Weg zur Unabhängigkeit bringen mußte. Und es lag ferner daran, daß er während der innenpolitischen Krise, die 1936 ausbrach, weil der junge König Edward VIII. an der 
Absicht festhielt, die zweimal geschiedene Amerikanerin Mrs. Simpson zu heiraten, in einer Weise für den späteren Herzog von Windsor Partei nahm, daß sein Anfall von feudalistischer Lehnstreue - Stoff für einen Cervantes - die unvermeidliche und am 10. Dezember 1936 vollzogene Abdankung des Königs zu verzögern und eine dem ganzen Commonwealth höchst unangenehme Affäre ungebührlich zu verlängern drohte. Indes handelte es sich dabei nur um temporäre Rückschläge, von denen er sich wieder erholte, und bis 1938/39 war er überdies zu einem weithin anerkannten Experten in deutschlandpolitischen und in den mit der deutschen Gefahr zusammenhängenden rüstungspolitischen Fragen geworden. Sein Urteil über München hatte Gewicht, und er nannte die Konferenz von München am 5. Oktober 1938 in einer großen Unterhausdebatte eine „totale, durch nichts gemilderte Niederlage“. Er setzte hinzu: „Das ist nur der Beginn ..., der erste Vorgeschmack eines bitteren Tranks, der uns Jahr für Jahr kredenzt werden wird." 256

Ende der zwanziger und Anfang der dreißiger Jahre war Winston Churchill noch ein sozusagen "radikaler" Appeaser gewesen. Damals hatte er mehrmals - so als 1931 das von Reichskanzler Brüning und seinem Außenminister Curtius zur Vorbereitung des „Anschlusses“ lancierte Projekt einer Zollunion zwischen Deutschland und Österreich zur Debatte stand - dafür plädiert, die einigermaßen vertretbaren deutschen Wünsche zur Revision der Pariser Vorortsverträge jetzt zu erfüllen ${ }^{257}$. Er hatte sich dabei vornehmlich von drei Ubberlegungen leiten lassen: Erstens müsse - so der alte Feind des Kommunismus und des kommunistischen Rußland - das Deutsche Reich zu einem festen Bollwerk gegen Bolschewismus und Sowjetunion gemacht werden, wofür das Land auch außenpolitische Erfolge brauche; zweitens wären die Sieger gut beraten, wenn sie die deutschen Ansprüche befriedigten, solange sie noch eindeutig stärker seien als die $\mathrm{Ge}$ schlagenen des Krieges und folglich den Revisionsprozeß noch unter Kontrolle halten könnten; drittens gelte es, der Weimarer Republik den Rükken gegen die Nationalsozialisten zu stärken, die uferlose Pläne hätten und entschlossen seien, Krieg zu führen, und auch für diesen Zweck komme es darauf an, der Republik außenpolitische Erfolge zu verschaffen ${ }^{258}$. Sein Urteil über die Nationalsozialisten stand früh fest, und so hat er seine bisherige Auffassung von richtiger britischer - und überhaupt westlicher Deutschlandpolitik sofort aufgegeben, nachdem Hitler deutscher Reichskanzler geworden war und sein Regime stabilisiert hatte. Von nun an mußte, wie Churchill die Dinge sah, alles darauf konzentriert werden, Europa gegen die nationalsozialistische Gefahr zusammenzuschließen.

Zunächst setzte er dabei seine Hoffnung auf eine Sammlung im Rahmen des Völkerbunds und auf die Aktivierung des Systems der kollektiven Si-

256 Taylor, Munich, S. 903; Gilbert, Churchill, V, S. 1000.

257 Gilbert, Churchill, V, S. $451 \mathrm{f}$.

258 Ebenda. 
cherheit. „In der Zahl liegt Sicherheit“, schrieb er am 8. März 1935 an seine Frau. „Nur in der Zahl liegt Sicherheit.“259 Jedoch stellte sich bald die Ohnmacht des Bundes heraus, und Churchill wandte sich mit Eifer Projekten einer Allianzpolitik alten Stils zu, die der kollektiven Sicherheit durch die Zusammenarbeit der europäischen Großmächte mehr Substanz geben sollten. Dabei war er durchaus bereit, alten und ans Herz gewachsenen Feindschaften abzuschwören. „Angesichts der Gefahr aus Deutschland“, so konstatierte am 19. April 1936 Sir Maurice Hankey, Sekretär des Committee for Imperial Defence und des Kabinetts, „hat er seinen heftigen antirussischen Komplex früherer Tage begraben und ist nun offenbar ein Busenfreund von Mr. Maisky [dem Londoner Botschafter der Sowjetunion] “260 Aber ein Bündnissystem allein konnte nicht genügen. Die dazu fähigen Großmächte hatten vielmehr ihre militärische Kraft erheblich zu steigern, um es mit dem Jahr für Jahr militärisch stärker werdenden Deutschland notfalls auch aufnehmen zu können. Nur von Verträgen allein würde sich ein Hitler sicherlich nicht beeindrucken lassen. Gelang es aber, eine erfolgreiche Bündnispolitik mit der erforderlichen Rüstungsanstrengung zu verbinden, so mußte eine Phalanx von Staaten entstehen, die in der Lage war, das nationalsozialistische Deutschland in Schach zu halten und von kriegerischen Abenteuern abzuschrecken. Ein Krieg gegen Deutschland wurde, sofern dies alles rechtzeitig geschah, überflüssig. Naturgemäß hielt es Churchill für einen Gipfel der Narrheit, den gefährlichen Leuten in Berlin auch noch Machtgewinne zu ermöglichen und sogar förmlich zuzuschanzen. Was der Weimarer Republik hătte gegeben werden sollen, hatte Hitler selbstverständlich verweigert zu werden. In einer Unterhaltung mit dem Führer der Sudetendeutschen Partei, die geraume Zeit vor München stattfand, setzte er Konrad Henlein auseinander, daß er nicht grundsätzlich gegen die Erfüllung der sudetendeutschen Forderungen sei, daß man jedoch die Sudetengebiete unter keinen Umständen einem Hitler überlassen dürfe, der solche Erfolge lediglich als Sprungbrett für sehr viel weiter zielende expansionistische Absichten nützen werde. So entwickelte sich Churchill zum beredtesten Anwalt einer zielbewußten britischen Bündnispolitik, zum leidenschaftlichsten Apostel einer energischen britischen Rüstungspolitik und zum überzeugtesten Verfechter einer britischen Außenpolitik, die sich Ansprüchen des nationalsozialistischen Deutschland in den Weg stellte. Da die Kabinette Baldwin und Chamberlain eine Außenpolitik verfolgten, die seiner Auffassung genau entgegengesetzt war, und da die beiden Kabinette nach seiner Meinung vor allem auf den Feldern der Bündnis- und der Rüstungspolitik nichts oder doch viel zu wenig taten, wuchs er notwendigerweise auch in die Rolle des schärfsten und des beharrlichsten Kritikers der offiziellen Politik der Londoner Regierung. 
Churchill dachte dabei nicht nur in machtpolitischen Kategorien und keineswegs allein an politische oder wirtschaftliche Interessen Großbritanniens und des Commonwealth; die Erhaltung des europäischen Kräftegleichgewichts verstand er nicht bloß als eine Notwendigkeit für die äußere Sicherheit Englands. Von 1932 bis 1938 legte er - der sich ohne Amt wieder der Geschichtsschreibung zuwandte - eine mehrbändige Biographie seines großen Ahnen John Churchill vor, des ersten Herzogs von Marlborough, der viele Jahre lang zusammen mit dem Prinzen Eugen gegen die Hegemonialpolitik des Frankreichs Ludwigs XIV. gekämpft hatte. So hatte sich in sein Bewußtsein eine Vorstellung von der gesamteuropäischen Wächterrolle Großbritanniens tief eingebrannt, die er einmal in einem Brief an Lord Rothermere mit der Reihung illustrierte: „Elizabeth - Philip II/ William III, Marlborough - Louis XIV/Pitt-Napoleon/We-Wilhelm II!"'261 In all diesen großen Konflikten der europäischen Geschichte war aber Großbritannien, in Winston Churchills Verständnis, nicht einfach - als Haupt einer Staatenkoalition - zu Felde gezogen, um auf dem europäischen Kontinent die Vorherrschaft einer bestimmten Macht zu verhindern, vielmehr war es in jedem Falle vor allem darum gegangen, die hegemonialen Tendenzen einer Macht abzuwehren, die - vom katholischen Spanien der Inquisition über das absolutistische Frankreich bis zum wilhelminischen Deutschland - Europa mit einer freiheitsfeindlichen Ideologie und mit einem freiheitsfeindlichen politischen System bedroht hatte.

Erst recht schrieb er in der Auseinandersetzung mit dem nationalsozialistischen Deutschland dem Gegensatz zwischen zwei grundverschiedenen Systemen ethischer, geistiger und politischer Werte die entscheidende Bedeutung zu. Einmal hat er gesagt: „Sozialismus ist schlecht, Chauvinismus ist noch schlimmer, und die beiden vereint, in einer Art verderbtem italienischen Faschismus, sind das übelste Credo, das je von Menschen ersonnen wurde." 262 Wenn das Deutschland Hitlers den europäischen Kontinent unterwerfen sollte, mußte nicht nur die staatliche Selbständigkeit der europäischen Länder ausgelöscht werden, diese barbarische, ja inhumane Diktatur, abstrusen und menschenverachtenden Doktrinen huldigend, mußte vielmehr auch "die parlamentarische Demokratie und die liberale Zivilisation“ vernichten, wie er am 24. September 1936 in einer Rede ausrief. ${ }^{263}$ Churchill empfand das Dritte Reich und seine Politik stets als eine äußerste Gefährdung der politischen Kultur Westeuropas und namentlich Großbritanniens, deren Wesen er im übrigen gerade tief in sich einsog. Kaum war die Biographie Marlboroughs abgeschlossen, hatte er nämlich eine wiederum auf mehrere Bände angelegte - dann allerdings erst nach dem Zweiten Weltkrieg erscheinende - „Geschichte der englischsprechenden Völker“ in

261 Ebenda, S. $648 \mathrm{f}$.

262 Colville, The Fringes of Power, S. 332.

${ }^{263}$ Gilbert, Churchill, V, S. 788. 
Angriff genommen, und obwohl er darin, wie schon in seinen bisherigen Werken, mit Lust und Sachverstand die Dramatik politischer Konflikte lebendig werden ließ oder grandiose literarische Schlachtenbilder malte, geriet ihm die Arbeit doch, ihrer inneren Konzeption nach, zur Erzählung der Herkunft und der Entfaltung einer politischen Kultur, ihrer trotz aller verschlungenen Umwege stetigen Verbesserung und Verfeinerung, zur Erzählung der geschichtlichen Verwirklichung von Freiheit und Humanität. Es gehört zu den bemerkenswertesten Elementen jener Jahre, daß sich als der wichtigste Widersacher Chamberlains und dann für lange Zeit auch Hitlers nicht irgendein ordinärer Politiker herausschälte, lediglich mit den ordinären Eigenschaften eines erfolgreichen Politikers begabt, mit Energie, Zähigkeit, Geschick, sondern ein Mann, der sich im Laufe seiner Karriere zum profunden Kenner und zum liebenden Hüter - fast durfte man sagen: zur Personifizierung - der Tradition britischer Außenpolitik und der Essenz des politischen Geistes Englands entwickelt hatte.

In der ungewissen Stimmung, die nach München in Großbritannien herrschte, trug allein schon die Besonderheit seiner politischen Persönlichkeit dazu bei, Churchill besondere Aufmerksamkeit, besonderen Respekt und - bei weiterer Verschärfung der internationalen Krise oder bei Krieg eine besondere Anwartschaft auf die Führung des Landes zu sichern. Daß seine Warnungen - nachträglich auch jene, mit denen er vor München der Regierung jahrelang so lästig gefallen war - jetzt große Beachtung fanden, lag aber nicht zuletzt daran, daß allenthalben, selbst im eigentlichen Regierungslager, zu dem ja der Frondeur Churchill, obwohl er seit 1924 wieder zu den Konservativen gehörte, nicht zu zählen war, ein Stimmungsumschwung einsetzte, der auf eine Annäherung an den Standpunkt Churchills hinauslief. Vielen, die bis zum September 1938 an die Richtigkeit oder an die Unvermeidbarkeit der Chamberlainschen Appeasement-Politik geglaubt hatten, versetzte die Realität von München einen bösen Stoß. Sie empfanden genau das, was Churchill aussprach: Großbritannien hatte vor einer politischen Erpressung kapituliert und dabei ein Land mit liberaldemokratischer Verfassung im Stich gelassen, es einer üblen Tyrannei zum Fraße vorgeworfen. Und da war die peinigende Frage, ob man sich mit einem politischen Akt, der Bitterkeit und Scham weckte, tatsächlich für längere Zeit Ruhe erkauft habe. Den Zwiespalt der Gefühle, den die Anhänger Chamberlains nun erlebten, hat Harold Nicolson in einen treffenden Satz gefaßt. „Es ist wirklich schwierig“, so schrieb er, „zu sagen: ,Dies ist die bedeutendste diplomatische Großtat in der Geschichte; deshalb müssen wir unsere Rüstung verdoppeln, um nie wieder einer solchen Demütigung ausgesetzt zu sein!" 264 Wer die Niederlage spürte und besorgt in die Zukunft sah, stand jedoch bereits, auch wenn das noch nicht offen zum Ausdruck kam, zwischen Chamberlain und Churchill; er räumte, wenn er etwa die 
Forderung erhob, Großbritannien müsse mehr rüsten, ein, daß Chamberlains Kritiker die Ziele Hitlers und die Natur des nationalsozialistischen Deutschland womöglich richtiger einschätzten als der Premier.

Sogar Kabinettsmitglieder konnten sich dem Trend zu Churchillschen Auffassungen nicht entziehen, so Handelsminister Oliver Stanley, Erziehungsminister Lord de la Warr und Luftfahrtminister Lord Swinton. Auch Chamberlains Außenminister gesellte sich zu den Zweiflern. Lord Halifax, ein Aristokrat, der Bildung und Gelehrsamkeit mit der Liebe zur Fuchsjagd verband, hatte vor und nach seiner von 1926 bis 1931 währenden Amtszeit als Vizekönig in Indien mehreren Kabinetten angehört, als Erziehungsminister, Landwirtschaftsminister, Kriegsminister und Lordsiegelbewahrer; nachdem ihn Chamberlain im Februar 1938 an die Spitze des Foreign Office gestellt hatte, wo er Anthony Eden ablöste, war er, was Hitler und Deutschland anlangte, stets dem Urteil des Premiers gefolgt und gleichfalls der Ansicht gewesen, daß der Friede um fast jeden Preis bewahrt werden müsse. Aber das Erlebnis von München und der Art und Weise, in der Hitler in den Wochen vor München agiert hatte, verstörte Lord Halifax, der auch ein tief religiöses Mitglied der Anglikanischen Kirche war, und schreckte ihn auf. Als er den aus München zurückkehrenden Chamberlain am Londoner Flughafen abholte, riet er dem davon überraschten Premier noch während der Autofahrt, sofort eine Koalitionsregierung unter Einschluß der Labour-Partei zu bilden und in ein neues Kabinett auch Eden und Churchill aufzunehmen ${ }^{265}$. Gewiß sind aus den Zweifeln vorerst kaum Konsequenzen gezogen worden, und auf dem Felde der Rüstungspolitik wurde zunächst lediglich beschlossen, die Luftabwehr Großbritanniens zu verstärken und zu diesem $Z$ weck auch mehr Jagdflugzeuge zu bauen und mehr Jagdflieger auszubilden. Doch abgesehen davon, daß die rüstungspolitische Entscheidung - wie sich dann 1940/41 herausstellte - richtig und von größter militärischer Bedeutung war, begann in Großbritannien - und das gilt in ähnlicher Form auch für Frankreich - sogleich nach München ein politisches Klima zu entstehen, in dem das Land auf weitere Reizungen aus Deutschland überaus empfindlich reagieren mußte.

Und eben solche Irritationen wurden von den nationalsozialistischen Herren des Deutschen Reiches prompt geliefert. Schon die von Hitler und Ribbentrop befohlene Rundfunk- und Pressekampagne gegen Duff Cooper, Eden und Churchill wirkte nicht nur als ungehöriger Versuch der Einmischung in die inneren Angelegenheiten Großbritanniens, etwa in die Freiheit der Regierungsbildung, und damit als ein Indiz für eine gefährliche Steigerung der nationalsozialistischen Arroganz, sondern vor allem als völlig unverständliche Brüskierung eines Staates, der Hitler und Deutschland gerade zu einem gewinnbringenden Triumph verholfen hatte. Viele britische Beobachter fragten sich, ob diese ansonsten sinnlose Kampagne wo- 
möglich den Zweck verfolgte, die deutsche Bevölkerung, die Chamberlain in München zugejubelt hatte und den Premier noch monatelang mit Beifall bedachte, sobald er in einer Wochenschau auftauchte, auf weitere Akte einer antibritischen Politik und am Ende auf einen Krieg gegen England einzustimmen; schließlich war der Feldzug vom „Führer“ mit seiner Saarbrükkener Rede persönlich eröffnet worden und bloß ganz selten von anerkennenden Worten an die Adresse Chamberlains und seines Lagers begleitet. Unvergleichlich stärker wirkte aber im November 1938 die „Reichskristallnacht", der von Hitler gebilligte und von Goebbels inszenierte reichsweite Pogrom gegen die deutschen Juden.

Noch am 31. Oktober hatte Herbert v. Dirksen, der deutsche Botschafter in London, nach Berlin berichtet, Chamberlain werde demnächst neue britisch-deutsche Besprechungen vorschlagen, um, auf der Grundlage von München, die britisch-deutsche Annäherung weiter zu fördern ${ }^{266}$. Am 17. November schrieb er jedoch, seine Ankündigung treffe "gegenwärtig nicht mehr zu“, und als „die beiden wichtigsten Rückwirkungen der antijüdischen Welle in Deutschland“ nannte er: "Die Niedergeschlagenheit, die sich gerade der aktiv für eine deutsch-englische Freundschaft eintretenden Elemente des englischen Volkes bemächtigt hat, und die Beeinträchtigung der Stellung Chamberlains." Die deutschfreundlichen Kreise in England seien „seelisch betroffen“ und, in ihrem Glauben an die Möglichkeit einer deutsch-englischen Verständigung irre“ geworden; ihre „Tatkraft" sei „gelähmt“, ihre "moralische Unterstützung, ihr Antrieb“ fehlten nun dem Kabinett ${ }^{267}$. Für einen ansonsten nicht gerade regimekritischen Diplomaten war das, in einem amtlichen Bericht an das Auswärtige Amt, eine starke Sprache, und Dirksen kannte England inzwischen gut genug, um zu wissen, daß es seit 1933 in Großbritannien - von wenigen Ausnahmen abgesehen - keine „deutschfreundlichen Kreise" mehr gab, d.h. keine Kreise, die dem nationalsozialistischen Deutschland freundschaftlich gesonnen gewesen wären; wer sich als „deutschfreundlich" gerierte und für die deutschenglische Verständigung eintrat, tat das, wie Chamberlain selbst ja auch, meist nur, um einem Krieg aus dem Wege zu gehen 268 . In der ihm eben noch möglichen Form wollte Dirksen Berliner Lesern sagen, daß der jetzt mit der „Kristallnacht“ gegebene Hinweis auf eine vielleicht unveränderlich böse Natur des NS-Regimes - der Hinweis auf die von München offenbar unberührt gebliebene Roheit der nationalsozialistischen Führer, auf ihre anscheinend gänzlich ungeschwächte Lust an Gewaltanwendung und auf ihre sichtlich ungebrochene ideologische Verbohrtheit - den Glauben vieler Briten an die Vermeidbarkeit eines Krieges mit Deutschland schwer erschüttert und damit die Grundlage der Politik Chamberlains in Frage gestellt habe.

266 ADAP, D, 4, Nr. 260.

267 Ebenda, Nr. 269.

268 Nicolson, Diaries and Letters, S. 254. 
Wie genau Dirksen den Nagel auf den Kopf getroffen hatte, zeigt etwa die Reaktion des damaligen britischen Marineattachés in Berlin. Ebenfalls Mitte November notierte Kapitän Troubridge, ein biederer und mitnichten philosemitischer Seemann, der aber über eine unbestechliche Beobachtungsgabe verfügte und neben gesundem Menschenverstand zuverlässige ethisch-moralische Wertmaßstäbe besaß, in seinem Tagebuch, daß der Pogrom eine Wende in den britisch-deutschen Beziehungen bedeute: er selbst habe in seiner Berliner Stellung seit Jahren aufrichtig und eifrig an einem Ausgleich zwischen Großbritannien und Deutschland gearbeitet, doch sei damit jetzt Schluß; solange diese Bande von Nationalsozialisten in Deutschland am Ruder sei, könne es keine Verständigung geben, werde Europa keinen Frieden haben ${ }^{269}$. Dirksen hatte gegen Ende seines Berichts vom 17. November noch geschrieben: „Die Gegner Chamberlains sind nicht müßig gewesen, die neue deutschfeindliche Welle zur Kritik und zu erneuten Angriffen auszunutzen, daß ein Zusammengehen mit einem Land, in dem solche Härten möglich sind, aus weltanschaulichen Gründen abgelehnt werden müsse. Die von Frankreich propagierte Ablehnung der deutschen Kolonialforderungen ist von den deutschfeindlichen Kreisen in England bereitwillig aufgegriffen und verstärkt worden." Der Botschafter war nicht schlecht informiert. Die „Kristallnacht“ hatte in der Tat Konsequenzen für die kolonialen Ansprüche des Deutschen Reiches, nur daß diese - über Empörung und Resignation bereits hinausgehenden - ersten praktischen Konsequenzen aus dem Pogrom nicht von Gegnern Chamberlains, sondern von seinem Kabinett gezogen wurden. Unter der Leitung Malcolm MacDonalds, des Kolonialministers, hatte sich eine Studiengruppe tatsächlich seit einiger Zeit mit dem Problem beschäftigt, wie Deutschland in den Besitz kolonialer Territorien gebracht werden könne. Am 14. November erklärte indes MacDonald im Außenpolitischen Ausschuß des Kabinetts, angesichts der Ereignisse in Deutschland werde die Arbeit an jenem Problem vorerst eingestellt ${ }^{270}$.

Chamberlain selbst ist von der "Kristallnacht" ebenfalls hart getroffen worden. Am 10. November, noch ehe ihn Nachrichten über den Pogrom der seine Höhepunkte in der Nacht vom 9. auf den 10. und am 10. hatte erreichten, schrieb er voller Freude an seine Schwester, William Astor habe aus Berlin den Eindruck mitgebracht, daß Hitler ihn, Neville Chamberlain, möge 271 . In der Sitzung des Außenpolitischen Ausschusses vom 14. November äußerte er sich jedoch zum ersten Male „sehr besorgt über die enttäuschende Entwicklung der Dinge in Deutschland seit der Münchner Regelung“. Mehr noch: er akzeptierte die von seinem Außenminister gezogene Folgerung, daß es zur Zeit keine Fortsetzung der Bemühungen um

269 Aufzeichnung Captain Troubridge, 16.11.1938; ungedruckt, im Besitz des Verf.

270 Taylor, Munich, S. $937 \mathrm{f}$.

271 Ebenda, S. 938. 
eine britisch-deutsche Annäherung geben könne, und er stimmte Lord Halifax auch zu, als dieser meinte, nach der „Kristallnacht“ sei es wohl angezeigt, das Tempo der britischen Rüstung zu erhöhen und einen weiteren Versuch zur Trennung Mussolinis von Hitler zu unternehmen. Aber der Premierminister war noch nicht hart genug getroffen worden. In Wahrheit dachte er gar nicht daran, das britische Rüstungsprogramm - über die kurz zuvor beschlossene Verstärkung der Luftabwehr hinaus - zu beschleunigen oder auszuweiten. Jedenfalls tat er nichts, und am 22. November, als er in einer Kabinettssitzung berichtete, wie er sich bei dem britisch-französischen Konsultationsgespräch zu verhalten gedenke, das zwei Tage später in Paris stattfinden sollte, teilte er seinen Kollegen mit, er werde es den französischen Freunden so klar wie nur irgend möglich machen, daß sie im Kriegsfall auch künftig - wie schon vor München - lediglich mit einem britischen Expeditionskorps von zwei Divisionen rechnen dürften ${ }^{272}$. In diesem Sinne sprach er dann auch am 24. mit Daladier, und als ihn ein paar Tage später Kriegsminister Leslie Hore-Belisha aufsuchte, um ihn vielleicht doch zu energischeren Maßnahmen gegen den unfertigen Zustand der Armee zu bewegen, tröstete er seinen Besucher mit der Bemerkung, da die britische Armee so klein sei, ,lohnt es sich doch nicht, sich darüber Sorgen zu machen, ob sie fertig ist oder nicht" 273 .

Aber sogar Chamberlains Vertrauen in den deutschen „Führer“ wurde, wenngleich es noch existierte, hinfälliger und hinfälliger. Mitte Dezember kehrte Ivone Kirkpatrick, bislang an der Botschaft in Berlin, ins Foreign Office zurück. Der Diplomat, der an etlichen Treffen britischer Politiker mit Hitler - auch an den Begegnungen zwischen Hitler und Chamberlain teilgenommen hatte und daran die Erinnerung mitbrachte, wie ihm angesichts der gelegentlich durchbrechenden „bösartigen Arroganz“ des „Führers" einige Male körperlich übel geworden ${ }^{\text {war }}{ }^{274}$, brachte seinen Vorgesetzten auch eine wichtig klingende Information. Ein pensionierter deutscher Beamter, ein guter Bekannter des kürzlich verabschiedeten Generals Beck, habe ihm erzählt, so berichtete Kirkpatrick, daß Hitler, gegen die britische Politik aufgebracht, beschlossen habe, Großbritannien im März anzugreifen; am Anfang werde ein überraschender Luftangriff auf London stehen ${ }^{275}$. Chamberlain nahm die Erzählung, in der sich Wahres - die damalige Grundtendenz Hitlerschen Denkens - mit Falschem - Entschluß zum Angriff im März - mischte, bezeichnenderweise zum Anlaß, für den nächsten Tag, den 17. Dezember, eine Sondersitzung von Ministern einzuberufen, und während dieser Sitzung hielt es der Premierminister durchaus für möglich, daß die Nationalsozialisten den „Plan gefaßt haben, uns einen Schlag zu versetzen, wenn wir Miene machen, gegen Hitlers östliche Ambi-

\footnotetext{
272 Ebenda, S. 932.

273 Ebenda, S. 933.

274 Nicolson, Diaries and Letters, S. 414.

275 Taylor, Munich, S. 943.
} 
tionen zu intervenieren“; wahrscheinlicher sei allerdings, daß Hitlers nächster Zug in östliche Richtung gehen werde 276. Die Ministerien der Streitkräfte wurden jedenfalls angewiesen, sich auf erhöhte Gefahr im kommenden März einzustellen, und einige Tage später beschloß das Committee of Imperial Defence (CID) eine abermalige Beschleunigung des Luftschutzund Luftabwehrprogramms. Sonst geschah zwar nichts, aber der Vorfall zeigte einen Chamberlain, bei dem gerade ein Prozeß der Ablösung stattfand: Das Hitler-Bild, das er bei seiner Appeasement-Politik stets vor Augen gehabt, das ihn zu seinen Flügen nach Berchtesgaden, Godesberg und München bewogen hatte, begann zu zerfallen; die Ängste und Besorgnisse, die unter der zur Schau getragenen Selbstgewißheit und Kritikunempfindlichkeit offensichtlich am Werke waren, löschten gerade die Züge des Wunschbilds einen nach dem andern aus und zeichneten Linie um Linie das wahre Bild ein.

Um so wichtiger schien dem Premier das von Lord Halifax vorgeschlagene und inzwischen tatsächlich vereinbarte Treffen mit Mussolini zu sein. Während der Außenminister nur mit gedämpften Erwartungen nach Rom fuhr und sich neben einer gewissen Verbesserung der Beziehungen zum Duce vornehmlich eine stärkere Wirkung des Besuchs auf die öffentliche Meinung in Italien erhoffte, glaubte Chamberlain, wie er am 21. Dezember in einer Kabinettssitzung erklärte, daß man sich - dies sei der definitive Zweck der Reise - „die guten Dienste von Signor Mussolini in Berlin sichern“ könne; der Duce müsse dafür gewonnen werden, „Herrn Hitler davon abzuhalten, sich wie ein ,tollwütiger Hund" aufzuführen"277. Am 11. Januar 1939 trafen Chamberlain, Lord Halifax und Sir Alexander Cadogan, der beamtete Staatssekretär des Foreign Office, in Rom ein. Mussolini und Ciano feierten die Gäste mit einigem Gepränge, wichen jedoch zunächst einer ernsthaften politischen Unterhaltung aus. Chamberlain reagierte auf die Taktik des Duce mit Hilflosigkeit und handelte sich am folgenden Morgen eine Mahnung des ansonsten gelassenen und überlegten Cadogan ein: „Wir müssen ... Musso auf das Thema Hitler und dessen Intentionen bringen. Wir müssen von hier eine gewisse Zusicherung mitnehmen, daß Musso versuchen wird, Hitler zurückzuhalten, und wiederum hier die Vorstellung zurücklassen, daß es, wenn Hitler nicht zurückgehalten wird, Krach gibt." 278 Chamberlain gelang es indes auch in den folgenden Gesprächen nicht, aus Mussolini mehr herauszuholen als die jede tiefere Erörterung abblockende Behauptung, sein Freund Hitler denke überhaupt nicht an Krieg, und vor der zweiten Aufgabe, die Cadogan genannt hatte, versagte er kläglich. Schon am ersten Abend der Zusammenkunft sagte Mussolini zu seinem Schwiegersohn, daß diese Besucher aus London nicht aus dem glei-

276 Ebenda.

277 Ebenda, S. $950 \mathrm{ff}$.

278 Ebenda, S. 951. 
chen Holz geschnitzt seien wie Francis Drake und all die anderen großartigen Abenteurer, die das Empire geschaffen hätten; man habe es vielmehr mit den müden Abkömmlingen einer langen Reihe reicher Männer zu tun: „Und sie werden das Empire verlieren." 279 Graf Ciano gewann in den Besprechungen den Eindruck, daß die Briten so schreckgebannt auf die deutsche Aufrüstung starrten wie das Kaninchen auf die Schlange und daß sie nicht kämpfen wollten. Wie verächtlich die Italiener den britischen Besuch von Anfang an behandelten, wird klar, wenn man sich vor Augen hält, daß Mussolini acht Tage vor dem Eintreffen Chamberlains in Rom den Deutschen hatte mitteilen lassen, er sei nun zum Abschluß eines deutsch-italienisch-japanischen Militärpakts bereit und wünsche die Unterzeichnung der Vertragsdokumente noch Ende Januar. Wäre das Vorhaben nicht an der japanischen Zurückhaltung gescheitert, hätte also etwa zwei Wochen nach der Rückkehr Chamberlains aus Rom eine feierliche Zeremonie den Beitritt Italiens zu einer ausdrücklich antiwestlichen Allianz besiegelt und die offenbar düpierten Briten globaler Lächerlichkeit preisgegeben. Chamberlain hatte es in Rom nicht vermocht, die italienische Einschätzung der Londoner Politik zu korrigieren. Im Gegenteil. Wenn Graf Ciano das Ergebnis des britischen Besuchs in die Worte faßte: „Nichts von Bedeutung!"280 so war das infolgedessen nicht ganz richtig. Angesichts der Schwachherzigkeit, die sie bei ihren britischen Gästen diagnostizieren zu dürfen glaubten, waren Mussolini und Ciano mehr denn je zur Umwandlung des Antikominternpakts in ein Militärbündnis und notfalls auch, falls Japan ewig zögern sollte, zu einem bloß zweiseitigen italienisch-deutschen Pakt bereit. Gegenüber dieser britischen Regierung mußte sich ein derartiger Vertrag hervorragend zum politischen Druckmittel eignen.

Noch immer zu grandioser Selbsttäuschung fähig, schrieb Chamberlain, aus Rom zurückgekehrt, am 15. Januar an seine Schwester: „Ich habe alles erreicht, was ich zu bekommen erwartete, und mehr als das, und ich bin überzeugt davon, daß die Reise die Friedenschancen merklich verbessert hat." ${ }^{281} \mathrm{Da}$ ihm die römische Bevölkerung, wie einige Monate zuvor die Münchner, zugejubelt hatte, redete er sich ein, die Reise sei ein Erfolg gewesen, und am 18. Januar nahm er es, in einer Kabinettssitzung, auch als Grund für Optimismus, daß Mussolini während der römischen Gespräche stets - statt sich gemäß dem Reisezweck gegen Hitler einspannen zu lassen - „loyal“ den „Führer" verteidigt hatte; das spreche doch für den Charakter des Duce ${ }^{282}$. Aber wie dünnhäutig die britischen Politiker - Chamberlain eingeschlossen - in Wahrheit bereits geworden waren, zeigte sich gerade in den Tagen nach dem Rom-Besuch. Mitte Januar liefen in London etliche Berichte, meist aus irgendwelchen geheimdienstlichen Quellen, ein, die

279 Zit. nach Taylor, Munich, S. 951.

280 Ebenda, S. 952.

281 Ebenda. S. 953.

282 Ebenda, S. $953 \mathrm{f}$. 
abermals, wie im Dezember die Nachricht Kirkpatricks, besagten, daß Hitlers nächste Aktion ein Angriff im Westen sein werde, und zwar nannten einige Berichte die Niederlande als erstes Opfer. Es war nun sehr bezeichnend, daß diese frei erfundenen Informationen, deren Herkunft sich irgendwo im Dunkel verlor, nicht nur bei rüstungswilligen Militärs, denen sie überaus gelegen kamen, sondern auch in Regierungskreisen anfänglich durchaus Glauben fanden, und die „Holland-Panik“, die sofort ausbrach, produzierte in wenigen Tagen und Wochen weit mehr als erregte Diskussionen ${ }^{283}$.

Auf militärischem Gebiet traf das britische Kabinett endlich die bislang von Chamberlain und seinen Gefolgsleuten immer wieder verhinderte Entscheidung, das im Kriegsfall auf den Kontinent zu entsendende Expeditionskorps erheblich zu verstärken und wesentlich besser auszurüsten; zwei weitere Maßnahmen wurden jetzt immerhin in einer Weise erörtert, die auf baldige Beschlüsse deutete: die Schaffung eines Versorgungsministeriums, das die Rüstungsanstrengungen zentral steuern und intensivieren sollte, und die Einführung der allgemeinen Wehrpflicht. Auf politischem Gebiet begann die britische Regierung - die auch Präsident Roosevelt unterrichtete - unverzüglich mit Sondierungen in Paris, Brüssel und Den Haag, um gegen die Bedrohung durch Deutschland, das offenbar den Versuch mache, wie man den Belgiern am 16. Februar sagte, „Europa durch Gewalt zu beherrschen", eine gemeinsame Front der anscheinend zuerst gefährdeten Länder aufzubauen. Die Antwort der beiden grundsätzlich neutralen Staaten war naturgemäß enttäuschend: sowohl Holland wie Belgien weigerten sich, schon vor einem deutschen Angriff irgendwelche politischen oder militärischen Abreden mit den westlichen Großmächten zu treffen und damit ihren neutralen Status zu kompromittieren. Auf der anderen Seite bekräftigten beide Staaten, daß sie entschlossen seien, sich im Falle eines deutschen Angriffs zur Wehr zu setzen, und angesichts dieser Bekräftigung kamen Frankreich und Großbritannien - die jetzt auch die Kontakte ihrer Generalstäbe enger gestalteten - zu dem Schluß, daß eine gemeinsame Front praktisch bereits dann entstehe, wenn die dafür erforderliche klare Vereinbarung vorläufig nur von den Großmächten getroffen werde. So verpflichteten sich Großbritannien und Frankreich, einen deutschen Einfall in Holland und in die Schweiz - letztere Ergänzung wünschten die Franzosen - als Kriegsgrund zu betrachten; für Belgien existierte eine solche Verpflichtung schon seit 1937. Trotz der geographischen Limitierung war damit im Grunde bereits das Prinzip aufgestellt, daß man die nächste deutsche Grenzüberschreitung mit Krieg beantworten werde, sofern das überfallene Land Widerstand leiste. Die „Holland-Panik“ hatte mithin eine Verdeutlichung der britisch-französischen Haltung bewirkt, die einer Verhärtung gleichkam, und eine Entschlossenheit geweckt, die bei erneuter deut- 
scher Aktivität den Abschied von der Appeasement-Politik zur Gewißheit machte.

Mangels Nahrung ebbte jedoch die „Holland-Panik“ wieder ab, und nach einigen Wochen regte sich allenthalben erneut die Hoffnung, daß die totalitären Staaten vielleicht doch Ruhe halten könnten und ein Krieg gegen sie vielleicht doch zu vermeiden sei. Am 8. März berichtete Lord Halifax in einer Kabinettssitzung, Frank Ashton-Gwatkin, ein Wirtschaftsexperte des Foreign Office, sei gerade aus Berlin zurückgekehrt, wo er mit Göring, Ribbentrop und Wirtschaftsminister Walter Funk gesprochen, „eine sehr freundliche Atmosphäre" vorgefunden und den Eindruck gewonnen habe, „daß keine unmittelbaren Abenteuer größerer Natur ins Auge gefaßt“ seien ${ }^{284}$. Einen Tag später gab Chamberlain der Presse ein überaus optimistisches Interview: das Ende des Bürgerkriegs in Spanien sei in Sicht und das könne zu einer Verständigung zwischen Frankreich und Italien führen; Oliver Stanley, der Handelsminister, werde am 17. März nach Berlin fahren, um dort aussichtsreiche Wirtschaftsgespräche zu beginnen; mit einer Abrüstungskonferenz sei noch vor Jahresende zu rechnen. Die Zeitungen brachten das Interview am 10. groß heraus. Sir Samuel Hoare, der Innenminister, ein kluger, geschickter und intriganter Politiker, der seit Jahren zu den Säulen der Appeasement-Politik gehörte und erheblichen Anteil an der Fernhaltung Churchills von einem Regierungsamt hatte, malte am Abend des 10. März in öffentlicher Rede ein prächtiges Gemälde von einer Zukunft des Friedens und der Prosperität, die Europa der Zusammenarbeit zwischen den Führern Großbritanniens, Frankreichs, Deutschlands und Italiens verdanken werde ${ }^{285}$.

Um so heftiger war der Schock, als Hitler ein paar Tage später die Tschechoslowakei zerstörte, statt zusammen mit den Westmächten und Italien ihre neuen Grenzen zu garantieren, wie es der Vereinbarung von München entsprochen hätte. Alle Erscheinungen der „Holland-Panik“ kehrten zwangslăufig wieder, allerdings - ebenso zwangsläufig - in viel größeren Dimensionen und mit schwererwiegenden Konsequenzen. Von nun an konnte es niemand mehr wagen, öffentlich für die Appeasement-Politik einzutreten. Gerade diejenigen, die das eben noch mit so rosigen Prognosen getan hatten wie Sir Samuel Hoare, sahen sich nicht allein aufs schlagendste, sondern auch aufs blamabelste widerlegt. Manche wandelten sich tatsächlich, so Lord Lothian, der einer der eifrigsten und einflußreichsten Anhänger von Appeasement gewesen war, jedoch schon nach der „Kristallnacht" in einem Brief an Kolonialminister Malcolm MacDonald dagegen plädiert hatte, einem Staat mit einer derart brutalen Rassenpolitik Kolonien zu geben ${ }^{286}$; jetzt forderte er mit Nachdruck eine feste Deutschland-

284 Ebenda, S. 956.

256 Ebenda.

286 Weinberg, The Foreign Policy of Hitler's Germany, S. 522. 
politik Großbritanniens 287 . Andere mochten nach wie vor größte Opfer für angezeigt oder für vertretbar halten, wenn dadurch einer militärischen Konfrontation mit Deutschland zu entgehen war, doch hatten sie unter der Wucht der Ereignisse und angesichts der allgemeinen Empörung über Hitlers Aktion zu verstummen. In den Monaten seit München immer wieder hart mitgenommen und allmählich mit schwindender Zuversicht kämpfend, hatte die Appeasement-Fraktion gleichwohl bis zuletzt existiert und ihre Standarten hochgehalten; nun war sie mit einem Male, als relevanter Faktor, aus der politischen Landschaft Großbritanniens verschwunden.

Die Fraktion hätte auch keinen Führer mehr gehabt. Eine der wichtigsten Folgen des Hitlerschen Streichs bestand darin, daß der britische Premierminister diesen Streich mit Recht als eindeutige Widerlegung der zwei tragenden Grundannahmen seiner bisherigen Kontinental- und Deutschlandpolitik ansah. Chamberlain hatte geglaubt, Hitler vertrauen und das nationalsozialistische Deutschland saturieren zu können. Beides war nun als Irrtum erwiesen. Bei den ersten Nachrichten über den deutschen Coup hatte sich Chamberlain zwar noch um Gelassenheit bemüht und alle nur erreichbaren Gründe zusammengesucht, die eine passive Hinnahme des Coups rechtfertigen konnten. Am 15. März gab er im Unterhaus eine Erklärung ab, in der er sich vornehmlich auf die Ausrufung der slowakischen Unabhängigkeit durch den Preßburger Landtag berief. Wohl sagte er, daß die Aktion Hitlers den „Geist“ des Münchner Abkommens verletze, und er wies auch auf den „bedauerlichen Umstand“ hin, daß die Deutschen erstmals von der Politik abgewichen seien, ,in das Reich nur benachbarte Massen von Menschen deutscher Rasse zu inkorporieren“, und jetzt ein Territorium besetzt hielten, „das von Menschen bewohnt wird, mit denen sie rassisch gar nicht verbunden sind“". Doch lehnte er es andererseits ab, sich "heute“ schon „Anklagen des Vertrauensbruchs, wie sie in aller Munde sind“, zu eigen zu machen, und er betonte, daß die britische Regierung bei der Regelung von Streitfragen nach wie vor der Diskussion den Vorzug vor der Gewalt gebe 288 . Mancher gewann so den Eindruck, aus der Rede des Premiers spreche die Entschlossenheit, weiterhin auf Appeasement-Kurs zu bleiben. Hätte sich dieser Eindruck bestätigt, wäre Chamberlain vermutlich nicht mehr lange Premierminister geblieben; in politischen Kreisen wurde bereits über seine Ablösung durch Lord Halifax gesprochen. Aber der Eindruck, den er mit seinen ersten Reaktionen erweckte, täuschte.

Schon in der Sitzung vom 15. März hatte sich Chamberlain mit dem Kabinett - das allerdings den von Lord Halifax gemachten Vorschlag ablehnte, Sir Nevile Henderson abzuberufen, den britischen Botschafter in Berlin - dazu entschieden, die Reise Oliver Stanleys nach Deutschland „zu

287 Ebenda, S. 618.

288 Parliamentary Debates, Fifth Series. House of Commons. Official Report Bd. 345, Sp. 437. 
verschieben“. Am 16. März sagte er, als er mit Halifax und R.A. Butler lunchte, Staatssekretär im Foreign Office und bislang ein zuverlässiger Streiter für die Appeasement-Politik: „Ich bin zu dem Schluß gekommen, daß ich den Naziführern nicht noch einmal vertrauen kann."289 Drei Tage später schrieb er an seine Schwester: „Sobald ich Zeit fand, darüber nachzudenken, erkannte ich, daß es unmöglich ist, mit Hitler auszukommen, nachdem er alle seine eigenen Versicherungen in den Wind geschlagen hat." 290 Doch räsonierte Chamberlain nicht nur in kleinem Kreise und in einer vertraulichen Korrespondenz. Er begründete seinen Sinneswandel auch öffentlich, was die Abkehr der Nation von Appeasement naturgemäß stabilisieren mußte, und im Kabinett machte er aus seiner eigenen Preisgabe der bisherigen Orientierungspunkte britischer Deutschlandpolitik eine offizielle Kurskorrektur der Regierung. Zunächst nutzte er eine Rede, die er am 17. März im heimischen Birmingham über wirtschaftliche Probleme hielt, zu jenen bitteren Worten an die Berliner Adresse, die dort Goebbels so mißfielen. Nachdem er die scheinbare Vorsicht seiner zwei Tage zuvor im Unterhaus abgegebenen Erklärung ausdrücklich mit der Zurückhaltung begründet hatte, die der verantwortliche Regierungschef zu üben habe, wenn er nur über unvollständige Informationen verfüge, nachdem er ferner seine Politik bis zum Münchner Abkommen noch einmal dargelegt und verteidigt hatte, fuhr er fort ${ }^{291}$ :

„Wie können die Ereignisse dieser Woche in Einklang gebracht werden mit den Zusicherungen, die ich Ihnen zitierte? Zweifellos hatte ich als Mitunterzeichner des Münchner Abkommens ein Recht auf jene Konsultation, die in der Münchner Erklärung vorgesehen war, wenn Herr Hitler es aufzulösen wünschte. Statt dessen hat er sich ein Selbsthilferecht angemaßst. Noch ehe der tschechische Präsident empfangen und vor Forderungen gestellt wurde, denen zu widerstehen er nicht die Macht hatte, waren die deutschen Truppen auf dem Marsch und binnen weniger Stunden waren sie in der tschechischen Hauptstadt.

Der gestern in Prag erlassenen Proklamation zufolge sind Böhmen und Mähren dem Deutschen Reich angeschlossen worden. Nicht-deutsche Einwohner, zu denen natürlich die Tschechen gehören, werden dem Deutschen Protektor im Deutschen Protektorat unterstellt. Sie haben sich den politischen, militärischen und wirtschaftlichen Bedürfnissen des Reiches zu unterwerfen. Sie werden Staaten mit Selbstverwaltung genannt, aber das Reich übernimmt ihre Außenpolitik, ihre Zölle und Akzisen, ihre Bankreserven und die Ausrüstung der entwaffneten tschechischen Armee. Und vielleicht das Unheimlichste: Wir hören wieder vom Auftauchen der Ge-

290 Ebenda.

291 Documents concerning German-Polish Relations and the Outbreak of Hostilities between Great Britain and Germany on September 3, 1939, London 1939, Nr. 9. 
stapo, der geheimen Staatspolizei, und von der gewohnten Geschichte der Massenverhaftungen prominenter Persönlichkeiten mit den Folgen, die uns allen vertraut sind.

Jeder Mann und jede Frau in unserem Land, die sich an das Schicksal der Juden und der politischen Gefangenen in Österreich erinnern, müssen heute von Kummer und Sorge erfüllt sein. Wer kann hindern, daß sich sein Herz in Sympathie dem stolzen und tapferen Volk zuwendet, das so plötzlich ein Opfer dieser Invasion wurde, dessen Freiheiten beschnitten sind und dessen nationale Unabhängigkeit dahin ist. Was ist aus der Erklärung ,keine territorialen Ansprüche mehr' geworden? Was ist aus der Versicherung, wir wollen keine Tschechen im Reich' geworden? Wieviel Rücksicht hat man genommen auf den Grundsatz der Selbstbestimmung, worüber Herr Hitler in Berchtesgaden mit mir so heftig diskutierte, als er die Trennung des Sudetengebietes von der Tschechoslowakei und dessen Einverleibung in das Reich forderte? ... die Dinge, die sich diese Woche unter völliger Mißachtung der von der Deutschen Regierung selbst aufgestellten Grundsätze ereignet haben, ... müssen uns allen die Frage nahelegen: ,Ist dies das Ende eines alten Abenteuers, oder ist es der Anfang eines neuen?

,Ist dies der letzte Angriff auf einen kleinen Staat, oder sollen ihm noch weitere folgen? Ist dies sogar ein Schritt in Richtung auf den Versuch, die Welt durch Gewalt zu beherrschen?"“

Nach solch eindrucksvollen und aus Chamberlains Munde fast sensationellen Sätzen kündigte der Premier seinen Zuhörern an, daß die britische Regierung unverzüglich in Besprechungen mit den Commonwealth-Ländern und mit Frankreich eintreten werde, ,mit denen wir so eng verbunden sind“, und daran knüpfte er den bemerkenswerten Hinweis, „daß auch andere, die wissen, daß wir an dem, was in Südosteuropa vorgeht, nicht desinteressiert sind, unseren Rat und unsere Meinung wohl gerne einholen werden". Offensichtlich gab der britische Regierungschef jedem, der hören wollte, zu verstehen, daß die übrigen Staaten der von Deutschland bedrohten Region künftig mit britischem Schutz rechnen dürften. Am Tag danach bestätigte Chamberlain diesen revolutionären Wandel der britischen $\mathrm{Au}$ Benpolitik in einer Kabinettssitzung 292 :

„Der Premierminister sagte, wir seien bis vor einer Woche von der Annahme ausgegangen, daß wir mit unserer Politik, die Beziehungen mit den diktatorischen Mächten weiter zu verbessern, fortfahren könnten, und daß diese Mächte zwar Ziele hätten, die Ziele aber begrenzt seien ...

Der Premierminister sagte, er sei nun definitiv zu dem Schluß gekommen, daß Herrn Hitlers Haltung es unmöglich mache, auf der alten Basis mit dem Nazi-Regime zu verhandeln ... Auf keine der Versicherungen, die von den Nazi-Führern gegeben würden, könne man Vertrauen setzen... 
Der Premierminister sagte, daß er auf der Basis dieses Schlusses, und nach Beratung mit dem Außenminister und anderen sofort erreichbaren Kollegen, seine Rede in Birmingham gehalten habe...

Der Premierminister sagte, daß er seine Rede in Brimingham als eine Herausforderung an Deutschland in der Frage betrachte, ob Deutschland Europa durch Gewalt beherrschen wolle oder nicht. Daraus folge, daß Deutschland, wenn es einen weiteren Schritt in Richtung Herrschaft über Europa mache, die Herausforderung annehme ... Er stimme daher mit der Auffassung des Außenministers überein, daß wir, wenn Deutschland auch nach der gegebenen Warnung bei seinem Kurs bleibe, keine andere Wahl hätten, als die Herausforderung aufzunehmen...,

Mit dieser Absage an die Appeasement-Politik, die vom Kabinett „warm gebilligt" wurde, befand sich Chamberlain im übrigen auch in Übereinstimmung mit der französischen Regierung. In Frankreich vollzog sich der gleiche Wandlungsprozeß wie in Großbritannien. Wenige Monate zuvor war Daladier bei seiner Rückkehr aus München mit frenetischem Jubel empfangen worden. Jetzt begann der Begriff „Appeasement“ den Ruch des Unanständigen anzunehmen. Am 15. März kam es zu einer stürmischen Unterredung $z$ wischen dem französischen Botschafter in Berlin und Staatssekretär v. Weizsäcker, in der Robert Coulondre, noch ohne offizielle Richtlinie aus Paris, bezeichnenderweise von sich aus "mit gewisser innerer Erregung“, wie Weizsäcker notierte, dartat, „wie sehr er beeindruckt sei durch den Einmarsch unserer Truppen im Widerspruch mit dem Münchener Abkommen, im Gegensatz zu dem Vertrauensverhältnis, was er hier vorzufinden geglaubt, und zu den Zielen, die er sich für seine hiesige Mission gesetzt habe“. Seinem eigenen Bericht zufolge faßte Weizsäcker „den Botschafter gleich ziemlich scharf an“ und erklärte ihm, ,er möge mir doch nicht von dem Münchener Abkommen reden, das angeblich verletzt sei, und möge uns keine Lehren erteilen. München habe zwei Elemente enthalten, nämlich die Bewahrung des Friedens und das französische Desinteressement an den Ostfragen. Frankreich möge doch endlich seinen Blick nach Westen auf sein Imperium lenken und nicht von Dingen reden, wo seine Beteiligung erfahrungsgemäß den Frieden nicht fördere."293 Mit einer solchen - Realitätsverleugnung und hochfahrende Arroganz mischenden Pflichtübung im Geiste Ribbentrops, zu der sich Weizsäcker, im Grunde der gleichen Meinung wie der Franzose, genötigt sah, war aber kein Eindruck mehr, war keine Politik mehr zu machen. Daß sich der Staatssekretär am 17. März eine Viertelstunde lang weigerte, die offizielle Protestnote gegen die „klare Verletzung des Geistes und des Buchstabens der am 29. September 1938 in München unterzeichneten Verträge" in Empfang zu nehmen, als sie Coulondre - wie zuvor schon sein britischer Kollege - überrei- 
chen wollte, war ebenfalls nur noch eine Geste politischer Hilflosigkeit ${ }^{294}$. Völlig unbeeindruckt schrieb Coulondre in seinen Berichten295:

„Im Namen des völkischen Prinzips hatte das Reich im September den Anschluß der dreieinhalb Millionen Volksdeutschen des Sudetenlandes durchgefochten. In Mißachtung eben dieses Prinzips annektiert es heute acht Millionen Tschechen, die durch die Aufgabe des Sudetenlands wehrlos geworden waren...

Deutschland hat damit wieder einmal seine Mißachtung aller schriftlichen Verpflichtungen und seine Vorliebe für die Methode der brutalen Gewalt und der vollendeten Tatsachen deutlich bekundet. Mit einer einzigen Handbewegung hat es die Münchener Vereinbarungen ebenso wie den Wiener Schiedsspruch zerrissen und damit erneut bewiesen, daß seine Politik nur ein leitendes Prinzip kennt: günstige Gelegenheiten ausfindig zu machen und jede erreichbare Beute zu ergreifen. Das ist die Moral von Gangstern und Dschungelbewohnern...

Hitler-Deutschland hat soeben seine Maske abgeworfen. Bisher hatte es sich gegen alle imperialistischen Tendenzen verwahrt. Es hatte behauptet, es verfolge allein das Ziel, alle Deutschstämmigen in Mitteleuropa unter Ausschluß Fremdstämmiger soweit wie möglich in einer einzigen Volksfamilie zu vereinen. Heute wird offenbar, daß der Machthunger des Führers keine Grenzen mehr kennt.

Es ist ebenso deutlich geworden, daß es eine vergebliche Hoffnung ist, dem Führer mit anderen Argumenten erfolgreich zu begegnen, als mit den Mitteln der Gewalt. Das Dritte Reich zeigt für eingegangene Verträge und übernommene Verpflichtungen die gleiche Mißachtung wie das Kaiserreich Wilhelms II. Deutschland bleibt das Land der, Fetzen Papier".

Die nationale Sicherheit wie auch der allgemeine Weltfriede verlangen also vor allem vom französischen Volk einen gewaltigen Aufwand an Disziplin und die Zusammenfassung aller Energien des Landes; dies allein wird es Frankreich gestatten, mit Hilfe seiner Freunde seine Interessen gegenüber einem so furchtbaren Gegner wie dem Deutschland Adolf Hitlers zu behaupten und zu verteidigen, diesem Deutschland, das jetzt auf die Eroberung ganz Europas ausgeht...

Es muß aber auch die Frage gestellt werden, ob es zeitlich noch möglich ist, im Osten eine Schranke aufzurichten, die wenigstens in gewissem Rahmen den deutschen Drang nach dem Osten aufhalten kann, und ob wir nicht die günstige Gelegenheit ausnutzen müssen, die uns gegenwärtig die Erregung und die Besorgnis in den Hauptstädten Mitteleuropas bieten, besonders in Warschau."

294 ADAP, D, 5, Nr. 20.

295 R. Coulondre, Von Moskau nach Berlin 1936-1939. Erinnerungen des französischen Botschafters, Bonn 1950, S. $376 \mathrm{ff}$. 
Die Empfindungen und Gedanken, die Robert Coulondre in seinen Berichten niederschrieb, entsprachen genau den Empfindungen und Gedanken des französischen Ministerpräsidenten. Edouard Daladier stellte nach dem Prager Handstreich im Ministerrat fest, „es gebe nun nichts mehr, als sich auf den Krieg vorzubereiten" 296 , und am 29. März erklärte er in einer Rundfunkrede: „Ich habe gesagt, und ich halte dies aufrecht, daß wir keinen Zoll unseres Bodens, nicht ein einziges unserer Rechte aufgeben werden.“ Ferner rief er aus: „Frankreich hofft, daß der Friede gerettet werden kann, denn es haßt den Krieg. Aber wenn der Krieg ihm aufgezwungen oder als letzte Alternative vor Untergang und Ehrlosigkeit angetragen würde, wird es sich mit einmütiger Kraftanstrengung zur Verteidigung der Freiheit erheben." 297 Vor dem Exekutivkomitee der Radikalen Partei unterstrich er, daß ,wir nein sagen zu dem sogenannten Lebensraum“298, und wenn das auch vor allem auf die italienischen Aspirationen im Mittelmeerraum und in Südosteuropa gemünzt war, so galt es doch zugleich für Deutschland, zumal Italien seine Ansprüche allenfalls mit deutscher Hilfe durchsetzen konnte. Und Daladier wußte sich bei seiner Abkehr von München - wie in London Chamberlain - einig mit einer klaren Mehrheit der von ihm repräsentierten Bevölkerung. Im Ministerrat meinte er sogar, die Nation sei so empört, daß sie jede schwache und zaudernde Regierung wegfegen würde; er könne nicht ,in ein Café gehen, ohne die Leute aufstehen und ihm zurufen zu sehen: ,Machen Sie weiter, man wird Ihnen folgen!" 299

In solcher Atmosphäre, in der die Furcht vor uferloser deutscher Aggression allgemein geworden war und einen ersten Höhepunkt erreicht hatte, diese Furcht aber nicht mehr, wie bisher, die Neigung zum Rückzug gebar, sondern die Bereitschaft zum Widerstand, reichten kleine Vorfälle und sogar bloße Gerüchte aus, um große Effekte zu provozieren. Am 16. März suchte Virgil Tilea, der rumänische Gesandte in London, Sir Orme Sargent auf, einen engen Mitarbeiter des beamteten Staatssekretärs im Foreign Office, Sir Alexander Cadogan, und teilte mit, seine Regierung habe auf Grund geheimer Berichte und anderer Quellen Anlaß zu der Annahme, daß Deutschland schon in den nächsten Monaten Ungarn auf Vasallenstatus reduzieren werde, um dann Rumänien in gleicher Weise wie die Tschechoslowakei zu zerlegen, und das „mit dem Endziel, ein deutsches Protektorat üer das ganze Land zu errichten“. Obwohl er erklärte, nicht offiziell, sondern lediglich persönlich zu sprechen, stellte er dann die Frage, ob

296 Jean-Pierre Azéma, Die französische Politik am Vorabend des Krieges, in: Sommer 1939. Die Großmächte und der europäische Krieg, hrsg. v. W. Benz / H. Graml, Stuttgart 1979, S. 284.

298 Ebenda, S. 285.

299 Ebenda. 
Großbritannien nicht erwägen könne, Rumänien einen Kredit von 10 Millionen Pfund zum Kauf von Kriegsmaterial zu gewähren. Am nächsten Tag bekam Tilea Gelegenheit zu einer Unterredung mit Lord Halifax und Cadogan, und diesmal ergänzte er seine erste Erzählung durch die Behauptung, bereits jetzt hätten die Deutschen, und zwar ultimativ, das Monopol über die rumänischen Exporte - einschließlich des rumänischen Erdöls und etliche interne wirtschaftliche Restriktionen gefordert. Die rumänische Regierung habe das Ultimatum abgelehnt, doch sei es von ,äußerster Dringlichkeit“, einen „präzisen Hinweis“ zu bekommen, welche Haltung Großbritannien einnehmen werde, falls „Rumänien das Opfer deutscher Aggression" werden sollte 300 .

Nun fanden in der Tat gerade deutsch-rumänische Wirtschaftsgespräche statt, bei denen die deutsche Delegation, geleitet von Ministerialdirektor Helmuth Wohlthat, einem Repräsentanten Görings in dessen Eigenschaft als „Beauftragter für den Vierjahresplan“, mit einiger Härte auftrat, und das am 23. März unterzeichnete Abkommen wurde von ungarischen oder polnischen und englischen Diplomaten sogleich als "Handelskapitulation“ Rumäniens charakterisiert ${ }^{301}$. Was Ungarn anlangte, so mußte das Land ohnehin schon als Vasall des Dritten Reiches gelten. Über die künftigen Absichten der nationalsozialistischen Führer ließ sich noch nichts Genaueres ausmachen. Die Ungarn selbst hatten jedenfalls „große Angst, daß wir sie schlucken wollen", wie Goebbels, der die ungarischen Magnaten und die Vertreter der magyarischen Gentry vielleicht noch weniger mochte als Hitler, mit Befriedigung konstatierte, als er in den letzten Märztagen am Anfang einer großen Reise durch Südosteuropa und den Nahen Osten in Budapest Station machte und in zahlreichen Unterredungen Eindrücke sammeln konnte ${ }^{302}$. Am 30. März notierte er, nach einem Empfang beim Reichsverweser Nikolaus v. Horthy, zum zweiten Male: „Die Ungarn haben alle eine furchtbare Angst, daß wir sie einmal schlucken!" und an diese Eintragung knüpfte er immerhin den bezeichnenden Kommentar: „Wer weiß?"303

Indes waren die Geschichten Tileas, der offenbar einige Informationen aus Bukarest falsch verstanden und dann im Übereifer gehandelt hatte, von den Realitäten des Frühjahrs 1939 doch um einiges entfernt. In der Gewitterschwüle, die über Europa lastete, genügten sie jedoch, um folgenreiche politische Aktivitäten in Gang zu setzen. Ohne sich durch eine Rückfrage in Bukarest zu vergewissern, jagten Halifax, Cadogan und Sargent, nervös geworden, sofort Telegramme an die britischen Missionen in Paris, Moskau, Warschau, Ankara, Athen und Belgrad, die Tileas Mitteilungen wiederhol-

300 Weinberg, The Foreign Policy of Hitler's Germany, S. 540 ff.; Taylor, Munich, S. 960.

301 APA, Botschaft Berlin, Mappe 20, Aufzeichnung Pilch, 25.3.1939.

302 Tagebücher von Joseph Goebbels, Bd. 3, S. 585.

303 Ebenda. 
ten und die Missionschefs beauftragten, bei ihren Regierungen festzustellen, wie sie auf die von Tilea geschilderte Entwicklung zu reagieren gedachten. Zwar meldete sich der natürlich ebenfalls unterrichtete britische $\mathrm{Ge}$ sandte in Bukarest, Sir Reginald Hoare, am Morgen des 18. März telefonisch und verlangte die Stornierung der Telegramme an die anderen Missionen; anschließend berichtete er schriftlich, die ,äußerst unwahrscheinliche" Story Tileas sei inzwischen vom rumänischen Außenminister Grigore Gafencu als völlig substanzlos bezeichnet worden ${ }^{304}$. Aber das Foreign Office setzte gleichwohl, wenn auch etwas beruhigter, die Arbeit an der Vorbereitung auf den von Tilea an die Wand gemalten Fall fort, zumal der rumānische Gesandte, als man ihn mit dem Bukarester Dementi konfrontierte, an seiner Version festhielt. Chamberlain wurde aus Birmingham zurückgeholt und die Bedrohung Rumäniens noch am 18. März auf einer Sondersitzung des Kabinetts diskutiert. Im Grunde diente die Tilea-Story ein anderer $Z$ wischenfall hätte früher oder später die gleiche Wirkung gehabt - nur als letzter und willkommener Anlaß, um endlich offiziell die Überzeugung zu formulieren und zur politischen Leitlinie zu erheben, die Lord Halifax in der Kabinettssitzung folgendermaßen umrissen hatte: „Das wahre Problem sei Deutschlands Versuch, die Weltherrschaft zu erreichen, was abzuwehren im Interesse aller Länder liege. Er stimme zu, daß wir das einzige Land seien, das eine solche Abwehr organisieren könne. Zweifellos sei es für dieses Land schwierig, wirksame Mittel für einen Angriff auf Deutschland zu finden, ob Deutschland nun Rumänien oder Holland angreife. Die Haltung der deutschen Regierung sei entweder Bluff, in welchem Falle sie durch eine öffentliche Erklärung von unserer Seite gestoppt würde, oder sie sei kein Bluff, in welchem Falle es notwendig sei, daß wir uns alle zusammenschließen, um ihr entgegenzutreten, und je früher wir uns vereinigten, desto besser sei es. Andernfalls könnten wir zusehen, wie ein Land nach dem anderen von Deutschland absorbiert wird."305 Chamberlain zog aus der Debatte das Fazit, es komme nun darauf an, die Frage zu klären, „ob wir ausreichende Zusicherungen anderer Länder erhalten können, die uns zu der öffentlichen Ankündigung berechtigen, daß wir uns jedem weiteren Akt der Aggression seitens Deutschlands widersetzen werden“306. Dieser Kabinettsbeschluß hielt die britische Diplomatie weiter in Bewegung, und wenn auch der verlangte Klärungsprozeß in den nächsten Tagen zu einem ebenso hektischen wie verworrenen diplomatischen Hin und Her entartete, begleitet von nicht minder konfusen Erörterungen in London selbst und in Paris, ergaben sich aus dem Durcheinander doch erstaunlich rasch einige Klärungen, die von den Regierungen Großbritanniens und Frankreichs als feste Orientierungspunkte akzeptiert wurden. Es

304 Taylor, Munich, S. 960.

305 Weinberg, The Foreign Policy of Hitler's Germany, S. 543.

306 Ebenda. 
sollte nur wenige Tage dauern, bis wiederum diese Orientierungspunkte die Westmächte veranlaßten, die Position, die sie nun gefunden hatten, mit einer dramatischen Geste, die ihrerseits einen bedeutsamen Prozeß anstieß, auch öffentlich klarzulegen.

Zunächst zerfiel die Vision einer umfassenderen europäischen Defensivallianz zu Staub, wie sie mit den Telegrammen an sieben europäische Hauptstädte impliziert worden war ${ }^{307}$. Die schwächeren Staaten reagierten ausweichend, und die UdSSR schlug eine internationale Konferenz vor, auf der Großbritannien, Frankreich, Polen, Rumänien und die Sowjetunion sich über ein gemeinsames Vorgehen verständigen sollten. Die Briten, die keine zeitraubende und womöglich Differenzen produzierende Konferenz wollten, sondern ein Signal, das Berlin schon in den nächsten Tagen gegeben werden konnte, verfielen nun auf die Idee einer Vier-Mächte-Erklärung. Großbritannien, Frankreich, die UdSSR und Polen sollten gemeinsam öffentlich ankündigen, einander konsultieren zu wollen, falls eine Aktion unternommen werden sollte, die eine "Bedrohung" der "Sicherheit und der politischen Selbstāndigkeit europäischer Staaten" darstelle. Auch dieser Gedanke - Lord Halifax hielt eine bloße Konsultationsankündigung ohnehin für „keine sehr heroische“ Geste - mußte wieder aufgegeben werden, weil sich sogleich herausstellte, daß Polen jede Assoziation mit der Sowjetunion - ob bei einer gemeinsamen Erklärung oder in einem Bündnis verweigerte; die Polen mißtrauten den Absichten auch eines befreundeten Rußland zutiefst, und sie dachten gar nicht daran, durch eine engere Verbindung mit der UdSSR den Zorn Hitlers auf Warschau herabzuziehen ${ }^{308}$. Beck, der noch immer hoffte, Polen zwischen Rußland und Deutschland unabhängig zu halten, hatte jedoch nichts dagegen, gerade diesem Zweck durch eine Aktivierung westlicher Beziehungen zu dienen bzw. gegen einen jetzt nicht mehr auszuschließenden deutschen Uberfall ernsthafte Vorkehrungen zu treffen, und so wies er Graf Edward Raczyński, den polnischen Botschafter in London, am 23. März an, Lord Halifax eine geheime bilaterale Übereinkunft anzubieten, in der Großbritannien und Polen einander zusichern würden, im Falle des Falles in Übereinstimmung mit den Grundsätzen der von London skizzierten Vier-Mächte-Erklärung zu handeln; die Geheimhaltung sei notwendig, so Beck, um Deutschland nicht zu reizen ${ }^{309}$.

Halifax, der Raczyński am 24. März empfing, fand - im Hinblick auf die doch wohl erforderliche Beteiligung Frankreichs - am bilateralen Charakter einer solchen Übereinkunft ebensowenig Geschmack wie - im Hinblick auf die angestrebte abschreckende Wirkung - an der Geheimhaltung. Doch brachte Becks Angebot Halifax und seine Mitarbeiter im Foreign Office

307 Taylor, Munich, S. 960.

308 Ebenda, S. 962.

309 Weinberg, The Foreign Policy of Hitler's Germany, S. $547 \mathrm{ff}$. 
dazu, über eine bloße Geste in Form der Konsultationsdeklaration hinauszudenken und eine ausgewachsene Defensivallianz ins Auge zu fassen, die Hitler bei einem neuen Abenteuer mit einem Zweifrontenkrieg konfrontieren sollte. Angesichts der polnischen - und im übrigen auch der rumänischen - Ängste war aber klar, daß die Sowjetunion in eine derartige Kombination nicht direkt einbezogen werden durfte. Um so größere Bedeutung erlangte Polen in den Überlegungen der westlichen Politiker - nicht schon in der Rolle des Opfers. Da Beck die deutsch-polnische Auseinandersetzung auch jetzt noch vor den Westmächten zu verbergen suchte, besaßen die Außenministerien in London und Paris über die Verschlechterung der Beziehungen zwischen dem nationalsozialistischen Deutschland und Polen keine präzisen Informationen, und als mutmaßlich nächstes Opfer Hitlers galt immer noch Rumänien. Doch mußte Polen für die Errichtung einer Abschreckungs-Allianz, die notfalls zur Kriegführung gegen das Deutsche Reich fähig war, als politischer und militärischer Faktor gewonnen werden. Wie Halifax das Ergebnis der Beratungen, die im Foreign Office am 25. und 26. März stattfanden, wiedergab: Da Polen sich nicht mit der Sowjetunion verbinden wolle und da es keine deutsch-russische Grenze gebe, sei „die Beteiligung Polens an jedem Plan, Deutschland im Falle einer Aggression aufzuhalten, unentbehrlich“, und Rußland könne man „nicht im Vordergrund des Bildes brauchen" 310 . Am Abend des 26. März konnte dem Premierminister bereits ein Vorschlag unterbreitet werden, der auf eine britisch-französische Verpflichtung hinauslief, Rumänien und Polen zu Hilfe zu kommen, falls sie von Deutschland angegriffen und sich dem Angriff widersetzen würden, wobei die britisch-französische Unterstützung Rumäniens an die Mitwirkung Polens gebunden war; Polen sollte außerdem nahegelegt werden, seinen Kriegseintritt an der Seite der Westmächte zuzusichern, wenn diese einer deutschen Aggression ausgesetzt sein bzw. Jugoslawien oder irgendeinem westeuropäischen Land gegen eine deutsche Aktion beistehen würden. Chamberlain billigte die Planskizze, und am 27. März stimmte auch der Außenpolitische Ausschuß des Kabinetts zu, Telegramme, in denen dieser Vorschlag zusammengefaßt war, zur weiteren Übermittlung an die Missionen in Paris, Warschau und Bukarest zu senden. Für den 3. April war zudem seit einiger Zeit ein Besuch Becks in London vereinbart worden, so daß also zur Festlegung der Funktion Polens eine zusätzliche Gesprächsmöglichkeit mit dem polnischen Außenminister unmittelbar bevorstand.

Die Debatten und die Konferenzen in Foreign Office und Kabinett resultierten aber nicht nur in der Entschlossenheit zu aktiver Bündnispolitik und in einer ersten Reißbrettskizze der Allianzplanung, sondern auch in der Formulierung eines für die künftige britische und französische Haltung höchst bedeutsamen Prinzips. Hatte die „Holland-Panik“ dem Grundsatz 
zur allgemeinen Anerkennung verholfen, daß es für die Notwendigkeit der Intervention Englands und Frankreichs gleichgültig geworden sei, welcher Staat das nächste Opfer einer deutschen Aggression sein werde, so ging man nun, unter dem Eindruck der Liquidierung des tschechoslowakischen Staates, noch einen Schritt weiter. Bereits am 18. März hatte Chamberlain im Kabinett erklärt, daß die Formierung der europäischen Staaten gegen das Deutsche Reich nicht "der Rettung eines bestimmten Opfers“ dienen könne; vielmehr komme es darauf an, „den Störenfried zu Fall zu bringen"311. Am 21. März konferierte Lord Halifax mit seinem französischen Kollegen Georges Bonnet, der Staatspräsident Albert Lebrun bei einem offiziellen Besuch in London begleitete, und in dieser Unterredung betonte auch der britische Außenminister, daß die Frage nicht laute, ob die Westmächte Rumänien oder Polen direkt zu Hilfe kommen könnten; die Frage habe zu lauten, ob die Westmächte in der Lage seien, „einen erfolgreichen Krieg gegen Deutschland zu führen" 312 . In der Sudetenkrise hatten die Verfechter der Appeasement-Politik noch häufig und mit großer Wirkung das Argument benutzt, Großbritannien und Frankreich seien ja doch nicht fähig, die Niederwerfung und Besetzung der Tschechoslowakei zu verhindern, ihre Intervention werde also zu spät kommen und sollte deshalb besser unterbleiben. Jetzt, im Frühjahr 1939, spielte es keine Rolle mehr, daß schwächere Mitglieder einer Anti-Hitler-Koalition zunächst einmal überrannt werden und als aktive Teilnehmer des Krieges fürs erste ausscheiden mochten; entscheidend war, ob sich die Koalition eine vernünftige Chance ausrechnen durfte, am Ende siegreich zu sein. Auch hierin zeigte sich, wie sehr seither die Furcht vor Deutschland zugenommen hatte und wie rasch andererseits die Bereitschaft stabil geworden war, den unerträglich werdenden Unruheherd bei seinem nächsten Ausbruch auszutreten.

Just in diesem Augenblick meldete sich Jan Colvin, Korrespondent der Londoner „News Chronicle“ in Berlin, bei Sir Reginald Leeper, dem Leiter der Presseabteilung im Foreign Office, mit einer alarmierenden Nachricht $^{313}$. Schon im Januar hatte Colvin von „einem zuverlässigen Gewährsmann" gehört, daß ein Proviantlieferant der deutschen Armee die Anweisung erhalten habe, die gleiche Menge an Rationen wie im September 1938 bereitzustellen, und zwar bis zum 28. März 1939 in einer Ecke Pommerns, „die einen groben Keil bildet, der auf den Eisenbahnknotenpunkt Bromberg im Polnischen Korridor zielt". Damals hatte Colvin mit der Information nichts weiter angefangen oder anfangen können. Nachdem er jedoch am 27. März in der deutschen Presse Berichte über deutschfeindliche Ausschreitungen in Bromberg gelesen hatte, die in seinen Augen eine verdächtige Ähnlichkeit mit den Greuelgeschichten über tschechische Grausam-

311 Weinberg, The Foreign Policy of Hitler's Germany, S. 543.

312 Taylor, Munich, S. 963.

313 Ebenda, S. $966 \mathrm{f}$. 
keiten aufwiesen, wie sie von der deutschen Propaganda vor München verbreitet worden waren, stellte er Zusammenhänge her, begann er einen unmittelbar bevorstehenden deutschen Einmarsch in Polen zu argwöhnen und sprach er über seinen Verdacht mit dem britischen Militärattaché in Berlin, Oberst Frank Mason-Macfarlane. „Mason-Mac“, wie er genannt wurde, verfügte $z$ war nicht über ähnliche Hinweise auf eine deutsche Aktion, hielt aber „einen raschen Stoß zum Abschneiden des Polnischen Korridors" durchaus für möglich und riet Colvin, sofort nach London zu gehen und dort die zuständigen Stellen zu unterrichten. Am 28. März traf Colvin in London ein, und Leeper brachte ihn am folgenden Tag mit Cadogan und Lord Halifax zusammen, die ihn ernst genug nahmen, um ihn noch am gleichen Tag dem Premierminister berichten zu lassen.

Chamberlain, der mittlerweile seinem deutschen Partner von München jede schurkische Überraschung zutraute und vom Foreign Office sicherlich darauf hingewiesen worden war, daß Colvin sich während der Sudetenkrise als seriöser Reporter gezeigt hatte, war ebenfalls sogleich tief beeindruckt. Nach der Befragung Colvins konferierte er lange mit Halifax. Ohnehin gerade im Begriff, zur Abschreckung Hitlers eine Allianz unter Einschluß Polens zu zimmern, und nun plötzlich besondere Eilbedürttigkeit annehmend, kamen der Premier und sein Außenminister überein, das rumänische Problem für einen Moment etwas zu vernachlässigen und zur „Abwehr eines schnellen Putsches Hitlers" sofort eine öffentliche Erklärung abzugeben, daß Großbritannien und Frankreich entschlossen seien, Polen im Falle eines deutschen Angriffs mit den Waffen zu unterstützen ${ }^{314}$. Bis zum Morgen des 30. März arbeiteten Halifax und sein Stab den Text einer solchen Erklärung aus, dazu die Botschaften nach Paris und Warschau, die dort die Zustimmung der französischen und der polnischen Regierung erwirken sollten. Danach wurden die geplante Aktion und die inzwischen vorliegenden Texte eingehend auf einer Sondersitzung des Kabinetts erörtert. Allen Anwesenden war klar, daß sie auf der Basis weniger und unbestätigter - auch vom Geheimdienst nicht bestätigter - Informationen debattierten, daß die vorgesehene Erklärung Hitler vielleicht nicht abhielt, sondern erst recht zur Gewaltanwendung reizte, daß Polen ein Hilfsversprechen bekam, ohne sich schon zu einer entsprechenden Gegenleistung verpflichtet zu haben. Am Ende setzte sich jedoch die Angst durch, von Hitler ein weiteres Mal überrumpelt zu werden. Dem „Führer“ mußte rechtzeitig deutlich gemacht werden, daß er sich mit einem Einfall in Polen einen Zweifrontenkrieg auf den Hals zog. Geschah das nicht, bestand die Gefahr, daß die deutschen Armeen Polen in kürzester Zeit überrannten, das dann sowohl für die geplante politische Abschreckungsallianz wie bei Versagen der Abschreckung als militärischer Partner in einem gleichzeitig in Ost und West gegen Deutschland zu eröffnenden Krieg ausfiel. Immerhin kam es 
zu einem Kompromiß. Statt Halifax zu folgen, der die recht präzise und deutliche Erklärung, die im Foreign Office entworfen worden war, abgegeben wissen wollte, doch erst nach Eingang genauerer Nachrichten, beschloß das Kabinett, den Rat Lord Chatfields zu akzeptieren, des Ministers für die Koordination der Verteidigung, und etwas allgemeinere Formulierungen zu wählen, die der Premierminister aber, in Anbetracht der Eilbedürftigkeit, noch am 31. März im Unterhaus verwenden solle. Nachdem die Zustimmung der französischen und der polnischen Regierung eingetroffen war, wurde denn auch so verfahren. Auf die erbetene Frage des Führers der Labour-Opposition, Clement Attlee, ob der Premierminister „eine Erklärung zur europäischen Lage abgeben könne“, antwortete Chamberlain ${ }^{315}$ :

„Wie ich diesen Vormittag sagte, hat Seiner Majestät Regierung keine offizielle Bestätigung der Gerüchte über einen geplanten Angriff auf Polen, und sie können daher nicht als wahr akzeptiert werden.

Ich nehme die Gelegenheit gerne wahr, abermals die allgemeine Politik der Regierung Seiner Majestät zu umschreiben. Sie ist stets eingetreten für die Methode der freien Unterhandlung zwischen den betroffenen Parteien zur Bereinigung der Differenzen, die zwischen ihnen entstehen können. Sie hält dies für den natürlichen und bestgeeigneten Weg dort, wo Differenzen bestehen. Nach ihrer Meinung sollte es keine Frage geben, die nicht durch friedliche Mittel gelöst werden könnte, und sie würde keine Rechtfertigung sehen dafür, daß man die Methode der Unterhandlungen durch die Gewalt oder durch Drohung mit Gewalt ersetzt.

Wie das Haus weiß, sind jetzt bestimmte Konsultationen mit anderen Regierungen im Gang. Um inzwischen, ehe diese Verhandlungen abgeschlossen sind, die Stellung der Regierung Seiner Majestät vollkommen klarzumachen, habe ich jetzt dem Hause mitzuteilen, daß im Falle einer Aktion, welche die polnische Unabhängigkeit klar bedrohen und gegen welche die Polnische Regierung entsprechend den Widerstand mit ihrer nationalen Wehrmacht als unerläßlich ansehen würde, Seiner Majestät Regierung sich während dieser Zeit verpflichtet fühlen würde, sofort der Polnischen Regierung alle in ihrer Macht liegende Unterstützung zu gewähren. Sie hat der polnischen Regierung eine entsprechende Zusicherung gegeben.

Ich darf hinzufügen, daß die französische Regierung mich ermächtigt hat, klarzustellen, daß sie in dieser Angelegenheit denselben Standpunkt einnimmt wie Seiner Majestät Regierung.“

Nun war in der Tat Klarheit geschaffen. Griff Hitler Polen an, bekam er auch Krieg mit den Westmächten. Angesichts der politischen, der geistigen, der kulturellen Gefahr, die das nationalsozialistische Deutschland mittlerweile in den Augen fast ganz Europas darstellte, hatte Großbritannien die Tradition der Lloyd George und Austen Chamberlain endgültig

315 Parliamentary Debates, London 1939, Bd. 345, Sp. 2415. 
preisgegeben und zum ersten Mal einen osteuropäischen Staat garantiert. Zwar galt die Garantie nur der Unabhängigkeit und nicht ausdrücklich den Grenzen Polens. Aber diese Formulierung war gewählt worden, um der polnischen Regierung die Freiheit zu Gesprächen mit Berlin zu lassen, nicht etwa um sich an der Garantierung der Grenzen vorbeizumogeln und damit die polnische Regierung zu Gesprächen mit Berlin zu zwingen. Chamberlains Erklärung war so formuliert, daß sie den Polen erlaubte, auch jede gewaltsame Durchsetzung eines territorialen Anspruchs Deutschlands als Gefährdung der polnischen Unabhängigkeit anzusehen und durch bewaffneten Widerstand den Beistand der Westmächte zu bewirken. Für die Garantiemächte war die Möglichkeit, daß ihre Interventionszusage die Verhandlungsbereitschaft Polens minderte, zweitrangig geworden. Daß Chamberlain eine potentiell so folgenreiche Verpflichtung auch im Namen Frankreichs übernehmen durfte, und das noch dazu öffentlich, signalisierte im übrigen ganz Europa und nicht zuletzt den Berliner Machthabern, welche Festigkeit - dank der Hitlerschen Politik - inzwischen die britischfranzösische Solidarität erlangt hatte.

Und das Gefühl der Eilbedürftigkeit hielt ebenso an wie das Bewußtsein der Solidarität. Einen Prozeß der Bündnisbildung vor Augen, den womöglich zahllose Ängstlichkeiten und Bedenklichkeiten - und namentlich das Problem der Position Rußlands - ungebührlich in die Länge zogen, setzten die Westmächte vorerst lieber die Politik der Garantie-Erklärungen fort. Nachdem Beck am Ende seiner Besprechungen in London, die vom 4. bis zum 6. April dauerten, die gleiche Garantie, die Polen von der britischen Regierung gegeben worden war, im polnischen Namen für Großbritannien ausgesprochen hatte - ansonsten begnügten sich die beiden Mächte damit, ihre feste Absicht zum Abschluß eines formellen Beistandspakts zu bekunden -, wurde am 13. April auch die rumänische Frage durch eine britische und französische Garantie der Unabhängigkeit Rumäniens vorläufig gelöst. $\mathrm{Daß}$ in die Erklärung für Rumänien gleich auch noch Griechenland einbezogen wurde, sollte als Warnung an die Adresse Italiens dienen, das am 7. April das Königreich Albanien - seit langem eine Art italienisches Protektorat - mit Truppen besetzt und nach der Verjagung König Zogus annektiert hatte, weil Mussolini und Ciano glaubten, als Faschisten und als die Führer des faschistischen Italien ein Äquivalent zu Hitlers Handstreich gegen die CSR zu brauchen. Daß Angriffe der Achsenmächte auf west- und nordeuropäische Staaten erst recht die Intervention der westlichen Großmächte auslösen würden, stand ohnehin fest, und so hatten London und Paris mit ihrer Serie von Garantien im Grunde den gesamteuropäischen Status quo, wie er bis zum April 1939 entstanden war, garantiert. Jeder weitere gewaltsame Versuch zur Veränderung, darauf hatten sie sich öffentlich festgelegt, daran öffentlich ihre Großmachtqualität geknüpft, bedeutete Krieg. Damit war eine der boshaften Ironien geboren, wie sie im Ablauf der Geschichte gar nicht so selten sind. Die Träger und Verfechter der Appea- 
sement-Politik hatten ja von 1931 bis zum Herbst 1938 keine Mühe und keine Blamage gescheut, ihre Staaten an den Grundsätzen der kollektiven Sicherheit und den Regeln des Völkerbunds vorbeizulotsen, der Verpflichtung zu automatischem Handeln gegen einen Friedensstörer zu entgehen, wie sie in der Satzung des Bundes verankert war; sie hatten mithin großen Anteil am Verenden der kollektiven Sicherheit. Im Frühjahr 1939 aber, nach der Zerstörung des Genfer Systems, in erheblich schwächerer Position und gegen einen wesentlich stärker gewordenen Feind, sahen sich nun ausgerechnet die Protagonisten von Appeasement zu dem mühsamen Versuch gezwungen, zu Mechanismen kollektiver Sicherheit zurückzukehren und die eigenen wie die anderen bedrohten Länder auf jene automatisch funktionierende internationale Solidarität einzuschwören, die sie selbst so lange verweigert hatten.

Als Chamberlain am 31. März Polen gegen einen deutschen Angriff die Waffenhilfe der Westmächte versprach, erntete er im Unterhaus Beifall von allen Seiten ${ }^{316}$. Dieser Beifall galt allerdings nicht Polen, sondern allein dem endlich ausgesprochenen Willen, Hitler künftig Widerstand leisten zu wollen. Die Polen waren, obgleich man sie nun plötzlich als die vermutlich nächsten Opfer der „Nazis“ anzusehen hatte, noch immer alles andere als populär. John Colville, der erst dem Premierminister Chamberlain und während des Krieges dem Premier Churchill als Sekretär diente, hat sich später daran erinnert, wie er in den Monaten nach München dachte, daß es den Polen, nachdem sie im Gefolge Hitlers den Tschechen so übel mitgespielt hatten, gerade recht geschähe, wenn jetzt sie drankämen ${ }^{317}$. Churchill bedauerte noch im Frühjahr 1939 lebhaft, daß nichts anderes mehr bleibe als die Zusammenarbeit mit den durch böse Taten belasteten Polen, nachdem man die Tschechen, „ein tapferes und demokratisches Volk“, im Stich gelassen habe ${ }^{318}$, und Harold Nicolson, sofort davon überzeugt, daß die Garantie eingelöst werden müsse, schrieb mit dem Blick auf die Polen grimmig, daß man bald für eine falsche Sache Krieg führen werde, doch habe man nur die Wahl zwischen einem solchen Krieg und der „Auslieferung ganz Europas an die Nazi-Herrschaft" 319 . Vor eine derartige Alternative gestellt, entschied sich in den Westmächten eine klare Mehrheit, wie immer über das Land gedacht werden mochte, das Hitler sich offenbar als weitere Beute ausgesucht hatte, für eine Politik des Widerstands. Nur noch wenige gingen so weit, über die Garantie so zu urteilen, wie zwei Tories, die sich im Unterhaus unterhielten: „Ich nehme doch an“, sagte der eine, „daß wir imstande sind, aus dieser widerwärtigen Garantie-Geschichte wieder herauszukommen?"“ „Oh, natürlich“, antwortete der andere, „wir haben ja Gott

316 Nicolson, Diaries and Letters, S. 393.

317 Colville, The Fringes of Power, S. 23.

318 Political Diary of Hugh Dalton 1918-1940, 1945-1960, hrsg. v. Ben Pimlott, London 1986, S. $263 \mathrm{f}$.

319 Nicolson, Diaries and Letters, S. 401. 
sei Dank Neville!"320 Die meisten - und zwar einschließlich des gewandelten und hier gröblich verkannten Neville Chamberlain - hätten sicherlich Henry Pownall zugestimmt, dem Leiter der Operations- und Nachrichtenabteilung im britischen Generalstab, der seinem Tagebuch anvertraute: „Eine kontinentale Verpflichtung, daß es nur so eine Art hat. Aber ich bin sicher, es ist die richtige Politik."321

Die meisten glaubten ja auch, daß die Politik der Garantien den Krieg eher verhindern als näherbringen werde, zumal die offene Verkündung des Abwehrwillens in den Augen der Briten und Franzosen keineswegs bedeutete, daß von nun an über deutsche Ansprüche nicht mehr geredet und verhandelt werden dürfe. Selbst Sir Robert Vansittart, Vorgänger Cadogans als beamteter Staatssekretär im Foreign Office, inzwischen von der Appeasement-Gruppe auf den Posten eines Diplomatischen Chefberaters abgeschoben, doch nach wie vor einflußreich und als scharfer Gegner des nationalsozialistischen Deutschland geltend - er sorgte mit Bedacht dafür, daß sich dieser Ruf in den Kriegs- und Nachkriegsjahren zum Ruf der Deutschfeindlichkeit steigerte -, selbst Vansittart meinte Anfang Mai 1939 in einer Unterhaltung lediglich: „Es ist an der Zeit, den Deutschen zu sagen, daß sie in Zukunft, nachdem sie in Österreich, der Tschechoslowakei etc. 100 Prozent ihrer Forderungen erfüllt bekommen haben, nicht mehr als äußerstenfalls 30 Prozent erwarten dürfen." ${ }^{222}$ Die Proklamierung des Abwehrwillens betraf die bisher von Hitler praktizierten Methoden. Damit mußte endgültig Schluß sein. Vansittart hatte hinzugesetzt, daß natürlich auch die „30 Prozent" nur dann zu haben seien, wenn die Deutschen sich auf die „Methode der Verhandlungen beschränken, sich anständig benehmen und dies, statt bloße Versprechungen zu geben, durch Taten beweisen“. Ob sich das nationalsozialistische Deutschland in diesem Sinne von den Garantie-Erklärungen der Westmächte beeindrucken ließ, war freilich ungewiß, doch schien kein anderer Weg gangbar zu sein. Wie es der skeptische Vansittart ausdrückte: „Vielleicht versteht Hitler, wenn wir unsere Muskeln spielen lassen; sicherlich versteht er nichts anderes." Etwa um die gleiche Zeit faßte Cadogan die Grundmotive der Garantie-Politik noch einmal in der Sprache des Foreign Office zusammen ${ }^{323}$ :

„Das Hauptziel unserer Garantie an Polen besteht darin, Deutschland von weiteren Aggressionsakten abzuschrecken und durch die Erlangung einer umgekehrten Garantie von Polen sicherzustellen, daß Deutschland, falls doch Krieg kommt, an zwei Fronten zu kämpfen hat ... Deutschland ist im Augenblick nicht in der Lage, einen $Z$ weifrontenkrieg zu beginnen. Wenn es jedoch freie Hand hätte, ostwärts zu expandieren und sich die

320 Ebenda.

321 B. Bond (Hrsg.), Chief of Staff. The Diaries of Lieutenant-General Sir Henry Pownall, Bd. 1, 1933-1940, Hamden, Conn., 1973, S. 197.

322 Diary of Hugh Dalton, S. 263.

323 Zit. nach Taylor, Munich, S. 969 f. 
Kontrolle über die Ressourcen Mittel- und Osteuropas zu verschaffen, dann könnte es kräftig genug sein, um mit überwältigender Stärke über die westlichen Länder herzufallen."

Indes zeitigten die britisch-französischen Manöver ihre tatsächlichen Effekte in politisch-diplomatischen Zusammenhängen, wo das von niemand erwartet worden war.

\section{Der Entschluß zum Angriff auf Polen}

Den geringsten Einfluß übte die Politik der Garantien, die mit Polen begonnen worden war, paradoxerweise auf den Fortgang der deutsch-polnischen Auseinandersetzung aus. In Warschau hatte bereits der Ribbentropsche Auftritt, mit dem Lipski am 21. März konfrontiert worden war, Klarheit geschaffen. Zunächst in dem Sinn, daß Außenminister Beck, seine Kollegen und seine Mitarbeiter endlich begriffen, wie illusionär ihre frühere Annahme von einer vorübergehenden Laune der Deutschen und wie berechtigt die wachsende Besorgnis der letzten Monate gewesen war. Als Lipski, der sich ungesäumt nach Warschau aufgemacht hatte, am 23. März im polnischen Außenministerium Bericht erstattete und Beck über die Einladung Ribbentrops informierte, brachte er einen Pessimismus mit, der die trübe Stimmung, die den Botschafter schon im Herbst des vergangenen Jahres, nach dem ersten Vorstoß Ribbentrops, ergriffen hatte, wie schieren Optimismus erscheinen ließ: In der Form noch höflich, sei der ReichsauBenminister in der Sache hart gewesen und habe unnachgiebig alle deutschen Forderungen wiederholt; auch hätten die Deutschen die Einkreisung Polens eingeleitet - Slowakei, Memel -, und er, Lipski, schließe nun sogar ein deutsches Ultimatum nicht mehr aus ${ }^{324}$. Im Gegensatz zum Herbst 1938 fand aber Lipski, der überdies Rücktrittsgedanken äußerte, diesmal weitgehend Glauben. Die Anwesenden - Außenminister Beck, sein Kabinettschef Graf Lubienski, Staatssekretär Graf Szembek, der Personalchef des Ministeriums Dr. Drymmer und der Leiter der Westabteilung Graf Jozef Potocki - suchten den aufgewühlten Lipski zu beruhigen und wieder aufzurichten, gaben jedoch allesamt zu, daß die Lage in der Tat überaus ernst geworden sei. Am folgenden Tag - nach Gesprächen mit dem Staatspräsidenten, mit dem Regierungschef und mit dem Generalinspekteur der Armee - berief Beck eine Konferenz der höheren Beamten des Außenministeriums ein, in der er ihnen, die bisher gepflegte Geheimniskrämerei preisgebend, eröffnete, daß Deutschland, eines der beiden Elemente, die stets die Lage Polens bestimmten, „die Eigenschaft der Berechenbarkeit verloren" habe und daß man vor dem Ernst der Situation die Augen nicht verschließen dürfe; in Deutschland scheine man „im Denken wie im Han- 
deln das Maß zu verlieren" 325 . Ganz ähnlich konstatierten und beklagten die Militärs, Generalstabschef Waclaw Stachiewicz und Marschall SmiglyRydz, daß man jetzt die „Unberechenbarkeit“ Deutschlands als Faktor ins Kalkül zu ziehen habe; unter dem Einfluß „dynamischer Parteikreise und Ribbentrops", so urteilte Stachiewicz, habe „sich die Politik Hitlers verändert“326. Einige Wochen später traf Graf Szembek in seinem Tagebuch die resignierte Feststellung, nach dem Abgang Schachts und Neuraths - merkwürdigerweise zählte er auch Göring zu den Abgehalfterten - und dem Machtantritt von Menschen wie Alfred Rosenberg, Goebbels und Ribbentrop habe sich in Deutschland eine große und grundsätzliche Veränderung vollzogen, „sodaß wir es heute nicht mehr mit dem Dritten, sondern mit dem Vierten Reich zu tun haben“327.

Doch fiel in Warschau sofort auch die Entscheidung darüber, wie auf den deutschen Druck zu reagieren sei: Nachgiebigkeit kam nicht in Frage. Graf Lubienski, der wie Lipski ein deutsches Ultimatum für möglich hielt, brachte die Ansicht aller zum Ausdruck, als er am 23. März, im Anschluß an den Bericht des Botschafters, sagte, Berlin werde, falls Polen in einem Punkt nachgebe, unweigerlich neue Forderungen präsentieren, und was die von Hitler und Ribbentrop offerierte Grenzgarantie angehe, so wisse man ja mittlerweile, daß „deutsche Grenzgarantien überhaupt nichts wert" seien. Am 24. März stellte Beck die Frage, wo die Linie verlaufe, hinter die Polen nicht zurückweichen dürfe, und er gab sich und seinen Mitarbeitern die Antwort, daß natürlich die territoriale Unversehrtheit des Landes verteidigt werden müsse, daß es aber ebenso unmöglich sei, ,in diesem Reizpunkt, der Danzig immer war, einen einseitigen und uns aufgezwungenen Vorschlag anzunehmen". Ganz unabhängig davon, was Danzig als Objekt wert sei - und in seinen Augen sei es sogar viel wert -, gehe es um die symbolische Rolle, die Danzig heute spiele. Wenn sich Polen jener Art westlicher Staaten anschließe, die sich ihre Rechte diktieren lassen, so wisse man nicht, wo das enden werde. Selbst Graf Szembek, ein nicht sonderlich streitbarer und außerdem Verhandlungen mit Deutschland grundsätzlich zugeneigter Diplomat, kam zu dem Schluß: „Meiner Meinung nach müssen wir den Deutschen jetzt die Zähne zeigen.“328

Die möglichen Konsequenzen einer solchen Haltung lagen auf der Hand. Zwar hegte Beck noch immer eine gewisse Hoffnung auf einen politischen Weg aus der Krise. Nachdem er in der Konferenz mit seinen Beamten konstatiert hatte, daß "der Feind" in Berlin das Maß zu verlieren scheine, fuhr er fort: „Er kann das Maß wiedergewinnen, wenn er auf eine feste Haltung stößt, was ihm bisher nicht passiert ist. Die Großen waren ihm gegenüber demütig, die Schwachen kapitulierten von vornherein, ohne

\footnotetext{
325 Ebenda, S. $528 \mathrm{f}$.

326 Ebenda, S. $548 \mathrm{f}$.

327 Ebenda, S. 582.

328 Ebenda, S. 527.
} 
auch nur ihre Ehre zu retten.“ Gestützt auf ein paar Divisionen, „spazieren die Deutschen heute durch ganz Europa“. Mit Polen könnten sie so nicht umspringen, und Hitler und seine Helfer wüßten das doch. Auf der anderen Seite war inzwischen klar, daß sich die Hoffnung auf deutsche Einsicht sehr leicht als trügerisch erweisen konnte, und auch für den äußersten Fall hatte man in Warschau die Entscheidung schon getroffen. Beck faßte - und zwar wiederum in Übereinstimmung mit dem Staatspräsidenten, dem Regierungschef und dem Generalinspekteur der Streitkräfte - diese Entscheidung in die schlichten, doch deutlichen Worte: „Ganz einfach! wir werden kämpfen!"329

Die Entschlüsse der polnischen Regierung waren gewiß von der Spekulation begleitet, daß Polen im Falle eines deutschen Angriffs die Unterstützung der Westmächte finden werde. Nachdem Hitler gerade das Münchner Abkommen zerrissen und die Fetzen des Vertrags Daladier und Chamberlain mit triumphierendem Hohn vor die Füße geworfen hatte, konnten Großbritannien und Frankreich eigentlich nicht umhin, so sagte man sich in Warschau, auf den nächsten Gewaltakt des „Führers“ auch militärisch zu reagieren. Am 12. April meinte z.B. Waclaw Grzybowski, der polnische Botschafter in Moskau, daß England Hitler nicht mehr ungestraft davonkommen lassen, „diesen kleinen Napoleon fertigmachen“"werde ${ }^{330}$, und eine Woche später stellte er fest, Hitler habe eine für Polen „wahrscheinlich nicht wiederholbare günstige Konstellation" zuwege gebracht ${ }^{331}$. Zum Zeitpunkt der beiden Äußerungen lagen die britische Garantie und die britisch-polnische Erklärung vom 6. April schon vor, doch waren die Grundelemente der Situation auch vorher zu erkennen und den polnischen Politikern durchaus bewußt gewesen. Seit dem 18. März hielt Beck außerdem die britische Frage nach dem polnischen Verhalten bei einer deutschen Aktion gegen Rumänien in Händen, seit dem 20. auch Londons Vorschlag einer britisch-französisch-polnisch-sowjetischen Anti-Aggressions-Erklärung. Dies erlaubte ebenfalls die Folgerung, daß die Politik der Westmächte im Begriff war, härter zu werden. Andererseits war am 23. und 24. März noch völlig unklar, wie lange der Prozeß der Verhärtung andauern und wie weit er gehen werde. Selbst eine erneute Aufweichung war noch denkbar. Schließlich hatten die Westmächte auch die Annexion Böhmens und Mährens lediglich mit papierenen Protesten quittiert, und angesichts der bisherigen Politik Chamberlains durfte niemand, solange sich Großbritannien nicht öffentlich oder vertraglich festgelegt hatte, ausschließen, daß die britische Regierung bei einem weiteren Hitlerschen Coup in Ost- oder Südosteuropa, statt so zu handeln, wie sie „eigentlich“ handeln mußte, doch wieder auf das Rezept zurückkam, sich Ruhe auf Kosten anderer zu erkaufen; 
und Frankreich hatte dem britischen Kurs zu folgen. Daneben gab es Unsicherheitsfaktoren, die speziell Polen betrafen. In Warschau wußte man gut genug, wie sehr das Ansehen Polens durch die anti-tschechische Komplicenschaft mit dem nationalsozialistischen Deutschland allenthalben gelitten hatte. Bestimmten die Gründe, die jetzt dafür sprachen, gegen Hitler Front zu machen, auch dann die Politik der Westmächte, wenn es um Polen ging? Am 14. September 1938 hatte Graf Raczynski die Frage von Lord Halifax verneint, ob die Westmächte auf polnische Unterstützung rechnen könnten, falls sie wegen der CSR in einen Krieg mit Deutschland verwikkelt werden sollten ${ }^{332}$. War das zu vergessen? Hierauf konnten noch keine sicheren Antworten gegeben werden. Insofern haben die verantwortlichen Politiker in Warschau ihre Entscheidung, Hitler Widerstand entgegenzusetzen, zwar in der Hoffnung auf britisch-französischen Beistand getroffen, aber letzten Endes doch nicht in Abhängigkeit vom Verhalten der Westmächte.

Ebensowenig Rücksicht nahm die polnische Regierung darauf, daß die totale oder partielle Besetzung ihres Landes zu erwarten stand, falls Hitler seine Armeen gegen Polen in Bewegung setzte. Hatte es Polen, wie das Beck und seine Kollegen riskierten, allein mit Deutschland aufzunehmen, war die Niederlage unabwendbar, die Besetzung gewiß und die politische Zukunft düster; man focht dann in der Tat ausschließlich darum, die Ehre und die Selbstachtung der Nation zu retten. Traten aber die Westmächte, wie das Beck und seine Kollegen erhofften, auf der Seite Polens in den Krieg ein, so war völlig offen, wie und wann sich die britisch-französische Intervention militärisch zugunsten Polens bemerkbar machen würde. Zwischen dem polnischen Generalstab und den Generalstäben der Westmächte hatten ja bislang nicht einmal flüchtige und oberflächliche Gespräche über eine militärische Zusammenarbeit und die Abstimmung von Operationsplänen stattgefunden. Eines war jedoch klar: Selbst bei einem relativ frühen Beginn französischer Offensiven konnte es nicht ausbleiben, daß Hitler einen beträchtlichen Teil der deutschen Streitkräfte, und zwar vor allem deren modernen Kern, in Polen einfallen ließ und daß die polnische Armee von einem solchen Ansturm zumindest weit nach Osten zurückgeworfen werden mußte. Kamen die französischen Offensiven erst später, war wiederum zunächst die militärische Katastrophe zu befürchten. Jedermann in Polen, der zählte, wußte das. Die Legende von den siegessicheren und übermütigen polnischen Politikern und Militärs, die vom Marsch nach Berlin geträumt hätten, ist tatsächlich nichts anderes als eine Legende, die ihre Geburt der nationalsozialistischen Propaganda verdankt, ferner einem Téil der polnischen Presse, der Zuversicht zu verbreiten suchte, und einer kleinen Minderheit rechtsextremistischer Schreihälse, die tyczne, Warschau 1985, S. 279. 
ein weiteres Beispiel dafür lieferten, welchen Schaden nationalistische Eiferer ihrem Land immer wieder zufügen.

Bei allem Selbstgefühl und bei allem Stolz auf die dem polnischen Staat zugeschriebene Großmachtqualität war Beck ebenso wie den Generälen sehr bewußt, daß die polnische Armee wohl mit einer hervorragenden Kampfmoral, aber nicht mit genügend modernen Flugzeugen, Panzern, Geschützen und Transportmitteln zu prunken vermochte, vor allem nicht im Vergleich zur deutschen Armee. Gewiß hatte die Regierung - angesichts der deutschen und der sowjetischen Rüstung - von 1936 bis 1939 Summen in die Streitkräfte und ihre Modernisierung investiert, die für polnische Verhältnisse gewaltige Dimensionen erreichten; die 4,2 Milliarden Zloty machten in dieser Zeit etwa die Hälfte des polnischen Staatshaushalts aus 333. Doch abgesehen davon, daß erhebliche Gelder - wie vor 1914 vom deutschen Kaiserreich - für ebenso kostspielige wie militärisch nutzlose Marineprojekte, z.B. für den Bau von U-Booten, verschwendet worden waren, steckte der Modernisierungsprozeß noch in der Anfangsphase. Niemand kam auf den verwegenen Gedanken, der polnischen Armee die Kraft zur offensiven Kriegführung gegen Deutschland zuzutrauen und ihr dann eine Offensive auch noch zuzumuten. Als am 19. Mai 1939 General Tadeusz Kasprzycki, der polnische Kriegsminister, und General Maurice Gamelin, der französische Generalstabschef, endlich eine Art Abrede über die Rollenverteilung im Kriegsfall trafen, vereinbarten sie selbstverständlich, daß die polnische Armee in der Defensive bleiben werde, wenn die Masse der deutschen Verbānde im Osten angreifen sollte. Selbst für die Alternative - „Wenn umgekehrt das Gros der deutschen Truppen Frankreich angreift ..."- legten sie lediglich fest, daß dann „die polnische Armee sich bemühen wird, die größtmögliche Zahl der deutschen Truppen zu binden“. Im Grunde lief die Verabredung darauf hinaus, daß die Polen vesprachen, ihre Haut so teuer wie möglich zu verkaufen, während die Franzosen zusagten, etwa zwei Wochen nach Kriegsbeginn eine größere Offensive zu eröffnen und damit die Hauptlast der Kriegführung zu übernehmen ${ }^{334}$.

In der ganzen Krisenperiode faßten die polnischen Politiker und Soldaten - von kleineren Vorstößen nach Ostpreußen abgesehen - keine ehrgeizigeren militärischen Operationen ins Auge, und das verbot sich erst recht in den für Polens Kurs entscheidenden Märztagen. Die polnischen Führer glaubten ja mit einem in Kürze präsentierten deutschen Ultimatum rechnen zu müssen. Als sie sich entschieden, ein solches Ultimatum abzulehnen und lieber zu kämpfen, riskierten sie also bewußt einen baldigen deutschen Angriff, obwohl ihnen durchaus klar war, daß der polnische Generalstab, bisher auf den Fall eines Krieges mit Rußland fixiert, gerade eben erst,

333 P. Stawecki, Wojsko Drugiej Rzeczypospolitý, in: Polska Odrodzona 1918-1939, red. Jan Tomicki, Warschau 1982, S. 233 f. 238 f.

334 Text in: J. Beck, Dernier Rapport. Politique Polonaise 1926-1939, Paris 1951, S. 345 f. 
am 4. März, angefangen hatte, sich über Gedankenspiele hinaus eingehender mit einem Krieg gegen Deutschland zu beschäftigen ${ }^{335}$, und obwohl seit der Monatsmitte die schockartige Erkenntnis auf ihnen lastete, daß die strategische Lage Polens durch die militärische Präsenz Deutschlands in der Slowakei nicht einfach schlechter, sondern praktisch bereits hoffnungslos geworden war. In dieser Situation durfte jemand schon als Optimist gelten, der dachte, mit militärischem Widerstand gegen den bevorstehenden deutschen Überfall sei bis zum Eingreifen der Westmächte vielleicht ein Teil des Landes vor deutscher Okkupation zu retten. Immerhin stand der militärische Widerstand, falls die französisch-britische Intervention kam, wenigstens im Dienste eines politischen Zwecks: Polen mochte von der Wehrmacht des Großdeutschen Reiches überrannt und besetzt werden, doch erwarb man durch den Kampf, den man der Wehrmacht lieferte, das Recht, bei der Friedenskonferenz am Tisch der Sieger zu sitzen.

Die Warschauer Regierung zögerte auch nicht, in Berlin für Klarheit über die Haltung Polens zu sorgen. Nachdem das polnische Kriegsministerium zwischen dem 23. und dem 25. März einige Regimenter, die im „Korridor" und in der Region um Danzig stationiert waren, durch die demonstrative Einberufung von Reservisten verstärkt hatte ${ }^{336}$, kehrte Lipski in die Reichshauptstadt zurück und überreichte dort Ribbentrop am 26. März ein Memorandum, das die Antwort der polnischen Regierung auf die am 21. des Monats erneut und fast schon ultimativ gestellten deutschen Forderungen enthielt. Beck schlug darin, wie bereits im vergangenen November, Verhandlungen sowohl über weitere Erleichterungen des Verkehrs zwischen Pommern und Ostpreußen wie über die Ablösung des Völkerbundstatuts für Danzig durch eine gemeinsame deutsch-polnische Garantie für die Freie Stadt vor: „Diese Garantie würde einerseits die freie Entwicklung des deutschen Volkstums und seines politischen Innenlebens befriedigen, andererseits die polnischen Rechte und Interessen sicherstellen. Die polnischen Interessen stimmen übrigens mit den wirtschaftlichen Interessen der Bevölkerung der Freien Stadt überein, da der Wohlstand derselben seit Jahrhunderten von dem polnischen Überseehandel abhängig ist." Die deutschen Forderungen wurden hingegen höflich, doch rundweg abgelehnt, und in seiner Erläuterung des Memorandums bemerkte Botschafter Lipski überdies, daß Außenminister Beck zwar gerne der deutschen Anregung folgen und Berlin einen Besuch abstatten werde, „es schiene ihm aber zweckmäßig, daß vorher die Fragen diplomatisch entsprechend vorbereitet worden seien"; in dürren Worten war damit dem Reichsaußenminister mitgeteilt, daß Beck die Einladung nach Deutschland ausschlagen werde, solange die Gefahr bestehe, dort wie Schuschnigg oder Hacha behandelt und mit 
der Pistolenmündung an der Schläfe zur Unterzeichnung eines deutschen Diktats genötigt zu werden 337 .

Zwei Tage zuvor hatten Beck und Lipski, wahrscheinlich um die Deutschen von einem ultimativen Vorgehen abzuhalten, das Auswärtige Amt bereits auf einem privateren Wege wissen lassen, wie man in Warschau die Situation Polens sah und welche Politik man in dieser Situation für richtig hielt. Am Morgen des 24. März hatte Graf Stanislaw Dembinski, Direktor des Berliner Büros der Polnischen Telegraphenagentur und ein enger Vertrauter Lipskis, von dem er schon des öfteren mit inoffiziellen diplomatischen Missionen betraut worden war, einen deutschen Freund und ehemaligen Schulkameraden dringlich zum Frühstück eingeladen, Baron von Stengl, bei dem Dembinski sicher sein konnte, daß über ihn jede wichtigere Außerung politischer Natur den Fürsten Bismarck erreichte, den stellvertretenden Leiter der Politischen Abteilung im Auswärtigen Amt. Während des Frühstücks in einem Berliner Hotel sagte Dembinski, die deutschpolnischen Beziehungen seien im Augenblick derart gespannt, daß er im Laufe der nächsten Tage eine deutsche Aktion gegen den „Korridor“ und gegen Danzig für möglich halte. Er habe daher seine Frau und seine beiden Kinder nach Polen geschickt, und für den Fall, daß er selbst plötzlich abreisen müsse, bitte er seinen alten Schulkameraden darum, sich, soweit das zulässig sei, um seine Wohnung und seine Möbel zu kümmern. Dann kam die eigentliche Mitteilung: Deutschland scheine in erster Linie die Eingliederung Danzigs in das Reich erzwingen zu wollen. Sollte dabei Gewalt angewendet werden, so bedeute das Krieg, weil Polen ein solches deutsches Vorgehen nicht widerstandslos hinnehmen werde. Doch müsse die polnische Regierung auch ein Ansinnen Deutschlands, über die Eingliederung Danzigs zu verhandeln, in schroffster Weise ablehnen, „da Polen aus den Verhandlungen, die deutscherseits mit Schuschnigg, Hacha und Urbsys geführt worden seien, seine Lehren gezogen habe“. Die polnische Regierung würde in ihrer Antwort auch darauf verweisen, daß zwischen Deutschland und Polen ein Vertrag mit zehn Jahren Laufzeit existiere, der keinerlei Verhandlungen über territoriale Fragen vorsehe. Danach machte Dembinski auf die europäische Konstellation aufmerksam. Wenn es denn zu einem deutsch-polnischen Konflikt kommen müsse, so besser jetzt als später. Im Augenblick sei die Einstellung in aller Welt dermaßen antideutsch, „daß Polen mit großer Bestimmtheit bei einem deutschen Angriff auf die Unterstützung der Westmächte rechnen könne“. Um dieser Warnung vor einem großen europäischen Krieg noch mehr Nachdruck zu geben, setzte Dembinski hinzu, die Lage sei für Polen so günstig, daß man in Warschau unter Umständen vielleicht sogar der Versuchung erliegen werde, „durch Provokationen in Danzig den Ausbruch eines Konflikts zu beschleunigen“ 338 .

337 Ebenda, Nr. 101.

338 Aufzeichnung Bismarck, 24.3.1939, PAA, Büro Staatssekretär, Polen 1, 34585 f. 
In Berlin blieben derartige Winke nahezu unbeachtet, jedenfalls an der höchsten Stelle, und als Lipski den polnischen Widerstand offiziell aktenkundig machte, reagierten Hitler und Ribbentrop nach wie vor mit Verständnislosigkeit. Daher gaben sie den Versuch, Polen politisch zu disziplinieren, nicht sofort auf, sondern hielten es einfach für notwendig, den Druck auf Warschau zu steigern, und zwar gänzlich unbeeindruckt davon, daß inzwischen detaillierte Informationen über die britische Reaktion auf die Aktion Tileas vorlagen, aus denen die Versteifung der britisch-französischen Haltung deutlich genug hervorging. Noch wurde auf Lockrufe nicht völlig verzichtet. Ribbentrop hatte am 21. März einmal mehr die Möglichkeiten einer aktiven deutsch-polnischen Ostpolitik an die Wand gemalt, dabei auch angedeutet, daß Polen, falls es sich auf die deutschen Forderungen einlasse, selbst in der Warschau offenbar so gefährlich erscheinenden slowakischen Frage auf - allerdings nicht genauer charakterisierte - deutsche Konzessionen rechnen dürfe, und auch in den folgenden Tagen tauchten da und dort noch immer solche Verheißungen auf. So berichtete der polnische Generalkonsul in München, Grabinski, am 27. März über ein Gespräch mit General Ritter v. Epp, in dem der Reichsstatthalter in Bayern zugegeben habe, daß Polen einen Zugang zur Ostsee haben müsse, aber der Meinung gewesen sei, daß dieser Zugang doch nicht unbedingt Danzig zu sein brauche, vielmehr Libau und Riga den Zweck ebenso gut erfüllen könnten; Grabinski vermutete, sicherlich mit Recht, daß Epp zu seinen Anspielungen vom „Führer“ oder von dessen engsten außenpolitischen $\mathrm{Ge}$ hilfen autorisiert gewesen sei ${ }^{339}$. Indes begann der Ton, der gegenüber den Polen angeschlagen wurde, noch schärfer zu werden, und die Drohungen begannen die lockenden Zukunftsbilder zu verdrängen.

Ein interner Vorgang in Berlin war für diesen Prozeß bezeichnend. Am Abend des 23. März bat Staatssekretär v. Weizsäcker den deutschen Botschafter in Warschau, Adolf v. Moltke, telefonisch darum, ,sich vorsorglich bei Minister Beck anzusagen“; im Laufe des nächsten Tages werde Moltke eine längere Instruktion erhalten, auf deren Basis er dann beim polnischen Außenminister den Bericht ergänzen solle, den der nach Warschau gereiste Lipski über sein letztes Gespräch mit Ribbentrop geben werde ${ }^{340}$. Die Instruktion wurde im Auswärtigen Amt auch ausgearbeitet, und wenn sie auch in der Tat, wie Weizsäcker schrieb, Polen vor die Wahl stellte: „Feind oder Freund!" so war in ihr andererseits die Rolle des Freundes recht verführerisch geschildert. Da hieß es, daß Deutschland, falls es zu einer gemeinsamen deutsch-polnischen Ostpolitik komme, bereit sei, „in der künftigen Gestaltung des ganzen ukrainischen Problems Polen das Primat zuzugestehen", und im Hinblick auf die Slowakei ließ sich das Reich in dem Papier sogar zu einer Art Entschuldigung herab: Der „Führer“ habe sich 
dem Appell der Slowakei zunächst nicht entziehen können, auch wäre es unmöglich gewesen, „das Verhältnis Deutschlands zu diesem Restbestandteil der früheren Tschechoslowakei einfach in der Schwebe zu lassen“; doch schließe der Vertrag mit der Slowakei „hinsichtlich seiner Effektivität einen außerordentlich weiten Spielraum in sich", und wenn die Entwicklung der deutsch-polnischen Beziehungen den Berliner Wünschen entsprechen sollte, „würde sich damit auch die Möglichkeit einer gemeinsamen Behandlung des slowakischen Problems durch Deutschland, Polen und Ungarn eröffnen"341. Vermutlich hätte es das Vertrauen der polnischen Politiker in deutsche Zusagen kaum wiederhergestellt, wäre ihnen in solchem Stile vorgeführt worden, daß Deutschland bereit war, den mit der Slowakei gerade eben abgeschlossenen Schutzvertrag in den Papierkorb zu werfen, nur weil das momentan der Berliner Polenpolitik in den Kram paßte. Aber Beck und seine Mitarbeiter konnten den Inhalt der Instruktion überhaupt nicht zur Kenntnis nehmen. Noch am 24. März sah sich Weizsäcker gezwungen, Moltke in Warschau anzurufen und ihm die peinliche Aufgabe zuzumuten, den bereits vereinbarten Gesprächstermin beim polnischen Außenminister abzusagen ${ }^{342}$. Weizsäcker bestätigte das Telefonat mit einem Brief an Moltke, in dem der Staatssekretär festhielt, daß der Entwurf der Instruktion zurückgezogen werden mußte, weil er, von Ribbentrop dem „Führer“ vorgelegt, nicht die Billigung Hitlers gefunden hatte ${ }^{343}$. Offenbar war in dem Dokument nach Hitlers Meinung zuviel Werbung enthalten.

In seiner folgenden Unterredung mit Lipski, am 26. März, verzichtete dann Ribbentrop auf jede versucherische Note ${ }^{344}$. Statt dessen erklärte er dem polnischen Botschafter, daß die Vorschläge in Becks Memorandum natürlich „keine Basis für eine deutschpolnische Lösung darstellen“ könnten. Die Einberufung polnischer Reservisten, sowohl vom OKW wie vom Reichsaußenminister selbst als rein defensive Maßnahme charakterisiert ${ }^{345}$, nahm er zum Anlaß, „mögliche Konsequenzen“ anzudrohen. Er bezeichnete den Vorgang als „eine merkwürdige Antwort auf mein kürzliches Angebot einer endgültigen Befriedung des deutsch-polnischen Verhältnisses“ und setzte schneidend hinzu: „Wenn die Dinge in dieser Richtung weiterliefen, so könne in Kürze eine ernste Situation entstehen. Ich könne Botschafter Lipski mitteilen, daß z.B. eine Verletzung des Danziger Hoheitsgebietes durch polnische Truppen von Deutschland in der gleichen Weise wie eine Verletzung der Reichsgrenzen betrachtet werden würde." $\mathrm{Er}$ schloß mit der Warnung, daß Polen die deutschen Forderungen annehmen oder mit bösen Folgen rechnen müsse. Am nächsten Tag bestellte Ribbentrop den Botschafter erneut, diesmal um ihm Berichte über deutschfeindli-

341 Ebenda, Nr. 73.

342 Ebenda, Nr. 88.

343 Ebenda.

344 Ebenda, Nr. 101.

345 Ebenda, Nr. 90, 101 (S. 102). 
che Ausschreitungen in Bromberg - Berichte, wie sie Jan Colvin alarmiert und zu seiner Reise nach London veranlaßt hatten - unter die Nase zu halten und in harschen Worten die polnische Regierung „für derartige Vorkommnisse voll verantwortlich" zu machen. Der Botschafter hatte von den Bromberger Vorfällen noch keine Kenntnis, wies aber auf die derzeit in Polen herrschende Nervosität hin und stellte dann die Frage, „ob man nicht ein paar ,Worte der Beruhigung für die beiden Völker finden könne“. Ribbentrop verneinte schroff, wiederholte, daß die am Vortag überbrachten Vorschläge Becks keine Grundlage für eine Regelung der deutsch-polnischen Streitpunkte darstellten, und konstatierte drohend: „Die Beziehungen beider Länder entwickelten sich daher stark abschüssig.“"346

$\mathrm{Zu}$ diesem Zeitpunkt glaubte Hitler noch immer, Polen mit derartigem Drohgerede mürbe machen zu können. Jedenfalls sagte er am 25. März mittags, daß sich Polen noch nicht entschieden habe: „Aber unser Druck wird verstärkt. Wir hoffen zum Ziele zu kommen.“347 Indes war der Erfolg Berliner Pressionen, angesichts des seltsamen polnischen Sträubens, doch zweifelhaft geworden, und so hatte sich der „Führer“ gleichzeitig veranlaßt gesehen, auch darüber zu deliberieren, was zu geschehen hatte, falls das Unbegreifliche eintreten und die Warschauer Regierung die deutschen Forderungen tatsächlich definitiv ablehnen sollte. Seine Überlegungen führten ebenso rasch wie die Konferenzen in Warschau zu einem eindeutigen Ergebnis, und das Ergebnis kam ebenfalls - nicht anders als der polnische Entschluß, notfalls zu kämpfen - unabhängig von den seit einigen Tagen verfolgten und in Berlin bekannt gewordenen britisch-französischen Bündnisprojekten zustande, selbst unabhängig von der Frage, ob deutscher Druck, polnische Angst und britisch-französischer Widerstandswille schon jetzt die Mitwirkung Polens bei den antideutschen diplomatischen Manövern der Westmächte zuwege brachten. Am 25. März hielt Generaloberst Walter v. Brauchitsch, der Oberbefehlshaber des Heeres, noch fest, daß der „Führer" das Problem Danzig nicht gewaltsam lösen wolle, „weil er Polen nicht den Briten in die Arme treiben möchte"348. Jedoch war Hitler zu einer solchermaßen noch halbwegs taktisch-rationalen Betrachtung und Behandlung des von ihm provozierten deutsch-polnischen Konflikts nur fähig, wenn und solange er seine Gedankenspiele von der Annahme bestimmen ließ, daß Polen am Ende doch nachgab. Spätestens am Tag vor der Unterredung Hitler-Brauchitsch stand bereits fest, was geschehen werde, falls Polen der Option für Deutschland weiterhin auswich. Als Staatssekretär v. Weizsäcker am 24. März dem Botschafter in Warschau mitteilte, daß der Gesprächstermin bei Außenminister Beck peinlicherweise abgesagt werden müsse, machte er seinem Freund Moltke zugleich klar, daß er sich

347 Tagebücher von Joseph Goebbels, Bd: 3, S. 583

348 ADAP, D, 6, Nr. 99. 
über die Folgen einer Fortsetzung des polnischen Widerstands weder telefonisch - die beiden hatten eben miteinander telefoniert - noch schriftlich äußern könne; darüber werde Legationsrat Rudolf v. Scheliha - ein vertrauenswürdiger, weil regimefeindlicher Angehöriger der Botschaft in Warschau, der sich gerade in Berlin aufhielt - mündlich berichten ${ }^{349}$. Für einen erfahrenen Diplomaten wie Moltke, der außerdem seine nationalsozialistischen Herren in Berlin ähnlich kritisch einschätzte wie Weizsäcker - gelegentlich sogar in Unterredungen mit Beck und Szembek eine erstaunlich offene Kritik am NS-Regime übte 350 -, war das deutlich genug. Am 25. März gab denn auch Hitler dem Oberbefehlshaber des Heeres die Weisung, nun mit der Vorbereitung einer militärischen Lösung der ,polnischen Frage“ - was etwas anderes war als die „Danziger Frage“ - zu beginnen 351.

Nur wenige Tage später fiel die endgültige Entscheidung. Was aus Warschau zu hören war, gab Hitler jetzt die Gewißheit, daß er nicht länger mit der polnischen Kapitulation rechnen durfte. In einem Bericht, den er offenbar schrieb, um Ribbentrop klarzumachen, welches Risiko der „Führer“ - der dann den Bericht ebenfalls las - laufe, wenn er mit Polen so umspringen wolle wie mit der CSR, schilderte Moltke lebhaft die zuversichtlich kriegerische Stimmung, die sich der Polen bemächtigt habe, seit sie glaubten, daß nun, nach der Besetzung Prags und dem Einmarsch ins Memelgebiet, ein deutscher Handstreich gegen Danzig unmittelbar bevorstehe. Am Ende des Berichts gab Moltke eine symptomatische Szene im polnischen Senat wieder: „Die erste Lesung des polnisch-litauischen Handelsvertrags, der der litauische Gesandte Szaulys in der Diplomatenloge beiwohnte, gab dem Senator Katelbach Veranlassung, Litauen im Namen des Senats zu versichern, daß Polen die schweren Erlebnisse, die Litauen soeben habe durchmachen müssen, aufs stärkste mitempfunden habe. An dem, langdauernden stürmischen' Beifall, den diese Erklärung hervorrief, beteiligten sich auch die beiden zu der Sitzung erschienen Minister und Vizeaußenminister Graf Szembek." 352 Kein Wunder, daß Goebbels an diesem Tag, nach einem Telefonat mit Hitler, in seinem Tagebuch notierte, die „Polacken“, wie er die Polen nun bezeichnenderweise nannte, ,sind und bleiben natürlich unsere Feinde" 353 . Schon am Tag danach konnten Hitler und seine Gefolgsleute einem weiteren Bericht Moltkes entnehmen, daß die Stimmung des Widerstands in Polen in der Tat mit der Politik der polnischen Regierung identisch war. Am Abend des 28. März hatte Außenminister Beck den deutschen Botschafter zu sich gebeten und Moltke - in einer Szene, die sicherlich zur Unterstreichung der polnischen Gleichberechtigung ebenso gedacht war wie zur Darlegung des polnischen Standpunkts - mitgeteilt, da

349 Ebenda, Nr. 88.

350 Szembek-Tagebuch, S. 474.

351 ADAP, D, 6, Nr. 99.

352 Moltke an AA, 28.3.1939, ebenda, Nr. 115.

353 Tagebücher von Joseph Goebbels, Bd. 3, S. 584. 
Reichsaußenminister v. Ribbentrop Botschafter Lipski erklärt habe, daß ein polnischer Gewaltakt gegen Danzig den casus belli bedeuten würde, sehe er, Beck, sich gezwungen, ,seinerseits die Erklärung abzugeben, daß, falls deutscherseits ein Versuch unternommen werden sollte, das Statut der Freien Stadt einseitig abzuändern, Polen hierin den casus belli sehen würde. Das Gleiche gelte auch, wenn etwa der Danziger Senat einen solchen Versuch unternehmen würde“. Nach der betonten Versicherung, Polen sei auch weiterhin zu Verhandlungen über eine vernünftige Lösung des Danziger Problems bereit, hatte Beck ferner gesagt, er wolle nicht verhehlen, ,daß er immer mehr den Eindruck gewinne, als ständen wir am Wendepunkt der deutsch-polnischen Beziehungen“. Noch könne alles in Ordnung gebracht werden. Aber: „Die Entscheidung liege jetzt bei Berlin““354 Und Berlin entschied sich sofort. Bevor er am 1. April in einer Rede zum Stapellauf des Schlachtschiffs „Tirpitz“ - in erster Reaktion auf Chamberlains Polen-Garantie - donnerte, daß das Deutsche Reich, weil es nicht bereit sei, „eine Einschüchterung oder auch nur Einkreisungspolitik auf die Dauer hinzunehmen", auch ohne den deutsch-britischen Flottenvertrag auskommen könne ${ }^{355}$, und bevor er anschließend an der viertägigen Jungfernfahrt des KdF-Schiffs „Robert Ley“ teilnahm, gab Hitler General Keitel den Befehl, sofort eine Weisung zur Vorbereitung von „Fall Weiß $\beta^{\prime}$, wie der Angriff auf Polen im internen Berliner Sprachgebrauch hieß, auszuarbeiten. Keitel hielt fest, daß „der Führer zum ,Fall Weiß noch folgendes angeordnet“ habe: „Die Bearbeitung hat so zu erfolgen, daß die Durchführung ab 1.9.39 jederzeit möglich ist.“"356 Bereits am 3. April konnte Keitel die fertige Weisung vorlegen, und am 11. April hat sie der am Abend des 4. von seinem Nordsee-Urlaub nach Berlin zurückgekehrte Hitler unterzeichnet ${ }^{357}$.

Der Entschluß, in einigen Monaten Polen anzugreifen, resultierte mithin allein aus der Entwicklung der deutsch-polnischen Beziehungen. Chamberlains Garantie vom 31. März mag als Peitschenhieb gewirkt haben, doch traf dann die britische Peitsche ein Pferd, das sich ohnehin bereits in vollem Galopp befand. Ebenso deutlich ist, daß Hitler und die NS-Führung im Frühjahr 1939 keineswegs plötzlich jene politischen und vor allem wirtschaftlichen Faktoren entdeckt hatten, von denen sie nach Ansicht späterer Historiker mit einer ,gewissen immanenten zwingenden Logik im Sommer 1939 zum ,blitzartigen' Losschlagen und zum kurzen, schnellen Raubzug als Ausweg aus dem Versorgungsdilemma" gezwungen worden seien 358 . Hätte sich Polen den Wünschen des „Führers“ gebeugt, wäre es ja 1939 überhaupt nicht zu einem Krieg gekommen, und Hitler hätte vermutlich

354 ADAP, D, 6, Nr. 118.

355 Völkischer Beobachter, 3.4.1939.

356 Ebenda, Nr. 149

357 Das Deutsche Reich und der Zweite Weltkrieg, Bd. 2, hrsg. v. Militärgeschichtlichen Forschungsamt Freiburg, Stuttgart 1979, S. 79.

358 Wendt, Großdeutschland, S. 169. 
im September tatsächlich den „Parteitag des Friedens“ inszeniert, den er am 1. April in seiner Wilhelmshavener Rede ankündigte; zuvor wäre AuBenminister Beck in Berlin erschienen, um in feierlicher Zeremonie Polens Beitritt zum Antikominternpakt zu vollziehen, auf dem Parteitag selbst hätte sich Gauleiter Forster mit seinen Mannen aus dem inzwischen ans Reich angegliederten Danzig besonders feiern lassen, und dem „Führer“ wäre es, wie er am 22. August vor den Militärs sagte, möglich gewesen, sich auf die Vorbereitung des dann wahrscheinlich für 1940 aufs Programm gesetzten Angriffskriegs im Westen zu konzentrieren.

Für Hitler lagen die Dinge einfacher. Die Klarheit über das polnische „Nein" weckte in ihm zunächst einmal die Emotion, mit der ein tyrannischer politischer Führer seines Schlages, ein selbstgemachter und im $\mathrm{Na}$ men einer Ideologie selbstgerecht handelnder Tyrann, normalerweise auf derartige Frustrationen reagiert: helle Wut und Vernichtungswillen. Die „böse Arroganz", von der Ivone Kirkpatrick gesprochen hatte, war nicht fähig, einen Widerstand zu ertragen, den zu leisten sich ein Schwächerer erfrechte. Dazu gesellte sich sogleich das hochentwickelte und äußerst reizbare Machtbewußtsein, das mittlerweile die ganze nationalsozialistische Elite auszeichnete: War den „Polacken“ wirklich nicht klar, mit wem sie es zu tun und daß sie zu parieren hatten? Nun gut! Wenn sie es tatsächlich nicht wahrhaben wollten, mußte ihnen eben auf andere Weise beigebracht werden, daß das Deutsche Reich, das nach der Annexion Österreichs und der Sudetengebiete, nach der Unterjochung Böhmens und Mährens, nach der Eingemeindung der Slowakei und dem Einmarsch ins Memelland gerade im Begriff stand, seinem politischen und wirtschaftlichen Einfluß auch Südosteuropa zu unterwerfen, den Ungehorsam eines Staates wie Polen nicht mehr tolerieren konnte. Wenn die nationalsozialistischen Führer und die NS-Propaganda den Polen in den folgenden Monaten Realitätsverlust, Mutwillen, Übermut, Unverschämtheit bescheinigten, so galt das nicht den Dummheiten nationalistischer polnischer Zeitungen oder den kriegs- und eroberungslustigen Parolen rechtsextremistischer polnischer Studenten. Vielmehr war damit schon gemeint, daß es für die Polen nicht länger zulässig sei, sich deutschem Willen zu widersetzen, und daß sie selbstverständlich die schwerste Strafe auf sich zögen, falls sie sich solches doch herausnähmen; bereits Ende März besagte der partei-interne Kommentar, daß ,jetzt der Kompaß auf Polen zeige“ und daß „auch dieser Staat den Todeskeim in sich trage " 359 .

Ähnlich simpel lautete die politisch-militärische Argumentation, mit der Hitler nun die Notwendigkeit eines Krieges gegen Polen begründete. Emotionale Aufwallung und Hybris mit Überlegungen verbindend, die er unter dem Diktat seiner ideologischen Wahngebilde als eiskalte Logik empfand, ergab sich für ihn aus der Weigerung Warschaus, das Zelt Polens im deut- 
schen Lager aufzuschlagen, eine klare Erkenntnis, die wiederum zu einer nicht weniger klaren Schlußfolgerung zwang. Eines wisse man jetzt, setzte er am 23. Mai den Oberbefehlshabern der Wehrmachtteile und ihren Stabschefs auseinander: „Der Pole ist kein zusätzlicher Feind. Polen wird immer auf der Seite unserer Gegner stehen. Trotz Freundschaftsabkommen hat in Polen immer die Absicht bestanden, jede Gelegenheit gegen uns auszunutzen." In einem Sieg Deutschlands über den Westen sehe Polen eine Gefahr und werde daher „uns den Sieg zu nehmen versuchen“. Daraus folge: „Es entfällt also die Frage, Polen zu schonen, und bleibt der Entschluß, bei erster passender Gelegenheit Polen anzugreifen." 360 Hitlers Kalkül lief mithin darauf hinaus, daß die Rückensicherung für das Unternehmen im Westen, da sich Polen einer Disziplinierung durch politische Mittel entzog, eben mit Waffengewalt besorgt werden mußte. Im übrigen verlor Hitler nie den Osten Europas jenseits von Polen aus den Augen. Auch für das Ausgreifen in diese Region - wann immer es kommen sollte - war Polen zum Hindernis geworden; wenn sich die Polen für den Raubzug nicht zur Verfügung stellten, hatte das Land ohnehin durch einen Feldzug verfügbar gemacht zu werden. Wie der Völkerbundskommissar in Danzig, der Schweizer Historiker und Diplomat Carl J. Burckhardt, die Essenz seiner Gespräche mit Hitler - der dem in Berlin wohlgelittenen Schweizer natürlich nichts über seine Westpläne verriet - wiedergab: „Entweder Ost-Politik gemeinsam mit Polen, oder Ostpolitik nach völliger Unterwerfung Polens nach dem Vorbild der Tschechoslowakei und, falls dies nicht zu erreichen, Besetzung und Zerstörung Polens." 361

Zugleich aber begann Hitler, als der Entschluß zur militärischen Lösung des polnischen Problems reifte und nachdem der Entschluß dann gefaßt war, an einem Krieg, den er ursprünglich überhaupt nicht beabsichtigt hatte, Aspekte zu finden, die es ihm erlaubten, sich selbst und anderen zu suggerieren, daß auch bei einem Feldzug in Polen das Notwendige mit durchaus Erwünschtem und Erfreulichem verbunden werden könne. Stellte es nicht einen Vorteil dar, wenn die junge Wehrmacht, ehe sie gegen die französische Armee anzutreten hatte, im Kampf gegen einen weit unterlegenen Feind eine Generalprobe veranstalten durfte? Schon im Vorjahr hatte ja der „Führer" auf einen solchen Test in einer tschechischen Kampagne gehofft, da nichts etwaige Mängel der Ausrüstung, der Ausbildung und der operativen wie der taktischen Prinzipien so schnell und unbarmherzig aufdeckt wie der sogenannte Ernstfall. Waren außerdem die auf den polnischen Schlachtfeldern zu erwartenden Siege nicht hervorragend geeignet, Moral und Selbstvertrauen der Truppe zu vervollkommnen? Lag es nicht im Interesse des Regimes, mit derartigen Triumphen eine von den Kriegen Preußens und des kaiserlichen Deutschland abgehobene national-

360 ADAP, D, 6, Nr. 433.

361 C. J. Burckhardt, Meine Danziger Mission 1937-1939, München 1960, S. 241. 
sozialistische Militärtradition zu begründen, bevor man in den ungewissen und sowohl von der Armee wie von der ganzen Nation Stehvermögen fordernden Orlog im Westen zog? In einem Gespräch mit seinen militärischen Adjutanten brachte Hitler Motive dieser Kategorie auf die Formel, er brauche - wie einst Friedrich der Große - einen „Ersten Schlesischen Krieg". 362

Wichtiger war ihm jedoch sicherlich die Überlegung, daß die Ausschaltung Polens, obwohl aus anderen Gründen beschlossen, doch auch schon zu einer höchst willkommenen Vergrößerung der deutschen Machtbasis genutzt, in einen Krieg um „Lebensraum“ verwandelt werden konnte. Bereits am 25. März hat Hitler, als er Generaloberst v. Brauchitsch die Bearbeitung der ,polnischen Frage“ befahl, konstatiert, daß er, falls Polen nun tatsächlich als Machtfaktor beseitigt werden müsse, ,an eine vom Ostrand Ostpreußens bis zur Ostspitze Schlesiens vorgeschobene Grenze" denke. Aber der Appetit wurde rasch noch größer. In der Weisung an die Wehrmacht, die am 3. April vorlag, war zusätzlich von der Eroberung und Eingliederung Litauens und Lettlands die Rede, „bis zu der Grenze des alten Kurland“, und am 23. Mai, als er seine Absichten im Hinblick auf Polen mit dem Begriff „Zertrümmerung“ umschrieb, teilte Hitler den Militärs klipp und klar mit: „Danzig ist nicht das Objekt, um das es geht. Es handelt sich für uns um die Erweiterung des Lebensraums im Osten und Sicherstellung der Ernährung, sowie die Lösung des Baltikum-Problems.“ Indes war der „Führer“ damals derart auf den kommenden Krieg mit den Westmächten fixiert, daß sich die Westpläne in jeden seiner Gedankengänge eindrängten. Bei der „Auseinandersetzung mit dem Westen“, so fügte er dem Lebensraum-Argument sogleich an, sei „es gut, einen größeren Ostraum zu besitzen“.

\section{Kontertanz der Mächte: das Versagen der „Achse“ und Hitlers Pakt mit Stalin}

Nachdem er die Entscheidung, Polen im Spätsommer zu schlagen und zu erobern, getroffen hatte, ist es Hitler offensichtlich nie mehr in den Sinn gekommen, die Angriffsabsicht wieder aufzugeben und die von deutscher Seite aufgeworfenen deutsch-polnischen Streitfragen doch noch durch Verhandlungen aus der Welt zu schaffen. Wer Gelegenheit hatte, den „Führer“ und seinen Außenminister genauer zu beobachten oder die Absichten und die Stimmung des "Führers“ in den Worten und der Haltung des Außenministers zu erkennen, war sich nicht im Zweifel, wohin die Reise ging. Staatssekretär v. Weizsäcker suchte Ende März und Anfang April allenthal-

362 Heeresadjutant bei Hitler 1938-1943. Aufzeichnungen des Major Engel, hrsg. v. H. v. Kotze, Stuttgart 1974, S. 60 f. 
ben offiziell den Eindruck zu nähren, daß es im deutsch-polnischen Verhältnis lediglich kleinere Störungen gebe, die bald verschwinden würden. Zum belgischen Botschafter etwa, der sich sehr besorgt nach dem Stand der Dinge erkundigte, sagte er, daß man in Berlin „die deutsch-polnische Lage nicht tragisch“ nehme: „Die Polen würden gewiß noch einsichtiger werden." 363 Für die Akten speiste er selbst die italienischen Freunde, die von Hitler und Ribbentrop noch kein Sterbenswörtchen über den Entschluß zum Krieg gehört hatten, jedoch etwas mißtrauisch geworden waren, mit beruhigendem Gemurmel ab. So hielt er am 30. März in einer Notiz fest, daß er dem Grafen Massimo Magistrati, Botschaftsrat an der italienischen Mission in Berlin und ein guter Freund des Grafen Ciano, erklärt habe, „die Polen seien zur Zeit noch recht schwerhörig, würden aber gewiß lernen, sich gefügiger zu zeigen, insbesondere hinsichtlich der selbstverständlichen Zugehörigkeit Danzigs zu Deutschland. Eine gefährliche Situation zwischen uns beiden vermöge ich nicht zu erkennen." 364 In Wahrheit unterrichtete Weizsäcker den italienischen Botschafter korrekt und genau über die antipolnische Wendung der deutschen Politik, so daß Attolico bereits am 18. April imstande war, einen alarmierenden Bericht nach Rom zu schicken: Er wisse, daß Hitler, getroffen in seiner Selbstliebe und enttäuscht von Polens Ablehnung der deutschen Freundschaft, ,gegenüber Polen in jenen sphinxhaften Zustand eingetreten ist, der jedem seiner Überfälle vorangeht". Er wisse, daß die deutschen Forderungen an Polen entweder gar nicht mehr oder nur ultimativ erhoben würden. Die politische Situation in Europa sei schon so klar definiert, Aktionen und Reaktionen seien so deutlich zu erkennen, daß es nicht mehr schwierig sei, die richtigen Schlußfolgerungen zu ziehen. Unter diesen Umstānden - vor allem im Hinblick auf die britisch-französische Intervention bei einem deutschen Schlag gegen Polen, die ja auch für Italien Konsequenzen hätte habe Rom ein Interesse daran und ein Recht darauf, nicht wieder vor ein Fait accompli gestellt zu werden. Es müsse rechtzeitig die Möglichkeit geschaffen werden, gemeinsam die Elemente eines Konflikts zu diskutieren, der, einmal ausgebrochen, Italien automatisch hineinziehen würde. Man dürfe sich nicht damit begnügen, „offiziell“ nach den deutschen Plänen gegenüber Polen zu fragen, vielmehr sei es notwendig geworden, auf einem erneuten Treffen Ciano-Ribbentrop zu bestehen ${ }^{365}$.

Aber Hitler legte nicht nur jenes „sphinxhafte“ Verhalten an den Tag, das Weizsäcker und Attolico so unheilverkündend fanden. Nach der Entscheidung für den Krieg setzten der „Führer“ und Ribbentrop sofort die Verwirklichung einer taktischen Konzeption in Gang, die eine Rückkehr zu Verhandlungen im deutsch-polnischen Konflikt bewußt ausschließen

363 Aufzeichnung Weizsäcker, 31.3.1939, PAA, Büro Weizsäcker, Polen 1, 34619.

364 Aufzeichnung Weizsācker, 30.3.1939, PAA, Büro Weizsācker, Polen 1, 34613.

365 AIA, Ap Germania, Attolico an Ciano, 18.4.1939. 
sollte und in der Tat praktisch fast unmöglich machte. Zunächst einmal schickten sie sich an, dafür zu sorgen, daß - nach dem bewährten Muster des Jahres 1938 - zwischen Polen und Deutschland ein Zustand der Spannung - der ständig steigenden Spannung - eintrat, der die Polen dazu verleitete, sich ganz unabhängig von der Auseinandersetzung um die auf den Tisch gelegten deutschen Forderungen ins Unrecht zu setzen und am Ende Angriffsgründe zu liefern, die in den Augen der deutschen und möglichst auch der europäischen Öffentlichkeit einigermaßen plausibel wirkten. Die Auswahl an geeigneten Methoden war freilich nicht groß. Neben aufreizenden Handlungen im nationalsozialistisch kontrollierten Danzig, die dort den „Topf am Kochen“ halten sollten, gab es im Grunde nur, wie im Falle der CSR, die Instrumentalisierung der rund 800000 Deutschen, die in Polen lebten. Da die Deutschen in Polen nicht geschlossen siedelten und in allen Teilen des Landes lediglich eine Minorität darstellten, fehlte es zwar an einer politischen Organisation, die im Stile der Sudetendeutschen Partei Konrad Henleins hätte agieren können. Aber der damals so wenig erfolgreiche zweite Teil des Rezepts der Sudetenkrise mochte in Polen mit besserem Effekt angewandt werden, d.h. man mußte versuchen, die deutsche Minderheit in der Rolle des unter unerträglicher Verfolgung leidenden Opfers polnischen Hasses erscheinen zu lassen, indem man die polnischen $\mathrm{Be}-$ hörden zu sekkierenden Maßnahmen und die polnische Bevölkerung zu Ausschreitungen gegen die deutsche Minderheit provozierte. Den Berliner Stellen war durchaus bewußt, daß sowohl die deutsche wie die europäische Öffentlichkeit und erst recht die nichtdeutschen Politiker und Diplomaten eine gewisse Resistenz gegen Berichte über die Leiden der sogenannten Volksdeutschen erworben hatten, seit niemand mehr daran zweifeln konnte, daß die vielstimmigen Klagegesänge über tschechische Greueltaten, von Rundfunk und Presse im Sommer 1938 und Frühjahr 1939 angestimmt, nichts als Propagandalügen gewesen waren; die skeptischen Reaktionen auf die ersten Meldungen über Zwischenfälle in Polen machten jene Resistenz vollends deutlich. Daher wies das Propagandaministerium die deutschen Medien an, zunächst noch vorsichtig zu verfahren und Nachrichten über Zwischenfälle "ohne sensationelle Aufmachung" zu bringen ${ }^{366}$. Mangels einer Alternative kam indes ein Verzicht auf die Schilderung polnischer Deutschenverfolgung nicht in Frage, zumal darauf gehofft werden durfte, daß es diesmal gelingen werde, der Propaganda eine gewisse Anzahl realer Vorfälle zu verschaffen.

So sind Polen in Danzig, z.B. polnische Zollbeamte, seit April mit immer neuen Schikanen bedacht worden, und zugleich kam es zu einer ungenierten, auf die Herausforderung der Warschauer Regierung angelegten Militarisierung der Freien Stadt: Teile der Polizei und nationalsozialistischer Organisationen wurden zum Kern militärischer Einheiten gemacht, 
die von der deutschen Wehrmacht - aus Ostpreußen - ganz offen personelle Verstärkung und auch schwerere Waffen erhielten ${ }^{367}$. Dem Amt Ausland/Abwehr im OKW gab man die Erlaubnis, das dichte Netz der Spionagezellen und Sabotagegruppen, mit dem Polen in den Jahren zuvor überzogen worden war, zu erweitern und auf den Tag X einzustellen, obwohl oder gerade weil die polnischen Behörden, denen diese Aktivitäten nicht verborgen bleiben konnten, darauf unter dem Druck des polnischen Militärs mit Verhaftungen reagieren mußten ${ }^{368}$. Im Sinne der Spannungssteigerung war aber etwas anderes noch viel wirksamer. Bereits in der ersten Aprilhälfte tauchten bei der deutschen Bevölkerung im „Korridor" Scharen von Agenten des SD und der Gestapo auf, die dort nicht nur Vertrauensleute und Mitarbeiter für die Zeit nach der Besetzung anzuwerben begannen, sondern auch allenthalben den Deutschen weismachten, daß - wie ein Mitglied der deutschen Vertretung in Warschau am 15. April an Botschafter v. Moltke schrieb - „der Einmarsch der deutschen Truppen kurz bevorstehe“. In dem Brief an Moltke hieß es weiter, daß die Verbreitung solcher Nachrichten, „die offenbar planmäßig erfolgt“, jede Beruhigung der deutschen Minderheit verhindere; die letzten Verhaftungsfälle im Korridor seien auch hieraus zu erklären, denn vielfach hätten die Leute offen zugegeben, „daß sie alle Vorbereitungen für den Empfang der deutschen Truppen treffen“. Dabei gäben sich die ,polnischen Behörden zurzeit die größte Mühe, alle Konflikte zwischen der polnischen und der deutschen Bevölkerung zu inhibieren"369. Ähnlich berichtete am 19. April der deutsche Generalkonsul in Thorn ${ }^{370}$. Wie vorherzusehen, nahm in der Tat die Zahl der Fälle zu, in denen sich die wachsende Nervosität der ebenso wütenden wie angstvollbedrückten Polen in Prügeleien und eingeworfenen Fensterscheiben entlud. Konsulate und Botschaft wiesen mit gebührendem Nachdruck darauf hin, daß das Treiben der Emissäre aus dem Reich unweigerlich zu einer Verschlechterung der Lage der deutschen Minderheit führen werde. Eben deshalb blieben jedoch die Beunruhigung der deutschen Minderheit und die dadurch bewirkte Aufreizung der polnischen Bevölkerung auch weiterhin wesentliche Elemente der reichsdeutschen Taktik ${ }^{371}$.

Auf der höheren politischen Ebene hingegen haben Hitler und Ribbentrop den Gesprächsfaden zwischen Berlin und Warschau einfach gekappt. Der Schnitt geschah gewiß im Anschluß an Chamberlains Polen-Garantie vom 31. März und parallel zu den Besprechungen, die Außenminister Beck vom 3. bis zum 6. April in London mit dem britischen Premier und Lord Halifax führte, war aber in Wirklichkeit von der Meinungs- und Entscheidungsbildung in London oder Paris und von der polnisch-britischen Annä-

\footnotetext{
367 Weinberg, The Foreign Policy of Hitler's Germany, S. $583 \mathrm{f}$.

368 Groscurth, Tagebücher eines Abwehroffiziers, S. 173.

369 Scheliha an Moltke, 15.4.1939, PAA, Botschaft Warschau, $566082 \mathrm{ff}$.

370 Küchler an A.A. und Botschaft Warschau, PAA, Botschaft Warschau, 566088.

$371 \mathrm{Vgl.} \mathrm{S.} 284$.
} 
herung ebenso unabhängig wie zuvor der Entschluß zum Angriff auf Polen. Tatsächlich kam Becks Reise nach London gar nicht ungelegen, bot sie doch eine willkommene Gelegenheit, die bereits vollzogene Wendung der eigenen Politik als bloße Reaktion auf britisch-polnische Feindschaft zu deklarieren und die deutsche Bevölkerung gegen Polen aufzubringen. Als Chamberlain und Beck am 6. April die wechselseitige britisch-polnische Garantie vereinbarten und die Absicht erklärten, einen Beistandspakt abzuschließen, schlug die NS-Propaganda sofort volle Töne an, um die britische Politik als „Einkreisung“ Deutschlands und Polen als Komplicen bei der Einkreisung zu denunzieren; mit dem Begriff „Einkreisung“ hatte ja schon die Propaganda des wilhelminischen Deutschland höchst erfolgreich gearbeitet. "Schärfster britischer Druck und verschlagene Überredungskünste“ hätten es zuwege gebracht, schrieb der "Völkische Beobachter" am 7. April, daß die polnische Regierung drauf und dran sei, der englischen Kriegspolitik zu folgen, ,einer Kriegspolitik, die in ihrem Wesen nichts anderes ist als eine Wiederholung des schmählich gescheiterten Versuchs von Versailles, das deutsche Volk durch eine bunte Kombination von artverschiedenen und von ganz ungleichartigen Interessen bewegten Völkern politisch und wirtschaftlich zu knebeln und seine endlich gewonnene nationale Einheit wieder zu zerstückeln“. Komme der britisch-polnische Pakt, werde Polen "Mitschuldiger eines europäischen Brandstiftungsversuchs" und setze sich damit, so hieß es drohend, dem gleichen Schicksal aus, „das andere, von den Roßtäuschern des demokratischen Westens verführte Nationen sich zugezogen haben“. Wenn Polen sich "heute plötzlich in die aggressive britische Einkreisungspolitik, deren einzig mögliches Ziel der Krieg gegen Deutschland ist, einreiht, so bricht es endgültig mit dem Kurs von 1934". Intern war man ehrlicher. So strafte eine Aufzeichnung, die am 21. April im Auswärtigen Amt entstand, die Propaganda mit folgenden Sätzen Lügen: „Die polnische Haltung zu den englisch-französischen Einkreisungsdemarchen läßt sich dahin zusammenfassen, daß Polen seine Beteiligung von dem Grad der Entschlossenheit der Westmächte, einer deutschen Aggression entgegenzutreten, abhängig gemacht hat. Solange es sich um Deklarationen kollektiver Art gehandelt hat, hat sich Polen schroff ablehnend verhalten, und erst als England sich bereit erklärte, Polen im Falle eines Angriffs sofortigen Beistand zu leisten, ist Polen auf die englische Anregung eingegangen und bat in dem Gefübl der immer stärker werdenden Bedrobung die Bedenken gegen eine ostentativ gegen Deutschland gericbtete Aktion zurïckgestellt.' 972

Tatsächlich hatte Staatssekretär v. Weizsäcker die deutsche Botschaft in Warschau bereits am 5. April, also einen Tag bevor die britisch-polnischen Besprechungen in London ihre Ergebnisse zeitigten, darüber informiert, daß Lipski in den nächsten Tagen noch einmal im Auswärtigen Amt emp-

372 Aufzeichnung Schliep, 21.4.1939, PAA, Büro Staatssekretär, Polen 1, 34674. 
fangen und dabei - unter Bezugnahme auf sein Gespräch mit Ribbentrop vom 27. März - „etwa folgendes“ zu hören bekommen werde: „Unser Polen gemachtes Angebot sei einmalig gewesen. Die Polnische Regierung habe anscheinend die Bedeutung dieses Angebots nicht ganz erfaßt. Wir könnten das nicht ändern. Die Zukunft werde ergeben, ob Polen gut beraten war. Der von Lipski vorgebrachte Gegenvorschlag sei bekanntlich von Reichsaußenminister als Basis für Verhandlungen bereits abgelehnt worden." Im Anschluß an diese Mitteilung bekam die deutsche Botschaft in Warschau einen Maulkorb verpaßt: „Bitte sich dort in materielle Gespräche über deutsches Angebot und polnisches Gegenangebot nicht mehr einzulassen. " 373 Botschafter v. Moltke, der alsbald ,in Urlaub" nach Deutschland zu gehen hatte, replizierte postwendend - und zwar ausdrücklich für die angekündigte Unterredung zwischen Weizsäcker und Lipski bestimmt mit einem Bericht über die polnische Zwangslage, wie sie von Becks Kabinettschef, dem Grafen Lubienski, gerade eben dargelegt worden sei. Die Furcht, daß ein deutscher Angriff auf Polen unmittelbar bevorstehe, so habe Lubienski ausgeführt, sei der Grund für die bündnispolitischen Bemühungen der Westmächte gewesen, „durch die Polen vor einem Angriff geschützt werden sollte“. Dennoch und „trotz des gleichzeitig erfolgten deutschen Druckes in der Danziger Frage habe Außenminister Beck diese englischen und französischen Paktvorschläge zurückgewiesen und habe streng an dem bilateralen Prinzip festgehalten. Wenn Herr Beck sich überhaupt auf die englische Garantieerklärung eingelassen habe, so sei das eine unmittelbare Folge des deutschen Versuchs, Polen durch Druck in Angst zu versetzen." Im übrigen habe Beck mit seiner intransigenten Haltung in der Danziger Frage „die deutsch-polnischen Beziehungen gerettet". Hätte er den deutschen Wünschen entsprochen, wäre er zur Demission gezwungen worden. „Durch eine derartige Entwicklung wäre zweifellos eine ausgesprochen deutsch-feindliche Politik in Polen eingeleitet worden, die schließlich sogar zu einem Bündnis mit der Sowjetunion hätte führen können." Nach wie vor habe die polnische Regierung den ehrlichen Willen zur Verständigung mit Deutschland, „aber ohne Druckanwendung und bei Aufrechterhaltung der beiderseitigen Unabhängigkeit“. Und wenn man heute in Berlin von einer gegen Deutschland gerichteten "Einkreisung" spreche, „so möge man doch auch einmal daran denken, in welchem Ausmaße Polen durch Deutschland im Zusammenhang mit den letzten politischen Ereignissen eingekreist worden sei“"374. Mit ähnlichen Argumenten suchte die polnische Diplomatie in jenen Tagen häufig auf den Berliner Entscheidungsprozeß einzuwirken, auch auf dem Umweg über ungarische und italienische Gesprächspartner, von denen man wußte, daß über sie polnische Äußerungen nach Berlin gelangten ${ }^{375}$. Im Mittelpunkt stand dabei meist

373 ADAP, D, 6, Nr. 159.

374 Ebenda, Nr. 167.

375 AIA, Ap Germania, Arone (it. Vertreter in Warschau) an Ciano, 27.5.1939. 
die - nach polnischer Meinung für deutsche Adressaten besonders wichtige - Versicherung, daß sich Polen unter keinen Umständen auf ein Techtelmechtel mit der Sowjetunion einlassen, „daß Polen keinem sowjetrussischen Soldaten der Land- oder Luftmacht jemals den Eintritt in sein Territorium gestatten werde“.376

Aber nach dem Willen Hitlers und Ribbentrops hatten im deutsch-polnischen Verhältnis Diplomatie und Politik ausgedient. Schon am 6. April immer noch vor der Veröffentlichung des Resultats der Londoner Verhandlungen Becks - mußte Weizsäcker dem polnischen Botschafter in der Tat mitteilen, daß „das Angebot des Führers an Polen ein einmaliges gewesen“ sei. Lipski machte den Versuch, die polnische Haltung mit der „begreiflichen Nervosität" zu rechtfertigen, die in Polen nach dem deutschen Einmarsch in die Tschechoslowakei ausgebrochen sei, und er betonte, daß das deutsche Ultimatum an Litauen die polnischen Besorgnisse naturgemäß noch vermehrt habe. Weizsäcker berichtete dazu: „Ich schnitt Lipski sofort das Wort ab, als er von einem ,Ultimatum' an Litauen sprach, machte seine Ausführungen über Truppenbewegungen anderer - die niemals gegen Polen gerichtet waren - lächerlich und erklärte ihm, es wäre mir verständlich gewesen, wenn er - Lipski - sich bei uns jetzt dafür bedankt hätte, daß wir dem heißen Wunsch Warschaus nach einer gemeinsamen ungarisch-polnischen Grenze kein Hindernis bereitet hätten. Kurzum, ich wies Lipskis Redensarten mit den naheliegenden Argumenten, von oben herab und gelassen zurück, worauf wir uns trennten."377 Als Außenminister Beck sich unmittelbar nach seiner Rückkehr aus London um eine Unterredung mit Botschafter v. Moltke bemühte, wurde ihm am 11. April bedeutet, daß dies derzeit nicht möglich sei, weil sich der Botschafter - ausgerechnet in solch spannungsvollen Tagen - auf Urlaub befinde ${ }^{378}$, und am 22. April schärfte Weizsäcker den Angehörigen der deutschen Botschaft in Warschau erneut ein, „sich bei etwaigen Gesprächen über die allgemeine politische Lage und über das deutsch-polnische Verhältnis bis auf weiteres völlig rezeptiv zu verhalten. Auch sonst wird die Botschaft vorläufig nach außen allgemein größte Zurückhaltung zu bewahren haben." 379 Die gleiche Instruktion - im Hinblick auf die deutsch-polnischen Beziehungen - ging an sämtliche deutsche Auslandsmissionen ${ }^{380}$, und in dem Telegramm an die deutsche Botschaft in Warschau sagte Weizsäcker auch, daß Moltke noch ein Weilchen in Deutschland bleiben und zu einer für den 28. April angekündigten Reichstagsrede des „Führers“ in Berlin sein werde.

Staatssekretär v. Weizsäcker verfolgte bei der Ausführung derartiger Instruktionen nicht ganz die gleichen Zwecke wie Außenminister v. Ribben-

376 Kordt, London, an AA, 19.4.1939, PAA, Büro Staatssekretär, Polen' 1, 34668.

377 ADAP, D, 6, Nr. 169.

378 Aufzeichnung Schliep, 11.4.1939, PAA, Büro Staatssekretär, Polen 1, 34656.

379 ADAP, D, 6, Nr. 247.

380 Ebenda, Nr. 159. 
trop und Hitler ${ }^{381}$. Der Leiter des Auswärtigen Amts stammte aus einer traditionsreichen Familie des deutschen Bildungsbürgertums, die Pfarrer und Theologen, Gelehrte und Wissenschaftler, doch auch Beamte und Politiker hervorgebracht hatte; sein Vater war von 1906 bis 1918 württembergischer Ministerpräsident gewesen. Ursprünglich Marineoffizier, der im Weltkrieg an der Skagerrak-Schlacht teilgenommen und das Ende des Kaiserreichs als Verbindungsmann der Marine in der Obersten Heeresleitung erlebt hatte, stach er bereits als Soldat durch Realismus, Augenmaß und Vernunft hervor, dazu durch die Fähigkeit zu selbständigem Urteil und die moralische Courage, am selbständigen Urteil auch gegen die Meinung der überwältigenden Mehrheit seines Milieus festzuhalten; so hat er in einer Marine, in der dies schon fast als Landesverrat betrachtet wurde, aus seiner - berechtigten - Skepsis gegen den unbeschränkten U-Bootkrieg kein Hehl gemacht. Solche Eigenschaften, zu denen sich ein diskreter, doch überaus wirksamer Charme gesellte, wuchsen auf dem Nährboden eines Wertesystems, das von tradiertem evangelischen Christentum ebenso bestimmt war wie von der Ethik des klassischen deutschen Humanismus, von soldatischer Dienstgesinnung ebenso wie von einem Patriotismus, in dem auch eine Portion jenes Nationalismus steckte, der das deutsche Bürgertum seit langem ergriffen hatte. Was ihn, der nach Kriegsende in den Auswärtigen Dienst eingetreten war und die Weimarer Republik auf diversen Auslandsposten vertreten hatte, zentrale Funktionen im nationalsozialistischen Regime akzeptieren ließ, erst - ab 1936 - die Leitung der Politischen Abteilung im Auswärtigen Amt und dann - ab Anfang 1938 - die Stelle des Staatssekretärs, war aber offenbar nicht jener Nationalismus, weniger auch persönlicher und sozusagen familiärer Ehrgeiz, der den Aufstieg in hohe Ämter gleichsam als Pflicht ansah. Ausschlaggebend scheint vielmehr ironischerweise gerade ein Wesenszug gewesen zu sein, durch den er sich von vielen seiner Standesgenossen vorteilhaft unterschied, nämlich die Bereitschaft zur Offenheit für moderne Strömungen, d.h., ins Politische übersetzt, eine demokratisch-soziale Ader, die ihn dazu brachte, die Vulgarităt und Brutalităt der Nationalsozialisten eine Zeitlang. zu übersehen und die NS-Bewegung als eine im Kern positive nationale und soziale Kraft des Volkes mißzuverstehen, der sich die älteren Eliten nicht versagen dürften. Staatssekretär geworden, erkannte er freilich rasch, daß ihn von Figuren wie Hitler und Ribbentrop Welten trennten, und er verschloß sich auch nicht, wie das die Mehrzahl der aus den alten Führungsschichten kommenden Würdenträger tat, der Einsicht, daß die Führer des Dritten Reiches, gelenkt von abstrusen und verbrecherischen Motiven, gefangen in gefährlichster Stupidität und leichtfertigstem Dilettantismus, geradewegs auf den Krieg

381 Vgl. R. Blasius, Über London den „großen Krieg“ verhindern. Ernst v. Weizsäckers Aktivitāten im Sommer 1939 in: J. Schmädeke u. P. Steinbach, Der Widerstand gegen den Nationalsozialismus, München 1985, S. $691 \mathrm{ff}$. 
zusteuerten, auf den Ruin der deutschen Nation und ganz Europas. Wenn er trotzdem in einem Amt blieb, das ihn faktisch tagtäglich zu einer persönlich und politisch höchst problematischen Komplicenschaft mit seinen nationalsozialistischen Chefs zwang, so leitete ihn dabei die Hoffnung, vielleicht doch auf den Gang der Dinge Einfluß nehmen und vielleicht doch die übelste Konsequenz der Hitlerschen und Ribbentropschen Politik verhindern zu können, den Krieg. Er hatte nicht vergessen, daß der ältere Bruder 1914 in Frankreich gefallen war und daß der Vater den Tod dieses Sohnes nie zu verwinden vermochte; auch hatte sich ihm tief ins Gedächtnis gegraben, wie oft vom Vater gesagt worden war, daß der Weltkrieg hätte vermieden werden können.

Es war nur natürlich, daß ein Mann wie Weizsäcker in Verbindung mit Widerstandskreisen trat, die sich um seinen ehemaligen Kollegen Ulrich v. Hassell, um Carl Goerdeler und um Ludwig Beck, den im Vorjahr verabschiedeten Generalstabschef, gebildet hatten, und daß sich um ihn selbst oppositionelle jüngere Diplomaten zu gruppieren begannen. In erster Linie aber suchte der Staatssekretär mit den Mitteln auf das Geschehen einzuwirken, die ihm sein Amt bot, also durch diplomatisch-politisches Handeln. Wenn er im direkten Umgang mit Polen die Instruktionen Hitlers und Ribbentrops nun getreulich ausführte und den deutsch-polnischen Gesprächskontakt unterbrach, so leiteten ihn vornehmlich drei Beweggründe. Da Weizsäcker klar erkannte, daß Außenminister Beck vorerst kaum Möglichkeiten hatte, Deutschland Konzessionen zu machen, hielt er es, wie er Attolico anvertraute, für besser, ein weiteres $\mathrm{Hin}$ und $\mathrm{Her}$ von deutschen Forderungen und polnischen Zurückweisungen zu vermeiden, das die Situation unweigerlich verschärfen mußte und angesichts der Natur Hitlers leicht mit einem plötzlichen Angriffsbefehl an die Wehrmacht enden konnte. Eine Atempause war ihm jedoch vor allem deshalb wichtig, weil er Zeit gewinnen wollte, um über Attolico die italienische und über den in seinem Sinn zuverlässigen Botschaftsrat Theo Kordt, der in London als Stellvertreter des Botschafters Herbert v. Dirksen fungierte, die britische Politik zu beeinflussen. Mussolinis Scheu vor einem großen europäischen Krieg mußte abermals, wie im Vorjahr am Ende der Sudetenkrise, ins Spiel gebracht werden, um Hitler zu bremsen und vom Sprung in den Krieg abzuhalten, während die Briten veranlaßt werden sollten, zur Abschreckung Hitlers definitive Klarheit über ihre Entschlossenheit zur Intervention zu schaffen. Allerdings erhoffte sich Weizsäcker von London noch etwas mehr. Im Blick auf den Charakter Hitlers und Ribbentrops stand für ihn fest, daß eine Lösung der Krise ohne Krieg nur dann möglich war, wenn Polen etwas später doch einige Konzessionen machte, und daher hatte man den Briten zu verdeutlichen, daß es ihre Aufgabe sei, Warschau von der trotz Garantie und Paktversprechen gegebenen - Notwendigkeit der Verständigungs - und das hieß am Ende auch einer gewissen Opferbereitschaft zu überzeugen. Letztere konnte im übrigen auch durch den Abbruch der 
deutsch-polnischen Gespräche gefördert werden, wenn ein zeitweiliges dräuendes Schweigen der deutschen Seite die Polen zermürbte; den Begriff "Zermürbungspolitik“ hat der Staatssekretär in jenen Tagen mehrmals gebraucht, so am 29. März in einer Unterredung mit dem Danziger Senatspräsidenten Arthur Greiser, zu dem er andererseits sagte, daß er es nicht für angezeigt halte, „Polen von Danzig her irgendwie zu provozieren“. Wenn es solchermaßen gelang, dem nationalsozialistischen Führungsgespann einen italienischen und einen britischen Zügel anzulegen, wenn es ferner gelang, die Polen vernünftig zu halten, dann, so kalkulierte Weizsäcker, mochte das Äußerste noch einmal vermieden werden. Freilich ist nicht zu verkennen, daß er sich im Rahmen dieser Konzeption - Produkt einer Verzweiflung, in der er die Dynamik nationalsozialistischer Außenpolitik ebenso unterschätzte wie er die britische Neigung zu einer partiellen Fortsetzung der Appeasement-Politik überschätzte - polnische „Vernunft" schon auch deshalb wünschte, weil seinem versaillesgeschädigten Nationalbewußtsein etliche Ansprüche des deutschen Revisionismus an Polen durchaus berechtigt $\mathrm{zu}$ sein schienen.

Hitler und Ribbentrop hingegen verstanden die Beendigung der diplomatischen Auseinandersetzung mit Polen als logische, ja als notwendige Konsequenz ihrer Entscheidung für den Krieg. Nachdem sie beschlossen hatten, Polen im Herbst anzugreifen, weil die mittlerweile für erforderlich gehaltene gänzliche Ausschaltung Polens allein durch Krieg erreicht werden konnte, waren Verhandlungen sinnlos geworden; die angemeldeten Forderungen interessierten ohnehin nicht, da man sie nicht um ihrer selbst willen, sondern lediglich zur politischen Disziplinierung Polens gestellt hatte, die nun als unmöglich gelten mußte. Verhandlungen bargen jetzt sogar große Gefahren. Es war nicht auszuschließen, daß die Warschauer Regierung bei einer Fortsetzung der Gespräche Vorschläge präsentierte, die in den Augen der deutschen und der europäischen Öffentlichkeit - jedenfalls vor dem Hintergrund des Kriegsrisikos - plausibel und vernünftig aussahen. Was dann? Man konnte sich nicht darauf einlassen, da man sonst vom Krieg weggedrückt wurde, lehnte man jedoch ab, setzte man sich ins Unrecht! In diesem Sinne wurde der Abbruch des Dialogs denn auch der deutschen Botschaft in Warschau erklärt: „Wir müssen verhindern, daß Polen uns den Ball wieder zurückspielt und dann so manövriert, als hätten wir ein polnisches Angebot unbeachtet gelassen." 382 Auf der anderen Seite durfte aber, namentlich im Hinblick auf die Stimmung in Deutschland, unter keinen Umständen der Eindruck von Verhandlungsunwilligkeit erweckt werden. In diesem Dilemma dachte sich Hitler einen Schachzug aus, der zwar außerhalb des Deutschen Reiches niemand täuschte, seinen innenpolitischen Zweck jedoch in der Tat weitgehend erfüllte.

Wie am 27. erbeten und bewilligt, wurden die deutschen Geschäftsträger in London und Warschau am 28. April, 12 Uhr mittags, im britischen bzw. polnischen Außenministerium empfangen, wo sie dann jeweils eine Note 
der Reichsregierung überreichten ${ }^{383}$. Wurde in der Note an Großbritannien die britische Regierung einer - natürlich gänzlich unbegründeten - Politik der „Einkreisung“ Deutschlands bezichtigt und, darauf gestützt, das deutsch-britische Flottenabkommen vom 18. Juni 1935 gekündigt - womit Hitler den Weg zu der inzwischen beschlossenen Expansion der deutschen Kriegsmarine geöffnet zu haben glaubte -, so hieß es in der Note an Polen, daß auf Grund der polnischen Beteiligung an der britischen Einkreisungspolitik, wie sie in der britisch-polnischen Erklärung vom 6. April zum Ausdruck komme, der deutsch-polnische Nichtangriffsvertrag vom 26. Januar 1934 nicht mehr bestehe. Die Vertragskündigung war in dem Dokument, das die polnische Regierung erhielt, mit der ersten offiziellen Nennung der deutschen Forderungen an Polen verbunden, der aber sofort die Feststellung folgte, Warschau habe den in "freundschaftlichem Geiste“ und in "freundschaftlichster Form" gemachten deutschen Vorschlag "glatt" abgelehnt; zuvor schon fand sich die Behauptung, die Reichsregierung müsse der Warschauer Politik entnehmen, „daß die polnische Regierung zur Zeit keinen Wert mehr darauf legt, für deutsch-polnische Fragen die Lösung in direkter freundschaftlicher Auseinandersetzung mit der Deutschen Regierung zu suchen". Mit keiner Silbe war in der Note an Polen die deutsche Erklärung vom 6. April zurückgenommen, daß über die deutschen Forderungen nicht mehr verhandelt werden könne, weil das „Angebot“ des „Führers" einmalig gewesen sei und Polen nicht rechtzeitig zugegriffen habe. Der Text lief im Gegenteil darauf hinaus, die politische Funkstille zwischen Berlin und Warschau, die an jenem 6. April mit Weizsäckers mündlicher Unterrichtung des polnischen Botschafters eingetreten war, nun auch schriftlich zu konstatieren, von der Drohung ganz zu schweigen, die Berlin mit der Kündigung des Nichtangriffspakts ausgesprochen hatte. Ans Ende beider Noten war von ihren Autoren jedoch die Versicherung placiert worden, daß die Reichsregierung „zu einer neuen vertraglichen Regelung bereit" sei, falls die - eben mit rüden und einseitigen Vertragsauflösungen bedachten - Regierungen Großbritanniens und Polens „Wert darauf legten“.

$\mathrm{Da}$ die Überreichung der deutschen Noten am 28. April, 12 Uhr mittags, in Szene gesetzt wurde, hatte seinen Grund darin, daß exakt zu dieser Zeit Adolf Hitler zu einer großen Rede im Reichstag anhob, mit der er den deutsch-polnischen Konflikt und die davon ausgelöste europäische Krise nicht nur offiziell, sondern erstmals auch öffentlich notifizierte ${ }^{384}$; bislang waren ja Konflikt und Krise sowohl für die deutsche wie für die europäische Öffentlichkeit noch ohne schärfere Konturen geblieben, da sie sich im wesentlichen - trotz Chamberlains Erklärungen im Unterhaus und trotz

382 ADAP, D, 6, Nr. 159.

383 Ebenda, Nr. 273, 274, 276, 277.

384 Verhandlungen des Deutschen Reichstags, Bd. 460, S. 23 ff. 
der paar Zwischenfälle auf Danziger oder polnischem Territorium - in den Amtszimmern von Ministern und Diplomaten abgespielt hatten. Zwar ist die Rede als Antwort des „Führers“ auf eine Botschaft des amerikanischen Präsidenten Franklin D. Roosevelt angekündigt worden. Roosevelt hatte am 14. April einen Appell an Hitler und Mussolini gerichtet, die Welt von der Furcht vor einem neuen großen Krieg zu befreien, zu einer Politik friedlicher Ziele und friedlicher Methoden zurückzukehren und - konkreter - eine internationale Abrüstungskonferenz zu ermöglichen. An einer Stelle der Botschaft verlangte Roosevelt von Hitler und Mussolini die Zusicherung, eine Reihe namentlich genannter Staaten nicht angreifen zu wollen. Die Staatenliste war etwas bunt ausgefallen; sie enthielt Finnland und Irland ebenso wie Portugal und Bulgarien, die Türkei ebenso wie den Irak und den Iran ${ }^{385}$. Mit böser Lust nutzte denn auch Hitler eine solche Gelegenheit, um den ganzen Appell des Präsidenten mit gröbstem Sarkasmus abzufertigen. Dies war vornehmlich für den innerdeutschen Konsum bestimmt, wenngleich es Hitler wohl auch gar nicht klar gewesen sein dürfte, daß er an der politischen Absicht und der politischen Wirkung des Rooseveltschen Schrittes ohnehin vorbeiredete; der Präsident verstand derartige Aktionen nicht zuletzt als Elemente einer langwierigen Anstrengung, die Amerikaner aus dem nach wie vor herrschenden Isolationismus herauszuführen. Aber von der Beantwortung der Botschaft Washingtons abgesehen, stellte sich der eigentliche Gehalt der Rede als eine große Abrechnung des „Führers“ mit der britischen Einkreisungspolitik und mit der polnischen Mitwirkung an den Londoner Anschlägen dar, wobei sich Hitler im Grunde darauf beschränkte, die beiden Noten, die gerade in London und Warschau präsentiert worden waren, ausgiebig zu zitieren und wortreich zu paraphrasieren. Was das direkte deutsch-polnische Verhältnis anging, so liefen seine Worte, wie die der Note an Warschau, darauf hinaus, daß allein schon die polnische Dreistigkeit, auf deutsche Forderungen mit Gegenvorschlägen zu reagieren, einer Verweigerung von Verhandlungen gleichkomme, daß also die polnische Ablehnung seines „einmaligen Vorschlags“ - bei dessen Annahme „Polen ... überhaupt kein gebender Teil, sondern nur ein nehmender" gewesen wäre - mit dem polnischen Abbruch der konkreten Verhandlungen über das deutsche „Angebot“ - dessen einzelne Punkte er zum ersten Mal öffentlich nannte - gleichgesetzt werden müsse. Am Ende, nachdem er die jeweilige Philippika mit der Mitteilung gekrönt hatte, daß das deutsch-britische Flottenabkommen bzw. der deutsch-polnische Nichtangriffspakt von ihm gekündigt worden sei, sprach auch er, wie die Noten, davon, daß Deutschland nach wie vor zu vertraglichen Regelungen bereit sei, falls die Regierungen Großbritanniens und Polens „Wert

385 ADAP, D, 6, Nr. 200. G. Moltmann, Franklin D. Roosevelts Friedensappell vom 14. April 1939. Ein fehlgeschlagener Versuch zur Friedenssicherung, in: Jahrbuch für Amerikastudien 9(1964), S. 91-109. 
darauf legten“; er hütete sich dabei, auch nur ein Wörtchen über Zweck und Gegenstand, über Form, Zeit und Ort neuer Verhandlungen zu verlieren.

Für die europäischen Nationen lag die politische Bedeutung der Rede Hitlers naturgemäß in der Kündigung der beiden Verträge, die überall als ein herausforderndes Signal nationalsozialistischer Expansionslust und Kriegsbereitschaft gedeutet wurde, fast schon als eine Art vorgezogene Kriegserklärung; ihre Wirkung bestand mithin in einer fühlbaren Steigerung der internationalen Spannung. Da Hitler dabei zu diesem Zeitpunkt lediglich das erwünschte Anwachsen der Kriegsfurcht registrierte und die Anzeichen für zunehmenden Widerstandswillen noch nicht recht wahrnahm, war er mit dem spannungsverschärfenden Effekt seiner Rede sehr zufrieden; einer der Zwecke, den er mit ihr verfolgt hatte, war damit erfüllt. Auch das zweite Ziel hielt er für erreicht. Mit der plumpen Verdrehung der Wahrheit, die seine Rede vom ersten bis zum letzten Wort gewesen war, hatte er ja in erster Linie die eigene Nation täuschen wollen, in deren Augen die Briten und die Polen zu den Schuldigen an der Zuspitzung der Situation, am Näherrücken eines Krieges gestempelt werden sollten, und bis zu einem gewissen Grad war ihm tatsächlich Erfolg beschieden. Eine Mehrheit der deutschen Bevölkerung akzeptierte, wenn auch mit mehr oder weniger starken Zweifeln, das gefälschte Alibi, weil in ihr seit etlichen Menschenaltern die Fähigkeit zu realistischem und vernunftorientiertem politischen Denken nur noch schwach entwickelt war, weil sie sich eine nationale Egozentrik anerzogen hatte, die gegen fremdes Recht und fremde Argumente weitgehend abstumpfte, weil sie vom NS-Regime gegen Zweifel verstärkende Informationen und Meinungen nahezu vollständig abgeschirmt und von den strikt kontrollierten eigenen Medien ausschließlich mit Nachrichten und Kommentaren gefüttert wurde, die den Machthabern nützlich und zuträglich dünkten. Selbst im liberalen und weltzugewandten Hamburg, so meldete das dortige polnische Generalkonsulat, habe die Gesellschaft das Organ für das Mißtrauen und die Angst der Welt vor Deutschland verloren. Man sehe nur noch die eigenen Ansprüche und Ziele, die man im Falle Polens, auch wenn es fast nirgends Haß gegen Polen gebe, für berechtigt ansehe ${ }^{386}$; in der Armee herrsche sogar, wie etwa der Konsul in Königsberg zutreffend diagnostizierte, eine gewisse Stimmung für einen polnischen Feldzug, ganz anders als im Vorjahr während der Sudetenkrise ${ }^{387}$. Jedermann in Deutschland habe Angst vor einem allgemeinen Krieg, berichteten die polnischen Beobachter aus Königsberg so gut wie aus Hamburg oder München, doch sei auf der anderen Seite nicht zu verkennen, daß die leichten Erfolge der letzten Jahre den Deutschen die Köpfe verdreht und ihnen Appetit auf weitere Gewinne gemacht hätten.

386 APA, Generalkonsulat Hamburg, 6.7., 3.8., 22.8.1939.

387 Szembek-Tagebuch, S. 476. 
Zudem seien die meisten Deutschen, auch wenn sie die Verantwortung für die entstandene Kriegsgefahr nicht mehr der eigenen Regierung, sondern allen möglichen fremden Mächten zuschrieben, paradoxerweise davon überzeugt, daß es dem politischen Genie des „Führers“ gelingen werde, auch den deutsch-polnischen Konflikt mit einem friedlich errungenen Erfolg oder doch mit einem lokalisierten deutsch-polnischen Feldzug zu beenden ${ }^{388}$. Alles zusammen, so konstatierte Prinz Stefan Lubomirski, Botschaftsrat an der polnischen Mission in Berlin, resigniert, garantiere jedenfalls, daß die deutsche Gesellschaft auch im Kriegsfall zunächst loyal zum Regime stehen und allen Befehlen der Regierung gehorchen werde; das gelte selbst für die Generalität, obschon den Militärs klar sei, daß Danzig einen bloßen Vorwand darstelle, hinter dem sich ein großer Eroberungsplan verberge ${ }^{389}$.

Warschau reagierte indes auf Hitlers Kündigung des Nichtangriffspakts in einer Weise, die Polen viele der im Herbst 1938 verlorenen Sympathien zurückgewann. Zur Unterstreichung der polnischen Gleichberechtigung duplizierte Beck exakt das deutsche Ritual, indem er die polnische Antwort ebenfalls in Form einer Note und einer großen Rede im Parlament gab, indem er ferner die Überreichung der Note am 5. Mai ebenfalls mit einer seiner seltenen Parlamentsreden zeitlich nahezu zusammenfallen ließ390. In der Note wie im Sejm spießte Beck einige der Hitlerschen Verdrehungen und Verschleierungen auf, vor allem aber legte er ohne Aufgeregtheit dar, daß und warum die deutschen Forderungen polnische Interessen verletzten und die polnische Unabhängigkeit gefährdeten, daß und warum sie also unannehmbar seien; dazu zeigte er - was nicht schwierig war -, daß Hitler unter "Verhandlungen“ offensichtlich eine Prozedur verstand, bei der die deutsche Seite ihre Forderungen stellte und die andere Seite sich glücklich schätzte, sofort annehmen und erfüllen zu dürfen. Im übrigen hob er beziehungsvoll die politische Bedeutung der britisch-polnischen Vereinbarung vom 6. April wie die der gleichartigen französisch-polnischen Verbindung hervor, und an die Adresse Moskaus war die Anspielung gerichtet, Deutschland habe Polen erfolglos zu einem gemeinsamen Raubzug gegen die Sowjetunion eingeladen: In den deutsch-polnischen Besprechungen, so sagte er, ,wurde auch noch anderes angedeutet, das weit über den Rahmen der zur Behandlung stehenden Fragen hinausging. Ich behalte mir vor, nötigenfalls auf diesen Punkt zurückzukommen." Am Ende der Note kam wiederum in genauer Entsprechung zum deutschen Vorgehen - die Bemerkung, daß Polen bei Respektierung seiner Gleichberechtigung selbstverständlich nach wie vor zu einer vertraglichen Regelung der deutsch-polnischen Beziehungen bereit sei, „falls die Deutsche Regierung Wert darauf

390 Weißbuch der Polnischen Regierung, Nr. 77, 78. 
legt“. Beck schloß mit den Sätzen: „Der Friede ist eine kostbare und erwünschte Sache. Unsere durch den Krieg in Blut getauchte Generation verdient sicherlich eine Periode des Friedens. Doch der Frieden, wie fast alles in dieser Welt, hat einen hohen, aber doch abschätzbaren Preis. Den Begriff des Friedens um jeden Preis kennen wir Polen nicht. Im Leben der Menschen, der Völker und der Staaten gibt es nur ein Gut, das keinen Preis hat: die Ehre!"

Der Außenminister hatte seinen Landsleuten aus dem Herzen gesprochen. Immer wieder war er während seiner Rede vom Beifall der Abgeordneten unterbrochen worden, auf der Rückfahrt vom Sejm zum Ministerium jubelten ihm zahllose Warschauer zu, die der Rundfunkübertragung an den allenthalben aufgestellten öffentlichen Lautsprechern oder am eigenen $\mathrm{Ge}$ rät zugehört hatten, und im Ministerium überreichte ihm eine Deputation seiner versammelten Mitarbeiter einen Strauß roter Rosen, dazu einen Stapel der aus allen Teilen des Landes bereits eingelaufenen Glückwunschtelegramme. Auch Diplomaten und Politiker anderer Staaten, namentlich der Westmächte, meldeten sich alsbald mit Anerkennung und Zustimmung. Dem Sejm war in der Tat ein großer Tag beschieden gewesen: Beck hatte gegenüber den deutschen Drohgebärden Festigkeit gezeigt, die Verläßlichkeit Polens als Bundesgenosse der Westmächte erwiesen und mit der an Moskau gerichteten Warnung vor Deutschland dem Anschein nach auch das gerade eröffnete französisch-britische Werben um die Sowjetunion erleichtert. Der Mann, der für die polnische Komplicenschaft bei Hitlers Aktion gegen die Tschechoslowakei verantwortlich zeichnete und von vielen noch nicht als absolut zuverlässiger Partner gegen das nationalsozialistische Deutschland angesehen worden war, hatte sich selbst und sein Land endgültig rehabilitiert und damit die westliche Unterstützungsbereitschaft noch um ein Jota sicherer gemacht.

Beck selbst sah freilich keinen Grund zu Gratulationen. In sein Arbeitszimmer zurückgekehrt, machte er seinem Unmut über den nach seiner Ansicht völlig deplacierten Enthusiasmus seiner Landsleute Luft, indem er die Rosen und die Depeschen, die er bekommen hatte, bös mißhandelte ${ }^{391}$. Zu deutlich stand ihm vor Augen, daß Pilsudskis Politik der direkten Verständigung mit Deutschland, als deren Exekutor er sich betrachtet hatte, gescheitert und seine Rede das Eingeständnis des Scheiterns gewesen war. $\mathrm{Zu}$ genau wußte er ferner, daß die öffentliche Festlegung Polens auf Widerstand gegen Deutschland, die er nach der Rede Hitlers für so richtig, notwendig und unvermeidlich hielt wie den Widerstand selbst, als das Verbrennen der Schiffe verstanden werden mußte und Polen nun endgültig einen überaus riskanten Weg in eine Zukunft voll unbekannter Gefahren 
betrat. Fünf Tage nach seiner Rede im Sejm schrieb er dem polnischen Botschafter in Rom, seinem alten Freund Boleslaw Wieniawa-Dlugoszewski, einen Privatbrief, in dem er seine in den Grundzügen ja ganz einfache Politik noch klarer und präziser umreißen konnte als in öffentlicher Rede. Schon bei seiner letzten Unterredung mit Hitler, am 6. Januar in Berchtesgaden, habe er, so berichtete er dem Freund in Rom, eine gefährliche Veränderung an „diesem Menschen bemerkt, den ich auf Grund von überdies konkreten - Beweisen seit 1934 für ein in Deutschland seltenes Beispiel der Vernunft in der Außenpolitik zu halten Grund hatte". Allzu einfache Erfolge, die der Indolenz und Entscheidungsschwäche seiner großen und kleinen Gegenspieler zuzuschreiben gewesen seien, hätten „diesen Menschen, mit dem man sich noch vor einem Jahr vernünftig über die europäische Politik unterhielt“, in einen Zustand versetzt, „der unsere Interessen bereits direkt bedrohte“. Hitler habe „das Maß verloren“. Er, Beck, habe daher "nach schwerem inneren Ringen“ die Entscheidung getroffen, die polnische „Politik von der Linie einer vernünftigen Verständigung mit diesem Nachbarn auf die Linie der réassurance zu verlagern". Anfänglich sei von ihm die Möglichkeit einer "Rückversicherung“ innerhalb der „Achse“ erwogen worden, doch habe Graf Ciano, als er sich im Februar in Warschau aufhielt, „nicht gezogen“. Also Rückversicherung bei den Westmächten: Während seines Besuchs in England sei ihm aufgefallen, daß sich dort die Einstellung radikal gewandelt habe und nun - so ist der Satz wohl zu ergänzen - nach dem Ende von Appeasement Polens Anlehnung an die Westmächte erlaube. Auch der „Kommandant“ habe einst vorhergesehen, daß aus den "ungesunden Romanzen mit den Deutschen“ - dies die Worte Pilsudskis - Schwierigkeiten resultieren würden, doch andererseits geglaubt, „daß wir keine vernünftige Beziehung mit den westlichen Staaten erreichen, wenn wir nicht - wenigstens eine Zeitlang - eine eigene deutsch-polnische Politik verfolgen“. So sei es ja nun gekommen, implizierte der Schüler des „Kommandanten“ und sagte ferner: „Auf den Garantievorschlag antwortete ich mit dem Prinzip der Gegenseitigkeit, weil ich glaube, daß es für uns trotz unserer Armut und Schwäche keine mittleren Lösungen geben kann. Entweder ziehen wir unseren Staat zur Großmachtstellung hoch oder wir werden - so oder so, nolens volens - zu irgendeiner Slowakei oder etwas Ähnlichem. Du wirst verstehen, daß ich - gemäß den Regeln der Schule, aus der wir beide stammen - die erste Lösung versucht habe." Der öffentlichen Meinung in Polen gefalle die Wendung zu einer Politik der Rückversicherung ,sogar allzu gut - ich persönlich bin mir des Risikos dieser Entscheidung bewußt“. Doch obwohl er das Risiko kenne, habe er sich entschließen müssen, den Polen geltenden Plänen der deutschen Politik den Weg zu verlegen. Die äußere wie die innere Lage Polens könne sich mithin noch verschärfen. Daher sei es möglich, daß er die Regierung übernehmen werde, aber ebenso möglich sei es, so schloß der ehemalige Oberst im Generalstab, daß er dann die von ihm geforderte Mobil- 
machungsstelle übernehme, nämlich den Befehl über eine Kavalleriebrigade 392 .

Drei Wochen später - und acht Tage nachdem Hitler in der Reichskanzlei seinen Militärs noch einmal die Notwendigkeit eines großen Eroberungskrieges eingehämmert hatte - kamen sogar Augenblicke des Schwankens. Am 30. Mai besprach Beck die Situation mit dem Grafen Szembek. Im Laufe des Gesprächs sagte der Außenminister, daß der Botschafter in Berlin, Lipski, mit den Nerven am Ende und amtsmüde sei. Er, Beck, trage sich mit dem Gedanken, Szembek nach Berlin zu schicken. Man müsse nämlich, obgleich es so aussehe, als ob man mit Deutschland nicht zusammenleben könne, doch noch versuchen, einen vernünftigen Kompromiß zu finden. Es gebe kleine Anzeichen, daß die Deutschen wieder mit Warschau reden wollten. Sicher: „Wenn es sein muß, gehen wir in den Krieg.“ Aber müsse es wirklich sein? Die Deutschen seien sich doch bewußt, daß sie, wenn sie ganz Polen besetzten, auf die Sowjets stoßen würden und die komplette Rote Armee gegen sich hätten. Schließlich habe er, Beck, den Einflüsterungen der Nationaldemokraten und Englands und Frankreichs nicht nachgegeben und kein Bündnis mit der Sowjetunion geschlossen. Auf den Einwand Szembeks, daß man ihm doch nachsage, zu deutschfreundlich und zu nachgiebig zu sein, erwiderte Beck, daß es ihm nicht darum gehe, nach Berlin jemand zu schicken, der als besonders kämpferisch gelte. Schließlich wolle er einen Kompromiß. Ein zweiter Weltkrieg in so kurzer Zeit sei einfach zuviel, und ,es muß alles getan werden, daß das nicht geschieht“. „Wenn ich Lipski abberufe, werde ich um das Agrément für Sie bitten." 393

Aber Lipski blieb auf seinem Posten. Becks Unsicherheit war doch nur die Sache von ein oder zwei Tagen. Die entscheidenden Orientierungspunkte seines Kurses hatten sich ohnehin nie geändert, und alsbald kehrte er auch wieder zu der am 5. Mai eingenommenen Haltung zurück, die eine Mitte Mai ergangene Weisung dahin zusammenfaßte, daß die Klärung der deutsch-polnischen Probleme nun, nachdem Polen seine Verhandlungsbereitschaft bekundet habe, von der Reichsregierung ausgehen müsse. Statt in Berlin um gut Wetter zu bitten. bemühte sich die polnische Diplomatie vielmehr darum, überall in Europa Sympathien für Polen, Verständnis für die polnische Politik und die Neigung zur Unterstützung Warschaus zu wecken. Noch im Juni übermittelte Becks Stellvertreter Arcziszewski den diplomatischen Vertretungen Polens einen Erlaß des Ministeriums, der für diesen Werbefeldzug Argumentationshilfen bot, jedoch zugleich recht treffend die mittlerweile in Warschau herrschend gewordene Auffassung wiedergab. Wie 1913/14 habe man es heute, so wurde in der Instruktion gesagt, mit deutschem Hegemonialstreben zu tun. Der Hitlerismus sei nur 
eine Spielart der Bedrohung, die das amoralisch gewordene Deutschland seit seiner 1870/71 eingeleiteten Verpreußung für Europa und die Welt darstelle. Die Beraubung der Ostvölker sei Bedingung des deutschen Sieges im Westen und im Süden. Polen habe im Frühjahr sein historisches „Nein“ Deutschland entgegengesetzt, ohne sich der Hilfe anderer zu vergewissern. Wer aber jetzt nicht an die Seite Polens trete, der akzeptiere die deutsche Hegemonie. Das Schicksal Polens entscheide auch über das Schicksal der baltischen Staaten, Ungarns usw. Selbst die skandinavische Neutralität werde unhaltbar, wenn man Deutschland nachgebe, und für Frankreich und England entstünden große Gefahren. „Im Zuge von Kriegsvorbereitungen und der Verwirklichung des Parteiprogramms unterscheiden sich die Lebensformen im zeitgenössischen Deutschland immer weniger von denen in der Sowjetunion." Deutschland stehe daher heute gegen Individualismus, Geist, Freiheit und Christentum. Die Sowjetunion sei schwach, schwächer als 1914 das zaristische Rußland; sie werde, weil nur zur Defensive fähig, zunächst passiv bleiben und erst am Vorabend des Friedensschlusses auf dem Plan erscheinen. Die Verteidigungslinien des Westens seien also die Grenzen Polens, Ungarns etc. Allein die Existenz Polens garantiere die Unabhängigkeit der osteuropäischen Staaten: „Fällt Polen, fallen sie auch!"394

Daß Hitler und Ribbentrop das politische Gespräch zwischen Berlin und Warschau unterbrachen, diente jedoch nicht nur dem Zweck, Verhandlungen aus dem Wege zu gehen, die nun als unangenehme Behinderung der eigenen Pläne empfunden wurden, weil sie die Reichsregierung in die Nähe eines in den Augen der internationalen wie der deutschen Öffentlichkeit plausiblen deutsch-polnischen Kompromisses in der Danzig- und der Korridor-Frage zu führen drohten. Wie ihre Rezepte zur Provozierung Unrecht schaffender antideutscher Reaktionen der Warschauer Regierung und der polnischen Bevölkerung zeigten, hatten die Häupter der Berliner Kriegspartei den Entschluß, Polen militärisch niederzuwerfen, naturgemäß mit der Überlegung verbunden, daß es im Grunde notwendig und jedenfalls höchst wünschenswert sei, einem Feldzug in Polen Störungen im Westen fernzuhalten, d.h. zumindest für die Dauer der Beseitigung des potentiellen Gefahrenherds im Osten jetzt wiederum irgendwie die politische und militärische Passivität der Westmächte zu sichern. Es lag auf der Hand, daß dafür die Reizung Polens zu übermäßig scharfen Antworten auf die deutschen Vorbereitungen nicht genügte. Solche Züge der deutschen Taktik bedurften der Ergänzung durch weitere Elemente, und als eines der zusätzlichen Elemente begriffen Hitler und Ribbentrop die vorübergehende Suspendierung deutsch-polnischer Verhandlungen. Wahrte die deutsche Regierung - bis zu den Tagen kurz vor dem deutschen Angriff - ein ominöses Schweigen, was die eben ausgesprochenen Forderungen an Warschau 
anging, während gleichzeitig durch die Zuspitzung der Lage in Danzig und durch die Häufung von $Z$ wischenfällen in Polen selbst die Spannung zwischen Deutschland und dem östlichen Nachbarn ständig stieg, dann, so kalkulierten der „Führer“ und sein Außenminister, mußten Kriegsangst und Friedensneigung in Großbritannien und Frankreich derart zunehmen, daß am Ende Lähmung eintrat. Auch Hitler und Ribbentrop verstanden also das plötzliche Verstummen gegenüber Warschau als Bestandteil einer Politik der „Zermürbung“, nur daß sie nicht, wie Staatssekretär v. Weizsäkker, Polen, sondern die Kabinette und die Bevölkerung der Westmächte zermürben wollten. Die Grundgedanken dieser Nervenkriegs-Strategie setzte Ribbentrop, als er am 5. und 6. Mai seinen italienischen Kollegen in Mailand traf, dem Grafen Ciano mit der Miene eines Mannes auseinander, der den Schlüssel zum Sieg - hier zum politischen Sieg - in der Tasche hat. Bereits jetzt, so konstatierte er triumphierend, seien in England und Frankreich „Zeichen von Ermüdung“ gegenüber dem polnischen Problem zu beobachten; es stehe fest, daß in einigen Monaten, wenn die Frage reif geworden sei, kein Engländer und kein Franzose für Polen marschieren werde 395 . Im weiteren Verlauf des Frühjahrs und Sommers 1939 registrierte es daher Ribbentrop auch mit tiefer Genugtuung - und in extremer Verkennung der tatsächlichen Simmungsentwicklung in Westeuropa -, wenn in Großbritannien und Frankreich, ausgelöst durch Gerüchte über unmittelbar bevorstehende dramatische Aktionen des Deutschen Reiches, immer wieder Wellen der Aufregung aufschäumten und abebbten 396 .

Als der Reichsaußenminister in Mailand mit dem Grafen Ciano konferierte, war er allerdings gerade im Begriff, ein weiteres und doch noch zuverlässiger scheinendes Mittel zur Isolierung des Angriffsobjekts zusammenzubrauen. Den britischen Versuchen, gegen die deutsche Kriegs- und Eroberungslust eine diplomatisch-politische Abschreckungsfront aufzubauen, mußte mit Stärkerem begegnet werden als mit der Provokation Polens und dem Spiel auf westeuropäischen Nerven. Wie Goebbels am 15. April in sein Tagebuch schrieb: „London arbeitet weiter an der Einkreisung. Man spricht vom bevorstehenden Krieg mit uns. Abenteurer. Wir müssen aber auf der Hut sein. Dieser altersschwachen Demokratie ist doch noch ... Nervenstärke zuzutrauen.“397 Sollte Großbritannien und Frankreich überzeugend dargetan werden, daß sie besser daran täten, dem Einfall der deutschen Armeen in Polen tatenlos zuzuschauen, schien neben allem anderen schon auch eine reale Veränderung der Machtlage in Europa notwendig, und das in demonstrativster und propagandistisch wirksamster Form. Freilich war das politische Arsenal der Berliner Machthaber im Frühjahr 1939 nahezu leer. Im Grunde hatten sie nur eine Möglichkeit,

395 AIA, Ap Germania, Ciano an Mussolini, 7.5.1939.

396 Ebenda, Attolico an Ciano, 7.7.1939.

397 Tagebücher von Joseph Goebbels, Bd. 3, S. 594. 
nämlich die seit dem Münchner Abkommen unternommenen Anstrengungen zur Umwandlung des Antikominternpakts in ein Militärbündnis zu intensivieren und endlich erfolgreich abzuschließen. Da einerseits in Japan nach wie vor - trotz des deutschen Machtgewinns vom März - keine Fortschritte verzeichnet werden konnten, am 4. Mai aus Tokio sogar eine vorläufige Absage in Berlin und Rom einlief 398 , andererseits aber die gewandelte europäische Situation und die aus dem Entschluß zum Überfall auf Polen resultierende Eilbedürftigkeit dringend nach Aktion verlangten, kamen Hitler und Ribbentrop zu dem Schluß, daß ihnen im Augenblick nichts anderes übrigbleibe, als auf die optimale Allianz, den Dreierpakt, zu verzichten und sich vorerst mit der zweitbesten Lösung zu begnügen, einem deutsch-italienischen Militärbündnis. So kam bereits am 15. April Göring zu einem zweitägigen Besuch nach Rom, um in einigen längeren Unterredungen mit dem Duce zu sondieren, ob dieser noch immer bereit war, sich tatsächlich auf den Ausbau der „Achse“ zu einem Militärpakt einzulassen 399 .

Wohl hatten Mussolini und Ciano in den ersten Monaten des Jahres 1939 mehrmals zu erkennen gegeben, daß sie es angesichts der japanischen Zögerlichkeit für das beste hielten, zunächst eben nur ein - in Europa ja fast ebenso effektives - Zweierbündnis zwischen Italien und Deutschland abzuschließen. Doch war selbst Hitler und seinen Gehilfen, die fremde Empfindungen und Empfindlichkeiten bloß noch undeutlich wahrnahmen, nicht verborgen geblieben, daß die endgültige Zerstörung der Tschechoslowakei und die Annexion Böhmens und Mährens durch das Deutsche Reich die italienischen Freunde tief verstimmt hatten. Ohne seinem Achsenpartner vorher auch nur eine Silbe zu sagen - ganz zu schweigen von Konsultation -,hatte Hitler gleich zwei internationale Vereinbarungen gebrochen und in historischen Müll verwandelt, an deren Entstehung Italien maßgeblich beteiligt gewesen war und an deren zumindest längerfristiger Existenz italienisches Prestige hing: das Münchner Abkommen vom 29. September und den Wiener Schiedsspruch vom 2. November 1938. Bernardo Attolico, der italienische Botschafter in Berlin, dem die Deutschen keine Chance gegeben hatten, seine Regierung rechtzeitig zu informieren, fühlte sich persönlich hinters Licht geführt und gegenüber seinen römischen Vorgesetzten in eine peinliche Lage gebracht. In bitteren Berichten machte er seinem Zorn über die deutsche Hinterlist Luft, wobei er den Hinweis nicht unterdrückte, daß es in Berlin ,nicht einen Diplomaten mehr gibt, der noch Vertrauen in Versicherungen des Führers setzt". Ebenso scharf geißelte er die Demütigung Italiens, die bereits zur definitiven Liquidierung des italienischen Einflusses in Budapest geführt habe, wo das nationalsozialistische Deutschland nun als der alleinige Wohltäter Ungarns gelte. Auch machte 
Attolico darauf aufmerksam, daß es nach dem Prager Coup höchste Zeit sei, die Deutschen, die ständig von ihrer Bescheidung auf Osteuropa redeten, nach ihren wahren Absichten in Südosteuropa zu fragen, wo Italien Interessen zu verteidigen habe: Richtete sich z.B. die deutsche Begehrlichkeit inzwischen nicht doch auch schon auf Kroatien? Sollte am Ende für Italien nur „das Wasser des Mittelmeers“ bleiben 400 ?

In Rom selbst waren Mussolini und Ciano nicht weniger verärgert und besorgt. Hitler goß noch Öl ins Feuer, indem er es tatsächlich fertigbrachte, den italienischen Freunden die offizielle Begründung für die Erledigung der Tschechoslowakei aufzutischen. Wie bei der Annexion Österreichs schickte Hitler den Prinzen Philipp von Hessen, Schwiegersohn des italienischen Königs, mit der Botschaft zu Mussolini, er, Hitler, sei zum Handeln gezwungen gewesen, weil die Tschechen ihre Armee nicht reduziert, auch noch nach München Kontakte zu Moskau unterhalten und die deutsche Minderheit mißhandelt hätten. „Diese Vorwände“, so wetterte Ciano, „taugen vielleicht für die Propaganda von Goebbels, wenn man aber mit uns spricht, sollte man uns solches Geschwätz ersparen."401 Mussolini wünschte der Presse die Mission des Prinzen vorzuenthalten. „Die Italiener würden mich ja auslachen", sagte er: ,Jedes Mal, wenn Hitler ein Land besetzt, sendet er mir eine Botschaft" ${ }^{402}$. Graf Ciano ließ denn auch Mackensen, den deutschen Botschafter in Rom, in unmißverständlichen und nur eben noch höflichen Worten wissen, daß sich Italien zwar nolens volens an der CSR desinteressiere, jedoch zu einer ähnlichen Tolẹrierung deutscher Aktivitäten nicht mehr imstande sei, wenn es um Kroatien gehe ${ }^{403}$, und einige Wochen lang sah es so aus, als wollten die faschistischen Führer den Rat Attolicos beherzigen, der am 18. März eine ausführliche Stellungnahme zu den Prager Ereignissen mit der Mahnung geschlossen hatte, ehe man die Bindungen der „Achse“ zu einer deutsch-italienischen Militärallianz fortentwickle, gelte es, die absolute Gleichheit der Rechte und Pflichten der beiden Partner zu sichern; namentlich müsse das elementarste Recht garantiert sein, nämlich das Recht auf Information und Konsultation ${ }^{404}$. Am 31. März hat Attolico, der zuvor in Rom gewesen war und nun im Namen des Duce zu sprechen vermochte, seinen Freund Weizsäcker in aller Form - und sicherlich nicht ohne Befriedigung - über die böse Stimmung in Rom unterrichtet 405 .

Hitler und Ribbentrop beeilten sich, den Italienern das deutsche Desinteresse an Kroatien zu erklären und die generelle italienische Angst vor einem Streben Deutschlands nach dem politischen und wirtschaftlichen

400 AIA, Ap Germania, Attolico an Ciano, 14.3.1939, 18.3.1939.

401 Graf Ciano, Tagebücher 1939-1943, Bern 1947, S. 52 ff.

402 Ebenda.

403 ADAP, D, 6, Nr. 15.

$404 \mathrm{Vgl}$. Anm. 400.

405 ADAP, D, 6, Nr. 140. 
Übergewicht in Südosteuropa als gänzlich unbegründet hinzustellen; der Reichsaußenminister schrieb Ciano noch am 20. März einen beruhigenden Brief406, und Mitte April gab sich auch Göring, als er nach Rom kam, große Mühe, den Duce im Namen des „Führers“ davon zu überzeugen, daß Deutschland „die Südosträume nicht für sich allein beanspruche“" 407 . Indes hatten Mussolini und Ciano, als sie Göring empfingen, ihre Aufregung längst überwunden und sich inzwischen zu der Ansicht bekehrt, daß jene Gründe, die vor Hitlers Prager Coup einen deutsch-italienischen Militärpakt als wünschenswert, ja als unentbehrliches Kernstück der künftigen italienischen Außenpolitik hatten erscheinen lassen, allesamt noch in Kraft seien und trotz des schlechten Benehmens der deutschen Partner nicht ignoriert werden dürften. Hätte eine alternative Politik nicht den Abschied von einer weiteren Verfolgung des mediterranen Imperialismus bedeutet? Gerade angesichts der Erfolge des nationalsozialistischen Deutschland waren die faschistischen Führer Italiens aber zu einem solchen Abschied weniger denn je bereit. Tatsächlich hatten sie, als sie am 7. und 8. April eine seit langem gehegte Absicht realisierten und Albanien besetzen ließen, auf die Errichtung des „Protektorats Böhmen und Mähren“ schon in einer Weise reagiert, die den Gegensatz zu den Westmächten, namentlich zu Frankreich, erheblich verschärfte und damit das faschistische Italien noch fester als bisher an Deutschland fesselte. Am 13. April garantierten Großbritannien und Frankreich die Unabhängigkeit Rumäniens und Griechenlands. Mit Recht verstand man das in Rom als ein Signal, das keineswegs allein für Berlin bestimmt war, sondern nicht zuletzt dem faschistischen Italien bedeuten sollte, daß weitere Anschläge gegen den Status quo im adriatischen, ägäischen und mediterranen Raum auf Widerstand stoßen würden; zumindest mußte jetzt eine höchst unbequeme Verstärkung der politischen Präsenz der Westmächte in Südosteuropa ins Kalkül gezogen werden. Gegen beides schien nur die Allianz mit Deutschland zu bleiben, zumal die britische Diplomatie auch in Ankara eine lebhafte Tätigkeit entfaltete, womit das gegen die deutschen und die italienischen Aspirationen gerichtete System auch noch durch den Einbau der Türkei gefestigt zu werden drohte. Mussolini und Ciano war durchaus klar, daß die faktische Abhängigkeit Italiens vom kräftigeren nördlichen Partner noch zunehmen mußte, wenn sie solchermaßen die Alternativlosigkeit faschistischer Außenpolitik fatalistisch akzeptierten, doch war es paradoxerweise gerade ihre Entschlossenheit, trotz der faktischen Abhängigkeit die politische Gleichberechtigung Italiens mit Deutschland zurückzugewinnen und zu behaupten, die für sie die Aussicht auf einen deutsch-italienischen Militärpakt endgültig unwiderstehlich machte. Allein im Rahmen einer derart festen und engen Allianz konnte es gelingen, so begannen sie sich einzureden, 
nein, im Rahmen einer derart festen und engen Allianz mußte es doch gelingen, so gaukelten sie sich alsbald vor, die gleichberechtigte Mitsprache Italiens in der „Achse“ und italienischen Einfluß auf die Berliner Politik zu sichern ${ }^{408}$. Und die Schaffung von Handhaben zur Kontrolle der Nationalsozialisten gewann plötzlich Dringlichkeit. In den letzten Märztagen und den beiden ersten Aprilwochen machten zwischen den diplomatischen Missionen und den Staatskanzleien Europas Gerüchte die Runde, daß sich das deutsch-polnische Verhältnis rapide verschlechtere, und die Italiener waren realistisch genug, um nicht einen Augenblick daran zu zweifeln, daß eine deutsche Aktion gegen Polen - noch dazu so rasch nach dem Prager Streich - die Intervention der Westmächte provozieren und damit jenen allgemeinen europäischen Krieg auslösen würde, den Italien unter allen Umständen vermeiden mußte. Am 14. April, einen Tag vor der Ankunft Görings in Rom und vier Tage vor Attolicos erstem - von Weizsäcker inspirierten - Alarmbericht über Hitlers Polenpläne, lud Graf Ciano Reichsaußenminister v. Ribbentrop zu einer "baldigen Aussprache“ nach Italien ein 409 .

Aus der „Aussprache“ der Minister, die schließlich am 6. und 7. Mai in Mailand stattfand, entwickelte sich dann ein Lehrstück in totalitärer Außenpolitik und Diplomatie, d.h. beide Seiten lieferten eindrucksvolle Illustrationen zu jenem politischen Gesetz, das da besagt, daß totalitäre Regime ihrem Wesen nach, weil sie auch auf internationalem Felde totalen Egoismus praktizieren und nach der totalen Macht trachten, allianzunfähig sind, ohne daß dies ihren Führern bewußt sein muß. Zwar bereitete der Abschluß eines Militärpakts, da ihn nun sowohl Hitler wie Mussolini wünschten, nicht mehr die geringsten Schwierigkeiten. Bereits am 22. Mai durften Ciano und Ribbentrop den fertigen Vertrag in Berlin unterzeichnen, einen Vertrag überdies, der die zwei Mächte dem Anschein nach auf Gedeih und Verderb aneinander band und daher die von den Propagandisten der "Achse“ erfundene Bezeichnung "Stahl-Pakt" offenbar verdiente. Dem Text zufolge hatte sich jeder Partner in der Tat vorbehaltlos dazu verpflichtet, dem anderen unverzüglich militärisch zu Hilfe zu kommen, falls dieser Krieg führen sollte, gleichgültig ob gegen einen einzigen Feind oder gegen eine feindliche Koalition, ebenso gleichgültig ob es sich dabei um einen Verteidigungs- oder um einen Angriffskrieg handelte 410 . In Wahrheit mußte jedoch der „Stahl-Pakt“, verstand ihn Mussolini im deutschen Sinne und nahm er folglich den Text ernst, für Italien so gefährlich sein, daß ein derartiges Verständnis des Vertrags der italienischen Seite von vornherein schlechthin unmöglich war und mithin niemand in Rom auch nur eine Sekunde lang ernstlich daran denken konnte, die eingegangene Verpflichtung

408 Siebert, Der deutsch-italienische Stahlpakt, S. $376 \mathrm{f}$.

409 AIA, Ap Germania, Attolico an Ciano, 14.4.1939.

410 RGB1, 1939, II, S. 826 ff. 
im entscheidenden Augenblick tatsächlich zu honorieren. Wenn aber der Vertrag für Italien praktisch unerfüllbar war, hatten auf der anderen Seite Hitler und Ribbentrop unausweichlich den Moment vor sich, in dem sie entdecken mußten, daß ihnen der "Stahl-Pakt“ nicht den geringsten Nutzen brachte, daß die Gestalt, die sie der Welt und sich selbst als furchterregenden Krieger präsentiert hatten, nicht einmal zur Vogelscheuche taugte. Es sollte lediglich ein Vierteljahr dauern, bis sich die wahre Natur des "Stahl-Pakts“ herausstellte, bis Mussolini und Ciano als vertragsbrüchige Schufte dastanden und - an ihrem eigenen Wertekanon gemessen - als verächtliche Schwächlinge obendrein, Hitler und Ribbentrop hingegen als mit Fug und Recht betrogene Betrüger. Schon bei der Unterzeichnung des Vertrags hatten indes die Partner die Problematik ihrer Verbindung zumindest geahnt. Eben deshalb glaubte ja jeder, den anderen in den Pakt förmlich locken zu müssen, indem er die Wahrheit über die eigenen Motive und Absichten so dicht einwickelte, daß sie nahezu unkenntlich wurde, und indem er daneben etliche ausgewachsene Lügen servierte. Doch hatten sich Deutsche wie Italiener nur allzu erfolgreich die Vorstellung suggeriert, daß die Fortsetzung der nationalsozialistischen und der faschistischen Expansionspolitik ein nationalsozialistisch-faschistisches Militärbündnis erfordere, und so zogen es Deutsche wie Italiener vor, die wohlverpackten Wahrheiten der anderen Seite zu ignorieren und sich - im Grunde wider besseres Wissen - an die faustdicken Lügen zu halten.

Am 22. Mai, als Ribbentrop und Ciano mit der Unterzeichnung des „Stahl-Pakts“ „unzweideutig“, wie Ciano dazu erklärte, „die vollkommene politische und militärische Solidarität Deutschlands und Italiens festlegten"411, war den Italienern, obwohl sie von ihren Berliner Freunden noch kein offizielles Wort über die deutschen Polenpläne gehört hatten, einerseits durchaus klar, daß Hitler Polen ins Visier genommen hatte; die Gerüchte, die mittlerweile in Europa über die Verschlechterung der deutschpolnischen Beziehungen kursierten, waren zu dicht und zu handfest geworden, um noch bagatellisiert werden zu können. Attolico hatte im April seinen ersten alarmierenden Bericht aus Berlin geschickt, und ganz abgesehen von der Kündigung des deutsch-polnischen Nichtangriffspakts, die Hitler am 28. April ausgesprochen hatte, war dem italienischen Außenminister am 6. Mai, als Ribbentrop in Mailand bemerkt hatte, in einigen Monaten werde kein englischer und kein französischer Soldat für Polen marschieren, das schönste und aussagekräftigste Indiz geliefert worden, das er sich nur wünschen konnte. Auch löste es in Rom Besorgnis aus, daß die Deutschen, nach den leichtfertigen Äußerungen Ribbentrops zu schließen, im Falle eines Angriffs auf Polen offenbar nicht mit der Intervention der Westmächte rechneten. Eine deutsche Aktion gegen Polen, und zwar noch im Jahr 1939, mußte mithin bereits als wahrscheinlich gelten; daß dann Ita- 
lien nicht an der Seite Deutschlands kämpfen werde, weil es nicht in der Lage sei, mit den im Gegensatz zur deutschen Meinung unweigerlich eingreifenden Westmächten anzubinden, stand für die italienische Führung ebenfalls fest.

Andererseits war Mussolini und Ciano nicht weniger klar, daß sie das Bündnis mit Deutschland vermutlich überhaupt nicht bekamen, wenn sie den Deutschen solche Wahrheiten ungeschminkt sagten, die Vorbehalte womöglich in den Vertrag selbst einzubauen suchten und mit beidem einer deutsch-italienischen Allianz jeden Wert für die deutsche Seite nahmen. So wagten sie ihre Unfähigkeit zu einem Krieg gegen Großbritannien und Frankreich und ihre daraus resultierende strikte Ablehnung eines allgemeinen europäischen Krieges lediglich in die Formel zu kleiden, daß die Achsenmächte einen derartigen Krieg frühestens 1942 inszenieren sollten, weil Italien noch einige Jahre der Vorbereitung brauche. Wohl wiesen sie auf die Notwendigkeit einer Wartefrist mit großem Nachdruck hin, so nachdrücklich, daß mit Händen zu greifen ist, wieviel Kriegslust und wie wenig Geduld sie ihren deutschen Partnern in Wirklichkeit zutrauten. Mussolini hatte schon in seinen Gesprächen mit Göring, Mitte April, unterstrichen, daß Italien noch nicht kriegsbreit sei412; in die Instruktionen, mit denen er Ciano für die Mailänder Unterredungen ausrüstete, schrieb er gleichfalls ausdrücklich zur Lektüre Ribbentrops bestimmt -, daß mindestens noch drei Friedensjahre erforderlich seien ${ }^{413}$, und am 30. Mai, acht Tage nach der Vertragsunterzeichnung, ließ er Hitler durch General Graf Ugo Cavallero eine mit der Ciano gegebenen Instruktion weitgehend identische Denkschrift überreichen, mit der er allein den Zweck verfolgte, Hitler ganz klar zu machen, daß Italien derzeit keinen Krieg führen könne ${ }^{414}$. Doch war all dies nicht genug, zumal Mussolini und Ciano gleichzeitig stets erklärten, daß selbstverständlich auch sie, wie die deutschen Freunde, den Krieg zwischen den beiden totalitären Staaten und den westlichen Demokratien für unvermeidlich hielten, und sie überdies bei jeder Gelegenheit wahrheitswidrig versicherten, daß der Ernstfall, wann immer und unter welchen Umständen er auch kommen möge, Italien an der Seite Deutschlands sehen werde. Mussolini und Ciano machten sich aber vor, den Deutschen reinen Wein eingeschenkt und damit genug getan zu haben. In diesem Bewußtsein glaubten sie sich dann berechtigt, Ribbentrops willkommene Mitteilung als ausreichend anzusehen, der „Führer" denke über die Notwendigkeit einer mehrjährigen Phase der Vorbereitung auf den großen Krieg nicht anders als sein Freund Mussolini. Solchermaßen beruhigt, gaben sie sich dann der Hoffnung hin, den „Stahl-Pakt“ als politisches Druckmittel gegen Frankreich und mit Hilfe der in Artikel I formulierten Konsulta-

412 ADAP, D, 6, Nr. 205, 211.

413 M. Toscano, Le Origine del Patto d,Acciaio, S. $142 \mathrm{ff}$.

414 ADAP, D, 6, Nr. 459. 
tionsklausel zugleich als Instrument kontrollierender Einwirkung auf die Berliner Politik benützen zu können.

Hitler und Ribbentrop wiederum wußten sehr genau, daß die Verhandlungen mit Italien ein jähes Ende finden mußten, wenn sie den italienischen Partnern klipp und klar sagten, daß Deutschland im Spätsommer Polen angreifen werde und mithin ein deutsch-italienischer Militärpakt inzwischen in deutschen Augen die Aufgabe bekommen hatte, die Westmächte von der Einmischung in den deutsch-polnischen Konflikt abzuschrecken oder aber, falls wider Erwarten die Abschreckung versagen sollte, intervenierende Westmächte mit einem zusätzlichen Feind zu konfrontieren. So spielte Ribbentrop schon die Möglichkeit einer militärischen Lösung der „polnischen Frage“ - so zuversichtlich er den Italienern darlegte, die deutsche Wehrmacht werde im Falle eines Krieges längstens zwei Wochen zur Erledigung Polens brauchen - herab, rückte sie jedenfalls, wenn er nicht gerade unbedacht redete, in unbestimmte Fernen, und leugnete erst recht, daß die deutsch-polnische Kontroverse die Gefahr eines Krieges mit den Westmächten heraufbeschwöre; von der oft und stereotyp wiederholten Behauptung abgesehen, daß Großbritannien und Frankreich nicht daran dächten, Polen zu Hilfe zu kommen, versicherte er mit großem Ernst, der „Führer", der auch für Deutschland noch eine Periode intensivster Rüstung haben wolle, sei keineswegs gewillt, bereits jetzt einen Krieg gegen die Westmächte zu provozieren oder auch nur zu riskieren. Daß die Kriegspartei in Berlin, an ihrer Spitze Ribbentrop selbst und natürlich vor allem Hitler, mittlerweile in Wirklichkeit zu höchster Risikobereitschaft gelangt war, hat der Reichsaußenminister lediglich in den Satz gefaßt, das nationalsozialistische Deutschland sei selbstverständlich auch während der kommenden Vorbereitungsjahre jederzeit zu einem Krieg fähig, den der „Führer“ dann „in einem raschen Waffengang“ oder, falls das nicht möglich sei, eben in einem mehrjährigen Konflikt zugunsten des Reiches entscheiden werde. Derartige Bemerkungen kamen so beiläufig, waren so vage und zum Teil auch so widersprüchlich formuliert, daß sie auf die Italiener zunächst als typisch Ribbentropsches Bramarbasieren oder doch als bloße Rhetorik wirkten, zumal angesichts der klaren sonstigen Zusicherungen Hitlers, die Ribbentrop übermittelte. So lockte der "Führer" seinen Achsenpartner mit Bedacht und List in einen Vertrag, den die Italiener bei klarer deutscher Sprache und bei Klarheit über die ja bereits feststehenden deutschen $\mathrm{Ab}$ sichten wohl kaum unterschrieben hätten. Am 23. Mai, einen Tag nach der Unterzeichnung des "Stahl-Pakts“, hat Hitler vor den Spitzen der Wehrmacht noch einmal betont, daß die italienischen Freunde über den Entschluß zum Angriff auf Polen nicht unterrichtet werden dürften ${ }^{415}$. Gleichwohl meinte er Italien nun als Verbündeten in der Tasche und Mussolini eine Rolle wie 1938 in München unmöglich gemacht zu haben. 
Allerdings konnten Italiener wie Deutsche nicht umhin, die wechselseitige Täuschung relativ rasch aufzugeben und damit die Problematik des „Stahl-Pakts“ - seine Gefährlichkeit für das faschistische Italien und seine Wertlosigkeit für das nationalsozialistische Deutschland - relativ rasch aufzudecken. Als erste wurden die Italiener alarmiert, weil sich die Hinweise auf einen baldigen deutschen Einfall in Polen oder zumindest einen ja nicht weniger friedensbedrohenden deutschen Handstreich in Danzig bereits im Juni zu häufen begannen. Naturgemäß blieben die militärischen Vorbereitungen der Wehrmacht nicht unbemerkt. Die italienischen Konsulate in Deutschland lieferten darüber detaillierte Berichte ${ }^{416}$, ebenso der eigene Geheimdienst und die Nachrichtendienste befreundeter Länder wie Ungarn ${ }^{417}$. Dazu kamen die vertraulichen Andeutungen, die Attolico von Weizsäcker erhielt, z.B. auch über die laufende Militarisierung Danzigs ${ }^{418}$. Am 26. Juni schrieb Attolico an Ciano, Graf Johannes Welczek, der deutsche Botschafter in Paris, der sich gerade in Berlin aufhalte, habe ihm erzählt, er sei von Ribbentrop persönlich unterrichtet worden, daß Deutschland das Problem Danzig etwa Mitte August gewaltsam lösen werde, und der italienische Missionschef knüpfte daran die Bemerkung, das Diplomatische Korps in Berlin befinde sich nicht mehr nur in Alarmstimmung, sondern schon in Verzweiflung; die Situation enthalte trotz aller Versicherungen Hitlers offensichtlich in der Tat Elemente der Gefahr und müsse, wie die persönliche Politik Ribbentrops, aufmerksam beobachtet werden ${ }^{419}$. Pietro Arone, der italienische Vertreter in Warschau, meldete, seine polnischen Gesprächspartner, etwa Graf Szembek, seien tief besorgt über die Lage in Danzig; der Staatssekretär habe keinen Zweifel daran gelassen, daß die polnische Regierung in einer Frage, die für das Deutsche Reich lediglich eine Sache des Prestiges, für Polen aber vital sei, keine einseitige Lösung durch Deutschland akzeptieren könne, obwohl sie sich bewußt sei, welch schweren Blutopfern das Land entgegengehe ${ }^{420}$.

Was Mussolini und Ciano bei alledem besonders in Unruhe versetzte, war ihre Beobachtung, daß die deutschen Partner einem Unternehmen gegen Polen offenbar leichten Sinnes entgegenstrebten, weil sie tatsächlich der Illusion anhingen, eine Intervention der Westmächte brauche nicht in Betracht gezogen zu werden. Zu den entsprechenden $\ddot{u}$ ßerungen, mit denen Ribbentrop bereits Anfang Mai den Grafen Ciano in Mailand irritiert hatte, gesellten sich nun - parallel zu den Meldungen über den deutschen Aufmarsch gegen Polen - weitere Indizien. Am 28. Juni berichtete z.B. Attolico aus Berlin, der dortige argentinische Botschafter habe ihm eine Unterredung mit Hitler geschildert, in der dieser gegen Polen gewütet und an-

416 AIA, Ap Germania, Attolico an Ciano, 13.7.1939.

417 Ebenda, Vinci (Budapest) an Ciano, 27.5.1939.

418 Ebenda, Attolico an Ciano, 1.7.1939.

419 Ebenda, Attolico an Ciano, 26.6.1939.

420 Ebenda, Arone (Warschau) an Ciano, 30.6.1939. 
gekündigt habe, daß er demnächst in der polnischen Frage binnen weniger Stunden „Gerechtigkeit schaffen“ werde: „In der Sicherheit, daß weder England noch Frankreich sich bewegen werden."421 Einige Tage später hatte Raffaello Guariglia, der italienische Botschafter in Paris, eine vertrauliche Unterhaltung mit dem in die französische Hauptstadt zurückgekehrten Grafen Welczek, in der sich der deutsche Diplomat bei seinem italienischen Kollegen darüber ausweinte, daß Ribbentrop nicht von der Meinung abzubringen sei, England und Frankreich würden es nicht wagen, gegen die deutsche Macht auch nur einen Finger zu rühren: Ribbentrop, so sagte Welczek, erinnere ihn an die Politik des kaiserlichen Deutschland, das 1914 nicht an die britische und 1917 nicht an die amerikanische Intervention glauben wollte. In Berlin sei er vom Reichsaußenminister als Diplomat alten Stils abgetan worden, der die Dinge durch eine französische Brille sehe. Ribbentrop habe sich tatsächlich eingeredet, daß die Nerven der Engländer und Franzosen dem geschaffenen Spannungs- und Mobilisierungszustand am Ende nicht gewachsen seien. Als er, Welczek, dem Minister entgegengehalten habe, dieser Spannungs- und Mobilisierungszustand wirke in Großbritannien und Frankreich eher einigend als schwächend, sei er von Ribbentrop mit Spott abgefertigt worden ${ }^{422}$. Mussolini und Ciano blieb gar nichts anderes übrig, als sich mit wachsender Ängstlichkeit zu fragen, ob sich der Bündnispartner womöglich schon in wenigen Wochen in ein polnisches Abenteuer stürzen und damit, weil ein solches Abenteuer unmöglich als lokalisierter Feldzug ablaufen konnte, schon in nächster $\mathrm{Zu}$ kunft eine Situation schaffen werde, in der Italien nur die Wahl zwischen der Verstrickung in einen aussichtslosen Krieg gegen die Westmächte oder dem peinlichen und auch politisch schädlichen Bruch der Allianz bleiben konnte. Am 2. Juli schrieb Graf Ciano an Attolico, daß die Lage genaueste Informationen über die deutschen Absichten in der Danzig-Frage erfordere; es sei notwendig, daß der Botschafter mit Ribbentrop selbst spreche, weil man endlich - und ein vernichtenderes Urteil über die bisherige Bewährung der Konsultationsklausel des „Stahl-Pakts“ ist kaum vorstellbar Kenntnis von den wirklichen Berliner Plänen haben müsse ${ }^{423}$.

Tatsächlich kam es am 6. Juli abends zu einem längeren Gespräch zwischen Attolico und Ribbentrop, das die italienischen Besorgnisse vollauf bestätigte, ja Mussolini und Ciano zeigen mußte, daß die Dinge in Berlin noch schlimmer standen, als man in Rom befürchtet hatte. Zunächst erging sich der Reichsaußenminister in martialischem Gerede, wie leicht es doch sei, Polen in 48 Stunden „zu zerquetschen“ und die Danziger Frage in Warschau zu lösen. Das polnische Problem sei für Deutschland, militärisch gesehen, geringfügiger als 1938 das tschechoslowakische Problem.

421 Ebenda, Attolico an Ciano, 28.6.1939.

422 Ebenda, Guariglia (Paris) an Ciano, 4.7.1939.

423 Ebenda, Ciano an Attolico, 2.7.1939. 
Auf Grund der besseren Qualität seiner Streitkräfte und des höheren Stands seiner Rüstung hätte Prag länger Widerstand leisten können als jetzt Warschau, das überdies nicht auf englischen und französischen Beistand zählen dürfe. Solche Tiraden, verbunden mit dem gewohnten Trugbild von der Schwäche Großbritanniens und Frankreichs, waren beunruhigend genug, da aus ihnen, obschon Ribbentrop eine direkte Frage Attolicos mit einem glatten und wahrheitswidrigen "Nein“ beantwortete, nur allzu deutlich die deutsche Entschlossenheit zu einem baldigen Schlag gegen Polen sprach. Danach aber folgte die noch bestürzendere Eröffnung Ribbentrops, daß die NS-Führung mittlerweile selbst einem Eingreifen der Westmächte mit gelassener und sogar freudiger Zuversicht entgegensehe. Wenn sich Frankreich doch verpflichtet fühlen sollte, Polen militärisch zu unterstützen, so solle es das, rief der Minister, ruhig tun: „Deutschland wünscht sich nichts Besseres." Gegen den Westwall sei die Maginot-Linie ein „Kinderspiel“; mehr als zwanzig bis dreißig Maginot-Linien seien die heutigen deutschen Befestigungen im Westen wert. Wenn Daladier wirklich so dumm sei, gegen das Reich vorzugehen, werde Deutschland Frankreich vernichten. „Fragen Sie Göring! Er wird Ihnen sagen, daß 5000 - ich sage 5000 - Flugzeuge bereitstehen, um Paris täglich zu bombardieren." Man werde die französische Hauptstadt „pulverisieren“. Auch England werde, wenn es nicht stillhalte, eben „der Zerstörung seines eigenen Imperiums entgegenschreiten“. Rußland? „Was kann Rußland tun? Nichts!“ Selbst wenn Moskau ein Abkommen mit den Westmächten schließe, werde es nicht marschieren. „Im übrigen, so murmelte mir Ribbentrop diskret zu, ,habe ich heute neue Instruktionen an Schulenburg [den deutschen Botschafter in Moskau] geschickt, die ausreichen werden, Stalin einen Floh ins Ohr zu setzen!“ Und Amerika? „Eine einzige Rede des Führers, in hunderttausenden von Exemplaren über den amerikanischen Kontinent verbreitet, hat genügt, Roosevelt eine schwere Niederlage zu bereiten." Doch würden sich die USA ohnehin nicht bewegen, und zwar aus Angst vor Japan, das auch ohne Militärpakt immer auf der Seite Deutschlands und Italiens stehen werde 424 .

Auf derart kriminellen Dilettantismus konnte man, wie das Attolico in seinem Bericht nach Rom denn auch tat, nur mit kaustischen Kommentaren reagieren. Andererseits hatte hier, das war nicht zu leugnen, der Außenminister des Deutschen Reiches gesprochen, mit dem von Italien einige Wochen zuvor ein Militärbündnis geschlossen worden war, und so verursachten Ribbentrops Stammtisch-Prahlereien neben hohnvollem Sarkasmus berechtigterweise vornehmlich Furcht. Es konnte diese Furcht auch nicht mehr recht dämpfen, daß Ribbentrop, nun wieder zu Hitlers Taktik der möglichst langen Täuschung Roms zurückkehrend, dem italienischen Botschafter anschließend treuherzig versicherte, der „Führer“, mit dem er 
erst gestern lange gerade über dieses Problem konferiert habe, trage sich, „während er alle Register für die Schlußabrechnung vorbereitet, nicht mit der Absicht, einen Konflikt zu provozieren, der in einen allgemeinen Konflikt ausarten könnte. Da könnt Ihr ganz sicher sein“. Und es konnte die Furcht der Italiener erst recht nicht mehr dämpfen, daß der Reichsaußenminister - ganz abgesehen von seiner ominösen Bemerkung über die „Register für die Schlußabrechnung “ - weitere bohrende Fragen Attolicos nach den wirklichen deutschen Plänen mit der sibyllinischen Auskunft abspeiste: „Ich kann Euch in klarer Weise versichern, daß Pläne absolut nicht existieren. Der Führer folgt den Ereignissen mit einer absoluten Ruhe. Er läßt sich nicht leicht zu unüberlegten Gesten hinreißen ... Er weiß den Moment abzuwarten. Wir haben stärkere Nerven als unsere Gegner." Nachdem Attolico in den folgenden Tagen weitere beunruhigende Informationen über den Kriegswillen der deutschen Führung erhalten hatte, und zwar von General Luigi Marras, dem italienischen Militärattaché in Berlin, der gute Beziehungen zu Admiral Canaris, dem Chef der deutschen Abwehr, unterhielt ${ }^{425}$, und wiederum von seinem Verbündeten Weizsäcker ${ }^{426}$, schickte er am 11. Juli, offensichtlich von Weizsäcker dazu ermuntert, einen Appell an Filippo Anfuso, den Kabinettschef des gerade aus Rom abwesenden Ciano: Der „Führer" werde sich Mitte August für Krieg oder Frieden entscheiden, und man müsse annehmen, daß er sich, auch wenn er einen allgemeinen Krieg im Augenblick eigentlich nicht wünsche, in Unterschätzung der Westmächte für einen Kurs entscheide, der zu einem allgemeinen Krieg führen werde. Da diesmal die Chancen für eine Aktion in letzter Minute, für ein neues „München“, wesentlich geringer seien als im Vorjahr, sei es dringend geboten, daß Italien jetzt sofort oder doch möglichst bald, solange eben vielleicht noch Aussichten bestünden, den Versuch unternehme, bremsend auf die Deutschen einzuwirken. Er halte es daher für richtig und notwendig, den seit einiger Zeit mehrmals wiederholten deutschen Wunsch nach einem erneuten Treffen Hitler-Mussolini umgehend aufzugreifen und zu akzeptieren ${ }^{427}$. Tatsächlich ist die Begegnung Führer-Duce Mitte des Monats definitiv vereinbart und auf den 4. August festgelegt worden; als Ort der Zusammenkunft wurde der Brenner gewählt.

Nun kam für die deutsche Seite der Moment, in dem sich die Lage und der Kurs des Achsenpartners deutlich abzeichnete, in dem also Klarheit über den wahren politischen Wert des „Stahl-Pakts“ zu gewinnen war. In den Tagen nach der Verabredung des Treffens am Brenner zerbrach man sich in Rom die Köpfe über die Frage, mit welchem Mittel denn wohl die Politik der Deutschen beeinflußt und der drohende Eintritt des Bündnisfalls vermieden werden könne. Mussolini und Ciano produzierten eine

425 Ebenda, Attolico an Ciano, 11.7.1939.

426 Ebenda.

427 Ebenda. 
Idee. Am 22. Juli schrieb Ciano an Attolico, Mussolini habe im Sinn, der Begegnung mit dem „Führer“ einen „echten Gehalt von größerer internationaler Reichweite“ zu geben, selbstverständlich „bei gleichzeitiger Bekräftigung der Unauflöslichkeit der deutsch-italienischen Freundschaft“"428. Was verbarg sich hinter solch nebulöser Formulierung? Am 24. Juli konnte Attolico in einem offiziellen Gespräch mit Weizsäcker schon etwas mehr sagen: Der Duce glaube nicht an die Möglichkeit eines lokalisierten Krieges Deutschland-Polen, „sondern erwartet dann einen allgemeinen europäischen Brand“. Wenn aber geschlagen werden müsse, „so sollten wir den richtigen Moment wählen und nicht die Anderen“. Würde nun die Besprechung am Brenner „eine bis auf weiteres friedliche Politik einleiten“, müsse „ein anderes bedeutsames Ergebnis herauskommen. Die dürftige Feststellung politischer Übereinstimmung genüge nicht." Wäre mit einer mehrjährigen Friedensperiode zu rechnen, sei die Lücke irgendwie konstruktiv zu füllen, ,vielleicht indem man mit den anderen Mächten: Deutschland mit Polen, Italien mit Frankreich, oder auch zwischen den größeren Mächten überhaupt ins Gespräch komme, wobei wir das Verdienst der Initiative für uns sichern müßten". Sowohl die Annahme wie die Ablehnung einer solchen Initiative würde zu Deutschlands und Italiens Gunsten auschlagen ${ }^{429}$. Einen Tag später wurde Attolico von Ribbentrop empfangen, und als der Botschafter eine nach Mussolinis Diktat gefertigte Aufzeichnung seines Stellvertreters, des mit Ciano verschwägerten und befreundeten Grafen Massimo Magistrati, überreichte und erläuterte, konnte der Reichsaußenminister feststellen, daß der Duce und Ciano tatsächlich, was nach den Eröffnungen Attolicos vom Vortag schon befürchtet werden mußte, die Idee einer großen internationalen Konferenz zur Erörterung der entstandenen Streitfragen geboren hatten und diese Idee am 4. August in aller Form Hitler zu unterbreiten gedachten. Der Charakter einer solchen Konferenz, so ließ Mussolini wissen, „müßte absolut europäisch sein, um, wie schon gesagt, einzig über die streng europäischen Probleme, d.h. diejenigen, welche die Beziehungen zwischen den großen europäischen Mächten interessieren, entscheiden zu können. Es würden so Rußland, da es eine Macht interkontinentalen Charakters ist, Amerika und Japan ausgeschlossen werden. Es würden sich deshalb um den Tisch nur Deutschland, Italien, Frankreich, Großbritannien, Polen (in Anbetracht seines direkten Interesses an diesen Problemen) und, um klar Polen selbst aufzuwiegen, Spanien, welches so ohne weiteres als westeuropäische Großmacht hingestellt würde. Falls man - eventuell - bei der Konferenz einen neutralen europäischen Beobachter zu haben wünscht, welcher in gewisser Weise die kleinen Länder darstellt, könnte man zum Beispiel an die Schweiz oder an Holland oder an Schweden denken." Ein entsprechendes Kommuniqué für die Zusammenkunft 
am 4. August hatte Magistrati auch gleich mitgebracht: „Der Führer und der Duce“, so lautete der in Rom formulierte Entwurf, „welche sich am Brennero getroffen haben, haben nach langer Prüfung der Lage gegen die Politik der Einkreisung der Achse, die von den großen Demokratien geführt wird, ihren Friedenswillen bekräftigt und haben in der Annahme übereingestimmt, daß eine Konferenz zwischen den interessierten Mächten, falls sie auf normalem diplomatischem Wege in geeigneter Weise vorbereitet wird, zu einer Lösung der hauptsächlichsten Probleme, welche Europa erregen, führen und den Völkern eine Zeit des Friedens und Wohlbefindens eröffnen könnte." 430

Mit Magistratis Aufzeichnung hielt Ribbentrop nun ein Schriftstück in Händen, das eine klare Ankündigung des italienischen Achsenpartners darstellte, aus dem „Stahl-Pakt“ desertieren zu müssen, falls Deutschland in nächster Zeit einen europäischen Krieg provozieren sollte. Zwar hieß es in der Aufzeichnung - und Attolico wiederholte das in seiner mündlichen Erläuterung -, daß Mussolini, wenn der „Führer“ jetzt Krieg führen wolle, selbstverständlich ebenfalls „zu jeder Stunde hierzu bereit sei“. Doch stand dazu der gesamte Inhalt dieser Mitteilung des Duce in einem so schroffen Gegensatz, daß der bloß rhetorische Charakter derartiger Einleitungssätze nur um so krasser hervortrat. Zunächst sagte Mussolini ohne Umschweife, daß er die deutsche Ansicht, eine Aktion gegen Polen sei zu lokalisieren, für grundfalsch halte: „Paris würde in den Krieg gehen und London könnte nichts anderes tun, als ihm zu folgen." Attolico ergänzte das mit der Bemerkung - in der ein geradezu vernichtendes Urteil über die Berliner Politik steckte -, daß für die Polen „der baldige Krieg die letzte und beste Karte wäre“. Danach erinnerte Mussolini an seine wiederholten Erklärungen, daß Italien aber für einen allgemeinen europäischen Krieg noch nicht bereit sei, und er legte ferner aufs beredteste einige andere Gründe dar, die für eine Verschiebung des großen Krieges sprächen; die deutschen Adressaten konnten eigentlich sofort erkennen, daß hier nicht ein Zögerer und Zauderer argumentierte, den es nur zu überzeugen und mitzureißen galt, sondern ein - jedenfalls im Moment - entschlossener Apostel des europäischen Friedens. Bei seiner Aufzählung erlaubte sich der Duce im übrigen auch deutliche Kritik an der deutschen Taktik: der geführte Nervenkrieg, so konstatierte er, habe „die demokratischen öffentlichen Meinungen“ geeint und außerdem den autoritären Staaten das Moment der Überraschung gekostet, womit sie sich einer ihrer größten Stärken begeben hätten, nämlich der Fähigkeit, „sich sofort, im unerwarteten Augenblick, bewegen zu können“. Die Krönung des italienischen Memorandums war jedoch der Gedanke, Hitler und Mussolini sollten als Ergebnis ihres Treffens die Welt mit dem Vorschlag einer großen europäischen Konferenz überraschen. 
Mussolini, Ciano und ihren diplomatischen Gehilfen stand selbstverständlich deutlich vor Augen, daß die Idee einer internationalen Konferenz der derzeitigen Zielsetzung und taktischen Planung Berlins, wie man sie inzwischen umrißhaft zu sehen vermochte, diametral entgegengesetzt sein mußte. Anders als 1938 vor München, wußten sie auch, daß Hitler die Auffassung vertrat, Konferenz-Diplomatie sei sowohl mit den Grundprinzipien nationalsozialistischer Außenpolitik wie mit einer erfolgreichen Vertretung der Interessen des Deutschen Reiches schlechthin unvereinbar; zuletzt hatte das Ribbentrop am 5. Mai Ciano auseinandergesetzt, als von den beiden Außenministern ein am Vortag gemachtes Angebot des Papstes erörtert worden war, öfentlich zu einer internationalen Konferenz zum Abbau der Spannung in Europa aufzurufen 431 . Eine Formel, die den tiefen Unterschied zwischen der italienischen und der deutschen Politik noch schärfer zum Ausdruck gebracht hätte, war schwerlich zu finden. Mussolini hat denn auch sicherlich nicht damit gerechnet, daß Hitler den Konferenz-Gedanken zähneknirschend oder gar freudig akzeptieren werde. Die Signalisierung der italienischen Haltung verfolgte vielmehr offensichtlich den Zweck, die Berliner Kriegspartei noch so rechtzeitig wieder zur Vernunft zu bringen, daß Italien der Eintritt des Bündnisfalls und die dann mit der italienischen Desertion verbundene schwere Beschädigung oder womöglich sogar Zerstörung der „Achse“ erspart blieb.

Ribbentrop begrüßte es, daß die Haltung des Duce klar sei, „falls der Führer den Krieg jetzt für opportun“ halte, und zum „Nervenkrieg“ bemerkte er, daß dieser „nur zu Gunsten der Achse ausfallen könne, deren Völker und Führung zweifellos bessere Nerven als die Gegenseite habe“. Dann aber wies er, „ohne dem Führer vorgreifen zu wollen“, den Konferenz-Gedanken zurück, wobei er am italienischen Vorschlag noch eine spezielle Bosheit entdeckte. Er halte es „nicht für möglich“, so sagte er, „sich mit der polnischen Regierung heute an einen Tisch zu setzen, nachdem diese uns seinerzeit erklärt hat, daß eine Weiterverfolgung des Angebots des Führers einen Kriegsgrund darstelle“. Im übrigen sei er der Meinung, „daß jede Friedensinitiative der Achse als ein Schwächezeichen von den feindlichen Mächten ausgelegt werde“. Bezeichnenderweise fügte er die treffende Beobachtung hinzu, es sei ausgeschlossen, „daß die Westmächte heute von sich aus einen Krieg" suchten, und ebenso bezeichnenderweise folgerte er daraus, „daß die Danziger Frage bei weiterem sturen Verhalten wie bisher in unserem Sinne gelöst" werden dürfe. So erklärte denn der Reichsaußenminister das Kommuniqué, das Mussolini diktiert und Magistrati mitgebracht hatte, ,für undenkbar“, und angesichts solch tiefgehender Divergenzen, die zudem auf den ersten Blick als unversöhnlich erschienen, verlor er jeden Enthusiasmus für die Begegnung zwischen „Führer“ und Duce. Am Schluß ihrer Unterredung diskutierten Ribbentrop und At- 
tolico bereits nur noch die Frage, wie und wo die Zusammenkunft so zu organisieren sei, daß man "den sensationellen Charakter eines Treffens an der Grenze" vermeide. Schließlich sprach sich Ribbentrop lebhaft dafür aus, den Treffpunkt nach Florenz zu verlegen oder nach Oberitalien, wo in den ersten Augustwochen Manöver der italienischen Streitkräfte stattfinden sollten, „da man im Falle Florenz den privaten Charakter der Reise des Führers hervorheben könne und andererseits das Manöver einen normalen Vorwand für das Treffen des Obersten deutschen Befehlshabers und des italienischen Befehlshabers liefere".

Wie nicht anders zu erwarten, stellte sich Hitler auf den gleichen Standpunkt wie sein Außenminister. Auf der anderen Seite nahmen auch die Italiener kein Wort zurück. Am 29. Juli erschien vielmehr Attolico bei Weizsäcker und teilte ihm mit, aus etlichen Telefongesprächen mit dem Grafen Ciano gehe hervor, „daß er bzw. der Duce doch an dem Konferenzgedanken hänge“. Nach wie vor gebe der - von Ribbentrop als „undenkbar“ bezeichnete - Entwurf des Kommuniqués für die Zusammenkunft am 4. August - „von Mussolini eigenhändig niedergeschrieben“, wie Attolico anmerkte - die Absichten des Duce am besten wieder. Ciano seinerseits habe ihn, Attolico, wissen lassen, „die Konferenzidee sei deswegen naheliegend, weil sie in einem Monat sich ganz von selbst aufdrängen werde“432. Mit dem letzten Satz sagten die Italiener ihren deutschen Verbündeten: In einem Monat werdet Ihr sehen, daß die Westmächte doch Ernst machen, und statt dann - vielleicht vergeblich - nach einem neuen „München“ suchen zu müssen, ist es doch klüger, eine München-Lösung der Polenkrise jetzt selbst vorzuschlagen. Unter den gegebenen Umständen kamen nun beide Seiten zu dem Schluß, daß es nicht genügte, Hitlers Reise nach Italien das Etikett "privat“ aufzukleben; es blieb nichts anderes übrig, als die Begegnung der beiden Diktatoren, die plötzlich zu einer für Berlin, doch auch für Rom höchst unangenehmen Demonstration von Zwietracht zwischen den Achsenpartnern zu werden drohte, ganz abzublasen. Da man sich aber nicht damit begnügen konnte, den jäh sichtbar gewordenen Riß in der „Achse“ bloß zu konstatieren, verständigte man sich darauf, daß die beiden Außenminister schnellstens versuchen sollten, die Beziehungen zwischen Rom und Berlin wieder zu ordnen. Für den 11. August wurde ein Treffen Ribbentrop-Ciano in Salzburg vereinbart.

Als der italienische Außenminister am 11. in Fuschl mit Ribbentrop und dann zweimal auch, am 12. und 13. August, auf dem Obersalzberg mit Hitler konferierte, kamen die Deutschen endlich, zwei Wochen vor dem Angriffsbefehl an die gegen Polen aufmarschierenden deutschen Armeen, mit der vollen Wahrheit heraus ${ }^{433}$. Ribbentrop teilte Ciano in dürren Worten

432 ADAP, D, 6, Nr. 737.

433 Documenti diplomatici Italiani (DDI), Serie 8, Bd. XIII, Nr. 1; ADAP, D, 7, Nr. 43, 47. 
mit, der „Führer" habe sich entschieden, Polen militärisch niederzuwerfen, und diese Entscheidung sei unwiderruflich. Selbst in seinem offiziellen Bericht an Mussolini konstatierte der italienische Außenminister "den irrationalen Willen zum Konflikt", den sein deutscher Gesprächspartner an den Tag lege, und in seinem Tagebuch notierte er: „Der Wille zum Krieg ist unerschütterlich. Er [Ribbentrop] weist jede Lösung zurück, die Deutschland Genugtuung geben und den Krieg vermeiden würde. Ich bin überzeugt, daß die Deutschen auch dann, wenn sie mehr bekämen, als sie verlangen, angreifen würden, weil sie vom Dämon der Zerstörung besessen sind." Verständnislos registrierte Ciano für den Duce, daß Ribbentrop in seiner Darstellung der Genesis des deutsch-polnischen Konflikts keine neuen Elemente geboten habe, sondern lediglich - wie im März nach der Besetzung Prags mit der Behauptung tschechischer Greueltaten - mit „dem bereits bekannten rabenschwarzen Bild von der Verfolgung der Deutschen in Polen und von der Kastration germanischer Männer durch polnische Soldateska“ operiere. „An neuen Fakten nichts!“ Im übrigen gehe der Reichsaußenminister von zwei Axiomen aus, über die man mit ihm nicht mehr diskutieren könne: 1.) Der Konflikt wird nicht allgemein werden; Europa wird bei der Zerquetschung Polens durch Deutschland untätig zuschauen. 2.) Wenn aber England und Frankreich doch intervenieren, ist es für sie unmöglich, Deutschland anzugreifen; am Ende ist der Sieg der totalitären Mächte sicher. „Ich wiederhole“, schrieb Ciano, „Diskussion darüber mit ihm unmöglich." Er, Ciano, habe klipp und klar bewiesen, daß nach allen Bedingungen der europäischen Politik eine Intervention der Westmächte unausweichlich sei. „Nichts zu machen! Ribbentrop verschließt sich in einfacher und klarer Negation: ,Meine Informationen und meine psychologische Kenntnis von England machen mich sicher, daß jede bewaffnete Intervention Englands auszuschließen ist."

Ribbentrops Hinweis auf seine „psychologische Kenntnis von England“ versah Graf Ciano mit einem spöttischen „sic!“, indes konnte der italienische Außenminister im weiteren Verlauf der Unterredung noch präziser als bisher feststellen, daß die deutsche Seite im Grunde sehr wohl mit dem Eingreifen Großbritanniens und Frankreichs rechnete, aber einer solchen Entwicklung eben mit Ruhe und Siegesgewißheit entgegensah. Als er z.B. daran erinnerte, daß man bisher doch immer einig gewesen sei, den großen Krieg erst in zwei oder drei Jahren zu führen, gab Ribbentrop das sofort zu, erwiderte jedoch, „daß eine neue Situation eingetreten sei, in der sich die Ereignisse überstürzen könnten“, in welchem Falle „Deutschland mit größter Entschiedenheit marschieren“" werde. Graf Ciano widersprach Ribbentrops Ansicht, der Zeitpunkt sei sehr günstig, energisch und nannte etliche Gründe dafür, daß es im Interesse der Achse liege, einen Konflikt jetzt noch zu vermeiden, aber der Reichsaußenminister verweigerte praktisch jede Erörterung auch dieses Punktes, und als Ciano den - von Mussolini gebilligten - Entwurf eines Kommuniqués für das Treffen der beiden Au- 
Benminister präsentierte, der zwar etwas vager formuliert war als jenes Kommuniqué, das die Italiener im Juli für die Begegnung Hitler-Mussolini vorgelegt hatten, doch ebenfalls deutlich Friedenswillen zum Ausdruck brachte, lehnte Ribbentrop rundweg ab. „Ich habe ihm“, so sagte Ciano, „lange und geduldig 1000 Gründe aufgezählt, die uns ein derartiges Vorgehen [d.h. ein derartiges Kommuniqué] als das opportunste und nützlichste annehmen ließen.“ Ohne Erfolg! „Verbohrt in seinen irrationalen Willen zum Krieg", habe Ribbentrop die italienische Initiative abzuwehren versucht, indem er sich nun wieder darauf zurückzog, ,wie eine Maschine und ohne plausible Begründung die beiden Sätze“ zu wiederholen, „daß der Konflikt lokalisiert bleiben werde und daß auch bei einem allgemeinen Konflikt der deutsche Sieg sicher sei“. Am Ende seines Berichts für den Duce schrieb Ciano: „Nach zehn Stunden Gesprächs mit Ribbentrop habe ich ihn mit der festen Überzeugung verlassen, daß er die Absicht hat, einen Konflikt zu provozieren, und daß er alle Initiativen zu einer friedlichen Lösung der Krise behindern wird."

Als er am 12. und 13. August mit Hitler selbst sprach, begegnete aber Graf Ciano einem noch stärkeren Kriegswillen als bei Ribbentrop. Der „Führer" nannte zudem, nachdem er sich zunächst ebenfalls über polnische Greuel und über das von ihnen provozierte Verlangen der deutschen Öffentlichkeit nach einem Krieg gegen Polen verbreitet hatte, den wahren Grund für seinen Entschluß zum Angriff: Polen stelle eine Bedrohung im Rücken Deutschlands und damit der Achse dar; selbst bei einer Politik der Zusammenarbeit und des Friedens mit Polen könne sich die Situation nicht grundlegend ändern, denn wenn eines Tages, wie das ganz unvermeidlich sei, Deutschland und Italien sich im Kampf gegen die Westmächte befänden, werde Polen dann eine Gelegenheit finden, Deutschland einen Stoß in die Flanke zu versetzen. In diesem Zusammenhang unterstrich Hitler - wie am Vortag Ribbentrop -, daß Italien doch vor dem gleichen Problem stehe, und zwar im Hinblick auf Jugoslawien. Daher müsse Italien, so sagte Hitler, die nächste Chance - also den deutschen Überfall auf Polen, hatte Ribbentrop erklärt - nutzen, um Jugoslawien „zu zerstükkeln, indem es Kroatien und Dalmatien besetzt“. Auf die Frage nach dem Zeitpunkt der deutschen Invasion in Polen antwortete Hitler ohne Umschweife, daß er spätestens Ende August losschlagen werde. Bei der Begründung des Termins genierte sich Hitler nicht, seinem italienischen Gast weismachen zu wollen, er habe genaue Informationen darüber, daß die Polen beabsichtigten, nach dem 15. Oktober Danzig zu besetzen und vielleicht sogar zu zerstören; ansonsten argumentierte er jedoch militärisch und wies darauf hin, daß angesichts der polnischen Straßenverhältnisse das nach dem 15. Oktober zu erwartende schlechte Herbstwetter größere Operationen von Panzern und motorisierter Infanterie unmöglich mache. Im übrigen sprach Ciano mit einem Manne, dem der Anlaß zum rechtzeitigen Überschreiten der polnischen Grenze offensichtlich nicht die geringsten 
Sorgen bereitete. Der Moment des Angriffs, so teilte Hitler dem italienischen Außenminister mit, werde nach einem „schwerwiegenden Zwischenfall" kommen oder nach einer erfolglosen deutschen Aufforderung an Polen, „seine politische Situation zu klären“ - welch vage Formulierung Ciano etwas ratlos ließ -, und wenn aus irgendwelchen Gründen weder das eine noch das andere eintrete, werde er, Hitler, eben „einen der vielen kleinen Zwischenfälle, die sich täglich in Danzig und im Korridor ereignen, als schwerwiegend ansehen".

Als Ciano auf die Möglichkeit britisch-französischer Hilfe für Polen hinwies, wischte Hitler den Einwand beiseite und bekräftigte die Versicherung Ribbentrops, daß der Konflikt lokalisiert bleiben werde: England und Frankreich würden gewiß sehr theatralische antideutsche Gesten machen, seien jedoch nicht fähig, Krieg zu führen, weil sie nicht genügend gerüstet hätten, ob es sich um die Waffen oder um den Geist handle. Als Ciano, der während beider Unterredungen Hitler wacker widerstand, daraufhin sagte, wie sehr ihn die ernsten Mitteilungen des „Führers“ und Ribbentrops überrascht hätten und daß zwischen Rom und Berlin doch eine mehrjährige Friedensperiode fest vereinbart worden sei, reagierte Hitler mit der Bemerkung, er stimme mit dem Duce nach wie vor darin überein, daß zwei oder drei - nicht mehr - weitere Vorbereitungsjahre nützlich gewesen wären, und er hätte diese Frist ja auch abgewartet, wenn die polnischen Provokationen und die Verschlechterung der Lage deutsches Handeln nicht dringlich machen würden. Um die Wirkung solch verräterischer Sätze abzuschwächen, setzte er eilends hinzu, daß das deutsche Vorgehen gegen Polen aber ohnehin keinen allgemeinen Krieg auslösen werde. Er sei daher sicher, keine italienische Hilfe verlangen zu müssen. Ciano nahm das zur Kenntnis und schrieb in sein Tagebuch: „Er hat beschlossen, zuzuschlagen, und er wird zuschlagen. Unsere Einwände vermögen ihn nicht im geringsten davon abzuhalten. Er wiederholt immer wieder, daß er den Krieg mit Polen lokalisieren wird; aber seine Behauptung, der große Krieg müsse geführt werden, so lange er und der Duce noch jung seien, bestärkt mich neuerdings in meiner Vermutung, daß er unaufrichtig ist." ${ }^{3} 34$ In der Unterredung selbst beantwortete Ciano Hitlers Versicherung, indem er - von der Bekundung seiner Überzeugung abgesehen, daß der „Führer“ diesmal nicht recht behalten werde - detailliert darlegte, warum es Italien vorziehen müsse, daß der allgemeine Konflikt „um den vereinbarten Zeitraum aufgeschoben" werde. Anschließend überreichte er nun auch Hitler ein Exemplar jenes Kommuniqués, das er am 11. bereits Ribbentrop gegeben hatte, und zwar mit dem Kommentar, der Duce müsse darauf bestehen, daß die Achsenmächte noch einmal öffentlich ihre Bereitschaft zu einer friedlichen Lösung der Spannungen bekräftigten. 
Es war alles vergebens. Hitlers Kriegswille zeigte sich in der Tat, wie Ciano konstatierte, keinem Argument mehr zugänglich, und da auf der anderen Seite auch der italienische Außenminister - obschon er nie eine Kündigung oder einen Bruch des „Stahl-Pakts“ ankündigte und am Rande einmal einräumte, der „Führer“, der schon so oft recht behalten habe, schätze möglicherweise auch jetzt die Haltung der Westmächte richtig ein - seinen Standpunkt nicht verließ, endete Cianos Besuch in Deutschland mit der beiderseitigen Erkenntnis, daß zwischen den Achsenpartnern eine im Augenblick nicht zu heilende Divergenz aufgebrochen sei. Hitler, Ribbentrop und Ciano sahen sich sogar, so peinlich das war, nicht imstande, irgendein gemeinsames Abschlußkommuniqué zu formulieren; angesichts ihrer totalen Uneinigkeit blieb ihnen nichts anderes übrig, als den Verzicht auf ein solches Kommuniqué zu vereinbaren und damit den deutsch-italienischen Zwist für alle Welt offenkundig zu machen.

Für Hitler und Ribbentrop stellte das negative Ergebnis der Gespräche in Fuschl und auf dem Obersalzberg sicherlich eine herbe Enttäuschung dar. Die ursprünglich vorgesehene Begegnung Führer-Duce hätte in deutschen Augen ja nicht zuletzt die Aufgabe erfüllen sollen, mit einer machtvollen Demonstration der Kriegsbereitschaft beider Partner des „StahlPakts“ die Westmächte gebührend zu beeindrucken, und obwohl die Umstände, die zur Ersetzung jener Begegnung durch ein Treffen der Außenminister geführt hatten, nichts Gutes verhießen, war in Berlin doch noch mit einem propagandistisch wenigstens einigermaßen verwertbaren Resultat auch des Ciano-Besuchs gerechnet worden. Statt dessen ein derart blamabler Fehlschlag, der in Paris und London, nachdem man ihn dort mit schadenfroher Aufmerksamkeit registriert hatte, sicherlich stimmungsbessernd wirken mußte! Und wenn man sich in Deutschland nach Cianos Abreise der Hoffnung hingab, zumindest den eigentlichen politischen $Z$ weck der Unterredungen mit dem italienischen Außenminister erreicht, nämlich der Konsultationsklausel des „Stahl-Pakts“ genügt und damit die Italiener wie immer sie über einen allgemeinen Krieg denken mochten - für den Ernstfall zur Bündnistreue verpflichtet zu haben, so entpuppte sich auch diese Hoffnung rasch als Illusion.

Hitler und Ribbentrop gaben den Italienern, die ihre nach den CianoGesprächen aufs höchste gesteigerte Nervosität freilich ohnehin zu intensivem Nachdenken über ihren künftigen Kurs zwang, selbst noch einen triftigen Grund, über Italiens Verhalten im Kriegsfall möglichst schnell Klarheit zu gewinnen und Klarheit zu vermitteln. Mit einer frechen Falschheit, wie sie unter Freunden und Verbündeten wahrlich selten ist, ignorierten sie die gemeinsame Vereinbarung über den Verzicht auf ein Kommuniqué und ließen am 13. August vom Deutschen Nachrichtenbüro eine „Amtliche Verlautbarung "veröffentlichen, in der Graf Cianos Besuch in Deutschland in der Tat als Erfüllung ,gegenseitiger Beratungspflicht und gegenseitigen Beratungsrechts auf Grund der bestehenden Freundschaft sowie auf 
Grund der formellen Abmachungen, die zwischen den beiden Ländern bestehen“, charakterisiert und in der überdies "die vollkommene Einmütigkeit Deutschlands und Italiens in der Außenpolitik“ - ausdrücklich auch auf Danzig und Polen bezogen - behauptet wurde 435 . Vermutlich glaubten Hitler und Ribbentrop, mit dieser Festlegung vor der internationalen Öffentlichkeit Italien das Ausscheren aus dem "Stahl-Pakt" tatsächlich unmöglich gemacht zu haben, zumal angesichts der persönlichen Eitelkeit und der sozusagen faschistischen Ehrsucht Mussolinis, die den Duce vor der Rolle des Schwächlings und des Verräters zurückscheuen lassen mußten; auch hofften sie wohl darauf, vor den Westmächten den Anschein deutsch-italienischer Einigkeit leidlich aufrechterhalten und damit den ursprünglichen propagandistischen Zweck der Zusammenkunft wenigstens partiell gerettet zu haben. In Wahrheit konnte das Manöver keine seiner taktischen Aufgaben erfüllen, mußte vielmehr - wie viele der Einfälle nationalsozialistischer Taktik, die ja überwiegend von totaler Rücksichtslosigkeit lebte - sofort auf die Erfinder zurückschlagen.

Selbstverständlich ließen sich die Politiker und Diplomaten Europas von der Verlautbarung nicht täuschen; sie waren für ihre Einschätzung der italienischen Politik nicht auf das D.N.B. angewiesen. Und die Italiener, überflüssigerweise verärgert, gereizt und vor allem zu postwendender Reaktion genötigt, beeilten sich jetzt erst recht, den "machiavellistischen“ Trick der Deutschen, wie Attolico schrieb, zu konterkarieren und genau das zu tun, „was Deutschland nicht will, nämlich jede nachträgliche Gutheißung verneinen: die Diskussion wieder aufnehmen“. Der Duce müsse dem Führer in einem Brief den "präzisen und kategorischen Willen Italiens“ entgegensetzen, d.h. im Augenblick erneut den Konferenz-Gedanken. Der Führer habe die Konferenz praktisch abgelehnt, aber nicht formell und nicht kategorisch. „Es ist notwendig, daß er es kategorisch und formell schriftlich tut. Er will die Konferenz nicht? Man denke an etwas anderes. Eine europäische diplomatische Aktion kann Warschau sehr wohl überzeugen, daß es in Verhandlungen mit Berlin eintreten muß. Eine solche Aktion festzulegen, ist alles andere als unmöglich, und man kann nicht - nur, weil man es sich in den Kopf gesetzt hat, was wirklich großer Männer und Länder unwürdig ist - einen europäischen Krieg entfesseln, der das Ende der Zivilisation bedeuten würde. Soll er den Mut haben, der Führer, schriftlich einen solchen Vorschlag abzulehnen." Italien müsse den Deutschen ferner abermals und schriftlich sagen, daß „Frankreich und England nicht umhin können, zu intervenieren“. Deutschland soll dann „das Gegenteil kategorisch und schriftlich versichern und die Verantwortung für seine Behauptung auf sich nehmen". Danach seien für Italien zwei Wege offen. Wenn es keinen Krieg wolle, so habe „es das heilige Recht dazu, weil es mündlich und schriftlich bereits wiederholt erklärt hat, daß es erst in drei oder vier Jahren 
fertig sein kann. Deutschland hat diese Gründe akzeptiert: also haben wir das Recht, wenn es jetzt den Krieg um jeden Preis will, es diesen allein führen zu lassen“. Wenn aber Italien dennoch bereit sei, Deutschland mit den Waffen zu unterstützen, so habe Berlin die Verpflichtung anzuerkennen, ,jene Mängel in unserer Bewaffnung zu beheben, die wir schon nachdrücklich aufgezeigt haben, und diese Vervollständigung muß vor unserem Kriegseintritt erfolgen“. Am Ende konstatierte Attolico: „Die diplomatische Schlacht um die Gleichwertigkeit der Rechte Italiens gegenüber Deutschland im Rahmen des Vertrages vom 22. Mai und in seinen Auswirkungen hat jetzt gerade begonnen. Es ist eine heilige Schlacht, und Italien wird siegen und damit den Frieden und die Zivilisation retten." 436

Attolico stellte solche Überlegungen am Abend des 13. August an, als ihm die D.N.B.-Verlautbarung vor Augen kam, und am 14. übermittelte er sie - nicht telegraphisch, sondern, weil er deutsches Mitlesen befürchtete, auf einem Sonderweg über das italienische Generalkonsulat in München nach Rom, wo er selbst, zur persönlichen Berichterstattung bei Mussolini, am 16. eintraf. Noch am 15. kam Graf Magistrati, Attolicos Stellvertreter, der auf Grund seiner Verwandtschaft und Freundschaft mit Ciano weit über seine dienstliche Stellung als Botschaftsrat hinaus Einfluß ausübte, in einer Aufzeichnung zu ganz ähnlichen Schlüssen wie der Botschafter ${ }^{437}$. Graf Ciano hatte aus Salzburg ohnehin einen festen Entschluß mitgebracht. In seinem Tagebuch schrieb er: „Ich kehre nach Rom zurück, angeekelt von Deutschland, von seinen Führern, von seiner Handlungsweise. Sie haben uns betrogen und belogen. Und heute sind sie im Begriff, uns in ein Abenteuer hineinzureißen, das wir nicht gewollt haben und das das Regime und das Land gefährdet. Das italienische Volk wird schaudern vor Schrekken, wenn es von dem Angriff auf Polen erfährt, und unter Umständen wird es sogar die Waffen gegen die Deutschen ergreifen wollen. Ich weiß nicht, ob ich Italien einen Sieg oder eine Niederlage Deutschlands wünschen soll, in Anbetracht des deutschen Verhaltens bin ich der Ansicht, daß wir die Hände frei haben, und ich schlage vor, entsprechend zu handeln und zu erklären, daß wir nicht die Absicht haben, uns an einem Krieg zu beteiligen, den wir weder gewollt noch heraufbeschworen haben.“438

Mussolini schwankte zunächst. Er sprach, nachdem ihn Ciano über den Kriegswillen Hitlers und Ribbentrops unterrichtet hatte, davon, daß es die „Ehre“ von ihm erfordere, „an der Seite Deutschlands zu marschieren“; dazu lockte ihn die kroatische und dalmatinische Beute, wie sie ihm von den deutschen Versuchern vor Augen gehalten worden war, schon sehr. Am Ende erwies sich aber die deutsche Spekulation auf die persönliche und die politische Eitelkeit Mussolinis ebenso als wirkungslos wie die Rei-

438 Graf Ciano, Tagebücher 1939-1943, S. 123. 
zung seiner imperialistischen Raublust. Mit den Berichten seiner Berliner Diplomaten bewaffnet, brachte Ciano den Duce in längeren Gesprächen dazu, wieder Vernunft walten zu lassen und der italienischen Außenpolitik einen Hauch von Seriosität zurückzugeben. So legte Mussolini am Tag nach Cianos Rückkehr aus Salzburg fest, daß Italiens „Trennung von Deutschland“, auch wenn dabei behutsam vorgegangen und ein schroffer Abbruch der Beziehungen vermieden werden müsse, nun vorzubereiten sei. Zwar verlor er Jugoslawien nicht völlig aus dem Blick. Noch sei es nicht gänzlich unmöglich, „daß die Demokratien einlenken“, sagte er. „In solchem Fall wäre es für uns nicht vorteilhaft, uns mit Deutschland zu überwerfen, da auch wir unseren Teil an der Beute bekommen müssen. Wir müssen also eine Lösung finden, die erlaubt: a) wenn die Demokratien angreifen, uns ,ehrenvoll' von den Deutschen zu lösen, b) wenn die Demokratien einlenken, die Gelegenheit zu benützen, um ein für allemal die Rechnung mit Belgrad zu begleichen. “439 Indes hoben derartige faschistisch-imperialistische Vorbehalte den grundlegenden Entschluß nicht auf, bei einer Intervention der Westmächte im unmittelbar bevorstehenden deutsch-polnischen Konflikt neutral zu bleiben, selbst wenn dies eine schwere Beschädigung der „Achse“ oder sogar ihr Ende zur Folge haben sollte, und da in Rom niemand ernstlich am Eingreifen Großbritanniens und Frankreichs zweifelte, spielten die jugoslawischen Aspirationen des Duce in der italienischen Politik praktisch nicht die geringste Rolle. Viel stärker fiel die alsbald auftauchende Befürchtung ins Gewicht, daß - angesichts der Entwicklung zwischen 1935 und 1939 - die internationale Position Italiens unter einem offenen Bruch mit Deutschland doch erheblich leiden würde. Mussolini, Ciano und ihre außenpolitischen Gehilfen gelangten daher zu der Auffassung, man dürfe sich nicht mit dem Versuch begnügen, Italien „ehrenvoll“ von Deutschland zu lösen, vielmehr stehe die italienische Diplomatie jetzt vor der noch schwierigeren Aufgabe, Berlin so zu behandeln, daß trotz der - unumgänglichen - Neutralität Italiens ein Zerbrechen der „Achse,, wenn irgend möglich - vermieden werde.

Zunächst mußte aber der Anschein deutsch-italienischer Übereinstimmung, wie ihn die D.N.B.-Verlautbarung zu erwecken suchte, zerstört und den deutschen Partnern der vielleicht tatsächlich entstandene Eindruck, sich die italienische Bundesgenossenschaft gesichert zu haben, genommen werden. Ein weiterer Grund für einen solchen Schritt lag darin, daß neben Staatssekretär v. Weizsäcker auch Abwehrchef Canaris die italienischen Freunde in Berlin mehrmals beschwor, Mussolini müsse ein deutliches „Nein“ zu den Plänen der Berliner Kriegspartei sagen; ein klares Wort aus Rom, daß Italien bei einem Krieg Deutschlands gegen die Westmächte neutral bleiben werde, sei möglicherweise das letzte Mittel, Hitler und Ribbentrop aus ihrer Verblendung zu reißen und innehalten zu lassen ${ }^{440}$. Wie439 Ebenda.

440 AIA, Ap Germania, Magistrati an Ciano, 16.8.1939. 
der in Deutschland, überreichte Attolico dem Reichsaußenminister am 18. August in Fuschl eine Note, die Mussolini bereits am 14. entworfen hatte. In der Note, die natürlich zur Weiterleitung an Hitler bestimmt war, hieß es nun in der Tat klipp und klar, daß Italien "- aus dem Reich wohlbekannten Gründen - sich im Augenblick nicht in derartig günstigen Umständen befindet, um vor dem Zeitpunkt, der in gemeinsamer Vereinbarung ins Auge gefaßt wurde, einen europäischen Krieg führen zu können“. Anschließend konstatierte der Duce zum soundsovielten Male, ein deutschpolnischer Konflikt könne nicht lokalisiert werden, und am Ende bekräftigte er erneut die Richtigkeit des Konferenz-Gedankens ${ }^{441}$.

Die Unterhaltung zwischen Attolico und Ribbentrop, die sich bei der Überreichung der Note entspann, glich in vieler Hinsicht der fruchtlosen Konfrontation von Standpunkten, die auch die Salzburger Gespräche Cianos charakterisiert hatte. Allerdings bemühte sich Attolico, jene zweite Möglichkeit der italienischen Diplomatie vorzubereiten, die er in seiner Aufzeichnung vom 14. August skizziert hatte und die tatsächlich die Bemäntelung der faktischen Neutralität Italiens erlauben mochte: Der Botschafter beschwor in lebhaften Worten die wirtschaftlichen Probleme Italiens, dessen hoher Bedarf an Rohstoffen bekanntlich über die im Kriegsfall so gefährdeten Schiffahrtswege gedeckt werden müsse; namentlich sei die Versorgung des Landes mit Kohle und Öl sicherzustellen. Ebenso eindringlich sprach er von den Schwächen der italienischen Luftabwehr und davon, wie schwierig es doch in der Praxis sei, von Deutschland Flak-Batterien zu bekommen. Es paßte zu Ribbentrop, daß er darauf mit einem Preislied auf die italienische Flotte antwortete, wogegen die englischen und französischen Schiffe doch ,im Grunde uralt" seien, und daß er außerdem auf die bald mögliche Ausbeutung polnischer Kohlereviere verwies; doch ging es selbst für seine Verhältnisse etwas weit, daß er mit großer Geste erklärte, er garantiere persönlich die Belieferung Italiens mit Öl, und daß er nicht minder großzügig versprach, sich selbstverständlich sofort um das FlakProblem zu kümmern. Auf Attolico machte er mit solchem Bombast freilich keinen Eindruck, und als der italienische Diplomat erwiderte, daß seine Bedenken mitnichten entkräftet seien, zog sich der Reichsaußenminister auf die entwaffnende Formel zurück, daß es in dem bevorstehenden Krieg weniger aufs Material ankomme als auf Führung: Es sei „undenkbar, daß Länder einen Krieg verlieren, die von Führer und Duce geführt werden“. Im übrigen mußte Attolico feststellen, daß sich Ribbentrop schließlich einfach weigerte, Sinn und Zweck der Botschaft Mussolinis zur Kenntnis zu nehmen. Nachdem der Botschafter am Ende der Unterredung gesagt hatte, er müsse darauf bestehen, daß der Duce mit der deutschen Beurteilung der Situation nicht einverstanden sei, gab sich Ribbentrop erstaunt: Er sehe nicht recht, worin das Fehlen der Übereinstimmung eigentlich be- 
stehe. Man sei sich in Berchtesgaden und Salzburg doch einig gewesen, behauptete er mit eiserner Stirn, und habe dort vereinbart, daß Rom der Beginn des Konflikts rechtzeitig mitgeteilt werde, damit Italien sich ebenfalls bereit machen könne ${ }^{442}$.

Am folgenden Tag hielten die Italiener den definitiven Beweis dafür in Händen, daß die Deutschen wirklich entschlossen waren, sich über jeden italienischen Einspruch hinwegzusetzen, ja daß die Führer des Reiches damit im Grunde bereits im Begriff standen, die Haltung und das Verhalten Italiens einfach zu ignorieren. Am 19. August wurde Attolico zu Ribbentrop bestellt, um die Antwort Hitlers auf Mussolinis Botschaft in Empfang zu nehmen, und diese Antwort des „Führers“ servierte dem Duce in brüsker Form eine Feststellung und drei Behauptungen, die weitere Gespräche praktisch ausschlossen. Erstens ließ Hitler wissen, daß die Entscheidung zum Angriff auf Polen getroffen sei und nicht mehr widerrufen werde. Zweitens informierte er Mussolini, daß der Feldzug in Polen lokalisiert bleiben werde, weil „England und Frankreich nicht wagen werden, die Achse anzugreifen“. Drittens belehrte er seinen römischen Freund, daß es, falls die Westmächte doch so verwegen sein sollten, Polen militärisch zu unterstützen, ,für die Achse schwer sein würde, jemals bessere Bedingungen für die Auseinandersetzung zu finden". Viertens prophezeite er, daß der Krieg, selbst wenn er „verallgemeinert“ werde, „angesichts der Übermacht der Achse nur von kurzer Dauer sein" werde ${ }^{443}$. Nun wußten die Italiener, daß ihnen tatsächlich nichts anderes mehr zu tun blieb, als auf dem eingeschlagenen Weg weiterzugehen und den Deutschen die italienische Neutralität so gut wie möglich zu verkaufen. Es galt, die Argumentation mit den wirtschaftlichen und militärischen Versorgungsnöten Italiens auszubauen, und Graf Magistrati hatte außerdem den gleichen brillanten Einfall wie sein Schwager in Rom: Selbstverständlich werde Italien den Verpflichtungen aus dem „Stahl-Pakt" nicht ausweichen, so sagten beide. Den Deutschen müsse eben klargemacht werden, daß gerade die wahre Bündnistreue den Verzicht Italiens auf jegliche militärische Aktivität erfordere, weil mit dieser militärischen Abstinenz eindeutig der größtmögliche Nutzen für die „Achse“ zu erzielen sei. Im übrigen seien die Deutschen davon zu überzeugen, daß die italienische Enthaltung nur vorläufig und daß für eine zweite Kriegsphase natürlich die militärische Intervention geplant sei444. Danach wurde der Begriff "Neutralität" von den Italienern in Acht und Bann getan. Daß Italien bei einem Eingreifen der Westmächte passiv bleiben werde, erfuhren die Deutschen aber sofort. Einen Tag, nachdem Attolico die Antwort Hitlers auf Mussolinis Botschaft bekommen hatte, erschien Magistrati bei Weizsäcker, um ihm, wenn auch etwas verklausuliert,

442 AIA, Ap Germania, Magistrati an Ciano, 19.8.1939.

443 DDI, 8, XIII, S. 73.

444 AIA, Ap Germania, Magistrati an Ciano, 23.8.1939. 
zu sagen, daß Italien, falls die Westmächte entgegen den deutschen Behauptungen und entsprechend den italienischen Warnungen zugunsten Polens eingreifen sollten, militärisch nichts unternehmen werde. Weizsäkker verstand seinen Besucher sehr gut und leitete seine Notiz über das Gespräch mit dem Kommentar an Ribbentrop weiter, daß Magistratis Mitteilung „meiner Ansicht nach entschieden beachtet werden muß“445.

Daß die NS-Führung die Haltung der Westmächte mittlerweile in der Tat mit jener arroganten Gleichgültigkeit betrachtete, mit der sie die italienischen Freunde erst entsetzte, dann erboste und schließlich zur Konzipierung einer Neutralitätspolitik nötigte, hatte mehrere Gründe. Anfänglich waren Hitler und Ribbentrop wohl tatsächlich überzeugt davon, daß Frankreich und Großbritannien weder willens noch - aus Mangel an mentaler und militärischer Vorbereitung - fähig seien, Polen zu Hilfe zu kommen, jedenfalls dann nicht, wenn der Abstand zwischen dem deutschen und dem westeuropäischen Rüstungsstand groß genug blieb, wenn ferner die deutsche Bündnispolitik - mit Italien und Japan oder mit Italien allein genügend Abschreckung bewirkte. So hatte sich Staatssekretär v. Weizsäkker am 15. April veranlaßt gesehen, in einen handschriftlichen Brief an den deutschen Botschafter in Rom, Hans-Georg v. Mackensen, einen Satz einzubauen, der nicht nur von Ironie triefte, sondern vor allem Mackensen vor Augen führen sollte, wie notwendig es sei, italienischen Widerspruch zu besorgen: „Es wird Sie interessieren“, schrieb Weizsäcker, „daß nach Ansicht von Herrn von Ribbentrop im Falle eines deutsch-polnischen Konflikts kein englischer Soldat mobilisiert werden würde." 446 Einige Monate später zeigte Weizsäcker aber in einem anderen Brief, daß zwar noch immer die gleiche Annahme ironisiert werden konnte, diese Annahme selbst jedoch zur rituellen Formel erstarrt war, hinter der keine wirkliche Überzeugung mehr stand. Als der deutsche Gesandte in Reval, Hans Frohwein, am 20. August berichtete, er habe in einem Gespräch mit dem stellvertretenden estnischen Außenminister der Hoffnung Ausdruck gegeben, „daß England und Frankreich in endlicher Einsicht der Konsequenzen dem wildgewordenen Polen unter Umständen doch Unterstützung versagen ... könnten " 447 , ermahnte der Staatssekretär den - in seiner tiefen Sorge zu wenig linientreu formulierenden - Gesandten, sich ,in Frage eines etwaigen Eingreifens Englands und Frankreichs“ einer „strengeren Sprache“ zu befleißigen: "Wir ... sagen vielmehr, daß wir ein Eingreifen der beiden Mächte nicht in Betracht zögen, weil diese dadurch ihren eigenen Bestand aufs Spiel setzen." 448

Zuviel war inzwischen geschehen, als daß man in Berlin an den Illusionen des Frühjahrs allzu lange hätte festhalten und auch noch im Sommer

445 ADAP, D, 7, Nr. 146.

446 ADAP, D, 6, Nr. 209.

447 ADAP, D, 7, Nr. 134.

448 Ebenda, Nr. 163. 
ernstlich an die Passivität der Westmächte hätte glauben können. Selbst Ribbentrop hat allmählich zur Einsicht kommen müssen, obwohl er sich der Wahrheit zweifellos länger verschloß als Hitler, der ja nicht mit der gleichen Borniertheit geschlagen war wie sein Außenminister und die Zeichen der Zeit früher erkannte. Da gab es nicht nur den einen festen und sicheren Orientierungspunkt, den die Westmächte in die politische Landschaft Europas setzten, indem sie die Unabhängigkeit potentieller Opfer des Dritten Reiches garantierten und sich damit unwiderruflich zum Schutz des europäischen Status quo verpflichteten. Zwei Tage vor der Garantie an Polen, am 29. März, hatte Premierminister Chamberlain bekanntgegeben, daß die britische „Territorial-Feldarmee“ von 13 auf 26 Divisionen verstärkt und daß außerdem die Ausrüstung dieser milizartigen Verbände dem Stand der Regulären Armee angeglichen werde449. Am 20. April, sieben Tage nach der Garantie an Rumänien und Griechenland, erfüllte der Premier eine Forderung, die von den Kritikern der Appeasement-Politik mit wachsender Ungeduld verfochten worden war, indem er endlich die Bildung eines sämtliche Rüstungsanstrengungen koordinierenden und intensivierenden „Ministeriums für Kriegslieferungen“ anordnete ${ }^{450}$. Sechs Tage später folgte die Verkündung der allgemeinen Wehrpflicht ${ }^{451}$; das britische Kabinett tat damit nicht nur einen dramatischen Schritt, sondern traf eine Maßnahme, die für britische Verhältnisse, so lange sich das Land nicht im Krieg befand, geradezu revolutionären Charakter hatte und selbst im Ersten Weltkrieg erst 1916 getroffen worden war. Zusammen mit energischen Versuchen zur quantitativen und qualitativen Verbesserung von Regulärer Armee, Luftwaffe und Marine, zusammen auch mit ständig steigenden Ausgaben für militärische Zwecke der unterschiedlichsten Art, sprachen solche Signale deutlich genug für die Ernsthaftigkeit der britischen Verteidigungsbereitschaft, zumal sich auf Grund der bislang geschehenen und der offensichtlich noch drohenden deutschen Gewaltakte auch in der britischen Bevölkerung eine Entschlossenheit zur Abwehr auszubreiten begann, die im Vorjahr gänzlich gefehlt hatte. Ähnlich entwickelten sich die Dinge in Frankreich.

Im übrigen haben Briten und Franzosen, sowohl öfentlich wie in den Kanzleien der Diplomaten, von April bis August auch oft genug gesagt, und zwar ohne die geringste Schwankung in der Stimme und ohne die leiseste Abschwächung der Botschaft, daß man auf eine erneute deutsche Grenzüberschreitung mit Krieg reagieren werde, gleichgültig wer das nächste Opfer sei und ob den Opfern sofort geholfen werden könne. Die deutsche Diplomatie, die damals in den wichtigeren europäischen Hauptstädten über erstrangige Missionschefs verfügte, verfolgte aufmerksam die prakti-

449 Archiv der Gegenwart 1939, Sp. 4003.

450 A. J. P. Taylor, English History 1914-1945, Oxford 1965, S. 445 f., 456.

451 Ebenda, S. 444. 
sche Präparation Westeuropas auf den drohenden Krieg, registrierte exakt den Stimmungsumschwung in den Westmächten und meldete beides ungeschminkt nach Berlin. So berichtete etwa der deutsche Botschafter in London, Herbert v. Dirksen, am 10. Juli, daß die Mehrheit der englischen Bevölkerung eine männliche Haltung einnehme und denke: „Wenn nun einmal der Krieg unvermeidlich ist, wollen wir ihn mit Entschlossenheit führen; je eher, desto besser, damit wir die Sache hinter uns haben und ruhigere Verhältnisse eintreten.“ Es lasse sich feststellen, „daß die Gegnerschaft gegen Deutschland im Zunehmen begriffen ist; daß die Kampfbereitschaft sich gehärtet hat; daß das Gefühl zugenommen hat, wir dürfen uns nichts mehr gefallen lassen, unsere Ehre ist im Spiel; wir müssen kämpfen; die Regierung darf nicht nachgeben“. Zu dieser Haltung, so kommentierte der Botschafter ohne Scheu vor dem Grimme Ribbentrops und Goebbels, ,haben die gemeldeten deutschen Pressestimmen über das dekadente England, über seine fehlende Bereitschaft, zu kämpfen, wesentlich beigetragen“. Dirksen schloß: „Der maßgebende Unterschied zwischen der englischen Stimmung im Herbst 1938 und jetzt ist der folgende: damals wollte die große Masse nicht kämpfen und war passiv; jetzt hat sie der Regierung gegenüber die Initiative übernommen und treibt das Kabinett vorwärts. “452

Die Führung des Dritten Reiches empfing die Botschaft aber auch direkt von den Regierungen der Westmächte. Am 13. April hatte z.B. der französische Ministerpräsident Daladier in einer Pressekonferenz mit großem Ernst die französische Zustimmung zu der britisch-polnischen Vereinbarung vom 6. April bekräftigt und mit Nachdruck auf das französisch-polnische Bündnis hingewiesen: „Frankreich und Polen garantieren sich unmittelbar und direkt gegen jede mittelbare oder unmittelbare Bedrohung ihrer lebenswichtigen Interessen." 453 Georges Bonnet, Außenminister Frankreichs und lange Zeit einer der namhaftesten und aktivsten französischen Appeaser, bat am 1. Juli den deutschen Botschafter in Paris zu sich, um $\mathrm{ihm}$ eine Note an die deutsche Regierung zu überreichen, in der es unzweideutig hieß: „Im vergangenen Dezember habe ich Herrn von Ribbentrop klar zum Ausdruck gebracht, daß die französisch-deutsche Erklärung übrigens im Einklang mit der Bestimmung des Artikels 3 - nicht als eine Beeinträchtigung der besonderen Beziehungen Frankreichs zu den osteuropäischen Ländern angesehen werden könne. Was insbesondere Polen anbetrifft, so haben die seit damals vorgekommenen Ereignisse das französische Bündnis verstärkt. In seiner Erklärung vom 13. April hat Herr Daladier eindeutig die Tragweite der Bindungen zwischen den beiden Ländern aufgezeigt. Ich lege Gewicht darauf, heute diese Bindungen der besonderen Aufmerksamkeit Herrn von Ribbentrops zu empfehlen und den unerschütter- 
lichen Willen Frankreichs, seine Verpflichtungen zu erfüllen und alle seine Kräfte in den Dienst des gegebenen Wortes zu stellen, scharf zu unterstreichen." Deutsche Unternehmungen, so endete Bonnet, die den bewaffneten Widerstand Polens auslösten, würden „das Französisch-Polnische Abkommen in Kraft setzen und Frankreich zwingen, Polen sofort Beistand zu leisten" 454 . Die gleiche Wahrheit hörten Hitler und Ribbentrop aus jeder ausländischen Hauptstadt, ob in Europa oder in Übersee, und in Berlin von jedem ausländischen Missionschef, mit dem sie sprachen, ob es sich um den argentinischen Botschafter handelte oder um den päpstlichen Nuntius. Die Italiener belegten ihre Überzeugung von der Londoner und Pariser Interventionsbereitschaft sogar mit Instruktionen des Foreign Office an den britischen Botschafter in Rom, die sie gestohlen hatten 455 .

Wenn sich die nationalsozialistischen Führer von alledem wenig beeindrucken ließen, so alsbald keineswegs mehr deshalb, weil sie den Warnungen nicht geglaubt hätten. Dazu waren die Informationen denn doch zu zahlreich, zu dicht, zu gleichförmig, zu eindeutig und zu plausibel; am Ende wären Hitler und Ribbentrop buchstäblich die einzigen mit Politik befaßten Europäer gewesen, die am Eingreifen Großbritanniens und Frankreichs noch gezweifelt hätten. Ihrer Haltung lag vielmehr in der Tat, wie sie den italienischen Partnern im Juli und August versicherten, die schiere Siegesgewißheit zugrunde. Prahlte Ribbentrop vor Attolico und Ciano von der Unangreifbarkeit der Achsenmächte und von der Zerstörung etwa doch intervenierender Westmächte, so gab er damit in der ihm eigenen Art tatsächlich einer Meinung Ausdruck, die ihn völlig beherrschte, zumal er sie von seinem „Führer" übernommen hatte, der diese Meinung lediglich nüchterner und in Gestalt eiskalten Kalküls präsentierte - auch in den diversen Ansprachen, die er von Mai bis August 1939 hielt, etwa vor den Spitzen des Militärs, wo er zur Beruhigung seiner Zuhörer zwar stets die Notwendigkeit der Isolierung Polens betonte, jedoch anschließend sogleich erläuterte, was bei einem Scheitern der Isolierungsversuche zu geschehen habe. Und im Ansatzpunkt entsprach ja auch Hitlers Kalkül, sofern man die Analyse auf die im Moment gegebene Situation beschränkte, durchaus der Wirklichkeit. Die Beobachtung der britischen und französischen Vorbereitungen, ob wirtschaftlicher oder militärischer Art, hatte ihn zu dem richtigen Schluß geführt, daß die Westmächte im Augenblick und noch für eine ganze Weile nur zu defensiver Kriegführung und zu ergänzenden Formen der wirtschaftlichen Kriegführung - etwa der Blockade Deutschlands und Italiens - imstande seien. Mit Fug und Recht folgerte er daraus, daß sie sein polnisches Unternehmen überhaupt nicht ernstlich zu stören vermöchten und er es sich ohne weiteres leisten könne, die deutsche Westgrenze - zumal dann, wenn es gelang, die Italiener bei der Stange zu halten 
und mit ihnen einen Teil der britisch-französischen Streitkräfte anderweitig zu beschäftigen - relativ schwach zu besetzen und die Masse des aktiven Feldheeres wie der Luftwaffe gegen Polen zu werfen. Nach Abschluß des Feldzugs in Polen konnte dann die Stoßarmee nach Westen verlegt werden, um so bald wie möglich Westeuropa anzufallen und zu erobern. Im Grunde, so erkannte der „Führer“ im Laufe des Frühjahrs und Sommers 1939 immer klarer, brachte die Erledigung des polnischen Problems nicht einmal eine nennenswerte oder gar beunruhigende Verschiebung der Termine seiner mittelfristigen Expansionsplanung mit sich, allenfalls eine gewisse - und Hitler bald offensichtlich nicht mehr unwillkommene - Beschleunigung des Ablaufs. Solche Überlegungen kamen der Berliner Kriegspartei naturgemäß um so realistischer vor, je deutlicher sich im gleichen Zeitraum abzeichnete, daß es gelingen werde, jene Waffe der Westmächte und namentlich Großbritanniens stumpf zu machen, die zunächst noch am ehesten gefürchtet werden mußte, nämlich die Blockade.

Am 12. August hatte sich Hitler während seines Gesprächs mit dem Grafen Ciano ein Telegramm bringen lassen, das nach seiner Behauptung aus der sowjetischen Hauptstadt stammte und die Mitteilung enthielt, „die Russen seien mit der Entsendung eines deutschen politischen Unterhändlers nach Moskau einverstanden“. Die deutsch-sowjetische Verständigung, mit Wissen und aktiver Unterstützung der Italiener seit Monaten gesucht, war mithin, so gab Hitler zu verstehen, in erreichbare Nähe gerückt, ja praktisch bereits gesichert ${ }^{456}$. Mit der kleinen Szene wollte der "Führer“ natürlich die so nervös gewordenen Römer beruhigen und ihnen mit einem Blick auf den Trumpf, den er gerade aus dem Ärmel ziehe und auf den Spieltisch der europäischen Politik knallen werde, Mut für den kommenden Konflikt machen. In der Sache hatte Hitler in diesem Falle jedoch nur wenig übertrieben. Zwar handelte es sich nicht um ein Telegramm, das aus Moskau gekommen wäre, sondern um eine bloße Nachricht aus dem Berliner Auswärtigen Amt, doch besagte die Nachricht in der Tat, daß der sowjetische Geschäftsträger in Berlin, Georgi Astachow, im Auftrag Wjatscheslaw Molotows, des Regierungschefs und Außenministers der Sowjetunion, an jenem 12. August im A.A. erschienen sei, um dort seinem mehrmaligen Gesprächspartner Julius Schnurre, dem Leiter des Referats OstEuropa in der Wirtschaftspolitischen Abteilung des Amts, zu eröffnen, daß man in Moskau an einer umfassenden Erörterung der zwischen Deutschland und der UdSSR schwebenden Fragen, ob wirtschaftlicher oder politischer Natur, interessiert sei, als Ort der Besprechungen Moskau vorschlage und es dabei der deutschen Seite anheimstelle, die Verhandlungen durch den deutschen Botschafter in Moskau ,oder eine andere zu entsendende Persönlichkeit" führen zu lassen ${ }^{457}$. Nach allem, was deutsche und sowjeti- 
sche Unterhändler in den vorhergegangenen Monaten und Wochen miteinander diskutiert hatten, dabei von mißtrauischer Unverbindlichkeit rasch zu unmißverständlicher Andeutung und alsbald zu unverhüllter Offenheit gelangend, machte Molotows Einladung nun klar, daß der sowjetische Diktator Josef Stalin das Ende der bloßen Fühlungnahmen für gekommen hielt, eine letzte Runde offizieller Verhandlungen wünschte und zum Abschluß deutsch-sowjetischer Verträge bereit war. Da andererseits Hitler mittlerweile ein wohl noch stärkeres Interesse an einer temporären Verständigung zwischen dem Deutschen Reich und der UdSSR hatte, stand also tatsächlich eine wahrhaft sensationelle Wendung im deutsch-sowjetischen Verhältnis bevor, eine Wendung überdies, die dem Anschein nach eine einschneidende und für Deutschland günstige Veränderung der europäischen Mächtekonstellation bewirken mußte.

Bis zum Münchner Abkommen vom 29. September 1938 hatte man in den Hauptstädten Europas den ideologisch-politischen Gegensatz zwischen Nationalsozialismus und Kommunismus, zwischen dem nationalsozialistischen Deutschland und dem kommunistischen Rußland als eine der festesten Größen europäischer Politik behandeln können. $Z$ war haben viele politische Beobachter durchaus erkannt, daß die nationalsozialistischen Führer des Deutschen Reiches die gegen Bolschewismus, Komintern und Sowjetunion gerichteten Tendenzen und Kampfparolen sehr wohl auch zu instrumentalisieren wußten, nämlich teils als Kitt, teils als Tarnung eines Allianzsystems, das weniger zur Abwehr der sowjetisch unterstützten Ausbreitung des Bolschewismus und des bolschewistischen Rußland bestimmt war, sondern mehr zur Förderung des nationalsozialistischen und des faschistischen Imperialismus. In einem Gespräch mit dem Grafen Ciano, am 24. Oktober 1936, hat Hitler selbst den Antibolschewismus als „das taktische Terrain" bezeichnet, auf dem sich neben der antisowjetischen zugleich eine aggressiv antiwestliche Bündnispolitik verfolgen lasse; zunächst komme es darauf an, vielen Ländern, welche zum Anschluß an Rom und Berlin geeignet seien, aber den deutschen und den italienischen Expansionismus fürchteten, die Angst vor einer Verbindung Deutschlands mit Italien zu nehmen, und das werde am besten dadurch erreicht, so meinte er, daß man ihnen "die italienisch-deutsche Union als Barriere gegen die innere und äußere bolschewistische Bedrohung" darstelle ${ }^{458}$. Der Antikominternpakt ist denn auch in diesem Sinne als ein Instrument der Sammlung und, wie Ciano ja in seinem Tagebuch anmerkte, als ein Vehikel antiwestlicher Politik benützt worden. Auf der anderen Seite war indes deutlich zu sehen, daß die ideologische Frontstellung gegen Kommunismus und Bolschewismus doch stets als ein wesentlicher Aspekt nationalsozialistischer Außenpolitik erhalten blieb, und nichts wies darauf hin, daß der ganz Europa wohlbekannte Appetit des Dritten Reiches auf osteuropäisches und 
nicht zuletzt russisches Territorium im Schwinden begriffen sei. So glaubte niemand damit rechnen zu müssen, daß die offensichtlich naturgegebene Feindschaft $z$ wischen Berlin und Moskau auch einmal von einem freundlicheren Verhältnis abgelöst werden könnte. Sogar der deutsch-sowjetische Handel war 1938 zu einem Rinnsal von jährlichen deutschen Exporten im Wert von 32 Millionen Reichsmark und von jährlichen deutschen Importen im Werte von 50 Millionen Reichsmark ausgetrocknet ${ }^{459}$.

Fast ganz Europa fand die deutsch-sowjetische Spannung recht nützlich. Die osteuropäischen Staaten, namentlich Polen, verzeichneten einen Gewinn an Sicherheit, weil sie die Sorge verloren, daß sich die beiden gefährlichen Großmächte auf ihre Kosten einigten, und in den westeuropäischen Staaten gelangten viele Politiker und Diplomaten, vor allem solche konservativer Couleur, entweder zu der Auffassung, daß man sich um dieses unheimliche kommunistische Rußland, weil es durch die deutsche Bedrohung neutralisiert sei, Gott sei dank überhaupt nicht mehr zu kümmern brauche, oder doch zu dem nicht minder angenehmen Schluß, daß man der mit Deutschland ohnehin tödlich verfeindeten UdSSR jedenfalls nicht den geringsten Preis für die Einreihung in diplomatisch-politische Fronten zum Containment des Dritten Reiches zahlen müsse. Letzere Ansicht zeichnete in Frankreich für die spielerisch-unernste Behandlung französisch-sowjetischer Bündnisprojekte und für den mangelnden Willen zur militärischen Konkretisierung der Projekte lange Zeit ebenso verantwortlich wie innenpolitische Rücksichtnahmen oder die Furcht davor, Hitler zu reizen, und in Großbritannien sahen die von antikommunistischen Konservativen geführten Kabinette Baldwin und Chamberlain, so wie die Dinge zwischen Berlin und Moskau standen, überhaupt keinen Grund mehr für eine Annäherung an die verhaßte und gefürchtete Sowjetunion und erhielten der europäischen Politik mit dem britisch-sowjetischen Gegensatz vorerst eine zweite feste Größe. Die Sowjetunion selbst befand sich dabei in einer etwas eigenartigen Position. In Moskau trauerte man der politisch, wirtschaftlich und militärisch so wertvollen Zusammenarbeit mit den konservativ-nationalen Kräften der Weimarer Republik nach. Der permanente Bürgerkrieg von oben, zu dem sich das bolschewistische System unter Stalin entwickelt hatte, machte außerdem die UdSSR zu einem politisch wie militärisch höchst verwundbaren Gebilde, und zwar schon ehe Stalin der Roten Armee jede Offensivkraft nahm, indem er 1937 und $1938 \mathrm{ihr}$ Offizierkorps schlimmer dezimierte, als es ein blutiger Krieg vermocht hätte, und indem er namentlich die höheren und mittleren Ränge nahezu komplett liquidieren ließ. Aus beiden Gründen hätten Stalin und seine außenpolitischen Berater den deutsch-sowjetischen Gegensatz nur zu gerne wieder begraben ${ }^{460}$. Da aber gelegentliche Fühler im nationalsozialistischen Berlin nicht das lei-

459 Aufzeichnung Wiehl, 6.2.1939, PAA, Büro Staatssekretär, Akten Rußland, 111284.

460 G. Weinberg, Germany and the Soviet Union, Leiden 1972. 
seste Echo weckten, blieb der Sowjetunion, die ihre Westgrenze ja auch im Hinblick auf die in Fernost entstandene japanische Bedrohung entlasten mußte, einige Jahre lang nichts anderes übrig, als Geschmack an den Prinzipien der kollektiven Sicherheit zu finden, in den zuvor wütend bekämpften Völkerbund einzutreten und in solchem Rahmen mit mäßigem Erfolg Versuche zum Paktieren mit den kapitalistischen Westmächten zu unternehmen, die Stalin mindestens ebenso als Feinde des kommunistischen Rußland betrachtete wie das nationalsozialistische Deutschland.

Das Münchner Abkommen und dann mehr noch die endgültige Liquidierung der Tschechoslowakei änderten jedoch die Dinge: erst für Hitler, anschließend für die Westmächte, schließlich auch und vor allem für die Sowjetunion. Als Hitler und Ribbentrop in den Monaten nach München einen Krieg gegen die Westmächte ins Auge zu fassen begannen, ergab sich daraus sofort und notwendigerweise die Wünschbarkeit wenigstens einer gewissen Verbesserung der deutsch-sowjetischen Beziehungen. Es kam dem „Führer“ dabei weniger darauf an, für die Dauer der Kämpfe im Westen die Rote Armee ruhig zu halten; in aller Welt - vermutlich auch in Rußland selbst - stimmten sämtliche militärischen Fachleute und sämtliche Politiker überein, daß Stalins „Säuberung“ die sowjetischen Streitkräfte tatsächlich der Fähigkeit zu offensiver Kriegführung beraubt hatte. Die Berliner Führungsgruppe dachte daher nicht sogleich an eine - innenpolitisch ja geradezu bedenkliche - Normalisierung des politischen Verhältnisses zwischen dem Deutschen Reich und der Sowjetunion. Wohl aber ließ die im Herbst 1938 mit Blick auf den Westkrieg beschlossene Forcierung der Rüstung die diversen Rohstoffe, die Rußland zu bieten hatte, in verlokkendstem Lichte erscheinen. Zumindest für eine Weile mußte die russische Wirtschaftskraft der militärischen Stärkung des Dritten Reiches dienstbar gemacht werden, und zunächst war es für die NS-Führung im Grunde eine sekundäre Frage, ob sich das solchermaßen gekräftigte Deutschland erst, wie nun vorgesehen, gegen den Westen oder doch schon gleich gegen den zeitweilig nützlichen östlichen Lieferanten wandte. So spielte Ribbentrop, der selbst die Konsequenzen der von ihm ebenfalls gewollten Entschlüsse Hitlers stets nur undeutlich erkannte, um die Jahreswende 1938/39 noch mit dem Gedanken, die Beziehungen zur Sowjetunion abzubrechen, weil er das offenbar für einen Köder hielt, mit dem Japan in den Militärpakt mit Deutschland und Italien zu locken sei, während Göring als oberster Wirtschafts- und Rüstungsboß bereits seit geraumer Zeit nachdrücklich eine Intensivierung des deutsch-sowjetischen Handels forderte ${ }^{461}$. Tatsächlich konnte zwischen Berlin und Moṣkau vereinbart werden, daß Julius Schnurre im Januar 1939 zu Wirtschaftsgesprächen nach Moskau kommen werde. Ein Querschuß Ribbentrops verhinderte jedoch die Reise Schnurres, und auch im Februar, als Graf Friedrich Werner 
von der Schulenburg, der deutsche Botschafter in Moskau, die Verhandlungen wieder aufnahm, und zwar direkt mit dem „Volkskommissar“ - d.h. Minister - für Außenhandel, Anastas Mikojan, blieben Resultate aus, weil sich auf deutscher Seite vorerst die Ansicht durchsetzte, daß man sich die russischen Rohstoffe - angesichts der Kreditwünsche Moskaus und angesichts des sowjetischen Verlangens nach ganz spezifischen Produkten der deutschen Industrie - eigentlich nicht leisten könne ${ }^{462}$. Es zeigte sich klar, daß ohne starke politische Motive nicht einmal der Handelsverkehr zwischen den beiden verfeindeten Mächten zu normalisieren war.

Mit der Besetzung Böhmens und Mährens und mit der bald danach getroffenen Entscheidung zum Angriff auf Polen stellten sich indes solche politischen Motive in Berlin ein. Zwar scheint Hitler, als er den Entschluß faßte, Polen militärisch auszuschalten und dabei auch gleich nach den baltischen Ländern zu greifen, im Moment bezeichnenderweise überhaupt keinen tieferen Gedanken an die möglichen Reaktionen der UdSSR verschwendet zu haben, aber die lebhafte diplomatische Aktivität, mit der die Westmächte jetzt auf die Bedrohung durch Deutschland antworteten, auch in Moskau, und die Überlegung, daß ein störungsfreier Ablauf der Kampagne in Polen immerhin angestrebt werden müsse, lenkten den Blick doch rasch auf die Sowjetunion. So hat Göring, der nun naturgemäß auch eine Chance witterte, der Beschaffung russischer Rohstoffe endlich näher zu kommen, am 16. April in Rom zu Mussolini gesagt, er „wolle den Führer fragen, ob man nicht durch gewisse Mittelsmänner vorsichtig bei Rußland mit dem Ziel einer Annäherung vorfühlen könne, um Polen dann auch mit Rußland zu beunruhigen" 463 . Das eigentliche politische Ziel bestand jedoch zunächst ganz simpel darin, den Anschluß der Sowjetunion an die unter britischer Führung offensichtlich entstehende Gruppierung feindlicher Mächte zu verhindern. Einige Wochen nach Görings Besuch in Rom herrschte innerhalb der NS-Führung bereits Einigkeit darüber, daß ein energischer Versuch gemacht werden müsse, die UdSSR und die Westmächte zu trennen; auch Ribbentrop war, wie er Anfang Mai während der Mailänder Konferenz zur Vorbereitung des „Stahl-Pakts“ dem Grafen Ciano auseinandersetzte ${ }^{464}$, für einen derartigen Versuch gewonnen, obschon er dem Effekt, den eine eventuelle deutsch-sowjetische Annäherung im strikt antisowjetischen Tokio haben mußte mit einigem Bangen entgegensah. Die Italiener nahmen die deutschen Überlegungen sehr freundlich auf. Mussolini, der sich später sogar für den Erfinder der Verständigung zwischen Berlin und Moskau hielt, riet zwar zu behutsamem Vorgehen und zur Einhaltung bestimmter Grenzen, einmal im Hinblick auf die Wirkung in Japan, zum anderen und vor allem im Hinblick auf den Schock, den

462 S. Hilger, Wir und der Kreml. Deutsch-sowjetische Beziehungen 1918-1941, Bonn 1964.

463 ADAP, D, 6, Nr. 211.

464 AIA, Ap Germania, Ciano an Mussolini, 7.5.1939. 
sonst die von Nationalsozialismus und Faschismus auf Antibolschewismus eingeübten eigenen Völker erleiden müßten. Aber als „petit jeu“, wie Mussolini zu Göring sagte, oder wenn „mit Diskretion und Sinn für Maß" verfolgt, wie Graf Ciano in Mailand zu Ribbentrop meinte, schien den Römern eine deutsche Politik, die einen Keil zwischen Westmächte und Sowjetunion trieb, durchaus richtig zu sein. Allerdings blieb in Berlin geraume Zeit unklar, wie man die Konkretisierung des guten Einfalls anzupacken habe, und so kam es auch zu keiner deutschen Initiative.

In London und Paris wiederum brach sich in der zweiten Aprilhälfte und im Laufe des Mai die Auffassung Bahn, daß die Haltung der Sowjetunion in einem Konflikt zwischen dem Dritten Reich und den Westmächten, der von einem deutschen Angriff auf Polen provoziert werde, sicher gemacht werden müsse. Es konnte nicht - wie bei Einleitung der Politik der Garantien angenommen - genügen, auf die naturgegebene Feindschaft zwischen dem nationalsozialistischen Deutschland und dem bolschewistischen Rußland zu bauen und, davon ausgehend, bei deutschem Ausgreifen nach Ostund Südosteuropa zumindest die wohlwollende Neutralität der Sowjetunion - verbunden mit materieller Unterstützung der Opfer deutscher Aggression - einfach zu unterstellen. Eine diplomatisch-politische Front zum Containment des deutschen Expansionismus mußte in Berlin doch sehr viel abschreckender wirken, wenn sich die Sowjetunion, statt im Hintergrund zu bleiben, offen in sie einreihte, und versagte die Abschreckung, mußten die militärischen Chancen einer Anti-Hitler-Koalition - mochte die Rote Armee noch so geschwächt sein - immerhin besser sein, wenn ihr die Sowjetunion als aktiver Partner angehörte. Gewiß gab es da das Problem der polnischen oder rumänischen Furcht vor sowjetischer Bundesgenossenschaft, und es war nicht recht zu sehen, wie man diese Schwierigkeit ausräumen sollte. Ebenso hemmend wirkte die eigene Abneigung gegen den Bolschewismus und das eigene Mißtrauen gegen ein von Bolschewiki geführtes Rußland. Nicht allein Premierminister Chamberlain, sondern ein Großteil der konservativen und bürgerlichen Politiker und Diplomaten in Großbritannien wie auch in Frankreich blickten einem eventuellen Bündnis zwischen ihren Ländern und der Sowjetunion mit einem Widerwillen entgegen, der Verhandlungen mit Moskau nicht förderlich sein konnte. Bald kamen noch andere Hindernisse in Sicht. Gleichwohl gehorchten die Regierungen in London und Paris der Notwendigkeit. Am 8. Mai schlug das britische Kabinett der sowjetischen Regierung vor, sich der Politik der Garantien, mit der sich die Westmächte zur Abwehr weiterer Verletzungen des europäischen Status quo verpflichtet hatten, durch eine öffentliche Erklärung anzuschließen 465 , und am 25. Mai gingen Großbritannien und Frankreich noch einen großen Schritt weiter, indem sie Stalin einen förmlichen Beistandspakt $z$ wischen den Westmächten und der UdSSR offerier- 
ten466. Über den westlichen Entwurf für einen solchen Pakt, über einen sowjetischen Gegenentwurf und über einen neuen britisch-französischen Entwurf setzten dann auch Verhandlungen ein, für die Chamberlain am 8. Juni - charakteristisch für den Mangel an Enthusiasmus, mit dem er und andere das Allianzprojekt behandelten - einen zwar sehr fähigen, doch nicht gerade besonders hochrangigen Unterhändler nach Moskau schickte, nämlich den Leiter der Mitteleuropa-Abteilung im Foreign Office, Sir William Strang.

$\mathrm{Zu}$ diesem Zeitpunkt orientierte man sich im Kreml aber ohnehin bereits an ganz anderen Visionen. Die im Münchner Abkommen gipfelnde Appeasement-Politik der Westmächte hatte die sowjetischen Führer zweifellos schockiert und verstört. München bedeutete den Ausschluß der Sowjetunion von der Regelung kontinentaleuropäischer Fragen, und nach dem Willen der im Münchner „Führerbau“ konferierenden Politiker war der Ausschluß offenbar als Dauerzustand gemeint. Indem das Abkommen immerhin eine gewisse deutsche Expansion in östliche Richtung erlaubte und zugleich den Weg zur wirtschaftlichen wie politischen Dominanz Deutschlands in Mittel- und Südosteuropa öffnete, verringerte es außerdem die Sicherheit der Sowjetunion; jedenfalls war der nach eigenem Anspruch tödlichste Feind der UdSSR erheblich gekräftigt worden. Jene Außenpolitik, die das Heil der Sowjetunion im System der kollektiven Sicherheit und in der Verbindung mit den Westmächten gesucht hatte, mußte zumindest als böse diskreditiert gelten, zumal nun der Verdacht an Plausibilität gewann, Großbritannien und Frankreich seien darauf aus, den deutschen Expansionismus auch künftig nach Osten und nicht zuletzt gegen das verhaßte bolschewistische Rußland abzulenken. Unter den gegebenen Umständen lag es für Stalin und seine Berater sogar nahe, Überlegungen anzustellen, ob nicht doch die Möglichkeit einer direkten Verständigung mit dem plötzlich so stark und gefährlich gewordenen Deutschland bestand.

Wenn sie den miserablen Stand der deutsch-sowjetischen Beziehungen und dessen Ursachen bedachten, nämlich die antibolschewistische ideologische Grundorientierung und die bekanntermaßen vornehmlich auf Osteuropa zielende expansionistische Grundtendenz des nationalsozialistischen Deutschland, konnte es ihnen freilich nur als nahezu hoffnungslos erscheinen, die deutsche Gefahr ausgerechnet durch Annäherung an Deutschland entschärfen zu wollen. Daher verbot es sich, aus München sofort allzu sichtbare Konsequenzen zu ziehen. Zunächst hatte sich die Sowjetunion wie zuvor als eine Macht zu gerieren, die gleich den westlichen Demokratien auf Abwehr der faschistischen „Aggressoren“ eingeschworen und immer noch für eine energische Politik des Widerstands zu haben sei. So blieb die Sprache der Sowjetunion, ob in der Diplomatie oder in Presse und Rundfunk, fast unverändert demokratienfreundlich und achsenfeind- 
lich, auch fehlte es nicht an Gesten, die bekunden sollten, daß in Moskau nach wie vor die Neigung zur Gemeinsamkeit mit den Westmächten dominiere. Am 9. Februar 1939 empfing Iwan Maiski, der sowjetische Botschafter in London, einige prominente britische Politiker zum Lunch. Als einer der Gäste, Harold Nicolson, auf die Frage Maiskis - es war bereits etlicher Wodka geflossen -, wie es denn nun in Europa weitergehe, scherzhaft antwortete, die Sowjetunion werde sich wohl demnächst gezwungen sehen, dem Antikominternpakt beizutreten, sagte der Botschafter, daß Rußland durch München gewiß tief verletzt worden sei und daß man im Westen nicht mehr mit sowjetischen Avancen rechnen dürfe: „Wenn aber (und hier wurde er ernst)“, notierte Nicolson, „wir Annäherungsversuche machen sollten, würden wir Rußland nicht so distanziert oder gekränkt finden, wie wir vielleicht angenommen hätten." 467 Auf der anderen Seite hielt man es im Kreml offenbar für angezeigt - und jedenfalls für unschädlich -, Berlin doch einmal ein Signal zu geben, daß die Sowjetunion nicht mit unzerreißbaren Banden an die Westmächte gefesselt sei.

Auf der ersten Sitzung des 18. Parteikongresses der KPdSU machte Stalin am 10. März in seinem Rechenschaftsbericht Ausführungen zur sowjetischen Außenpolitik, die politische Beobachter in aller Welt und in der Tat nicht zuletzt die deutschen Diplomaten aufhorchen ließen. Nachdem er konstatiert hatte, daß die kapitalistischen Staaten einen Ausweg aus ihren Krisen in einem „zweiten imperialistischen Krieg“ suchten, in einem Krieg, der durch die „Angreiferstaaten“ bereits von China bis Spanien entfesselt sei, fuhr Stalin fort, der Kampf der Angreiferstaaten richte sich gegen die Interessen Englands, Frankreichs und der Vereinigten Staaten, die ihrerseits den Angreifern Konzession um Konzession schenkten. Die Schwäche der demokratischen Mächte erkläre sich, abgesehen von ihrer Furcht vor revolutionären Entwicklungen im Falle eines neuen Krieges, in erster Linie daraus, daß sie das Prinzip der kollektiven Sicherheit aufgegeben hätten und zu einer Politik der Nichteinmischung und der Neutralität übergegangen seien. Dieser Politik liege der Wunsch zugrunde, die Angreiferstaaten auf andere Opfer abzulenken. Solche Versuche müßten aber nicht unbedingt gelingen, implizierte der sowjetische Diktator und attakkierte dann jene britischen, französischen und amerikanischen Zeitungen, die da lautstark behauptet hätten, die Deutschen würden, nachdem nun die Karpatho-Ukraine in ihrem Machtbereich liege, bis zum Frühjahr 1939 auch noch die Sowjet-Ukraine in Besitz nehmen: „Es sieht so aus, daß dieser verdächtige Lärm den Zweck verfolgt hat, Wut der Sowjetunion gegen Deutschland zu erzeugen, die Atmosphäre zu vergiften und ohne sichtbare Gründe einen Konflikt mit Deutschland zu provozieren." Natürlich erklärte Stalin, daß man in der Sowjetunion die Drohungen der Angreifer nicht fürchte und bereit sei, jeden Schlag der Kriegstreiber, die sich gegen 
die Unantastbarkeit der Sowjetgrenzen zu wenden suchten, mit einem Doppelschlag zu beantworten, doch formulierte er anschließend zwei Grundsätze sowjetischer Außenpolitik, die in westlichen Ohren noch feindseliger und in deutschen Ohren noch einladender klingen mußten als die bisherigen Passagen seiner Rede: Erstens werde die KPdSU ,auch weiterhin eine Politik des Friedens und der Festigung der geschäftlichen Verbindungen mit allen Ländern"verfolgen, zweitens werde die KPdSU Vorsicht ualten „und unser Land nicbt in Konflikte durch Kriegstreiber bineinzieben lassen, die gewobnt sind, sich von anderen die Kastanien aus dem Feuer bolen $z u$ lassen' 468 .

Der Kreml gab noch weitere Zeichen. Am 18. März reagierte auch die Sowjetunion mit einer formellen Note auf die Zerschlagung der Tschechoslowakei und die Annexion Böhmens und Mährens. Aber anders als die am gleichen Tag in Berlin überreichten Noten der Westmächte enthielt das sowjetische Schriftstück, das auch bezeichnenderweise nur der deutschen Botschaft in Moskau zugestellt wurde, keinen Protest gegen das deutsche Vorgehen, sondern brachte lediglich zum Ausdruck, daß die sowjetische Regierung die Einverleibung des geschaffenen Protektorats und praktisch auch der Slowakei in das Deutsche Reich nicht anerkennen könne ${ }^{469}$. In einer Unterhaltung mit Graf Schulenburg begründete Außenkommissar Litwinow den sowjetischen Schritt ausdrücklich damit, daß die Sowjetunion angesichts der britisch-französischen Aktivität nicht habe passiv bleiben können, und er hob außerdem den Unterschied zwischen Protest und bloßer Nichtanerkennung hervor. Auf Schulenburgs Frage nach der praktischen Bedeutung der sowjetischen Note antwortete Litwinow mit der gleichen betonten Gleichgültigkeit, „die Sowjetregierung habe eben ihren Standpunkt klarstellen wollen" 470 . Etwa zur gleichen Zeit sagte Litwinow zur Frau des japanischen Botschafters in Moskau, Togo, er wisse genau, daß die Verhandlungen zwischen Japan und den Achsenmächten über ein deutsch-italienisch-japanisches Militärbündnis in erster Linie an der gegenwärtig vornehmlich antiwestlichen Haltung Deutschlands und Italiens gescheitert seien, und an diese an sich schon bemerkenswerte Äußerung knüpfte Litwinow die noch bemerkenswertere Prophezeiung, Deutschland und Italien ständen im Begriff, ,ihr Verhältnis zur Sowjetunion zu arrangieren“. Da der sowjetische Außenkommissar selbstverständlich genau wußte, daß seine Sätze den Weg zur deutschen Moskauer Botschaft finden würden, kam seine Prophezeiung einem Wink an die deutsche Adresse gleich, ein solches Arrangement zwischen UdSSR und Achsenmächten sei, was die sowjetische Seite betreffe, durchaus möglich. Tatsächlich hat Frau Togo ihr Gespräch mit Litwinow „unter dem Siegel tiefster Verschwiegenheit“ 
sogleich Botschaftsrat Werner v. Tippelskirch erzählt, der mit Recht kommentierte, man könne ,an derartigen Beobachtungen nicht vorübergehen" 471 . Einige Wochen später, am 4. April, nahm die sowjetische Nachrichtenagentur TASS zu Meldungen in der französischen Presse, die Sowjetunion habe sich verpflichtet oder werde sich verpflichten, ,im Kriegsfall Polen mit Kriegsmaterial zu versorgen und ihren Rohstoffmarkt für Deutschland zu sperren“, folgendermaßen Stellung: „Die TASS ist ermächtigt zu erklären, daß diese Meldung nicht den Tatsachen entspricht, da die Sowjetunion niemandem solche Versprechungen gegeben und keine solchen Verpflichtungen übernommen hat."

Indes blieben die sowjetischen Signale in den Märzwochen notwendigerweise noch vage. Die Situation und ihre Entwicklung waren undurchschaubar, und es galt, sich alle Optionen offenzuhalten. So durfte es Stalin nicht riskieren, durch eine verfrühte - sichtbare - Hinwendung zu Deutschland die dann womöglich resignierenden Westmächte zu einer Fortsetzung ihrer Appeasement-Politik zu veranlassen; damit hätte er selbst dazu beigetragen, Hitler tatsächlich freie Hand im Osten zu verschaffen. Von den letzten Tagen des März bis Mitte April muß es jedoch im Kreml zu einem Klärungsprozeß gekommen sein, der zu einer eindeutigen sowjetischen Präferenz führte. In diesen fünfzehn Tagen bekam Stalin nämlich für seine künftige Außenpolitik zwei feste Orientierungspunkte geliefert. Erstens: Nachdem er - nicht zuletzt durch den in Tokio postierten sowjetischen Spitzenagenten Dr. Richard Sorge - schon vom Stand der deutsch-japanischen Verhandlungen und von der daran ablesbaren temporären Westschwenkung des nationalsozialistischen Expansionismus Kenntnis erhalten hatte, freilich ohne dabei in die Berliner Entscheidungsprozesse genauer eingeweiht zu sein und Sicherheit über die deutschen Pläne zu haben, erhielt er jetzt - und zwar vor allem durch einen der unmittelbar Beteiligten, den in Warschau stationierten und mit Botschafter v. Moltke befreundeten Legationsrat Rudolf v. Scheliha - zuverlässige, exakte und detaillierte Informationen über die Wende im deutsch-polnischen Verhältnis und über die deutsche Absicht, Polen demnächst militärisch auszuschalten ${ }^{472}$. Zweitens: Mit den Polen, Rumänien und Griechenland gegebenen Garantien machten gleichzeitig die Westmächte klar, daß sie, weit davon entfernt, die Appeasement-Politik fortsetzen zu wollen, entschlossen seien, die nächste deutsche Grenzüberschreitung mit ihrer militärischen Intervention zu beantworten.

Diese beiden neuen Fixpunkte der europäischen Lage eröffneten aber der sowjetischen Politik, so wie Stalin die Dinge offenbar sah, die erfreulichsten Aussichten. Die britisch-französische Politik der Garantien - und

471 Ebenda, Nr. 51.

472 F. W. Deakin / G. R. Storry, The Case of Richard Sorge, London 1966; Weinberg, The Foreign Policy of Hitler,s Germany, S. 533. 
hierin lag ihre eigentliche und wichtigste Wirkung - befreite die sowjetische Führung von der bislang stets lebendigen Furcht, das kapitalistische Westeuropa könne, um sich selbst Ruhe zu erkaufen und dabei gleich noch den Bolschewismus auszutilgen, der Aggressivität des nationalsozialistischen Deutschland wirklich die Bahn nach Osten freigeben oder die $\mathrm{Ag}$ gressivität gar auf die Sowjetunion hetzen. Nun stand definitiv fest, daß Hitler die von ihm gewünschte „freie Hand im Osten“ eben nicht bekommen werde. Statt dessen bot sich ganz im Gegenteil plötzlich Moskau die vielleicht einmalige - Chance, den deutschen Expansionismus nach Westen zu lenken und in einem sicherlich langwierigen Konflikt mit den Westmächten zu erschöpfen. Es war lediglich nötig, daß Hitlers Entschluß zum Überfall auf Polen, der nun den Krieg Deutschlands mit Großbritannien und Frankreich automatisch auslöste, stabil blieb, und dazu konnte die sowjetische Politik einen gewichtigen Beitrag leisten. So durfte sich die Sowjetunion der von London angestrebten diplomatisch-politischen AntiHitler-Koalition, die den „Führer“, wenn sie komplettiert wurde, wirklich abschrecken mochte, naturgemäß nicht anschließen. Vielmehr kam es darauf an, den "Führer" noch zu ermuntern, am besten durch eine sowjetischdeutsche Verständigung, die Deutschland für den Kriegsfall die wohlwollende Neutralität der Sowjetunion verhieß. Daß angesichts der deutschen Absicht zum Angriff auf Polen und angesichts des damit einzugehenden Risikos eines Krieges gegen die Westmächte zum ersten Mal seit 1933 ein starkes deutsches Interesse an einer zumindest temporären deutsch-sowjetischen Entspannung bestand, hat Stalin jetzt ohne weiteres unterstellen können.

Tatsächlich mußte Hitlers Interesse an Rückenfreiheit so groß sein, daß zusätzlich zur Fesselung Deutschlands im Westen sogar die Möglichkeit auftauchte, für die wohlwollende Neutralität - und die mit ihr verbundene großzügige Wirtschaftshilfe - einen vom Dritten Reich unmittelbar und sofort zu zahlenden Preis einzustreichen. Mit anderen Worten: In Stalin setzte sich die Vorstellung fest, daß ihm die von Hitler geschaffene Situation eine grandiose Chance bescherte, der Verwirklichung eigener - an zaristischen Vorbildern orientierter - imperialer Träume näherzukommen; zunächst sollte es wenigstens gelingen, in Kooperation mit dem Dritten Reich jene Territorien zurückzuholen, die dem durch Krieg, Revolution und Bürgerkrieg geschwächten Rußland zwischen 1917 und Ende 1920 abgenommen worden waren, von Finnland über die baltischen Staaten und das östliche Polen bis zum rumänischen Bessarabien. Gelang es, die Hand aufs Baltikum zu legen und mit Deutschland Polen zu teilen, entstand zwar - und das war ein an sich durchaus beunruhigender Gedanke - eine gemeinsame deutsch-russische Grenze. Aber im Hinblick auf die zugleich bewirkte Verstrickung des gefährlichen westlichen Nachbarn in einen Krieg mit den Westmächten schien man sich die ansonsten bedenkliche Nähe leisten zu dürfen. Bedachte man die Erschöpfung, die ein langer und bluti- 
ger Krieg zwischen Deutschland und den Westmächten beiden Seiten bringen würde, wirkte es ja nicht einmal mehr unrealistisch, wenn man darauf spekulierte, diese Erschöpfung für weitere imperialistische Vorstöße auszunutzen.

$\mathrm{Daß}$ im übrigen die Westmächte nicht bereit waren, den sowjetischen Eintritt in die Anti-Hitler-Koalition mit der Zustimmung zu der plötzlich realisierbar erscheinenden Befriedigung des russischen Revisionismus zu honorieren, war ebenfalls bereits zwischen Mitte März und Mitte April klar genug geworden, als Frankreich und namentlich Großbritannien - trotz ihrer nach Hitlers Prager Coup akuten Ängste vor neuen deutschen Streichen - eine irritierende und aus Moskauer Sicht politisch gänzlich unbrauchbare Neigung an den Tag gelegt hatten, auf die baltische, polnische und rumänische Furcht vor der sowjetischen Bundesgenossenschaft Rücksicht zu nehmen. Für derlei Geschäfte brauchte Stalin offenkundig Partner mit der gleichen Skrupellosigkeit und der gleichen Menschenverachtung, über die er selbst gebot, eben Partner wie die nationalsozialistischen Herren Deutschlands. Zwar konnte er die Verhandlungen mit den Westmächten nicht einfach abbrechen oder einschlafen lassen; sie mußten vielmehr - bis der deutsche Fisch an der Angel hing - mit jenem Maß an Eifer fortgesetzt werden, das einen Abschluß als jederzeit möglich aussehen ließ; ansonsten wäre ja Hitler der Notwendigkeit enthoben gewesen, auf sowjetische Avancen einzugehen. Aber von dieser taktischen Funktion abgesehen, besaßen die Gespräche mit den Westmächten für Stalin seit Mitte April keine ernsthafte Bedeutung mehr. Initiativen, Mühen und den beharrlichen Willen zum Erfolg investierte die sowjetische Führung vielmehr in die Realisierung der deutschen Option.

Am 17. April suchte der sowjetische Botschafter in Berlin, Alexei Merekalow, Staatssekretär v. Weizsäcker auf, und zwar zum ersten Mal seit er am 13. Juli 1938 Hitler sein Beglaubigungsschreiben überreicht hatte. Als offiziellen Grund für seinen Besuch nannte er, wenig überzeugend, eine handelspolitische Nichtigkeit. Bald lenkte er das Gespräch auf Politik und erkundigte sich nach dem deutsch-polnischen Verhältnis, speziell nach angeblichen militärischen Zusammenstößen an der deutsch-polnischen Grenze. „Nachdem ich letztere dementiert und über die deutsch-polnischen Beziehungen einige ziemlich gelassene Bemerkungen gemacht hatte“, so berichtete Weizsäcker, „fragte der Russe mich unverblümt, was ich von dem deutsch-russischen Verhältnis hielte“. Der Staatssekretär antwortete zurückhaltend mit dem Hinweis auf den deutschen Wunsch nach einem befriedigenden Handelsverkehr zwischen den beiden Staaten. „Der Botschafter erklärte hierauf etwa folgendes: Die russische Politik sei immer geradlinig gewesen. Ideologische Meinungsverschiedenheiten hätten das russisch-italienische Verhältnis kaum beeinträchtigt und brauchten es auch Deutschland gegenüber nicht zu stören. Sowjetrußland habe die jetzigen Reibereien zwischen Deutschland und den westlichen Demokratien nicht 
gegen uns ausgenützt und wünsche das auch nicht zu tun. Es bestehe für Rußland kein Grund, warum es nicht mit uns auf einem normalen Fuße leben sollte. Aus normalen Beziehungen könnten auch wachsend bessere werden.“ Weizsäcker schloß seine Aufzeichnung: „Mit dieser Bemerkung, auf welche der Russe die Unterhaltung hingeführt hatte, beendete Herr Merekalow das Gespräch. Er hat die Absicht, in den nächsten Tagen zu einem Besuch nach Moskau zu reisen." 473

In Anbetracht der $z$ wischen den beiden Ideologien und Regimen bestehenden Todfeindschaft, in Anbetracht auch der nach wie vor laut bekundeten sowjetischen Zustimmung zu dem achsenfeindlichen Vorzeichen, unter dem die gleichzeitig und sichtbar geführten Bündnisgespräche zwischen Moskau und den Westmächten standen, war Merekalows Sprache ein geradezu schrilles Signal. Doch machte der Kreml seine neue Präferenz alsbald noch sehr viel deutlicher. Am 3. Mai verlor Litwinow sein Amt als Außenkommissar und wurde von Regierungschef Molotow abgelöst. Der jüdische und - ob zu Recht oder zu Unrecht - als überzeugter Verfechter einer westlich orientierten Politik der kollektiven Sicherheit geltende Funktionär hatte also einem Manne weichen müssen, der nicht nur als besonderer Vertrauter Stalins, sondern vor allem als gleichsam „russischer" erschien; das Revirement konnte mithin als Teil einer gewissen Entideologisierung der sowjetischen Politik und ihrer Rückkehr zur simplen Vertretung begrenzter russischer Interessen ausgegeben und verstanden werden, in solchem Rahmen dann als erster Schritt der Abkehr von der Kooperation mit Westmächten und Völkerbund. Der Wechsel ist denn auch allenthalben in diesem Sinne gedeutet worden, und politische Beobachter in Paris, London und nicht zuletzt Warschau zogen auch schon den Schluß, daß die Entwicklung nun auf eine deutsch-sowjetische Zusammenarbeit zulaufe: „I fear this terribly“, notierte Harold Nicolson am 4. Mai474. In Berlin wiederum kam es am 5. Mai zu einer Unterredung zwischen Legationsrat Schnurre und dem sowjetischen Geschäftsträger Georgi Astachow, in der Astachow sich größte Mühe gab, Schnurre beizubringen, daß der Ersetzung Litwinows durch Molotow in der Tat genau die Bedeutung zukomme, die man in Großbritannien und Frankreich befürchtete. Der sowjetische Diplomat knüpfte daran sogar die Frage, wie Schnurre berichtete, „ob uns dies Ereignis zu einer veränderten Einstellung der Sowjet-Union gegenüber bringen würde“. Es fehlte nur noch, daß er dem Beamten eines Regimes, das den Antisemitismus zur Staatsreligion erhoben hatte, sagte, jetzt, da wir euch diesen Juden als Verhandlungspartner erspart haben, könnt ihr doch ungescheut etwas freundlicher werden. Im übrigen benützte Astachow, als er die von Moskau gewünschte Zukunft der deutsch-sowjetischen Beziehungen umschreiben wollte, den Begriff „Rapallo“, d.h. er beschwor jenes

473 ADAP, D, 6, Nr. 215.

474 Nicolson, Diaries and Letters, S. 401. 
deutsch-sowjetische Abkommen, mit dem die antiwestliche und antipolnische Verbindung zwischen den konservativ-nationalen Kräften in Deutschland und den Bolschewiki im Kreml am 16. April 1922 erstmals auf eine vertragliche und dann bis 1933 haltbare Basis gestellt worden war 475 . Knapp zwei Wochen später, am 17. Mai, erschien Astachow erneut bei Schnurre, um - nach der Behandlung diverser wirtschaftlicher Fragen abermals mit Nachdruck darzutun, daß zwischen Dẹutschland und der Sowjetunion doch gar keine realen außenpolitischen Gegensätze bestünden und folglich kein Grund für eine Gegnerschaft der beiden Staaten vorliege; daß eine positive Veränderung der deutsch-sowjetischen Beziehungen möglich sei, beweise ja auch, so sagte er wie am 17. April Merekalow, das sowjetisch-italienische Verhältnis, das der Duce selbst nach Schaffung der „Achse“ ganz normal gehalten habe. Astachow sprach davon, daß man sich in der Sowjetunion durch Deutschland bedroht fühle, setzte jedoch hinzu: „Es sei gewiß möglich, dieses Gefühl der Bedrohung und das Mißtrauen in Moskau zu zerstreuen." Auch in dieser zweiten Unterredung erwähnte Astachow beziehungsvoll den Vertrag von Rapallo, und auf eine Zwischenfrage zum Fortgang der britisch-sowjetischen Verhandlungen äußerte er, wie Schnurre aufmerksam registrierte, „daß nach dem jetzigen Stande wohl kaum das von England gewünschte Ergebnis eintreten würde" 476 .

In Berlin reagierte man auf die sowjetischen Sirenengesänge, so lieblich sie klangen, auch noch zwischen Mitte April und Ende Mai mit Mißtrauen und größter Zurückhaltung. Zu stark war anfänglich der Argwohn, die Sowjets könnten, wenn man sich auf Verhandlungen mit ihnen einließ, dies nur benutzen, um bei ihren Gesprächen mit den Westmächten für ihre Bundesgenossenschaft einen höheren Preis herauszuschlagen; schlossen dann die Sowjets mit London und Paris ab, drohte der deutschen Seite neben der politischen Niederlage eine Blamage, die, weil vom ideologischen Todfeind zugefügt, doppelt peinlich gewesen wäre. Auf der anderen Seite brauchten die nicht weniger mißtrauischen Sowjets eine deutsche Erklärung, die ihnen die Gewißheit gab, daß Deutschland tatsächlich zu einer Annäherung an die Sowjetunion bereit war. $\mathrm{Zu}$ nahe lag in Moskau der Verdacht, den Deutschen werde es lediglich darum gehen, durch endloses Verhandeln - und ohne sich selbst binden zu wollen - den Anschluß der Sowjetunion an Frankreich und Großbritannien zu verhindern; fiel man darauf herein, konnte man am Ende in eine nicht nur unangenehme, sondern auch - angesichts der Konfrontation mit einem mittlerweile in Polen siegreichen Deutschland - ausgesprochen gefährliche Isolierung geraten. So trat trotz des deutschen Interesses an einer Verständigung mit dem Kreml und trotz der deutlich bekundeten sowjetischen Neigung, lieber mit Deutschland als mit den Westmächten zu kooperieren, eine Art Stagnation

475 ADAP, D, 6, Nr. 332.

476 Ebenda, Nr. 406. 
ein, wie sie charakteristischen Ausdruck in der ersten Unterredung fand, die Graf Schulenburg am 20. Mai mit dem neuen sowjetischen Außenkommissar Molotow hatte.

Zwar verlief das Gespräch, wie Schulenburg nach Berlin berichtete, „in freundschaftlicher Form", in einer Form, die eine Zeitlang für deutsch-sowjetische Unterhaltungen zur Regel werden sollte. Da dem Botschafter aber äußerste Vorsicht anbefohlen war, sprach er lediglich über das deutsche Interesse an der Ausweitung des Handels zwischen Deutschland und der Sowjetunion, wobei er auf das Projekt vom Januar zurückkam und die Entsendung Schnurres nach Moskau anbot; über Politik verlor er kein Wort. Auf der anderen Seite erklärte Molotow, daß die Sowjetunion nicht gewillt sei, sich auf die spielerische und unernste Art einzulassen, mit der das Deutsche Reich - wie das Ausbleiben Schnurres im Januar und das Einschlafen der anschließenden Moskauer Verhandlungen im Februar bewiesen - deutsch-sowjetische Kontakte behandle; ehe die Sowjetregierung der Wiederaufnahme von Besprechungen über wirtschaftliche Fragen zustimmen könne, müsse hierfür die „politische Basis“ geschaffen werden. Damit hatte der sowjetische Außenminister dem deutschen Botschafter wohl deutlich zu verstehen gegeben, daß die UdSSR an politischen Gesprächen mit dem Dritten Reich - wie ja schon mehrmals signalisiert - in der Tat interessiert und daß sie, nach einer Geste, mit der Berlin seriöse Absichten bekunde, sofort zur Aufnahme solcher Gespräche bereit sei, doch weigerte er sich beharrlich, auch nur einen Zentimeter weiter zu gehen; als Schulenburg ihn und danach den stellvertretenden Außenminister Potemkin eindringlich befragte, wie sich denn die Sowjetregierung die „politische Basis" vorstelle, blieben die beiden sowjetischen Funktionäre die Antwort schuldig, und Molotow verstand sich lediglich zu der Bemerkung, daß die Regierungen der zwei Staaten eben darüber „nachzudenken“ hätten, wie für die Erholung des Warenverkehrs eine „bessere politische Grundlage“ zu zimmern sei477.

Einen Augenblick lang schien die von Mißtrauen und Vorsicht bewirkte Stagnation dem ersten Versuch der Verständigung zwischen Drittem Reich und Sowjetunion sogar ein frühzeitiges Ende zu bescheren. Obschon Ribbentrop die Meinung durchaus teilte, daß die Sowjetunion vom Anschluß an die Westmächte abgehalten werden müsse, machte ihm doch, wenn er an die Wirkung auf Japan und an die mögliche Gefährdung seines „weltpolitischen Dreiecks" Berlin-Rom-Tokio dachte, jeder konkrete Schritt zur Annäherung an Moskau vorerst noch größtes Unbehagen, und so entschloß sich der Reichsaußenminister, aus Schulenburgs Bericht über die Unterredung mit Molotow sowjetische Ablehnung der Fortsetzung selbst von Wirtschaftsgesprächen herauszulesen, solche Ablehnung als Beweis für die Unvermeidbarkeit des sowjetischen Anschlusses an die Westmächte zu 
deuten und aus dieser Unvermeidbarkeit dann die Zwecklosigkeit weiteren deutschen Werbens um Moskau zu folgern ${ }^{478}$. Er sah sich in einem derartigen Verständnis der Lage noch bestärkt, als der japanische Botschafter in Berlin, Oshima, bereits die ersten Andeutungen Ribbentrops über deutschsowjetische Kontakte tatsächlich mit der Vorhersage quittierte, daß jede Verständigung Deutschlands mit der Sowjetunion in Japan verheerend wirken werde, ja daß danach an eine Allianz Japans mit den Achsenmächten nicht mehr zu denken sei; gerade die einem Bündnis mit dem Dritten Reich zuneigende Militärpartei in Tokio werde gänzlich negativ reagieren ${ }^{479}$. So hat Ribbentrop ein im Auswärtigen Amt formuliertes Instruktionstelegramm an Schulenburg, das den Botschafter ermächtigt hätte, ,in der Fortführung der Unterhaltung mit den Russen stärker aus der Reserve herauszutreten“, eine „Beruhigung und Normalisierung“ der politischen Beziehungen zwischen Berlin und Moskau anzubieten und auch schon für den Fall eines deutsch-polnischen Konflikts mit der Berücksichtigung „russischer Interessen“ zu winken, am Ende doch zurückgehalten 480 . Statt dessen wurde Schulenburg am 26. Mai angewiesen, „völlige Zurückhaltung" zu wahren; ferner teilte ihm das Auswärtige Amt mit, daß auch sonst niemand von der Botschaft Kontakt suchen dürfe und daß nicht einmal beabsichtigt sei, Schnurre demnächst nach Moskau zu entsenden ${ }^{481}$.

Jedoch bestand diese Gefährdung der Fühlungnahmen nur wenige Tage. Für die rasche Änderung der deutschen Haltung zeichneten aber nicht neue sowjetische Avancen verantwortlich. Zwar sandte Moskau sehr wohl weitere Signale seiner Annäherungsbereitschaft aus. So gab sich in Berlin Georgi Astachow große Mühe, für seine eigenen Anstrengungen im Auswärtigen Amt diplomatische Hilfstruppen anzuwerben, etwa den estnischen Gesandten, der am 2. Juni bei Staatssekretär v. Weizsācker erschien, um darzutun, daß - wie er als Kenner Rußlands wisse - das sowjetische Mißtrauen "gegenüber den demokratischen Staaten zweifellos größer sei als gegenüber den totalitären" und daß man im Kreml - wie er aus etlichen Gesprächen mit Geschäftsträger Astachow wisse - „eigentlich nur auf eine öffentliche Geste des Entgegenkommens gegenüber Moskau warte, um der erwähnten Stimmung Ausdruck zu geben" ${ }^{482}$. Molotow selbst hielt am 31. Mai vor dem Obersten Sowjet ein außenpolitisches Grundsatzreferat, dessen hervorstechendstes Charakteristikum ein derart feindseliges Mißtrauen gegen die „demokratischen Staaten“ war, daß die in der Rede ebenfalls zum Ausdruck gebrachte Bereitschaft, mit den Westmächten eine „Friedensfront" zu bilden, nicht recht überzeugend wirkte, zumal er an Stalins Wort erinnerte, die Sowjetunion werde nicht für andere die Kastanien aus dem

478 ADAP, D, 6, Nr. 442, 446.

479 AIA, Ap Germania, Attolico an Ciano, 27.5.1939.

480 ADAP, D, 6, Nr. 441.

481 Ebenda, Nr. 442.

482 Ebenda, Nr. 469. 
Feuer holen; dazu betonte Molotow, daß die Verhandlungen mit Großbritannien und Frankreich die Sowjetunion keineswegs dazu nötigten, auf wirtschaftliche Beziehungen zu Deutschland und Italien zu verzichten, und danach überraschte er die Welt mit der Ankündigung, daß die Wiederaufnahme der im Winter unterbrochenen deutsch-sowjetischen Handelsbesprechungen nicht ausgeschlossen sei483. Aber solche Äußerungen hatten auf die Meinungsbildung in Berlin keinen bestimmenden Einfluß mehr. Auch eine Intervention Schulenburgs kam dafür zu spät. Am 27. Mai hatte Weizsäcker einen Brief an den Botschafter geschrieben, in dem er die von Ribbentrop veranlaßte und am Vortag abgegangene Instruktion etwas ausführlicher begründete; in dem Brief sagte Weizsäcker unter anderem, daß nach Berliner Meinung - die der Staatssekretär freilich, wie er am 25. Mai schriftlich zum Ausdruck gebracht hatte, keineswegs teilte ${ }^{484}$ - deutsche Offenheit in Moskau „statt zu nützen vielleicht eher schaden und sogar vielleicht ein Tartarengelächter hervorrufen könnte“485. Schulenburg, von der Berliner Exegese seiner Mitteilungen über das Gespräch mit Molotow höchlichst befremdet, antwortete am 5. Juni: „Es scheint mir, daß man in Berlin den Eindruck gewonnen hat, als ob Herr Molotow bei der Unterhaltung mit mir einen deutsch-sowjetischen Ausgleich abgelehnt hätte. Ich habe mein Telegramm noch einmal durchgelesen und mit meinem Brief an Sie und mit meiner Aufzeichnung verglichen. Ich kann nicht entdecken [Ribbentrop setzte neben diesen Satz zwei riesige Fragezeichen], was diese Auffassung in Berlin hervorgerufen hat." In Wirklichkeit habe doch Molotow, so setzte der Botschafter mit Recht hinzu, „geradezu zu politischen Gesprächen aufgefordert", und mit Recht implizierte er, daß Molotows Ablehnung von Wirtschaftsverhandlungen vor der Schaffung einer „politischen Basis“ auf den Versuch hinauslaufe, das erkennbar starke deutsche Interesse an russischen Rohstoffen als Hebel zu benutzen und mit ihm Deutschland auf die Straße zur politischen Annäherung zu schieben ${ }^{486}$.

Zuvor schon, zwischen dem 26. und dem 29. Mai, hatte Hitler die Entscheidung getroffen, „daß nun doch“, wie Weizsäcker am 30. in einer Nachschrift zu seinem am 27. formulierten Brief an Schulenburg festhielt, „eine Fühlungnahme mit den Russen stattfinden soll und zwar durch ein Gespräch, was mir für heute mit dem Russischen Geschäftsträger aufgetragen worden ist". Offensichtlich fand der "Führer" die wirtschaftlichen, diplomatischen und militärischen Vorteile, die ihm eine temporäre Verständigung mit Moskau für den bevorstehenden Polenkrieg und für die dann ebenfalls drohende Auseinandersetzung mit den Westmächten bringen konnte, inzwischen so verlockend, daß ihn der negative Effekt in Tokio

485 Ebenda, Nr. 446.

486 Ebenda, Nr. 478. 
nicht mehr sonderlich interessierte; gelang es, den Westmächten die Sowjetunion als Bundesgenossen wegzuschnappen, mochte die Wirkung in London und Paris, wie er nun zu spekulieren begann, sogar derart kräftig ausfallen, daß Briten und Franzosen ganz davon abgeschreckt wurden, Polen militärisch zu Hilfe zu kommen. Aber wenn das nicht erreicht werden sollte, war jedenfalls - da die polnische Kampagne selbst ja als völlig unproblematisches Unternehmen erschien - der Rücken frei und durch die Verfügung über die unerschöpflichen Rohstoffe Rußlands die britische Blockade unwirksam gemacht. Daß er bei einer Annäherung an Rußland die eigenen Ambitionen im Baltikum zurückzustellen und darüber hinaus eine gewisse Westbewegung der Sowjetunion in Kauf zu nehmen hatte, dürfte ihm sofort bewußt geworden sein. Doch da er auch diesmal, wie bei allen seinen bisherigen Aktionen, völlig von den Aspekten und den tatsächlichen oder vermeintlichen Erfordernissen der momentanen taktischen Situation absorbiert wurde, wuchs in ihm die Bereitschaft, die zu erwartende sowjetische Preisforderung zu akzeptieren, zumal er natürlich nie aus den Augen verlor, daß er sich jede Zahlung ehebaldigst mit Zins und Zinseszins zurückholen werde.

So brachten es die Verfechter einer deutsch-sowjetischen Verständigung jetzt in kürzester Zeit fertig, Ribbentrop bei Hitler den Rang abzulaufen. Da waren einmal jene Vertreter des Auswärtigen Amts, die aus traditioneller borussischer Neigung zu prorussischer Politik wie auch zur Einschüchterung Polens - und zur vielleicht noch möglichen Vermeidung eines Krieges gegen die Westmächte - dafür eintraten, die plötzlich aufgetauchte Chance sogleich am Schopf zu packen und zu den guten deutsch-sowjetischen Beziehungen zurückzukehren, wie sie unter der Signatur „Rapallo“ in den Jahren von 1921 bis 1933 bestanden hatten. Und da war vor allem Göring, der sich nicht noch einmal eine Gelegenheit zum Ausbau des deutsch-sowjetischen Handels stehlen lassen wollte. Ein Abkommen mit Rußland eröffne der deutschen Wirtschaft „enorme Möglichkeiten“, so schwärmte er Mitte Juni Giuseppe Renzetti vor, einem Vertrauensmann Mussolinis, wogegen die Verbindung mit Japan, wie er sagte, „bislang keinen sichtbaren Vorteil gebracht" habe; die Japaner forderten immer nur und gäben nichts, sie zahlten nicht einmal für deutsche Lieferungen, obwohl Deutschland ihretwegen den chinesischen Markt eingebüßt habe. Vor einigen Wochen habe der japanische Botschafter Ribbentrop erklärt, daß Japan ein deutsch-sowjetisches Abkommen nicht tolerieren könne, und Ribbentrop sei davon doch tatsächlich beeindruckt worden. Sicher befinde sich der Reichsaußenminister als Repräsentant der Antikominternpolitik in den russischen Fragen in einer „delikaten Lage“, gab Göring zu, doch sei ebenso wahr, daß man in gewissen Situationen auf Nationen, die sich so benähmen wie die Japaner, keine Rücksicht nehmen dürfe. „Mir ist es wurstegal, was der japanische Botschafter sagt und macht, ich werde auf meiner Straße weitergehen, um den für Deutschland lebenswichtigen russischen 
Markt zu erschließen." 487 Bis zum 29. Mai hatte sich dann auch Ribbentrop der herrschenden Stimmung angepaßt. In einer Unterhaltung mit dem italienischen Botschafter Attolico, an der Weizsäcker und Friedrich Gaus, der Leiter der Rechtsabteilung des Auswärtigen Amts, teilnahmen, sprach er sich nun überzeugt für die Intensivierung der deutsch-sowjetischen Kontakte aus. Er griff sogar einen Vorschlag auf, den Weizsäcker am 25. Mai gemacht hatte, und bat in aller Form um italienische Vermittlung: Augusto Rosso, der italienische Missionschef in Moskau, müsse die Sowjets beschwören, nicht mit den Westmächten abzuschließen, wo sich doch gerade in Berlin eine pro-sowjetische Wendung abzeichne488.

In seiner Unterredung mit Astachow durfte Weizsäcker zwar keineswegs so weit gehen, wie es das von Ribbentrop verworfene Instruktionstelegramm Botschafter Schulenburg aufgetragen hätte, doch war ihm immerhin erlaubt worden, dem sowjetischen Diplomaten zuzugeben, daß die Moskauer These, in den deutsch-sowjetischen Beziehungen könnten Wirtschaft und Politik nicht völlig getrennt werden, richtig sei, und er war ferner zu der Versicherung ermächtigt, daß Deutschland, falls man das in Moskau wünsche, durchaus bereit sei, das deutsch-sowjetische Verhältnis in jenem Sinne zu normalisieren und weiter zu verbessern, wie am 17. April von Botschafter Merekalow und seither auch mehrmals von Astachow selbst angedeutet. In Berlin frage man sich freilich, ob eine solche Normalisierung inzwischen nicht unmöglich geworden sei, „nachdem Moskau den Londoner Lockungen vielleicht schon Gehör geschenkt habe“. Da aber „der Geschäftsträger und sein Botschafter im Auswärtigen Amt eine offene Sprache gesprochen“ hätten, wolle man sich „den Vorwurf ersparen, als hätten wir unsererseits hinter dem Berg gehalten“. Der Staatssekretär schloß: „Wir verlangten nichts von Moskau, wünschten nichts von Moskau, wir wollten uns aber auch von Moskau nicht später sagen lassen, wir hätten zwischen uns eine undurchdringliche Schweigemauer aufgerichtet." Astachow wiederum war in der Lage, „ohne weiteres“ zu erklären, daß Molotow am 20. Mai in seinem Gespräch mit Schulenburg mitnichten „in der Absicht gesprochen hat, vor weitere deutsch-russische Erörterungen einen Riegel vorzuschieben“, daß die sowjetische Regierung vielmehr ernstlich an einem politischen Dialog zwischen Deutschland und Rußland interessiert sei. Weizsäcker kommentierte, Astachow habe ihn überzeugt. Für die Augen Ribbentrops und Hitlers bestimmt, schrieb er: „Die Episode MolotowSchulenburg scheint mir demnach mehr das Produkt von Empfindlichkeit und Mißtrauen gewesen zu sein als eine planmäßige Abweisung.“489

$\mathrm{Daß}$ sich die beiden prospektiven Partner solchermaßen freundlich anlächelten, genügte denn auch, um zunächst einmal wenigstens die Wieder- 
aufnahme der Wirtschaftsgespräche zu bewirken. Mikojan empfing einige Male den für wirtschaftliche Angelegenheiten zuständigen Legationsrat an der deutschen Botschaft in Moskau, Gustav Hilger ${ }^{490}$, und es war bis Mitte Juni von deutscher Seite auch wieder davon die Rede, Schnurre in Moskau verhandeln zu lassen. Aber in den Unterredungen mit Hilger zeigte sich Mikojan - aus berechtigtem Mißtrauen, wie er sagte - sehr spröde, und die sowjetische Zustimmung zur Reise Schnurres nach Moskau knüpfte er an noch unerfüllte Bedingungen. Die sowjetische Reserve war gewiß auch eine Folge von Meinungsverschiedenheiten in den wirtschaftlichen Fragen. Mikojan ließ keinen Zweifel daran, daß die Reichsregierung vor dem Beginn der eigentlichen Besprechungen zusagen müsse, die von der Sowjetregierung im Februar präsentierten Kredit- und Lieferwünsche als Verhandlungsbasis anzuerkennen, und nach wie vor zögerten die Berliner Experten, diese Forderung zu akzeptieren; auch hat Hilger, der aus Berlin nur ungenügende und zeitweilig sogar widersprüchliche Instruktionen erhielt, notwendigerweise zu steif und zu negativ verhandelt. Der wichtigere Grund für die sowjetische Zurückhaltung ist jedoch darin zu sehen, daß Stalin und Molotow offensichtlich zu der Ansicht gelangten, die deutsche Festlegung auf eine sowjetfreundliche Politik sei noch nicht klar und noch nicht sicher genug. Sie warteten auf ein deutliches Zeichen aus Berlin, und ein solches Zeichen wollte wochenlang nicht kommen.

Auf der anderen Seite nahm gerade im Juni das sowjetische Interesse an einer Verständigung mit Deutschland womöglich noch zu. Im Laufe des Monats konnte nämlich Stalin definitiv feststellen, daß seine Annahme richtig gewesen und ein Abschluß mit den Westmächten, der seinen seit München geweckten Appetit befriedigt hätte, in der Tat unerreichbar war. Daß die Bündnisgespräche, die mit Sir William Strangs Ankunft in Moskau begannen, praktisch sofort an einem toten Punkt ankamen, lag ja nicht in erster Linie an der Person des Unterhändlers und an einer eventuellen - in Wirklichkeit jedoch nirgends erkennbaren - sowjetischen Verärgerung über einen hier vielleicht zum Ausdruck kommenden britischen Widerwillen gegen eine Allianz mit Moskau, auch nicht daran, daß Polen und Rumänien nach wie vor, ohne damit stärkeren britisch-französischen Druck zu provozieren, das Eingeständnis verweigerten, im Kriegsfall müsse die Rote Armee, wenn sich die UdSSR der Koalition gegen das Dritte Reich anschließen solle, ein Durchmarschrecht erhalten. Die eigentliche Ursache war vielmehr, daß die sowjetischen Vertreter sofort und nahezu unverhüllt den Anspruch der Sowjetunion auf die baltischen Staaten anmeldeten und daß die Vertreter der Westmächte ebenso rasch die Unfähigkeit ihrer Staaten zur Anerkennung derartiger Ansprüche zu verstehen geben mußten; Konzessionen einer bestimmten Qualität können die Regierungen liberaldemokratischer Staaten nur machen, wenn ihnen das Wasser bis zum Halse 
steht oder wenn sie zur Intervention gegen das kriminelle Betragen zweifelhafter Bundesgenossen sichtbar zu schwach und daher zu dessen Tolerierung verdammt sind. Stalin schob noch die Forderung nach, Großbritannien und Frankreich müßten der sowjetischen Regierung das Recht zubilligen, jedem der gegen deutsche Aggression zu garantierenden Nachbarn Rußlands bereits dann militärisch zu Hilfe zu eilen, wenn zwar kein deutscher Einfall gegeben sei, wohl aber eine, wie die Sowjets das nannten, ,indirekte Aggression“, z.B. ein mit den sowjetischen Interessen nicht verträglicher innenpolitischer Machtwechsel. Stalin sah natürlich klar, daß die Westmächte nicht bereit sein konnten, diese Forderung - die praktisch eine erste Skizze der Breschnew-Doktrin darstellte - anzunehmen; sie hätten damit den schon zum gierigen Griff bereiten Händen des sowjetischen Diktators nicht allein beträchtliche osteuropäische Territorien, sondern zugleich die Auslösung des Bündnisfalls überantwortet, was groteske Situationen am Horizont erscheinen ließ: Marschierte z.B. die Rote Armee in ein von Deutschland gar nicht angegriffenes baltisches Land ein, weil Stalin einen dort ablaufenden inneren Vorgang zur ,indirekten Aggression“ erklärte, und griff nun das Deutsche Reich - unter dem Vorwand, dem besetzten Land beistehen zu wollen - die Sowjetunion an, so wären die Westmächte unter Umständen verpflichtet gewesen, eine Sowjetunion zu unterstützen, die vor aller Welt als Aggressor dastand, und diesen Aggressor überdies gegen ein Deutsches Reich zu unterstützen, das dem Anschein nach einen gerechtfertigten Verteidigungskrieg führte. Indes hat Stalin die Forderung sicherlich nicht ernst gemeint. Sie diente ihm lediglich als taktisches Mittel, die Verhandlungen mit den Westmächten, die er bis zu einem Abschluß mit Deutschland brauchte, in die Länge zu ziehen. Die Verständigung mit Berlin hingegen dünkte Stalin wünschenswerter denn je ${ }^{491}$. Der lettische Gesandte sagte es in jenen Tagen Molotow ins Gesicht, daß sich die Sowjetunion für eine imperialistische Politik entschieden habe, die den ehemals zaristischen Gebieten gelte ${ }^{492}$.

Angesichts der Zurückhaltung, die von den Deutschen auf politischem Felde gewahrt wurde, blieb der sowjetischen Führung - neben der kühlen Behandlung des deutschen Rohstoffbedarfs - zunächst jedoch nur die Fortsetzung der Versuche, die Deutschen durch inoffizielle und indirekte Bekundungen der sowjetischen Verständigungsbereitschaft aus ihrer Reserve herauszulocken. So erschien Georgi Astachow am 14. Juni „ohne sichtlichen Anlaß" beim Gesandten Bulgariens in Berlin, Parvan Draganoff, und erläuterte diesem zwei Stunden lang, daß die Sowjetunion derzeit zwischen drei Möglichkeiten schwanke, nämlich dem Abschluß eines Paktes mit Großbritannien und Frankreich, einer weiteren Verschleppung der Verhandlungen mit den Westmächten und einer Annäherung an Deutschland.

491 A. B. Ulam, Stalin. The Man and his Era, New York 1974, S. $504 \mathrm{ff}$.

492 AIA, Ap Germania, Rosso (Moskau) an Ciano, 19.6.1939. 
„Gefühlsmäßig“, so gab Draganoff in einer Unterhaltung mit Ernst Woermann, dem Leiter der Politischen Abteilung im Auswärtigen Amt, die ÄuBerungen Astachows wieder, ,läge der Sowjetunion diese letzte Möglichkeit am nächsten, wobei weltanschauliche Fragen nicht mitzuspielen brauchten." Auch territoriale Ansprüche Moskaus deutete der sowjetische Geschäftsträger an, indem er erwähnte, „daß die Sowjetunion den rumänischen Besitz Bessarabiens nicht anerkenne". Dann sprach er von der sowjetischen Furcht vor einem deutschen Angriff und sagte: "Wenn Deutschland die Erklärung abgeben würde, daß es die Sowjetunion nicht angreifen wolle, oder mit ihr einen Nichtangriffspakt abschließen würde, so würde die Sowjetunion wohl von dem Vertragsabschluß mit England absehen. Die Sowjetunion wisse jedoch nicht, was Deutschland eigentlich wolle, wenn man von gewissen, aber nur sehr unklaren Anspielungen absehe.“493 Zwei Tage später, am 16. Juni, veröffentlichte die „Iswestija“ eine offizielle Stellungnahme zu einer Unterredung, die am Vortage zwischen Strang und den Botschaftern der Westmächte einerseits und Molotow und Potemkin andererseits stattgefunden hatte, und am Ende des Kommuniqués hieß es, groß aufgemacht: Das Ergebnis der Unterredung und der Überprüfung englisch-französischer Formulierungen für einen etwaigen Vertrag werde in Kreisen des Außenkommissariats ,als nicht ganz günstig eingeschätzt“. Andreij Shdanow, Mitglied des Politbüros, ließ dem am 29. Juni einen großen Artikel in der „Prawda“ folgen, in dem er konstatierte, die sowjetischen Gespräche mit den Westmächten seien in eine Sackgasse geraten, weil England und Frankreich die Sowjetunion nur als Werkzeug benutzen wollten, um sich - welche Wendung ja auch schon Stalin und Molotow gebraucht hatten - die Kastanien aus dem Feuer holen zu lassen, aber nicht mit dem ernsten Willen zum Abschluß eines Vertrags auf der Basis der Gleichberechtigung verhandelten. Am gleichen Tag, an dem der Aufsatz Shdanows veröffentlicht wurde, sagte der sowjetische Luftattaché in London zum Gehilfen des dortigen deutschen Luftattachés, der Sowjetregierung sei am Zustandekommen eines Pakts mit England und Frankreich „nichts gelegen“494. Ein paar Tage später, am 4. Juli, unternahm dann der italienische Botschafter in Moskau, inzwischen auf deutschen Wunsch von Graf Ciano entsprechend instruiert ${ }^{495}$, einen Versuch, zwischen Deutschen und Sowjets zu vermitteln, indem er Potemkin beizubringen suchte, in Rom wisse man genau, welch großen Wert die Reichsregierung auf eine Normalisierung der deutsch-sowjetischen Beziehungen lege. Molotows Stellvertreter erklärte daraufhin, „daß eine Einigung der Sowjetunion mit Deutschland die wirksamste Garantie des Friedens sein würde“ ${ }^{496}$, und Schulenburg ver-

493 ADAP, D, 6, Nr. 529.

494 Ebenda, Nr. 582; Soviet Documents on Foreign Policy, Bd. III, Oxford 1953, S. 352 ff.; Dirksen an AA, 29.6.1939, PAA, Büro Staatssekretär, Akten Rußland, 111462.

495 AIA, Ap Germania, Ciano an Rosso, 23.6.1923.

496 Ebenda, Rosso an Ciano, 4.7.1939. 
sicherte Augusto Rosso, daß der italienische „Flankenschutz“ gewiß sehr nützlich sei497. Tatsächlich war aber zu diesem Zeitpunkt der Durchbruch im Prozeß der deutsch-sowjetischen Annäherung bereits erzielt. Wie Schulenburg, der Moskau am 10. Juni verließ und sich vom 12. bis zum 24. Juni in Berlin aufhielt, dort feststellen konnte, lag das Schweigen, das die deutsche Seite nach dem Gespräch Weizsäcker-Astachow wieder wochenlang wahrte, vornehmlich an Ribbentrop, der auf den Standpunkt zurückgefallen war, daß der Anschluß Rußlands an die Westmächte doch nicht zu verhindern sei und daß der Draht nach Tokio unversehrt gehalten werden müsse. Er brachte es sogar fertig, bis zum 29. Juni eine Weisung Hitlers zu erwirken, den Russen sei mitzuteilen, daß Deutschland angesichts der unerfüllbaren sowjetischen Forderungen ,an einer Wiederaufnahme der Wirtschaftsbesprechungen mit Rußland z. Zt. nicht interessiert" sei ${ }^{498}$, und am 30. informierte Weizsäcker in Ribbentrops Auftrag Schulenburg, „daß auf politischem Gebiet nunmehr bis auf weitere Weisung genügend gesagt sei und daß im Augenblick das Gespräch von uns aus nicht wieder aufzunehmen wäre“ 499 . Indes wurde die erste Instruktion nicht durchgeführt, und die zweite kam zu spät, da die Ribbentropsche Abneigung gegen die deutsch-sowjetische Annäherung, die sich da anbahnte, schon zuvor ausmanövriert worden war. Abermals setzte sich bei Hitler die Allianz zwischen borussischem Traditionalismus und Görings Rohstoffinteresse durch. In die gleiche Richtung weisend, wie die Überlegungen, die der „Führer“ selbst anstellte, weil er von den taktischen Aspekten der außenpolitischen und militärischen Situation des Reiches besessen war, hatten die Argumente jener Allianz größere Kraft als die Argumente, die der Verfechter einer genuin nationalsozialistischen "Weltpolitik“ vorzubringen vermochte.

Als aktivster Protagonist der traditionellen preußischen Rußlandpolitik wirkte diesmal Graf Schulenburg. Nach Gesprächen mit Ribbentrop und der übrigen deutschen politischen Prominenz, in denen er seit dem 12. Juni die Stimmung und die Lage in Berlin rekognostizierte, besuchte Graf Schulenburg am 17. Juni Astachow, und in der Unterredung, die er bei dieser von der diplomatischen Etikette besorgten Gelegenheit mit dem sowjetischen Geschäftsträger führte, beschränkte sich der Botschafter nicht auf Höflichkeitsfloskeln. Offenbar war er durch seine Unterhaltung mit Ribbentrop zu der Ansicht gelangt, daß etwas zu geschehen hatte, wenn der noch so dünne Faden zwischen Berlin und Moskau nicht wieder reißen sollte. Seine Instruktionen weit überschreitend, ja im Grunde völlig ignorierend, bekannte er sich daher vor Astachow ganz offen und anscheinend auch mit ungescheuter Begründung zu einem starken deutschen Interesse an einer politischen Verständigung mit der Sowjetunion; Moskau dürfe

498 ADAP, D, 6, Nr. 583.

499 Ebenda, Nr. 588. 
und müsse daher endlich sein Mißtrauen aufgeben. Danach erörterten die beiden Diplomaten bereits nicht minder offen die Interessen, die es zwischen dem Deutschen Reich und der Sowjetunion abzustecken galt, ebenso die politische Form, die der Neuregelung des deutsch-sowjetischen Verhältnisses gegeben werden konnte; erstmals ist dabei der Begriff „Nichtangriffspakt" im direkten deutsch-sowjetischen Austausch gefallen ${ }^{500}$. Graf Schulenburg verschaffte sich aber außerdem bei seinen deutschen Berliner Gesprächspartnern die Ermächtigung, einen Einfall zu verwirklichen, den er noch vor seiner Abreise aus Moskau gehabt hatte ${ }^{501}$. Wie wäre es denn, so hatte er überlegt, wenn Berlin den Sowjets eine öffentliche deutsch-sowjetische Verlautbarung vorschlüge, daß die Beziehungen zwischen dem Deutschen Reich und der UdSSR nach wie vor vom freundschaftlichen Geiste des „Berliner Vertrags“ bestimmt seien, oder wenn auf irgendeine andere Weise der „Berliner Vertrag“ ins Spiel gebracht würde. Das mochte im Kreml als die gewünschte Klärung der deutschen Rußlandpolitik akzeptiert werden und damit einen positiven Fortgang der deutsch-sowjetischen Besprechungen ermöglichen; schließlich hatten sich das Reich und die Sowjetunion in dem am 24. April 1926 geschlossenen Vertrag, der „Rapallo" gewissermaßen durch Stresemanns Politik der Verständigung mit den Westmächten rettete, gegenseitige Neutralität zugesichert, falls einer der beiden Staaten in einen Verteidigungskrieg geraten oder dem wirtschaftlichen Boykott dritter Mächte ausgesetzt sein sollte. Tatsächlich durfte Schulenburg, nach Moskau zurückgekehrt, am 28. Juni Molotow nicht nur beteuern, daß Deutschland eine Normalisierung der Beziehungen zu Sowjetrußland begrüßen würde und „keine bösen Absichten gegen die Sowjetunion hege", sondern auch erklären, daß nach deutscher Auffassung „der Berliner Vertrag noch in Kraft sei“"502.

Molotow nahm Schulenburgs Darstellung „mit Genugtuung zur Kenntnis" und begriff auch sofort, daß der Botschafter mit der Erwähnung des Berliner Vertrags die deutsche Bereitschaft andeuten wollte, eine deutschsowjetische Verständigung in vertragliche Form zu kleiden. In der Tat scheint Stalin das Gespräch Schulenburg-Astachow und die Unterredung Schulenburg-Molotow als das politische Signal gewertet zu haben, das er seit Wochen erwartete, und als der deutsche Botschafter am 10. Juli - von Weizsäcker dazu am 7. ermächtigt ${ }^{503}$ - auch noch Mikojan mitteilen konnte ${ }^{504}$, daß die Reichsregierung, sofern die UdSSR besser auf den deutschen Rohstoffbedarf eingehe, gewillt sei, bei der Ausweitung des deutschsowjetischen Handels nun doch praktisch die sowjetischen Kredit- und Lieferwünsche vom Februar zu erfüllen, kamen die Dinge in eine Bewe-

500 Ebenda, Nr. 540; AIA, Ap Germania, Rosso an Ciano, 28.6.1939.

501 ADAP, D, 6, Nr. 490.

502 Ebenda, Nr. 579.

503 Ebenda, Nr. 628.

504 Ebenda, Nr. 642. 
gung, die von Manövern wie Ribbentrops Maulkorb-Instruktion nicht mehr zu bremsen war. Bereits am 15. Juli wurde Legationsrat Hilger von Mikojan unterrichtet, daß der stellvertretende Leiter der sowjetischen Handelsmission in Berlin, Babarin, inzwischen in Moskau gewesen und nun, mit entsprechenden Weisungen versehen, nach Berlin zurückgekehrt sei, um dort zusammen mit Schnurre die Besprechung der deutsch-sowjetischen Wirtschaftsfragen im Ernst aufzunehmen ${ }^{505}$. Das geschah denn auch, und da schon die ersten Kontakte günstige Ergebnisse zeitigten, hielt die sowjetische Regierung den Zeitpunkt für gekommen, beide Seiten öffentlich festzulegen. Während Molotow und Potemkin auf der einen Seite immer noch mit Strang über den Anschluß der Sowjetunion an eine europäische Anti-Hitler-Koalition diskutierten, brachte am 22. Juli jede Zeitung in der UdSSR eine Meldung über die Wiederaufnahme deutsch-sowjetischer Wirtschaftsverhandlungen. Zugleich bewiesen kleine freundschaftliche Gesten, wie rasch sich jetzt das Klima zwischen Berlin und Moskau besserte. So wurde Georgi Astachow nach München eingeladen, wo Hitler am 14. Juli den „Tag der deutschen Kunst 1939“ und am 16. Juli eine große Ausstellung im „Haus der deutschen Kunst“ mit einer Rede über seine und des Nationalsozialismus kulturelle Verdienste eröffnete. Astachow sah sich dermaßen ausgezeichnet, daß es Potemkin für angebracht hielt, sich bei Schulenburg dafür zu bedanken ${ }^{506}$. Umgekehrt lud die sowjetische Regierung am 24. Juli einen deutschen Wissenschaftler und einen Beamten des Berliner Landwirtschaftsministeriums zur Eröffnung der ersten großen landwirtschaftlichen Ausstellung Rußlands nach Moskau ein. Tatsächlich kamen - zwar nicht mehr rechtzeitig zur Eröffnung, aber am 14. August nur wenig später und übrigens kurz nach dem Eintreffen einer britischfranzösischen Militärmission - nicht zwei, sondern drei Deutsche in die sowjetische Hauptstadt: Professor Conrad Meyer, Obmann des landwirtschaftlichen Forschungsdienstes, Ministerialdirektor Moritz vom Reichsernährungsministerium und als Vertreter des Reichsnährstands Graf Grote, der Landesbauernführer von Mecklenburg 507.

Dazu beschränkten sich die Wirtschaftsexperten Schnurre und Babarin alsbald nicht mehr auf die Ausarbeitung eines deutsch-sowjetischen Kredit- und Handelsvertrags. Am 26. Juli lud Schnurre, und zwar im Auftrag des mittlerweile von Hitler wieder disziplinierten und nun definitiv auf deutsch-sowjetische Verständigung eingeschworenen Ribbentrop, Babarin und Astachow zum Abendessen in ein Berliner Restaurant ein. Das Gespräch, das sich bei dieser Gelegenheit entwickelte, berührte wirtschaftliche Fragen nur am Rande, machte vielmehr, von beiden Seiten zielbewußt dahin geführt, endgültig den Weg zu einem politischen Abkommen frei und erbrachte sogar schon eine erste Skizze der deutsch-sowjetischen Interes-

505 Ebenda, Nr. 677.

506 Ebenda, Nr. 727.

507 ADAP, D, 7, Nr. 20. 
senabgrenzung, wie sie dann später tatsächlich fixiert werden sollte. Nach Bemerkungen Astachows über die früher so enge Zusammenarbeit und außenpolitische Interessengemeinschaft zwischen Deutschland und Rußland setzte Schnurre seinen Gästen auseinander, daß eine derartige Zusammenarbeit auch jetzt wieder erreichbar sei, ,entweder in Anlehnung an das, was früher gewesen wäre (Berliner Vertrag) oder eine Neuordnung unter Berücksichtigung der beiderseitigen lebenswichtigen Interessen“. Im Grunde sei das gar nicht so schwierig, „denn außenpolitische Gegensätzlichkeiten, die eine solche Ordnung zwischen den beiden Ländern ausschlössen, bestünden meiner Meinung nach auf der ganzen Linie von der Ostsee bis zum Schwarzen Meer und dem Fernen Osten nicht“. Außerdem gebe es, bei aller Verschiedenheit der Weltanschauung, selbst in der Ideologie Deutschlands, Italiens und der Sowjetunion „ein Gemeinsames,, „Gegnerstellung gegen die kapitalistischen Demokratien. Wir hätten ebensowenig wie Italien etwas gemeinsam mit dem kapitalistischen Westen." Daher sei es geradezu paradox, wenn „die Sowjet-Union als sozialistischer Staat sich jetzt ausgerechnet an die Seite der westlichen Demokratien stellen wolle“. Was könne England denn Rußland bieten? „Bestenfalls die Beteiligung an einem europäischen Krieg und die Feindschaft Deutschlands, doch wohl kaum ein erstrebenswertes Ziel für Rußland. Was könnten wir dagegen bieten? Neutralität und Herausbleiben aus einem etwaigen europäischen Konflikt und, wenn Moskau wolle, eine deutsch-russische Verständigung über die beiderseitigen Interessen, die sich ebenso wie in früheren Zeiten zum Nutzen für beide Länder auswirken würde.“ Astachow antwortete, „unter lebhafter Zustimmung von Babarin“, der Weg der Annäherung an Deutschland sei derjenige, der den Lebensinteressen der beiden Länder am besten entspreche. Anschließend erkundigten sich die sowjetischen Diplomaten mehrmals beziehungsvoll, ob denn wohl Deutschland die baltischen Staaten, Finnland und Rumänien als seine Interessengebiete ansehe oder dort neben wirtschaftlichen doch auch politische Interessen habe. Schnurre versicherte ihnen, „daß sich aus all diesen Fragen jedenfalls kein deutschrussischer Interessengegensatz ergebe“. Selbst die Teilung Polens wurde bereits in Umrissen besprochen. Danach fragte Astachow, „ob dann, wenn eine hochgestellte sowjetische Persönlichkeit sich mit einer hochgestellten deutschen Persönlichkeit“ über die erörterten Probleme unterhalten könnte, ,ähnliche Ansichten von uns vertreten würden“. Schnurre hat das bejaht. „Astachow betonte zum Schluß, wie wertvoll ihm diese Unterhaltung gewesen wäre. Er werde sie nach Moskau berichten und hoffe, daß sie dort sichtbare Spuren in der weiteren Entwicklung hinterlassen werde." 508

Während der Unterredung hatte Astachow einmal gesagt, daß der Prozeß der deutsch-sowjetischen Verständigung sicherlich längere Fristen beanspruchen werde, wogegen Schnurre erklärt hatte, daß jetzt der richtige 
Zeitpunkt sei. In der Tat ergab sich nun, da die sowjetischen Initiativen in Berlin aufgenommen worden waren und dort endlich die deutliche Bekundung der Bereitschaft zu politischen Gesprächen hervorgerufen hatten, geradezu eine Umkehrung des Verhaltens der beiden angehenden Kompagnons: Die bislang so zögerlichen Deutschen begannen zu drängen, die bisher lockenden Sowjets gaben sich plötzlich zurückhaltend. Auf der deutschen Seite spielte gewiß auch die bekannte Ungeduld Ribbentrops eine Rolle, der, einmal auf deutsch-sowjetische Verständigung festgelegt, möglichst schnell ein dramatisches Spektakel haben wollte, das der historischen Bedeutung des Vorgangs und der historischen Größe der beteiligten Akteure angemessen war. Stärker wirkte jedoch die Furcht, Stalin könne sich im letzten Moment doch noch zum Abschluß mit Großbritannien und Frankreich entschließen. Diese Furcht, immer wieder durch ungerechtfertigt optimistische Gerüchte über den Stand der britisch-französisch-sowjetischen Verhandlungen belebt, erhielt gerade in den letzten Julitagen kräftig Nahrung, als bekannt wurde, daß England und Frankreich zur Erörterung der militärischen Kooperation demnächst sogar schon eine Militärmission nach Moskau entsenden würden. Da solchen Militärgesprächen normalerweise die politische Einigung vorausgeht, machten die Meldungen über ihren bevorstehenden Beginn doch einigen Eindruck in Berlin. Erst nachdem die britisch-französische Militärmission am 11. August in Moskau eingetroffen war - ein paar Tage zuvor hatte Sir William Strang die sowjetische Hauptstadt verlassen -, stellte sich der wahre Sachverhalt zweifelsfrei heraus: Die Mission war nicht nur, wie man zuvor schon in ganz Europa kopfschüttelnd registriert hatte, von durchaus zweitrangigen Offizieren geführt, sie besaß überdies weder klare Instruktionen noch gar Vollmachten für ernsthafte Verhandlungen. Weit davon entfernt, der militärischen Ausgestaltung einer politischen Verständigung zu dienen, sollte die Mission im Gegensatz zum Normalfall gerade das Scheitern der politischen Gespräche, wie es in der Rückberufung Strangs zum Ausdruck kam, verschleiern; in der Hoffnung, daß Hitler Polen nicht anfallen werde, solange die Westmächte zumindest dem Anschein nach mit der Sowjetunion noch über eine gemeinsame Politik berieten, trachteten die Briten, denen die Idee mit der Militärmission gekommen war, einfach danach, die Moskauer Verhandlungen möglichst bis in den Herbst hinein zu verlängern. Der Hauptgrund für das Wachsen des deutschen Eifers ergab sich aber aus Hitlers Terminplan. Wie der „Führer“ die Dinge sah, mußte eine Vereinbarung mit der Sowjetunion, wenn sie die vielleicht doch noch nicht definitiv zur Intervention entschlossenen Westmächte, mehr noch die ständig nervöser werdenden Italiener und nicht zuletzt die einen Zweifrontenkrieg scheuenden eigenen Militärs gebührend beeindrucken sollte, ja vor dem Befehl, der die deutschen Armeen gegen Polen in Bewegung setzte, getroffen und als letzter politischer Trumpf ausgespielt werden. Da der Angriffsbefehl spätestens zur Monatswende August/September zu geben war, besser noch etliche 
Tage früher, wurde in den Gesprächen mit Moskau die Zeit allmählich recht knapp. Stalin wiederum, über die deutschen Pläne wohlunterrichtet, fand es offensichtlich gute Taktik, das Gefühl der Eilbedürftigkeit in Berlin noch zu steigern; je eiliger es die Deutschen hatten, desto mehr war mit ihrer Bereitschaft zu rechnen, die expansionistischen Wünsche Moskaus ohne Feilschen und zur Gänze zu akzeptieren.

Zwei Tage nach der Unterhaltung Schnurres mit Astachow und Babarin erhielt Schulenburg von Weizsäcker die Weisung, nun auch in Moskau klar zu sagen, daß Deutschland gewillt sei, sich mit der Sowjetunion über das Baltikum und Polen zu verständigen ${ }^{509}$. Schnurre schickte dieser Instruktion am 2. August einen Brief hinterdrein, in dem er eindrucksvoll schilderte, mit welch „außerordentlicher Dringlichkeit“ das „Problem Rußland“ mittlerweile in Berlin behandelt werde: „Ich habe in den letzten zehn Tagen täglich mindestens eine mündliche oder telefonische Besprechung mit dem Herrn R.A.M. gehabt und weiß, daß er auch mit dem Führer in einem ständigen Meinungsaustausch hierüber steht. Es kommt dem Herrn R.A.M. darauf an, die Frage Rußland nicht nur nach der negativen Seite hin (Störung der englischen Verhandlungen), sondern auch nach der positiven Seite hin (Verständigung mit uns) möglichst rasch zu irgendeinem Ergebnis zu bringen." 510 Tatsächlich vermochte Ribbentrop nicht abzuwarten, bis Graf Schulenburg mit Molotow sprechen konnte, vielmehr bestellte er noch am 2. August Astachow zu sich, um dem Geschäftsträger ,im Ton der Gelassenheit" und „ohne irgendwelche Eile zu zeigen“, wie er selbst glaubte, mitzuteilen, „es gebe kein Problem von der Ostsee bis zum Schwarzen Meer, was zwischen uns nicht zu lösen sei“; vor allem bot der Reichsaußenminister - in „leichter Andeutung“, wie er meinte - praktisch die Aufteilung Polens zwischen Deutschland und der Sowjetunion an ${ }^{511}$.

Gleichwohl fand Graf Schulenburg, als er am 3. August von Molotow empfangen wurde, einen Gesprächspartner vor, der sich zwar in der Unterhaltung „ungewöhnlich aufgeschlossen“ gab, der aber kein Entgegenkommen in der Sache zeigte; obschon der Botschafter die deutsche Bereitschaft betonte, lebenswichtige Interessen Moskaus an der Ostsee zu sichern und bei einem deutsch-polnischen Konflikt alle sowjetischen Interessen in Polen zu wahren, verharrte der Außenkommissar, wenn er auch Schulenburgs Mitteilungen freundlich aufnahm, auf dem Standpunkt, daß für eine veränderte Einstellung Deutschlands zu Rußland „vorläufig noch die Beweise fehlten“512. Doch hüteten sich die Sowjets davor, den Dialog - über eine gewisse Verlangsamung hinaus - ernstlich zu stören oder gar zu unterbrechen. Am 10. August - an welchem Tag die britisch-französische Militärmission in Leningrad russischen Boden betrat - durfte Astachow in einer

509 Ebenda, Nr. 736.

510 Ebenda, Nr. 757.

511 Ebenda, Nr. 758, 760.

512 Ebenda, Nr. 766. 
Unterredung mit Schnurre sagen, „daß er nochmals aus Moskau eine ausdrückliche Weisung bekommen habe zu betonen, daß die Sowjetregierung die Verbesserung der Beziehungen zu Deutschland wünsche“. Der Geschäftsträger wiederum hörte sich wohlwollend Schnurres Beteuerung an, daß im Falle eines deutsch-polnischen Krieges „die deutschen Interessen in Polen durchaus begrenzt seien. Sie brauchten in keiner Weise mit irgendwelchen sowjetischen Interessen zu kollidieren, wir müßten diese Interessen nur kennen." 513 Und als Folge der beiden Unterredungen überbrachte Astachow am 12. August - die britischen und französischen Offiziere präparierten sich gerade für ihre erste Sitzung mit der von Marschall Woroschilow geleiteten sowjetischen Militärmission - immerhin jene Einladung zu einer umfassenden Erörterung der deutsch-sowjetischen Beziehungen in Moskau, mit der Hitler am gleichen Tag in seiner Besprechung mit dem Grafen Ciano Eindruck zu machen suchte.

Derart ermuntert, beauftragte Ribbentrop noch am 14. August den Grafen Schulenburg, Molotow aufzusuchen und ihm mitzuteilen, daß der Reichsaußenminister persönlich nach Moskau kommen wolle, um dem Außenkommissar und Stalin die Auffassung des „Führers“ zu „Fragen wie: Ostsee, Baltikum, Polen, Südost-Fragen usw." auseinanderzusetzen. Die Reise dürfe außerdem nicht verzögert werden: „Die durch die englische Politik hervorgerufene Zuspitzung der deutsch-polnischen Beziehungen sowie die englische Kriegstreiberei und die damit verbundenen Bündnisbestrebungen machen eine baldige Klärung des deutsch-russischen Verhältnisses erforderlich. Die Dinge könnten sonst ohne deutsches Zutun einen Verlauf nehmen, der beiden Regierungen die Möglichkeit abschneidet, die deutsch-russische Freundschaft wieder herzustellen und gegebenenfalls auch territoriale Fragen Osteuropas zu klären." 514 Als Schulenburg die Weisung Ribbentrops am 15. August ausführte, nahm Molotow „Inhalt mir aufgetragener Mitteilung mit größtem Interesse entgegen, bezeichnete sie als außerordentlich wichtig und erklärte, daß er seiner Regierung hierüber gleich berichten und mir in Kürze Antwort geben werde. Schon jetzt könne er erklären, daß Sowjetregierung deutsche Absichten nach Verbesserung Beziehungen zu Sowjetunion lebhaft begrüße und angesichts meiner heutigen Mitteilung nunmehr an Aufrichtigkeit dieser Absichten glaube.“ Was Ribbentrops Moskau-Besuch betraf, legte Molotow jedoch einen auffallenden Mangel an Enthusiasmus an den Tag. Eine solche Reise, so behauptete er, bedürfe gründlicher Vorbereitung; schließlich müsse man in Moskau erst die Antwort auf drei Fragen kennen: Sei Deutschland wirklich bereit, einen Nichtangriffspakt mit der Sowjetunion abzuschließen? Sei Deutschland willens, in Tokio auf eine Besserung der sowjetisch-japani- 
schen Beziehungen hinzuwirken? Und wie stehe es mit einer gemeinsamen Politik gegenüber den baltischen Staaten?515

In Berlin brannte jetzt die Zeit auf den Nägeln. Ribbentrop jagte Schulenburg umgehend wieder zu Molotow: Selbstverständlich laute die deutsche Antwort auf alle drei Fragen ,Ja,!! Dies müsse der Botschafter, so hieß es in der Instruktion des Reichsaußenministers vom 16. August, „sofort“ Molotow versichern und dabei erneut betonen, daß er, Ribbentrop, bereit sei, ,von Freitag, den 18.8., jederzeit im Flugzeug nach Moskau zu kommen mit der Vollmacht des Führers, über den Gesamtkomplex der deutsch-russischen Fragen zu verhandeln und gegebenenfalls entsprechende Verträge zu unterzeichnen". 516 Molotow blieb aber, als er am 17. August abermals mit Schulenburg sprach, unerschütterlich dabei, daß der Besuch des Reichsaußenministers gut vorbereitet werden müsse, und mit bärenhafter Ironie setzte er hinzu, die Sowjetregierung scheue das Aufsehen, das eine derartige Reise hervorrufen würde; sie ziehe es vor, ohne viel Aufhebens praktische Arbeit zu leisten. In Wahrheit präsentierte er für den Empfang Ribbentrops in Moskau eine neue Bedingung: Nach Meinung der Sowjetregierung sei, wenn der Nichtangriffspakt abgeschlossen werde, zusätzlich ein „spezielles Protokoll“" zu vereinbaren, „das die Interessen der vertragschließenden Teile an diesen oder jenen Fragen der auswärtigen Politik regelt und das einen integrierenden Bestandteil des Paktes bildet" 517 .

Schulenburgs Bericht in Händen, ließ Ribbentrop noch am 18. August nach Moskau kabeln, der Botschafter habe sich für den 19., und zwar unbedingt schon für den Vormittag, einen weiteren Termin bei Molotow zu sichern. Er müsse dem Außenkommissar erklären, daß natürlich auch die Reichsregierung unter normalen Umständen eine bedächtigere Prozedur vorziehe: „Die ungewöhnliche gegenwärtige Lage mache aber nach Auffassung des Führers notwendig, eine andere Methode anzuwenden, die schnell zum Ziele führe. Die deutsch-polnischen Beziehungen verschärften sich von Tag zu Tag. Wir müßten damit rechnen, daß jeden Tag $Z$ wischenfälle eintreten könnten, die den Ausbruch eines offenen Konfliktes unvermeidlich machten. Nach der ganzen Haltung der Polnischen Regierung hätten wir die Entwicklung der Dinge in dieser Beziehung keineswegs in unserer Hand. Der Führer hält es für notwendig, sich bei Bemühungen um Klärung deutsch-russischen Verhältnisses nicht vom Ausbruch eines deutschpolnischen Konflikts überraschen zu lassen. Er hält vorherige Klärung schon deshalb für notwendig, um bei diesem Konflikt russischen Interessen Rechnung tragen zu können, was ohne solche Klärung natürlich schwer sei." Mithin sei eine sofortige Moskaureise des Reichsaußenministers dringend geboten, der mit einer Generalvollmacht des „Führers“ kommen werde, den Gesamtfragenkomplex erschöpfend und abschließend

515 Ebenda, Nr. 70.

516 Ebenda, Nr. 73, 75.

517 Ebenda, Nr. 105. 
zu regeln. Selbstverständlich sei der Reichsaußenminister auch in der Lage, „ein spezielles Protokoll zu unterzeichnen, das Interessen beider Teile in diesen oder jenen Fragen der auswärtigen Politik regelt, z.B. Regelung Interessensphäre im Ostsee-Gebiet, Frage Baltenstaaten usw." 518.

Der Botschaft Ribbentrops, die Schulenburg tatsächlich noch am 19. an den Mann brachte, konnten Stalin und Molotow, die ja sehr gut wußten, daß über den Zeitpunkt des Beginns deutsch-polnischer Feindseligkeiten allein in Berlin entschieden wurde, entnehmen, daß Hitler den Befehl zum Angriff auf Polen bereits in wenigen Tagen geben wollte und daher jetzt bereit war, zur vorherigen Sicherung eines dramatischen deutsch-sowjetischen Vertragsabschlusses in der Tat jede sowjetische Forderung zu erfüllen. Die Dinge hatten sich also ganz nach den Moskauer Wünschen entwickelt. Wohl um hinsichtlich des Angriffsdatums definitiv Klarheit zu gewinnen, spielten die nun so stürmisch umworbenen Sowjets aber noch einmal die Spröden. So hielt Molotow auch am 19. August - die Unterredung fand nicht, wie Ribbentrop angeordnet hatte, am Vormittag, sondern zwischen 14 und 15 Uhr nachmittags statt - zunächst hartnäckig daran fest, daß zwar die Reisepläne des Reichsaußenministers an sich positiv eingeschätzt werden müßten, es jedoch „vorläufig nicht möglich sei, auch nur annähernd den Zeitpunkt der Reise zu bestimmen“. Alle Gegenargumente des deutschen Botschafters prallten am sowjetischen Außenkommissar ab wie an einer Wand. Erst in einer zweiten Unterredung, zu der Schulenburg um 16.30 Uhr erneut in den Kreml gebeten wurde, verstand sich Molotow zu einer Konzession. Seit Ende Juli war zwischen den Wirtschaftsexperten der deutsch-sowjetische Handels- und Kreditvertrag ausgearbeitet und unterschriftsreif gemacht worden; er sollte an eben diesem 19. August in Berlin unterzeichnet werden. Finde die Unterzeichnung tatsächlich statt - was dann auch der Fall war -, so könne Ribbentrop, wie Molotow nun zugab, ja etwa eine Woche später, also am 26. oder 27. August, nach Moskau kommen. Zugleich erhielt Graf Schulenburg den sowjetischen Entwurf für einen Nichtangriffspakt zwischen Deutschland und der UdSSR ${ }^{519}$.

Wirklich stellte sich sogleich heraus, daß Hitler nicht einmal mehr sechs oder sieben Tage zu warten vermochte. In seinem Zeitplan gefangen und daher von steigender Nervosität befallen, unternahm er jetzt einen höchst ungewöhnlichen Schritt. Am Nachmittag des 20. August ging der Text eines Telegramms nach Moskau ab, das Hitler direkt an Stalin richtete. Der „Führer“ des Dritten Reiches flehte darin den sowjetischen Diktator förmlich an, den Reichsaußenminister doch schon am 22. August, „spätestens aber am Mittwoch, den 23. August zu empfangen“. Ribbentrop habe „umfassendste Generalvollmacht zur Abfassung und Unterzeichnung des Nichtangriffspakts, sowie des Protokolls“, versicherte Hitler, nachdem er 
zuvor schon klargemacht hatte, daß es beim Nichtangriffspakt eigentlich nicht mehr um „Abfassung“ gehe, sondern nur noch um „Unterzeichnung“: „Ich akzeptiere“, so ließ der „Führer" vorsorglich und werbend wissen, „den von Ihrem Außenminister Herrn Molotow übergebenen Entwurf des Nichtangriffspakts." 520 Natürlich sollte Graf Schulenburg das Telegramm Hitlers, das am 21. August um $0.45 \mathrm{Uhr}$ in Moskau eintraf, ,umgehend“ Molotow aushändigen, und ein nachgesandtes Telegramm Ribbentrops an Schulenburg befahl dem Botschafter, ,alle Energie“ walten zu lassen ${ }^{521}$. Doch verstrich, während Hitler und Ribbentrop auf Kohlen saßen, der ganze Vormittag, und erst um 15.00 Uhr nachmittags konnte Schulenburg das Telegramm des „Führers“ Molotow übergeben. Damit hatte die Spannung allerdings ein Ende. Der deutschen Absichten nun völlig sicher, und zwar sowohl im Hinblick auf Polen wie im Hinblick auf die Bereitschaft zum Vertragsabschluß mit der Sowjetunion, brauchte sich Stalin nicht länger zu zieren. Daß die deutsche Bereitschaft nicht mit einem aufrichtigen Willen zu einer längerfristigen Verständigung identisch, sondern ausschließlich zur Bewältigung momentaner Schwierigkeiten in der strategischen und taktischen Situation des Dritten Reiches gedacht war, ist den Sowjets auch jetzt nicht einen Augenblick lang unklar gewesen; in einer der Unterredungen mit Schulenburg hatte Molotow spöttisch bemerkt, das Beispiel Polen beweise, daß man die „Dauerhaftigkeit" von Nichtangriffspakten mit Deutschland bezweifeln müsse ${ }^{522}$. In der Gewißheit aber, daß der Angriff auf Polen, den man Hitler mit der sowjetischen Neutralität fraglos erheblich erleichterte, Deutschland in einen langwierigen Krieg mit den Westmächten verstricken werde, der das Reich von der UdSSR ablenken und überdies Moskau zunächst einmal störungsfreie eigene Raubzüge in Ost- und Südosteuropa ermöglichen mußte, in dieser Gewißheit durfte die reine Funktionalität der mithin lediglich temporär gemeinten neuen Rußlandpolitik Deutschlands, so glaubte Stalin, getrost ignoriert werden. Bereits um 17.00 Uhr wurde Graf Schulenburg wieder zu Molotow bestellt, der eine freundlich gehaltene Antwort Stalins auf das Telegramm Hitlers überreichte, an deren Ende der Satz stand: „Die Sowjetregierung hat mich beauftragt, Ihnen mitzuteilen, daß sie einverstanden ist mit dem Eintreffen des Herrn von Ribbentrop in Moskau am 23. August. gez. Stalin“ 523.

Der angeblich jedes Aufsehen scheuende Molotow schlug nun sogar vor, den Abschluß eines deutsch-sowjetischen Nichtangriffspakts und die Moskaureise Ribbentrops bereits am 22. August mit einem Kommuniqué der Weltöffentlichkeit anzukündigen, was in Berlin mit Vergnügen akzeptiert wurde ${ }^{524}$. Einen Tag später war es dann tatsächlich so weit. Ribbentrop und

520 Ebenda, Nr. 142.

521 Ebenda, Nr. 149.

522 ADAP, D, 6, Nr. 579.

523 ADAP, D, 7, Nr. 158, 159.

524 Ebenda, Nr. 160, 170. 
Molotow unterzeichneten, praktisch ohne weitere Verhandlungen, einen Nichtangriffs- und Neutralitätspakt, dazu ein geheimes Zusatzprotokoll, in dem Deutschland der Sowjetunion freie Hand gegenüber Finnland, Estland, Lettland und dem rumänischen Bessarabien zugestand; für den Fall „einer territorial-politischen Umgestaltung der zum polnischen Staate gehörenden Gebiete“ wurden „die Interessensphären Deutschlands und der UdSSR ungefähr durch die Linie der Flüsse Pissa, Narew, Weichsel und San abgegrenzt" ${ }^{25}$. Beide Partner waren - und in der Nacht vom 23. auf den 24. August fand das seinen Ausdruck in zahlreichen Trinksprüchen zufrieden: Das Dritte Reich hatte für den bevorstehenden Krieg den Rükken im Osten freigemacht und sich den Zugriff auf die wirtschaftlichen Ressourcen Rußlands gesichert, für die Sowjetunion war eine kräftige Westbewegung vorgezeichnet. Bei der Berliner Kriegspartei herrschte besondere Freude. Mochten die Bündnisgespräche mit dem AntikominternPartner Japan gescheitert sein, mochte der „Stahlpakt,-Partner Italien beunruhigende Zeichen seiner Neigung zur Desertion aus der Allianz geben, so war es nun auf der anderen Seite gelungen, ausgerechnet die bolschewistische Sowjetunion als Bundesgenossin zu gewinnen und damit dem Anschein nach all die anderen Fehlschläge mehr als wettzumachen.

\section{Die letzten Augusttage: Hitler zwingt Europa in den Krieg}

Noch am 24. August wieder nach Berlin zurückgekehrt, erstattete der erfolgstrunkene Ribbentrop seinem „Führer“ im Beisein Görings und Weizsäckers einen enthusiastischen Bericht über seine Moskauer Erfahrung, wobei er, der in den Augen der aus den frühen Stadien der NSDAP stammenden NS-Elite keineswegs als „alter Parteigenosse“ galt und in den Reihen der „Alten Kämpfer“ nicht einen Freund besaß, die hübsche Bemerkung machte, er habe sich in der sowjetischen Hauptstadt „gewissermaßen wie zwischen alten Parteigenossen gefühlt" 526 . Ansonsten aber konnte der Reichsaußenminister alsbald jene Entdeckung machen, die der „Führer“ bereits am Vortag zu ahnen begonnen hatte: Der deutsch-sowjetische Pakt, zuletzt so hektisch angestrebt und mit so beträchtlichen Konzessionen an die neuen Partner erkauft, brachte dem Dritten Reich zwar fraglos eine gewisse und im Hinblick auf die zu erwartende britische Blockade auch nicht unwichtige Verbesserung der wirtschaftlichen Situation, daneben jedoch lediglich eine leichte und angesichts des ohnehin sicheren Erfolgs gänzlich überflüssige militärische Entlastung für den Feldzug in Polen. Letzteres durfte schon Ende August genutzt werden, als die sowjetische Regierung

525 Ebenda, Nr. 228, 229.

526 Weizsäcker, Erinnerungen, S. 254. 
auf deutschen Wunsch Meldungen in der westeuropäischen Presse dementierte, die Sowjetunion reduziere die Truppen an ihrer Westgrenze, und das Dementi aus freien Stücken noch mit dem Zusatz versah, die Sowjetunion habe ihre Streitkräfte an der sowjetisch-polnischen Grenze natürlich nicht verringert, sondern verstärkt ${ }^{527}$.

Nicht daß der Pakt ohne politische Wirkungen geblieben wäre, doch handelte es sich durchweg um negative Effekte. So zeigte sich, daß Mussolini mit seiner Vorhersage recht behielt, eine zu weitgehende Annäherung an die UdSSR werde zu Unruhe in den auf Antibolschewismus gedrillten eigenen Reihen führen. Tatsächlich provozierte der Pakt in der völlig verstörten NS-Bewegung eine seit langem nicht mehr aufgetretene Neigung zu Kritik. Reichsleiter Alfred Rosenberg, der ideologische Papst der NSDAP, kommentierte am 22. August in seinem Tagebuch: „Unsere Presse läßt nach Anweisungen vom AA schon alle Würde vermissen... Als ob unser Kampf gegen Moskau - ein Mißverständnis gewesen sei und die Bolschewiken die wahrhaften Russen seien mit alten Sowjetjuden an der Spitze! Die Umärmelung ist mehr als peinlich." Und drei Tage später notierte Rosenberg, der die üble Versündigung an der antibolschewistischen Mission Deutschlands freilich nicht Hitler, sondern dem verhaßten Ribbentrop anlastete: „Ich habe das Gefühl, als ob sich dieser Moskau-Pakt irgendwann am Nationalsozialismus rächen wird." 28 Gewiß wäre die interne Kritik noch viel kräftiger und breiter ausgefallen, hätte sich nicht die Mehrzahl der NS-Funktionäre - wie die Mehrheit der Bevölkerung - für eine Woche in der beruhigenden Illusion gewiegt, mit dem deutsch-sowjetischen Vertrag sei es dem „Führer“ immerhin gelungen, einen großen europäischen Krieg in letzter Minute zu verhindern. Als taktischer Genieblitz, der die Westmächte vom Kriegseintritt abhielt und damit, von Polen abgesehen, den Frieden sicherte, wurde der ideologisch-politische „Verrat“ verziehen oder doch milder beurteilt. Allerdings versetzte der Pakt auf der anderen Seite - was der NS-Führung vorerst verborgen blieb - etliche der bereits entstandenen konservativ-nationalen Widerstandsgruppen in Aufregung und frischen Umsturzeifer, weil sie von der Verbindung zwischen $\mathrm{Na}$ tionalsozialisten und Bolschewiken eine Kräftigung des linken Flügels der NS-Bewegung und jener traditionsfeindlichen Tendenzen der NS-Politik befürchteten, die sie gelegentlich mit der Bezeichnung „brauner Bolschewismus" charakterisierten ${ }^{529}$. Auf außenpolitischem Felde sahen die Dinge nicht besser aus. Am 25. August hielt Ribbentrop einen Einspruch der japanischen Regierung gegen den deutsch-sowjetischen Vertrag in Händen,

527 ADAP, D, 7, Nr. 360, 387, 388, 424, 446.

528 Das politische Tagebuch Alfred Rosenbergs aus den Jahren 1934/35 und 1939/40, hrsg. v. H.-G. Seraphim, Göttingen 1956, S. 73, 75.

529 H. Mommsen, Gesellschaftsbild und Verfassungsplāne des deutschen Widerstandes $\mathrm{H}$. Graml, Die außenpolitischen Vorstellungen des deutschen Widerstandes, in: $\mathrm{H}$. Graml (Hrsg.), Widerstand im Dritten Reich, Frankfurt 1986. 
der, so verstand man es in Tokio, mit dem Geiste des Antikominternpakts unvereinbar sei, und am 28. August stürzte die japanische Regierung. Ministerpräsident Hiranuma begründete die Demission des Kabinetts vornehmlich damit, daß die sonderbare Lage, welche durch den deutsch-russischen Pakt entstanden sei, eine völlige Neuorientierung der japanischen Außenpolitik notwendig mache 530 .

In Europa wurde indes nicht einer der politischen Zwecke erreicht, die man in Berlin mit Ribbentrops Moskaureise zu erreichen gehofft hatte. Sicherlich hatte die Sowjetunion nun definitiv und vor aller Welt darauf verzichtet, sich mit den Westmächten gegen Deutschland zu verbinden; am 25. August reiste die britisch-französische Militärmission aus Moskau ab. Aber abgesehen davon, daß gleichzeitig Deutschland seine bisher beanspruchte Wächterrolle gegen das bolschewistische Rußland aufgab und damit die letzten europäischen Sympathien für das Dritte Reich dahinschwanden, war dieser Verzicht Moskaus schon mit der zunächst einmal zugestandenen Stärkung des potentiellen Hauptopfers der NS-Politik unverantwortlich hoch bezahlt worden. Und daneben trat nicht die geringste Veränderung in der europäischen Konstellation ein. Bereits am 23. August zeigte sich, daß die Bundesgenossenschaft Italiens nicht um ein Jota sicherer gemacht worden war. Um $10 \mathrm{Uhr}$ vormittags wurde Reichsfinanzminister Graf Schwerin-Krosigk, der sich gerade in Rom aufhielt, von Graf Ciano empfangen, und anschließend berichtete Graf Schwerin ungesäumt nach Berlin, daß der italienische Außenminister wohl die Bedeutung der Reise Ribbentrops nach Rußland gewürdigt, jedoch hinzugefügt habe, daß der Moskauer Paktabschluß leider, wie ihm das die Botschafter Großbritanniens und Frankreichs „soeben ausdrücklich und sehr ernst bestätigt" hätten, ohne Einfluß auf die Polen - und Deutschlandpolitik der Westmächte bleiben werde; mithin ändere sich auch nichts an der Lage Italiens, für das der bei einem deutschen Angriff nach wie vor unvermeidliche Krieg gegen Briten und Franzosen um mindestens drei Jahre zu früh komme ${ }^{531}$. Was den Kurs Englands betraf, so beeilte sich Premierminister Chamberlain, noch am 22. August, kaum daß Ribbentrops Moskaureise bekannt geworden war, Hitler in einem Brief - der dem „Führer“ am nächsten Tag ausgehändigt wurde - klipp und klar zu sagen, daß er nicht glauben dürfe, mit dem deutsch-sowjetischen Vertrag Englands Bündnistreue gegenüber Polen erschüttert zu haben. „Kein größerer Fehler“, so schrieb Neville Chamberlain, „könnte begangen werden. Welcher Art auch immer das deutschsowjetische Abkommen sein wird, so kann es nicht Großbritanniens Verpflichtung gegenüber Polen ändern." Der Premier, der auf die - oberflächlich gesehen - blamable diplomatische Niederlage der Westmächte durchaus angemessen, ja eindrucksvoll reagierte, nämlich mit fester Entschlos-

531 ADAP, D, 7, Nr. 227. 
senheit, tiefem Ernst und souveräner Würde, setzte hinzu: „Es ist behauptet worden, daß, wenn Seiner Majestät Regierung ihren Standpunkt im Jahre 1914 klarer dargelegt hätte, jene große Katastrophe vermieden worden wäre. Unabhängig davon, ob dieser Behauptung Bedeutung beizulegen ist oder nicht, ist Seiner Majestät Regierung entschlossen, dafür zu sorgen, daß im vorliegenden Falle kein solch tragisches Mißverständnis entsteht." 532 Die Kernpunkte dieses Schreibens wurden am Abend des 22. August in Form einer offiziellen Regierungserklärung auch veröffentlicht. Danach lag der Kurs Frankreichs ebenfalls fest, wo aber ein großer Kriegsrat der führenden Politiker und Militärs am 23. August auch noch ausdrücklich feststellte, wie vor dem deutsch-sowjetischen Vertrag habe Frankreich auch jetzt keine andere Wahl, als Polen gegen einen deutschen Angriff beizustehen ${ }^{533}$. Mit anderen Worten: die deutsch-sowjetische Vereinbarung war sicherlich - trotz der seit langem kursierenden Gerüchte und der seit langem gehegten Befürchtungen - eine saftige politische Sensation, doch im Grunde kein rechter politischer Erfolg Berlins.

Nicht einmal in dem Staat, der während der kommenden Wochen und Monate mit Sicherheit am meisten Leid zu erwarten hatte, in Polen, übte der Pakt, den Ribbentrop in Moskau abgeschlossen hatte, irgendeinen praktischen Einfluß aus, obwohl nun feststand, daß das Schicksal des Landes - zumindest kurzfristig - die vierte Teilung sein werde. Naturgemäß hatte man in Warschau die deutsch-sowjetischen Kontakte genau beobachtet und die Verständigung zwischen Nationalsozialisten und Bolschewiken durchaus kommen sehen. Zwar nicht der polnische Botschafter in Moskau. Grzybowski hatte die Stadien der deutsch-sowjetischen Annäherung mit bagatellisierenden Kommentaren begleitet und eine Verständigung zwischen Berlin und Moskau stets als unmöglich hingestellt ${ }^{534}$. In seinem wohl letzten Bericht aus Moskau setzte dann der Botschafter am 29. August Außenminister Beck auseinander, daß der entgegen seinen Prognosen nun doch zustande gekommene deutsch-sowjetische Vertrag politisch im Grunde bedeutungslos sei: „Sie werden sehen, daß der Pakt bis Sonntag vorbei ist"" 535 In Warschau selbst war man jedoch realistischer gewesen, und auch das Resultat der deutsch-sowjetischen Verhandlungen wurde jetzt ernster beurteilt als von Grzybowski. Aber an den politischen und militärischen Entschlüssen änderte sich nichts, der Wille zum Widerstand erfuhr nicht die geringste Schwächung. Noch vor der Vertragsunterzeichnung in Moskau, am 17. August, hatte der im polnischen Innenministerium für Minderheitenfragen zuständige Ministerialdirektor Zyborski einen der Führer der deutschen Minderheit, Senator Hasbach, empfangen, der „beabsichtigte, die Beschwerden der deutschen Volksgruppe über die ge-

532 Ebenda, Nr. 200.

533 G. Bonnet, La Defense de la Paix, Bd. II, Genf 1953, S. 305 ff.

534 Szembek-Tagebuch, S. $378 \mathrm{ff} ., 641,740$.

535 Ebenda, S. 711. 
genwärtige Unterdrückung und Verfolgung an der Hand einer überreichten Denkschrift zur Sprache zu bringen“. Zyborski fand es „erstaunlich, daß die deutsche Volksgruppe glaube, in diesem Augenblick mit irgendwelchen Einzelbeschwerden kommen zu können“, wo doch die Absichten Berlins auf eine restlose Aufteilung Polens hinausliefen. „An der Hand einer vorliegenden Karte Polens, in der die Siedlungslage der Nationalitäten eingetragen war, führte Zyborski aus, wie nach den Informationen Warschaus die Teilungsabsichten Berlins seien. Er legte dar, daß man in Berlin eine neue Grenzziehung beabsichtige mit einem Bogen, der von Ostpreußen dicht an den Toren Warschaus vorbei bis Oberschlesien geht; dann sei Galizien als altes österreichisches Kronland und selbstverständlich das Herzogtum Teschen das Ziel der deutschen Wünsche. Die übrig bleibenden Gebiete sei man bereit, Rußland zu übergeben." Auch sprach Zyborski davon, daß am Ende die „Aussiedlung“ aller Polen nach Sibirien kommen werde. Jedoch werde sich das polnische Volk, so schloß der Ministerialdirektor, „gegenüber der vom Reich eingeleiteten 4. Teilung Polens mit allen zu Gebote stehenden Mitteln zur Wehr setzen“536. Graf Lubienski, Becks Kabinettschef, konstatierte - gewiß beeindruckt, doch ohnehin fatalistisch gestimmt - lediglich, der deutsch-sowjetische Pakt bedeute eigentlich keine Veränderung der Situation, da „Rapallo“ im Grunde immer in Kraft gewesen sei537.

Nicht anders reagierte die polnische Bevölkerung. Ihre Stimmung war naturgemäß schon vor dem Moskauer Paktabschluß düster gewesen: im Hinblick auf den als unausweichlich erwarteten Krieg mitsamt der Niederlage und der Besetzung des Landes, dazu unter dem Eindruck einer allmählich bis zum Stillstand fortschreitenden Lähmung von Handel und Wandel, die, verursacht von der nun bereits seit Monaten andauernden Spannung und Kriegsfurcht, mittlerweile fast jedermann traf. Am 18. Juli schickte der deutsche Generalkonsul in Posen einen Bericht an das Auswärtige Amt, in dem bei der Schilderung der polnischen Stimmung nur Wörter wie „niedergeschlagen“, „gedrückt“, „Beklemmung“ und „Unsicherheit“ gebraucht wurden ${ }^{538}$. Eine solche Charakterisierung stand freilich in krassem Gegensatz zur offiziellen Lesart vom Übermut der Polen, und daher wies der Geschäftsträger in Warschau, Johannes v. Wühlisch, der inzwischen Gefangener der eigenen Propaganda geworden war, am 25. Juli sämtliche deutschen Konsulate in Polen an, sofort Berichte über die Stimmung im Lande vorzulegen. Mit der geballten Wucht der gesammelten Eindrücke hoffte er, den Generalkonsul in Posen - der ja nur, wie er dem eigentlichen Empfänger des Posenschen Memorandums, dem Leiter der Ostabteilung im Auswärtigen Amt, Schliep, versicherte, seinen „engeren Amtsbezirk“ übersehe schlagend $\mathrm{zu}$ widerlegen ${ }^{539}$. Nachdem einige Tage später die Stellungnah-

536 Vermerk, 18.8.1939, PAA, Büro Staatssekretār, Polen 1, $35015 \mathrm{f}$.

537 Szembek-Tagebuch, S. 689.

538 Generalkonsulat Posen an AA, 18.7.1939, PAA, Botschaft Warschau.

539 Wühlisch an Schliep, 25.7.1939, PAA, Botschaft Warschau. 
men aus Krakau, Lemberg, Kattowitz, Thorn, Lodz und Teschen eingelaufen waren, ergab sich jedoch, und zwar trotz des erkennbaren Bemühens der Autoren, den offenkundigen Wünschen des Auftraggebers entgegenzukommen, daß der Posener Generalkonsul, der in seinem zweiten Bericht mannhaft seine am 18. Juli niedergelegte Auffassung wiederholte, praktisch bestätigt wurde. Allerdings stellte sich ebenfalls heraus, daß sich die allgemeine Niedergeschlagenheit offensichtlich sehr wohl mit der - oft von der Hoffnung auf die Hilfe der Westmächte gestützten - Entschlossenheit zum Widerstand gegen den in Kürze losbrechenden deutschen Angriff vertrug und daß die lange Dauer der Krise dieser Entschlossenheit kaum etwas anzuhaben vermochte ${ }^{540}$. Nach der Meldung von der deutsch-sowjetischen Verständigung, deren Bedeutung für das polnische Schicksal in Polen niemand erklärt zu werden brauchte, lastete die düstere Stimmung gewiß noch schwerer auf dem Land, doch blieb der Wille, sich zu wehren, ungebrochen.

Hitler freilich könnte in der Aussicht auf die unmittelbar bevorstehende Vertragsunterzeichnung für einige Augenblicke tatsächlich noch einmal in die Illusion zurückgefallen sein, ein deutsch-sowjetischer Pakt werde die Westmächte davon abhalten, an der Seite Polens in den Krieg gegen Deutschland einzutreten. Als er am 22. August die Spitzen der drei Wehrmachtteile ein letztes Mal auf dem Obersalzberg versammelte, um sie mit einer großen Ansprache psychisch für den Kriegsbeginn zu wappnen, hat er jedenfalls Ribbentrops Moskaureise zur Beruhigung der Militärs benutzt und dabei gesagt: „Damit habe ich den Herrschaften [in England und Frankreich] ihre Waffen aus der Hand geschlagen. Polen ist in die Lage hineinmanövriert worden, die wir zum militärischen Erfolg brauchen." Einige der naiveren Generäle und Admiräle dürften solche Sätze denn auch in der Tat als krönende Argumente für die von Hitler mit großer Verve verfochtene Behauptung verstanden haben, Großbritannien und Frankreich seien weder willens noch fähig, Polen militärisch beizustehen. Jedoch ist es in Wahrheit unglaubhaft, daß sich der „Führer" selber in derartigen Illusionen gewiegt hat. Ein allzu beträchtlicher Teil seiner Ansprache war bereits dem Zweck gewidmet, seine Zuhörer mit dem Gedanken vertraut zu machen, daß es wohl auch gegen die Westmächte gehen werde, und dafür hatte er die simple und im Moment ja auch militärisch durchaus anwendbare Formel parat: „Wir werden den Westen halten, bis wir Polen erobert haben." Im Grunde lief seine Rede auf den - gelungenen - Versuch hinaus, die im Hinblick auf einen Westkrieg tief besorgten Offiziere bei der Gewohnheit schlichter Befehlsausführung zu halten und ihr Vertrauen zur politischen Leitung möglichst ungeschmälert zu bewahren, indem er einer-

540 Konsulat Teschen, 27.7., Konsulat Krakau, 27.7., Konsulat Lemberg, 27.7., Generalkonsulat Kattowitz, 27.7., Generalkonsulat Thorn, 29.7.1939, Botschaft Warschau (zusammenfassender Bericht), o.D. (Anfang August 1939), PAA, Botschaft Warschau. 
seits das angenehme Unwahrscheinliche als das Wahrscheinliche vorgaukelte, aber andererseits das tatsächlich und gefürchtete Wahrscheinliche als das zwar Unwahrscheinliche, doch selbstverständlich Einkalkulierte immerhin erwähnte. Ähnliche Zwecke verfolgte Hitler, wenn er in jenen Tagen mit anderen deutschen Funktionären sprach, etwa mit seinen Diplomaten, wie am 23. und 24. August mit Staatssekretär v. Weizsäcker, der in diesen Gesprächen glatt bestritt, daß der deutsch-sowjetische Vertrag die Deutschland- und Polenpolitik der Westmächte beeinflussen werde ${ }^{541}$. Für seine eigene Rechnung wird es Hitler genügt haben, daß er mit dem Moskauer Pakt der kommenden britischen Blockade ihre Gefährlichkeit weitgehend genommen hatte. Wie wenig der „Führer“ jetzt noch auf die Meinung und mithin auch auf die Politik Westeuropas gab, verriet er am 22. August nicht zuletzt dadurch, daß er den versammelten Militärs sowohl für die Kriegführung gegen Polen wie für die deutsche Politik im besetzten Polen eine Brutalität ankündigte, mit der sich Deutschland für eine Weile aus dem Kreis der zivilisierten Staaten ausschließen mußte. Immer wieder gebrauchte er Wendungen wie „brutales Vorgehen“, „hart und rücksichtslos", "gegen alle Erwägungen des Mitleids hart machen“, und in diesem Sinne sagte er, wie Generalstabschef Franz Halder notierte: „Ziel: Vernichtung Polens $=$ Beseitigung seiner lebendigen Kraft. Es handelt sich nicht um Erreichen einer bestimmten Linie oder einer neuen Grenze, sondern um Vernichtung des Feindes, die auf immer neuen Wegen angestrebt werden muß.“ Jede „sich neu bildende lebendige polnische Kraft" sei „sofort wieder zu vernichten" 542 .

Im sicheren Gefühl, die besseren Karten in der Hand zu haben und den Krieg getrost riskieren zu können, beantwortete daher Hitler den Brief, in dem Chamberlain am 22. August dargetan hatte, daß die deutsch-sowjetische Verständigung nichts an den polnischen Verpflichtungen Großbritanniens ändere, am folgenden Tag mit einem ebenso verlogenen wie vor allem naßforschen Schreiben ${ }^{543}$. So sprach der "Führer" von der "Welle furchtbaren Terrors", die über die Deutschen in Polen hereingebrochen sei, von den „entsetzlichen Greueln“, die an ihnen verübt würden. Aber abgesehen davon, daß das Los der Deutschen in Polen die nationalsozialistischen Herren Deutschlands bis zum Frühjahr 1939 ohnehin keinen Deut gekümmert hatte, schäumte die „Welle furchtbaren Terrors“ auch jetzt allein im Reich der Propaganda, in dem allerdings die zuständigen Abteilungen der „Volksdeutschen Mittelstelle“ und des Reichspropagandaministeriums nicht weniger erfindungsreich und produktiv waren als im Vorjahr

541 Weizsācker, Erinnerungen, S. $252 \mathrm{ff}$.

542 Halder, Kriegstagebuch, S. 25; vgl. IMT, XXVI, S. 338 ff.; W. Baumgart, Zur Ansprache Hitlers vor den Führern der Wehrmacht am 22. August 1939. Eine quellenkritische Untersuchung, in: VfZ 16 (1968), S. 120-149; ders., Zur Ansprache Hitlers vor den Führern der Wehrmacht am 22. August 1939, in VfZ 19 (1971), S. 301-304.

543 ADAP, D, 7, Nr. 200, 201. 
während der Sudetenkrise. Tatsächlich gehört es zu den auffallendsten Erscheinungen jener Monate, daß es zwar seit dem Frühjahr 1939 immer wieder zu kleineren Zusammenstößen zwischen angstvoll-gereizten Polen und Deutschen kam, ob letztere nun im Hinblick auf den bevorstehenden Einmarsch der deutschen Armee freudige Erwartung an den Tag legten oder nicht, daß aber die Zahl schwerer Zwischenfälle erstaunlich gering blieb; bei ernsteren Anschlägen oder Auseinandersetzungen handelte es sich im übrigen fast stets um das Werk der Agenten reichsdeutscher Einrichtungen, namentlich des SD und der Gestapo, gegen deren Treiben die deutschen Konsulate im Juli und August ebenso fruchtlos protestierten wie im April und Mai544. Ferner behauptete Hitler, daß Polen versuche, „durch wirtschaftliche Maßnahmen die Freie Stadt Danzig umzubringen, das heißt, durch eine Art von Zollblockade der Danziger Bevölkerung die Lebensgrundlagen zu vernichten“, und diese Behauptung war womöglich noch weiter von der Wahrheit entfernt als sein Märchen von den „entsetzlichen Greueln“. Die wirtschaftlichen Schwierigkeiten und die Zollprobleme Danzigs kamen - wenn man von der allgemeinen wirtschaftlichen Misere im polnischen Hinterland absieht - allein auf das Konto der Provokationen und Schikanen, die sich die nationalsozialistischen Satrapen in Danzig ausdachten, mittlerweile unterstützt von einem der auf die Produktion von Krisen spezialisierten Handlanger Hitlers, von Edmund Veesenmayer, der sich bereits im Sommer 1938 und dann Mitte März 1939 in der Slowakei schmutzigen Lorbeer verdient hatte.

Vor Brauchitsch und Halder hatte Hitler den wahren Gehalt der antipolnischen Anklagen am 14. August selber demaskiert, als er die relative Passivität der Polen ausdrücklich als Argument dafür ins Treffen führte, daß man sich in Warschau der britischen und französischen Hilfe keineswegs sicher sei: „Wenn Zusagen Englands gegeben würden, wäre Polen viel frecher." 545 Auch gab er bei solchen Gelegenheiten ohne weiteres zu, daß er über die sehr erfolgreichen britisch-französischen Einwirkungen auf Warschau, doch um Gottes willen Zurückhaltung zu üben und den Deutschen keine Vorwände zu liefern, wohl unterrichtet war. Ebenso wußte er, daß seine Erfindungen und Aufbauschungen außerhalb Deutschlands von jedermann durchschaut wurden, erst recht von seinen politischen und diplomatischen Mit- und Gegenspielern. Aber derartige Kleinigkeiten konnten den Mann, der im Begriff stand, große Geschichte zu machen, nicht mehr kümmern. Wie sagte er am 22. August: „Ich werde propagandistischen Anlaß zur Auslösung des Krieges geben, gleichgültig, ob glaubhaft. Der Sieger wird später nicht danach gefragt, ob er die Wahrheit gesagt hat oder nicht." Er hatte denn auch bereits Unternehmen in Auftrag gegeben, mit denen er,

544 Bericht Konsulat Lemberg, 10.6.1939; Generalkonsult Thorn, 19.8.1939, PAA, Botschaft Warschau; dazu Wühlisch an AA, 18.8.1939, ADAP, D, 7, Nr. 106.

545 Halder, Kriegstagebuch, S. 11. 
vornehmlich zur propagandistischen Beeinflussung der eigenen Nation, im passenden Augenblick sogar - über polnischen „Terror" in Polen hinaus polnische militärische Aktionen auf reichsdeutschem Boden vorzuspiegeln gedachte. Sein Scherge Heydrich bereitete z. B. einen Überfall auf den Sender Gleiwitz vor, den Spezialisten des SD in polnischen Uniformen durchzuführen und bei dem auch - um die Glaubwürdigkeit zu erhöhen - am Ort der Handlung Tote in polnischen Uniformen zurückzubleiben hatten, nämlich zu diesem Zweck ermordete - im internen Sprachgebrauch „Konserven" genannte - Konzentrationslagerhäftlinge ${ }^{546}$.

So nahm der "Führer" in seinem Antwortschreiben keinen Anstand, dem britischen Premier mitzuteilen, daß er "die Frage Danzig und die des Korridor" - wobei er bei letzterer das "Wie" offen ließ - lösen werde, ob das den Briten passe oder nicht. Chamberlains Warnung, Hitler dürfe nicht glauben, der deutsch-sowjetische Pakt werde ihm ein strafloses Vorgehen gegen Polen erlauben, quittierte er mit dem Satz: „Sie teilen mir, Exzellenz, im Namen der Britischen Regierung mit, daß Sie in jedem solchen Fall des Einschreitens Deutschlands gezwungen sein werden, Polen Beistand zu leisten. Ich nehme diese Ihre Erklärung zur Kenntnis und versichere Ihnen, daß sie keine Änderung in die Entschlossenheit der Reichsregierung bringen kann. " Daß Chamberlain in seinem Brief darauf hingewiesen hatte, sein Kabinett werde am 24. August vom Unterhaus ein Ermächtigungsgesetz bekommen, bewog den Oberbefehlshaber einer Armee, die ihren Aufmarsch an den deutschen Grenzen schon fast vollendet hatte und kurz vor dem Einfall in Polen stand, zu der ungewöhnlich heuchlerischen, vor allem aber spannungsverschärfenden Erwiderung, die Reichsregierung habe Kenntnis davon erhalten, daß die britische Regierung Mobilmachungsmaßnahmen beabsichtige, die gegen Deutschland gerichtet seien: „Ich teile daher Euerer Exzellenz mit, daß ich im Falle des Eintreffens dieser militärischen Ankündigungen die sofortige Mobilmachung der deutschen Wehrmacht anordnen werde." Die Unterredung, während der Hitler ein derartiges Schreiben dem britischen Botschafter zur Lektüre und zur Weiterleitung nach London übergab, verlief entsprechend stürmisch; der Augenzeuge Weizsäcker charakterisierte Hitlers Gehabe als „hysterisch" 547 . Nachdem Sir Nevile Henderson das Zimmer in Hitlers „Berghof“, wo die Unterhaltung über die Bühne gegangen war, verlassen hatte, schlug sich der „Führer“ freilich auf die Schenkel und sagte lachend: „Dieses Gespräch überlebt Chamberlain nicht, sein Kabinett wird heute abend stürzen."548 Hitler wußte natürlich sehr gut, daß nichts weniger wahrscheinlich war als der Sturz eines britischen Kabinetts, das gerade besondere Vollmachten bekam, und selbst er wußte gut genug, daß der Nachfolger Chamberlains,

$546 \mathrm{~J}$. Runzheimer, Die Grenzzwischenfälle am Abend vor dem deutschen Angriff auf Polen, in: W. Benz/H. Graml, Sommer 1939, S. 107-147.

547 Weizsācker, Erinnerungen, S. 252.

548 Ebenda. 
wenn denn die große Symbolfigur der Apppeasement-Politik fallen sollte, ein anderer sein würde als ein weiterer Appeaser. Die Bemerkung ist nur zu erklären, wenn man sie ganz simpel als Ausdruck dafür nimmt, daß Hitler die Haltung Großbritanniens gleichgültig geworden war. Vermutlich wollte er lediglich sagen: ,Jetzt hab ich's aber diesen hochnäsigen Briten noch einmal tüchtig gegeben, bevor's losgeht."

Es hat denn auch weder das Denken noch das Handeln Hitlers in irgendeiner Weise beeinflußt - noch überhaupt einen Berliner Kommentar hervorgerufen -, daß das Kabinett Chamberlain, statt am Abend des 23. zu stürzen, am 24. August das gewünschte Ermächtigungsgesetz tatsächlich bekam und der Premier in einer großen - wenngleich gewohnt trockenen Rede vor dem Unterhaus erneut kategorisch versicherte, daß Großbritannien und Frankreich trotz des nunmehr unterzeichneten deutsch-sowjetischen Pakts ihre Polen gegenüber eingegangenen Verpflichtungen selbstverständlich erfüllen würden. Dies hinderte Hitler nicht daran, am Nachmittag des gleichen 24. einen Plan zur Besorgung eines weiteren propagandistisch verwertbaren $Z$ wischenfalls zu genehmigen, nämlich einen Plan zur Zuspitzung der Krise in und um Danzig, den Edmund Veesenmayer inzwischen ausgeheckt hatte. Am 21. August hatte Veesenmayer dem Auswärtigen Amt - lediglich zur Information - mitgeteilt, sein Plan sehe folgendermaßen aus: „1. Nach längeren Verhandlungen in der Zollbeamtenfrage deren endgültiges Scheitern. Schuld auf Seite der Polen. 2. Dann erfolgt völlige Beseitigung aller polnischen Zollbeamten und Aufhebung der Zollgrenze nach Ostpreußen. 3. Es erfolgen Reaktionen der Polen so oder so. 4. Daraufhin Festnahmen zahlreicher Polen im Danziger Gebiet und Aushebung zahlreicher polnischer Waffenlager. Die Auffindung dieser Waffenlager ist gesichert. 5. Erfolgt darauf keine ausreichende Aktion der Polen als Antwort, dann soll zuletzt die Westerplatte [eine zu Polen gehörende Landzunge im Danziger Hafengebiet] angegangen werden." Am 24. abends erhielt nun Weizsäcker von Veesenmayer die Nachricht, daß der Plan bis auf Punkt 4 vom „Führer" gebilligt worden sei549. Einen Tag zuvor hatte übrigens der Danziger Senat - in klarem Widerspruch zur Rechtslage - den Gauleiter der Danziger NSDAP, Albert Forster, zum Staatsoberhaupt der Freien Stadt erklärt, vermutlich um ihm so etwas wie eine völkerrechtliche Plattform zur Proklamierung der Vereinigung Danzigs mit dem Reich zu schaffen. Polen protestierte, konnte aber nichts unternehmen, da es sonst seinerseits - und gegen den Willen der Westmächte - zur Verschärfung der Situation beigetragen hätte.

Danach hielt der „Führer" noch drei weitere vorbereitende Schritte für erforderlich. Im Laufe des 25. August, in der ersten Tageshälfte, entstand ein Brief an Mussolini, in dem Hitler seinem Freund zunächst die Eile in

549 Veesenmayer an Weizsäcker, 21.8.1939, PAA, Büro Staatssekretär, Polen 2, 35059; ADAP, D, 7, Nr. 244. 
der letzten Phase der deutsch-sowjetischen Verhandlungen und etwas entschuldigend die bereits erreichte Enge der deutsch-sowjetischen Beziehungen zu erklären suchte; der Duce hatte ja davor gewarnt, bei der Annäherung an Moskau zu weit zu gehen. Anschließend erläuterte Hitler jedoch, daß der Angriff auf Polen nun nur noch eine Frage von Tagen sei, und er gab dem „Stahlpakt,,-Partner zu verstehen, daß er auf Italiens Bündnistreue zähle. Am Nachmittag, 15.20 Uhr, hat Botschafter v. Mackensen dieses Schreiben Mussolini überreicht ${ }^{550}$. Kurz nach Mittag traf Hitler ferner, inzwischen vom Obersalzberg nach Berlin zurückgekehrt, mit dem in die Reichskanzlei bestellten Sir Nevile Henderson zusammen. Im Ton konzilianter als am 23. August, setzte er dem britischen Botschafter auseinander, er habe sich - angeregt durch Hendersons Äußerung vom 23., er hoffe noch immer auf eine deutsch-britische Verständigung - „die Dinge noch einmal durch den Kopf gehen lassen und wolle heute England gegenüber einen Schritt unternehmen, der genau so entscheidend sei wie der Schritt Rußland gegenüber, der zu der kürzlichen Vereinbarung geführt habe“. Natürlich müsse ihm zugebilligt werden, so fügte er eilends hinzu, zuerst einmal die Probleme „Danzig und Korridor" zu lösen, wobei er wiederum offenließ, was er im Falle des Korridors unter Lösung verstand; Deutschland könne die "mazedonischen Zustände an seiner Ostgrenze" nicht länger hinnehmen. Danach aber werde er, dazu sei er bereit und entschlossen, ,an England mit einem großen und umfassenden Angebot herantreten". Er bejahe das Britische Imperium und sei willens, „sich für dessen Bestand persönlich zu verpflichten und die Kraft des Deutschen Reiches dafür einzusetzen“, sofern die begrenzten kolonialen Forderungen Deutschlands erfüllt und die Verpflichtungen des Reiches respektiert würden, die sich aus dessen freundschaftlichem Verhältnis mit Italien und neuerdings auch mit Rußland ergäben 551 . Henderson übernahm es, dieses "große Angebot“ am nächsten Morgen persönlich nach London zu bringen und dem Premierminister vorzulegen. Schließlich empfing Hitler um 17.30 Uhr noch Robert Coulondre, den französischen Botschafter, um ihm eine ähnliche Botschaft an Ministerpräsident Daladier aufzutragen. Im Falle Frankreichs begnügte er sich allerdings damit, die Ankündigung des Angriffs auf Polen mit der Erklärung zu verbinden, daß er keinen Krieg mit dem westlichen Nachbarn wünsche und Elsaß-Lothringen doch schon als französischen Besitz anerkannt habe. Mit derartigen Stückchen aus dem Arsenal seiner Diplomatie glaubte der „Führer“ sein Szenario komplettiert zu haben, und zwischen den Gesprächen mit den Vertretern der Westmächte, um 15.02 Uhr, erteilte er der Wehrmacht den Angriffsbefehl: Am Morgen des 26. August,

550 ADAP, D, 7, Nr. 266.

551 Ebenda, Nr. 265.

552 Gelbbuch der Französischen Regierung. Diplomatische Urkunden 1938 bis 1939, Basel 1940, S. 327 ff.; Coulondre, Von Moskau nach Berlin, S. $421 \mathrm{ff}$. 
4.30 Uhr, hatten sich danach die deutschen Streitkräfte gegen Polen in Bewegung zu setzen 553 .

Von den drei diplomatischen Schritten des 25. August hat Hitler allerdings, das ist ohne weiteres zu sehen, lediglich den ersten so gemeint, wie er selbst sie nach außen darbot. Den Kriegseintritt Italiens an der Seite Deutschlands wünschte er in der Tat, wie sich wenig später noch ganz klar zeigen sollte, und das ist allein schon ein schlagender Beweis dafür, daß er, wie das ja auch seiner immer deutlicher zu Tage getretenen eigenen Einschätzung der britisch-französischen Politik entsprach, nicht mehr damit rechnete, das Eingreifen der Westmächte durch diplomatische Aktivitäten noch verhindern zu können; bei einem lokalisierten Feldzug gegen Polen wären die Italiener nicht gebraucht worden und hätten auch gar keinen Feind gehabt, wie er zum Kriegführen doch wohl nötig ist. Kalkulierte er aber die Intervention Großbritanniens und Frankreichs ein, dann konnten die Gesten, die er gegenüber London und Paris machte, unmöglich - über eine durch Verwirrung vielleicht zu erreichende Verzögerung des Kriegseintritts hinaus - zur Beeinflussung der Politik Englands und Frankreichs gedacht sein. Daß die Parallelen zur diplomatischen Musik, mit der er Aktionen wie die Remilitarisierung des Rheinlands und die Isolierung der Tschechoslowakei begleitet hatte, tatsächlich nur scheinbar waren, ließ sich jedoch auch an anderen Indizien ablesen.

Sowohl Henderson wie Coulondre haben dem „Führer“ mit allem Nachdruck, dessen sie fähig waren, zum soundsovielten Male versichert, daß eine Überschreitung der polnischen Grenze durch deutsche Truppen für ihre Länder den Bündnisfall bedeuten werde; Hitler hat das achselzuckend zur Kenntnis genommen und sich davon nicht abhalten lassen, den Angriffsbefehl zu geben. Auch setzte er die deutschen Armeen in Bewegung, ohne die - falls ernst gemeint, doch zumindest fragliche - Wirkung seiner Manöver abzuwarten. Was das ,große Angebot" an London betraf, so stand sogar fest, daß sich die britische Regierung damit frühestens am Vormittag des 26. August eingehender zu beschäftigen vermochte, also erst nach dem Beginn der deutschen Offensive, und die Vorstellung, das britische Kabinett könne für die Rückkehr auf Appeasementkurs gewonnen werden, während und womöglich weil bereits deutsche Panzer über polnische Straßen rasselten und zahllose polnische Ortschaften in Flammen standen, ist so abenteuerlich, daß sie nicht einmal einem Dilettantismus mit Brutalität verbindenden Politiker wie Hitler unterstellt werden kann. Dies alles gilt erst recht, wenn man die Natur seiner Offerten ins Auge faßt. Mit Frankreich machte er sich überhaupt keine Mühe: daß er Daladier mitteilen ließ, die Franzosen dürften Elsaß-Lothringen behalten, wenn sie seine Kreise in Polen nicht störten, war gewiß eine Dreistigkeit, vornehmlich aber eine leere Geste, die Paris nicht den kleinsten Anreiz zum Verzicht auf die pro-polni- 
sche Intervention offerierte. Bei Großbritannien arbeitete Hitler mit einem größeren rhetorischen Aufwand, doch in der Sache präsentierte er London - mit der in Aussicht gestellten Respektierung von Empire und Commonwealth - die gleiche Verbindung von plumper Unverschämtheit und politischer Inhaltslosigkeit wie Paris. Göring, der in London - die Zukunft war schließlich ungewiß - sicherlich seinen Ruf als halbwegs vernünftiger und friedensfreundlicher Mann wahren wollte, ließ über den schwedischen Industriellen Birger Dahlerus, und zwar mit Wissen Hitlers, der sich davon offenbar eine Steigerung der Konfusion in britischen Regierungskreisen versprach, das gleiche "Angebot" an Lord Halifax und Chamberlain gelangen; daß er dabei im Übereifer gleich auch noch erklärte, das Deutsche Reich sei bereit, das britische Empire im Mittelmeer gegen den „Stahlpakt,,-Partner Italien und im Pazifik gegen den Antikominternpakt-Partner Japan zu unterstützen, gegebenenfalls auch militärisch, krönte die ganze Aktion mit einem weiteren eindrucksvollen Beweis für die absolute Treulosigkeit und folglich totale Geschäftsunfähigkeit der nationalsozialistischen Führer Deutschlands 554 .

Wenn aber Hitlers Botschaften an Daladier und gerade auch an Chamberlain nicht zur Annahme bestimmt waren, nicht dazu, im letzten Augenblick einen Keil zwischen Polen und Westmächte zu treiben, bleibt als Erklärung lediglich ein innenpolitischer Zweck. Offensichtlich handelte es sich bei der diplomatischen Aktion um nichts anderes als um einen Teil der „Einkreisungs“-Propaganda: Die Westmächte, so suchte Hitler der eigenen Nation zu suggerieren, wollten Deutschlands berechtigtes Vorgehen gegen Polen nur zum Anlaß nehmen, das wieder zu stark gewordene Reich zu vernichten, und nicht einmal die großherzigsten Angebote des friedfertigen „Führers“ seien imstande, sie von ihrem Vernichtungswillen abzubringen; den ja überwiegend politisch urteilslosen Deutschen sollte so das Gefühl vermittelt werden, wenigstens gegen England und Frankreich einen Verteidigungskrieg zu führen.

Noch am 25. August lieferte Hitler einen weiteren Beweis dafür, daß seine Handlungsweise in der Tat in diesem Sinne zu interpretieren war. Kaum hatte ihn Coulondre verlassen, erreichte ihn die Nachricht, daß Großbritannien und Polen den am 6. April bereits angekündigten Beistandspakt jetzt tatsächlich - als demonstrative Antwort auf den deutschsowjetischen Vertrag - abgeschlossen hatten. Daß die Nachricht ihn selbst tiefer berührte, ist in den Gerüchteküchen von Reichskanzlei, Auswärtigem Amt, $\mathrm{OKH}$ und $\mathrm{OKW} \mathrm{zwar}$ begreiflicherweise angenommen worden, jedoch sonst nicht zu sehen und auch angesichts seiner Erwartungen höchst unwahrscheinlich; sie hat denn auch nicht die geringste Aktivität ausgelöst. Wohl aber ist erkennbar, daß ihn die zweite Nachricht, die fast gleichzeitig

354 B. Dahlerus, Der letzte Versuch. London-Berlin. Sommer 1939, München 1948, S. 51 ff.; DBFP, 3, VII, No 285. 
mit der ersten in der Reichskanzlei eintraf, sowohl überraschte wie etwas aus der Fassung brachte. Als Antwort auf sein Schreiben an den Duce, das Mackensen um 15.20 Uhr überreicht hatte, kam kurz nach 18.00 Uhr ein Brief aus Rom, in dem Mussolini einerseits herzliches Einverständnis mit Hitlers Rußlandpolitik und auch mit seiner Polenpolitik bekundete, andererseits indes klipp und klar wissen ließ, daß Italien das Reich militärisch nicht unterstützen werde, wenn die Westmächte einem von Deutschland angegriffenen Polen zu Hilfe kommen sollten 555 . An sich hätte ihn auch diese Mitteilung nicht mehr überraschen dürfen, und in den Vortagen hatte er ja selber gewisse Zweifel an der italienischen Haltung geäußert. Doch als er nun im entscheidenden Augenblick die volle und nicht mehr zu verdrängende Wahrheit lesen mußte, als er ferner die noch spezifischere Wahrheit zur Kenntnis zu nehmen hatte, daß sein Moskauer Coup nicht einmal die italienische Politik in seinem Sinne zu beeinflussen vermochte, schockierte ihn das doch. Daß es ihn derart treffen konnte, zeigt deutlich genug, wie fest er im Grunde mit dem Krieg gegen die Westmächte rechnete; andernfalls hätte ihn der Brief Mussolinis ziemlich gleichgültig lassen können. So aber machte er sofort einen Versuch, den Duce vielleicht doch noch umzustimmen. In Mussolinis Schreiben hatte es - in Fortentwicklung der von Attolico erfundenen Taktik - gleisnerisch geheißen: „Unsere Intervention kann indessen unverzüglich stattfinden, wenn Deutschland uns sofort das Kriegsmaterial und die Rohstoffe liefert, um den Ansturm auszuhalten, den die Franzosen und Engländer vorwiegend gegen uns richten werden." Postwendend schickte Hitler einen Brief nach Rom, in dem er den Duce bat, den italienischen Bedarf zu präzisieren 556.

Nachdem Mackensen dieses Schreiben noch am 25. August - 21.30 Uhr - Mussolini ausgehändigt hatte, sprach der Duce sofort von Flak für die Industrie Oberitaliens; von Flak für das Heer, von Rohstoffen wie Kupfer, Zinn, Blei, Nickel, Eisen, Kohle und Benzin; für den folgenden Tag kündigte er eine komplette Liste der italienischen Forderungen an ${ }^{557}$. Als dann diese Liste, von Mussolinis Mitarbeitern zusammengestellt, um die Mittagszeit des 26. bei Ribbentrop und Hitler einging, fand der „Führer" seinen Schock vom Vortag bestätigt, und jetzt konnte auch sein Außenminister der die Liste bis zum Mittag des 26. mehrmals aufgeregt in Rom angemahnt hatte - wirklich nicht mehr umhin, die italienische Entschlossenheit zur Neutralität endlich zu begreifen und in Rechnung zu stellen. So furchteinflößend war die Liste 558 , die von 150 Flakbatterien über 7 Millionen Tonnen Mineralöl bis zu 600 Tonnen Wolfram und 600 Tonnen Molybdän alles aufführte, was die momentane Lieferkraft Deutschlands mit Sicherheit überstieg, daß jeder Zweifel behoben war: Indem sie den Kriegseintritt Ita-

555 ADAP, D, 7, Nr. 271.

556 Ebenda, Nr. 277.

557 Ebenda, Nr. 282.

558 Ebenda, Nr. 301. 
liens an offensichtlich unerfüllbare Bedingungen knüpfte, verfolgte die Molybdän-Liste ausschließlich den Zweck, Italiens Flucht aus dem Bündnisvertrag als unausweichlich aussehen zu lassen und damit einen offenen Bruch mit den Deutschen zu vermeiden; auch sollte der Flucht etwas mehr Würde gegeben werden. Jeweils vier Briefe schrieben „Führer" und Duce vom 25. bis zum 27. August, und am Ende kam heraus, daß Italien seinen "Stahlpakt"-Partner Deutschland im Kriegsfall lediglich mit Arbeitskräften konkret unterstützen würde, wobei Mussolini nicht verfehlte, seinem Schmerz über die von den Umständen erzwungene Bescheidung in bewegenden Worten Ausdruck zu verleihen 559 .

Wenn also den Faschisten die Flucht in Würde nicht so ganz geriet, fühlten sie sich im übrigen doch von einer schweren Last befreit, nachdem sie ihre längst getroffene grundsätzliche Entscheidung den Berliner Freunden jetzt endlich ohne weitere Verklausulierung mitgeteilt hatten. Da sie sich gleichzeitig beeilten, auch in London Klarheit über ihre Haltung zu schaffen, wo die italienische Friedfertigkeit naturgemäß mit Erleichterung registriert und mit Worten der Dankbarkeit quittiert wurde, glaubten sie sich plötzlich tatsächlich in der Rolle neutraler Beobachter, die berechtigt seien, der Entwicklung mit gelassener Aufmerksamkeit zu folgen und dabei scharfen Blickes nach Chancen zum Nutzen Italiens zu spähen. Ein bezeichnendes Beispiel für diese neue Distanziertheit der italienischen Politiker und Diplomaten lieferte Graf Magistrati in einem Brief, den er seinem Schwager Ciano am 28. August schrieb 560 . Alle machten nun Vorhersagen und Bewertungen, so sagte er, und auch er erlaube sich seinen Beitrag. Dann konstatierte er - im Hinblick darauf, daß der bevorstehende Konflikt von den Angreifern nicht zur Wahrung vitaler Interessen eröffnet wurde, sondern allein dem irrationalen Kriegswillen der NS-Führung zu verdanken war -, daß „kein Krieg jemals überflüssiger gewesen ist als dieser“, und deshalb - so fuhr er in gleichwohl immer noch krasser Verkennung der Natur und der Antriebe seiner nationalsozialistischen Partner fort - werde die Auseinandersetzung nicht lang sein. Nach ersten harten Schlägen werde die Überzeugung allgemein werden, „daß das Spiel die Kerze nicht wert ist". Auch sei praktisch keiner in der Lage zu siegen. Als einziges Land werde, natürlich, Polen verlieren. Alle anderen müßten sich an einem gewissen Punkt festfahren, und das recht schmerzhaft. Weder könne Deutschland hoffen, England und Frankreich tödlich zu treffen, noch dürften sich England und Frankreich einbilden, Deutschland niederzuwerfen, ein Land mit 85 Millionen und heute freiem Rücken. Er wünsche sich deshalb, daß an einem bestimmten Punkte, in der unvermeidlichen Depression beider Lager, die Initiative für einen Waffenstillstand ergriffen werde, und dies könne dann nur die Prärogative Mussolinis und Italiens sein. Ita- 
lien sei das einzige Land, das angesichts der Unversehrtheit seiner Kräfte in der Lage bleiben werde, das Steuer zu übernehmen und Europa den Frieden ,aufzuerlegen“.

Hitler war freilich vom Ausfall Italiens lediglich etwas aus der Fassung gebracht. Zwar hob er den schon erteilten Angriffsbefehl noch am 25. August $-z$ wischen dem ersten und dem zweiten Brief Mussolinis, um 19.30 Uhr - wieder auf, und dank einer glänzenden organisatorischen Leistung des Generalstabs gelang es tatsächlich, die bereits in Bewegung gesetzte Militärmaschine zu stoppen. Auch ist unverkennbar, daß der Anhaltebefehl in der Tat von den Nachrichten aus Rom ausgelöst wurde. Aber die militärische Entscheidung bedeutete keineswegs den ersten Schritt zum Verzicht auf die Absicht, Polen anzugreifen. Ebensowenig ging es dem „Führer“ darum, Zeit für diplomatische Manöver zu gewinnen, die Großbritannien vielleicht doch noch von Polen trennen mochten; war er bisher schon sicher, daß die Westmächte eingreifen mußten, so selbstverständlich erst recht jetzt, nachdem London und Warschau soeben einen demonstrativen Beistandspakt geschlossen hatten. Der Abfall Italiens nötigte ihn vielmehr gerade deshalb zu einem Aufschub der militärischen Operationen, weil er von der britisch-französischen Intervention überzeugt war. Scharfsichtige italienische Beobachter in Berlin wie Graf Magistrati haben denn auch die wahren Beweggründe Hitlers sofort zutreffend diagnostiziert ${ }^{561}$. Es war Hitler durchaus bewußt, daß der Angriffsbefehl, den er am 25. gab, eigentlich, als Folge seiner Ungeduld, zu früh kam, dem militärischen Vorbereitungsplan, wie er ihn im Frühjahr selber terminiert hatte, um einige Tage vorauseilte. Am 25./26. August war der Aufmarsch weder im Osten wirklich abgeschlossen noch vor allem im Westen. Im Osten hatte Hitler solche Unfertigkeit in Kauf nehmen zu dürfen geglaubt, weil die deutsche Armee der polnischen in allen Belangen so hoch überlegen war, im Westen hingegen im Vertrauen auf die Fesselung stärkerer britischer und französischer Streitkräfte durch den Bundesgenossen Italien. Am Abend des 25. August, zwischen 19.00 und 19.30 Uhr, hat der Oberbefehlshaber des Heeres, Generaloberst v. Brauchitsch, Hitler nachdrücklich darauf aufmerksam gemacht, daß die Armee noch etliche Tage brauche, um tatsächlich fertig zu sein ${ }^{562}$, und jetzt verstand sich der „Führer" zu einer derartigen Änderung des Zeitplans, da er einsah, daß das Ausscheiden Italiens zwei militärische Reaktionen einfach erzwang: Angesichts der Entlastung, die Italiens Neutralität den Westmächten bescherte, war es erstens unabweisbar geworden, die ohnehin sehr dünne Besetzung der Westfront sogleich wenigstens bis zur größtmöglichen Dichte zu verstärken, und schien es zweitens geboten, die Schlagkraft der Ostarmee noch um einiges zu erhöhen, damit die polnische Kampagne so rasch wie nur irgend erreichbar abgeschlossen werden 
und die Wehrmacht ehebaldigst in voller Stärke im Westen aufmarschieren konnte.

Die Vorgänge der folgenden Tage haben diese Motivation des Anhaltebefehls eindeutig bestätigt. Auf militärischem Felde brachten sie in Deutschland gesteigerte Aktivität, lief die Komplettierung des deutschen Aufmarsches im Osten wie im Westen auf höchsten Touren. Daran änderte sich auch nichts mehr, als Hitler sich und seiner Umgebung nun plötzlich einzureden suchte, daß Italiens Ausscheren im Grunde militärisch bedeutungslos, ja eher günstig sei, weil ein neutrales Italien vermutlich noch mehr britisch-französische Truppen binde als ein kriegführendes Italien; wahrscheinlich brauchte Hitler, der den italienischen „Verrat" ohnehin in erster Linie dem Hof und der Kirche zuschrieb, solche unsinnigen Argumente, um seinem nach wie vor bewunderten Freund Mussolini die römische Neutralitätspolitik verzeihen zu können. Auf diplomatischem Felde kam es hingegen bezeichnenderweise zu keiner vergleichbaren Anstrengung, und die spärlichen diplomatischen Manöver, die Berlin tatsächlich unternahm, dienten offensichtlich nicht dem Zweck, Chancen zur Isolierung Polens zu schaffen und zu nutzen. Bezeichnenderweise handelte es sich bei jenen Manövern in keinem Falle um Berliner Initiativen, sondern stets nur um Reaktionen auf britisch-französische Schritte, ein Faktum, das allein schon eine zielbewußte deutsche Politik zur Trennung der Westmächte von Polen ausschließt. Gewiß waren die Reaktionen der Berliner Diplomatie so konstruiert, daß die Absicht erkennbar ist, namentlich in London vielleicht eine gewisse Verwirrung zu stiften; gelang es, die Westmächte einige Tage oder gar eine Woche vom Kriegseintritt abzuhalten, war das naturgemäß ein großer militärischer Gewinn. Ließen sich die Westmächte womöglich zu noch längeren Verhandlungen verleiten, während die Wehrmacht Polen überrannte, hätte Berlin ein derartiges Geschenk sicherlich dankbar entgegengenommen.

Indes lag die Chance, die Politik der Westmächte in diesem Sinne beeinflussen zu können, in Hitlers Augen bereits so weit außerhalb der Wahrscheinlichkeit, daß ihm andere Wirkungen seiner taktischen Schachzüge wesentlich wichtiger gewesen sein müssen. So wird es ihm als nützlich erschienen sein, seinen Gehilfen aus den traditionellen Eliten, vornehmlich den Soldaten, das Gefühl zu vermitteln, daß der „Führer“ wenigstens alles tue, um den durchaus bejahten Feldzug in Polen zu lokalisieren. Auch bot der Aufschub, zu dem ihn die militärischen Erwägungen nötigten, Gelegenheit, die Masse der Deutschen noch stärker gegen die Westmächte einzunehmen, wenn gezeigt werden konnte, daß die Regierungen in London und Paris die ausgestreckte Friedenshand des "Führers“ nicht ergriffen. Beides war alles andere als einfach, da Hitlers Taktik in den Tagen nach dem Anhaltebefehl in allererster Linie einem Ziel galt, das mit den Nebenzwecken im Grunde nicht recht vereinbar war. Es ging dabei um die Abwehr einer Gefährdung seiner Absichten, die sich unmittelbar aus dem 
Aufschub ergab. Bereits am 14. August hatte Hitler zu Brauchitsch und Generalstabschef Halder gesagt, er befürchte, daß ihm England den Angriff auf Polen „im letzten Augenblick durch Angebote erschwert“, und auch am 22. August rief er vor den Militärs, die sich auf dem Obersalzberg versammelt hatten: „Ich habe nur Angst, daß mir noch im letzten Moment irgendein Schweinehund einen Vermittlungsplan vorlegt." Vermutlich hatte diese Angst schon bei seinem verfrühten Angriffsbefehl eine Rolle gespielt, und die notwendig gewordene Verschiebung des Angriffs schuf dem westlichen Vermittlungseifer nun eine gar nicht mehr erwartete Frist zur Störung der Hitlerschen Pläne. Mithin kam es ihm zwar durchaus darauf an, den Anschein der Verständigungsbereitschaft zu erwecken, aber mehr noch darauf, der Verständigung selbst aus dem Wege zu gehen; er war entschlossen, sich nicht auf die Straße zu einem zweiten München zerren zu lassen.

So ist es schon überaus bemerkenswert, daß Hitler den Tag nach dem Anhaltebefehl, den 26. August, ohne die geringste diplomatische Aktivität verstreichen ließ. Hingegen wurde er an diesem Tag mit einer Aktion der französischen Regierung konfrontiert. Um 19.00 Uhr überreichte ihm Coulondre einen Brief des französischen Regierungschefs, in dem Daladier dem „Führer" einerseits noch einmal in unmißverständlichen Worten Frankreichs Bereitschaft zur Erfüllung seiner polnischen Verpflichtungen versicherte, andererseits aber geradezu flehentlich zu einem letzten Versuch aufforderte, den deutsch-polnischen Konflikt friedlich beizulegen. Kein Mensch, der ein Herz habe, würde es verstehen, schrieb Daladier, wenn ein solcher Versuch unterbliebe; die Entscheidung über Krieg und Frieden liege allein in den Händen des „Führers“, da es zwischen Polen und Deutschland keine Frage gebe, die nicht auf friedlichem Wege gelöst werden könne: „Ich als Chef der französischen Regierung, der ich eine gute Harmonie zwischen dem französischen und dem deutschen Volk wünsche und der ich andererseits durch Freundschaftsbande und durch das gegebene Wort mit Polen verbunden bin, bin bereit, alle Anstrengungen zu machen, die ein aufrichtiger Mensch unternehmen kann, um diesen Versuch zu einem guten Ende zu führen." 563 Hitlers Reaktion war sehr bezeichnend. In seinen Ohren klang Daladiers Botschaft schon so bedrohlich nach Vermittlung und schiedlich-friedlicher Beilegung des deutsch-polnischen Streits, daß er Coulondre, der den Sätzen des Ministerpräsidenten noch seinen eigenen Appell hinzufügte, sofort eine Abfuhr zuteil werden ließ, die den Botschafter nötigte, Daladier umgehend mitzuteilen, daß der „Führer“ den französischen Vorschlag abgelehnt habe564. Mit der schriftlichen Antwort, die er noch ankündigte, ließ sich Hitler dann auffallend Zeit. Erst um 16.00 Uhr am 27. August konnte Coulondre Hitlers Schreiben aus den Händen Ribbentrops entgegennehmen, und der Inhalt bestätigte überdies

563 ADAP, D, 7, Nr. 324.

564 Gelbbuch der Französischen Regierung, S. 342. 
die spontane und mündliche Reaktion des „Führers“. Zwar bekundete Hitler Verständnis für Daladiers Gefühle und Bedenken, aber danach wies er die Pariser Anregung rundweg zurück und praktizierte obendrein die sicherste Methode, die es für die erste Abwehr eines unwillkommenen Vermittlungsversuchs gibt: Er erhöhte seine Forderungen! Zum ersten Mal erklärte Hitler öffentlich und offiziell, daß er nicht nur Danzig verlange, sondern außerdem auch noch das ganze „Korridor“ genannte - und überwiegend polnisch besiedelte - Territorium ${ }^{565}$.

Von dieser Behandlung des französischen Appells abgesehen, die selbst jene Pariser Politiker enttäuschte und verstimmte, die noch immer zu den Anwälten einer Verständigung mit dem Dritten Reich gehörten ${ }^{566}$, ist Hitlers Schreiben an Daladier aber auch deshalb höchst bemerkenswert, weil es sich dabei nicht nur um die erste, sondern zugleich um die einzige sozusagen diplomatische Kommunikation zwischen Berlin und Paris handelte, die es in der Zeitspanne vom Anhaltebefehl bis zum Beginn der Feindseligkeiten überhaupt geben sollte. Gegenüber Frankreich wurde also nun von Hitler auf jegliche Politik verzichtet, und ein solcher Verzicht kann nur als letzter Beweis dafür verstanden werden, daß dem „Führer“ die Frage, ob Frankreich an der Seite Polens in den Krieg eintreten werde, gleichgültig geworden war. Im übrigen - und das ist nicht weniger bemerkenswert - sahen Hitler und sein Außenminister, die Reaktion auf das Schreiben Daladiers ausgenommen, auch am 27. August keinen Anlaß zu irgendwelchen diplomatischen Aktionen oder wenigstens Gesten. Am Abend des 27. kam Attolico zu Weizsäcker und brachte eine Idee Mussolinis mit. Der Duce sei bereit, Deutschland und seinen Widersachern folgenden Vermittlungsvorschlag zu unterbreiten: Polen und die Westmächte stimmen der sofortigen Rückkehr Danzigs zum Reich zu, Deutschland stimmt dafür einer anschließend einzuberufenden europäischen Konferenz zur Regelung der übrigen deutsch-polnischen Streitpunkte und zur Diskussion sonstiger internationaler Probleme zu. Jedoch brachte es nicht einmal der - mit einiger Hartnäckigkeit an seinem Konferenzgedanken festhaltende - Duce fertig, dem „Führer" eine politische Regung zu entlocken. Weizsäcker gab Mussolinis Botschaft sogleich an Ribbentrop weiter und erhielt den dürren Bescheid: „Eine Antwort wird dem Botschafter hierauf ... zur Zeit nicht gegeben werden." 567

In den folgenden drei Tagen lebten die Angehörigen der wichtigeren Berliner Dienststellen und Ministerien, vom Auswärtigen Amt bis zum $\mathrm{OKH}$, wirklich unter dem Eindruck, daß im Zentrum der Entscheidung, bei Hitler, Schwanken herrsche, daß der „Führer“ ebenso unsicher wie fieberhaft nach Möglichkeiten taste, den Feldzug in Polen doch noch irgend- 
wie ohne Intervention der Westmächte führen zu können. Zu diesem Eindruck trugen Gerüchte bei, daß zwischen Göring und der britischen Regierung ein schwedischer Vermittler hin- und herreise, und zwar mit beachtlichem Erfolg; tatsächlich ließ sich Birger Dahlerus, der seine aufrichtige Bereitschaft, der Erhaltung des Friedens zu dienen, mit einer großen Portion politischer Naivität und einem erstaunlichen Mangel an Menschenkenntnis verband, auch jetzt wieder zu politisch und mithin historisch völlig irrelevanten Missionen mißbrauchen: von Hitler, um in London nützliche Konfusion zu verbreiten, von Göring zu dem gleichen Zweck und darüber hinaus zur Pflege des britischen Göring-Bilds568. In Wahrheit ist aber auch für den 28., 29. und 30. August die nämliche Inaktivität - hinsichtlich eigener Initiativen - im Zentrum der Macht zu konstatieren wie in den Tagen zuvor, und die am 26. und 27. praktizierte Taktik fand ihre konsequente Fortsetzung.

Bis zum Abend des 28. August geschah ohnehin gar nichts. Hitler, angeblich auf hektischer Suche nach Wegen zur politischen Ausnutzung des durch den Anhaltebefehl geschenkten Aufschubs, ließ nach dem 26. und dem 27. einen weiteren vollen Tag vorbeigehen, ohne auch nur einen Finger zu rühren. Das einzige Lebenszeichen aus der Reichskanzlei, dem zu entnehmen war, daß dort überhaupt Überlegungen angestellt und Entscheidungen reif wurden, betraf nicht die Diplomatie, sondern das Militär. Generaloberst v. Brauchitsch, der das sogleich an seinen Stabschef weitergab, erhielt die Mitteilung, daß nun als neuer Angriffstermin der 1. September vorgesehen sei569. Am späteren Abend des 28. August kehrte jedoch Sir Nevile Henderson aus London zurück, und zwar mit der Antwort der britischen Regierung auf Hitlers Äußerungen vom 25. in der Tasche. Gegen 22.30 Uhr konnte er die britische Note und ihre deutsche Übersetzung in der Reichskanzlei übergeben, und als Hitler bei der ersten Lektüre feststellen mußte, daß aus dem Dokument - wie Ribbentrop am nächsten Tag; in einer Unterhaltung mit Attolico ungescheut einräumte 570 - tatsächlich der ernste und aufrichtige Wille zur Vermittlung zwischen Deutschland und Polen sprach, reagierte er bezeichnenderweise nicht anders als auf den Brief Daladiers: Er erhöhte seine Forderungen! Erstmals verlangte er jetzt auch gegenüber England neben Danzig den "ganzen Korridor" und überdies zum allerersten Mal nicht genauer umrissene Grenzkorrekturen in Oberschlesien; zur speziellen Entmutigung der Briten fügte er - was in der deutschen Aufzeichnung dieses Gesprächs Hitler-Henderson ebenso fehlt wie die Punkte Korridor und Oberschlesien - noch hinzu, daß die britische Regierung zum Beweis ihres guten Willens sofort einen Teil der kolonialen Ansprüche des Deutschen Reiches erfüllen müsse ${ }^{571}$.

568 Dahlerus, Der letzte Versuch, S. 61 ff., 75 ff., $100 \mathrm{ff}$.

569 Halder, Kriegstagebuch, S. 40.

570 ADAP, D, 7, Nr. 411.

571 DBFP, 3, VII, Nr. 450, 455. 
Allerdings stellte die Note den „Führer“ doch vor eine höchst unangenehme Schwierigkeit. Das Problem bestand nicht darin, daß die Londoner Regierung erneut in einer jeden $Z$ weifel ausschließenden Form ihren Willen kundmachte, auf einen deutschen Versuch zur gewaltsamen Lösung der polnischen Fragen mit dem Kriegseintritt Großbritanniens zu reagieren, oder daß sie - ohne Hitlers Angebot einer Garantierung des Empire mit einer Silbe zu erwähnen - die ausdrücklich formulierte Bereitschaft zu einer umfassenden deutsch-britischen Verständigung an die Bedingung einer vorherigen friedlichen Beilegung der deutsch-polnischen Krise knüpfte. Das Problem entstand vielmehr dadurch, daß Chamberlain und Halifax vorschlugen, die Streitpunkte zwischen Polen und Deutschland in direkten deutsch-polnischen Gesprächen - wie es sie ja seit dem 6. April auf Grund der deutschen Verweigerung nicht mehr gab - zu erörtern und zu regeln, und daß sie, dies vor allem, dezidiert erklärten, bereits die definitive $\mathrm{Zu}$ stimmung der Warschauer Regierung zum direkten deutsch-polnischen Gespräch besorgt zu haben; tatsächlich hatte die polnische Regierung ihre Einwilligung zu einem solchen Verfahren schon zwei Tage zuvor öffentlich - wenn auch in ganz allgemeinen Wendungen - ausgesprochen, und zwar in ihrer Antwort auf einen entsprechenden Appell, den Präsident Roosevelt am 25. August an Deutschland und Polen gerichtet hatte und den Hitler weder einer direkten noch gar einer sachlichen Replik würdigte, obwohl Roosevelt nach Eingang des positiven Telegramms aus Warschau seine Botschaft an die deutsche Adresse wiederholte. Einerseits lag es auf der Hand, daß die britisch-polnische Offerte nicht einfach abgelehnt werden durfte; auch die Abschreckung, wie sie Hitler in der Unterhaltung mit Henderson versucht hatte, konnte natürlich nicht genügen. Beides hätte die deutsche Führung allzu deutlich - und vor allem auch für die eigene Nation erkennbar - ins Unrecht gesetzt. Andererseits war ebenso klar, daß hier die Gefahr drohte, auf eine Bahn gezogen zu werden, die leicht beim erzwungenen Verzicht auf die mit Moskau ja praktisch gerade vereinbarte Teilung Polens und bei einem bloß partiellen Erfolg à la München enden mochte - sowohl als schmählich anzusehen wie im Blick auf die expansionistische Gesamtplanung als lästiger Aufenthalt.

Aber Hitler fand einen Ausweg aus dem Dilemma, und zum ersten Mal seit April blitzte. wieder ein Element jener propagandistisch-taktischen Gerissenheit auf, die er in früheren außen- oder innenpolitischen Krisen an den Tag gelegt, doch nach Erreichen des eigentlichen Höhepunkts der polnischen Krise offenbar für überflüssig erachtet hatte. Zunächst einmal suchte er abermals Zeit zu gewinnen. Derselbe Mann, der gleich behaupten sollte, bei der friedlichen Beilegung des deutsch-polnischen Streits gehe es angesichts der aufmarschierten Heere und angesichts des geradezu rasenden Wütens polnischer Terroristen buchstäblich um Stunden, ließ den ganzen 29. August ins Land gehen, ehe er sich erneut bemerkbar machte. Erst zwischen 19.00 und 20.00 Uhr bekam Sir Nevile Henderson, in die Reichs- 
kanzlei bestellt, aus Hitlers Hand die deutsche Antwort auf die britische Note ${ }^{572}$. In diesem Schriftstück forderte der „Führer" unzweideutig Danzig und den Korridor, dazu in recht unklarer Formulierung eine "Sicherung des Lebens der deutschen Volksgruppen in den restlich Polen verbleibenden Gebieten“. Anschließend erklärte er sich - obwohl er ohne Vertrauen zu Warschau sei und sich dazu allein um der künftigen deutsch-britischen Freundschaft willen verstehe - bereit, „die vorgeschlagene Vermittlung der Königlich Britischen Regierung zur Entsendung einer mit allen Vollmachten versehenen polnischen Persönlichkeit nach Berlin anzunehmen“. Bereits ein solches Verständnis von "direkten deutsch-polnischen Verhandlungen" verwandelte die dem Anschein nach ausgesprochene Annahme des britischen Vermittlungsvorschlags in Wirklichkeit in Ablehnung. Die genannten territorialen Ansprüche waren für Warschau ebenso unannehmbar wie ein Sonderstatus für die in Polen lebenden Deutschen, erst recht aber mußte es für die polnische Regierung unannehmbar sein, daß ihr Hitler zumutete, unter Verhandlungen die Entsendung eines Bevollmächtigten nach Berlin zu verstehen, der dort nichts anderes zu tun hatte, als mit seiner Unterschrift die Akzeptierung der deutschen Forderungen zu besiegeln.

Nun war freilich nicht auszuschließen, daß Briten und Franzosen, um ihrer Bündnispflicht doch noch zu entkommen, die Polen am Ende zwingen wollten, sich dem deutschen Diktat zu fügen, und um einer solch unerwünschten Entwicklung vorzubeugen, baute Hitler ein schon technisch unerfüllbares Element in die deutsche Note ein: der polnische Bevollmächtigte, so hieß es da, werde am 30. August, also gleich am nächsten Tag, in Berlin erwartet! Damit hatte Hitler das Kunststück fertiggebracht, die scheinbare Annahme der britischen Vermittlung faktisch in ein sowohl an Großbritannien wie an Polen gerichtetes Ultimatum umzufunktionieren, und zwar obendrein in ein praktisch unerfüllbares Ultimatum. Wohl bestritten Hitler und Ribbentrop vehement, ein Ultimatum gestellt zu haben, als Henderson auf den ultimativen Charakter der deutschen Note hinwies, doch handelte es sich in Wahrheit um nichts anderes, und im Fortgang der Dinge haben denn auch Hitler und Ribbentrop die Note sehr wohl als Ultimatum behandelt. Allerdings durfte nicht einmal ausgeschlossen werden, daß die britische Regierung doch willens und fähig war, trotz aller technisch-prozeduralen Schwierigkeiten noch am 30. einen polnischen Unterhändler nach Berlin zu schaffen. Für diesen höchst unwillkommenen Fall galt es, Vorschläge zu präparieren, die einerseits propagandistisch verwertbar zu sein, andererseits einen eben noch zeitgerechten Zusammenbruch der sogenannten Verhandlungen zu garantieren hatten; die Rechtsabteilung des Auswärtigen Amts und sonstige Gehilfen des „Führers“ waren am 29. und 30. August emsig damit beschäftigt, derartigen Sprengstoff zu pro-

572 ADAP, D, 7, Nr. 421. 
duzieren. Wie man sich in der Reichskanzlei dann die Abfolge des Geschehens vorstellte, spiegelte sich in einer Tagebuchnotiz von Generalstabschef Halder: „30.8. Polen in Berlin. 31.8. Zerplatzen. 1.9. Gewaltanwendung.“573 Im übrigen wiesen Hitler und Ribbentrop am 29. auch das Vermittlungsangebot, das Mussolini gemacht hatte, definitiv zurück: Ribbentrop eröffnete Attolico kühl, „daß die Dinge für derartige Anregungen schon zu weit vorgeschritten seien" 574 .

Am Vormittag des 30. August rief Henderson bei Weizsäcker an und teilte mit, die britische Regierung sei mit der Prüfung der deutschen Note beschäftigt, müsse aber jetzt schon feststellen, daß die deutsche Antwort auf die britische Anregung „etwas Ultimatives an sich“ habe und daß man nicht sicher sei, ob es gelinge, „die Polnische Regierung dazu zu bewegen, daß sie einen Bevollmächtigten noch heute hierher entsende“; Lord Halifax hatte bereits um 2 Uhr morgens Henderson telegrafiert, daß die deutschen Erwartungen in dieser Hinsicht „natürlich unvernünftig“ und unerfüllbar seien, und zwei Stunden danach kannte Ribbentrop die Auffassung des britischen Außenministers 575 . Am späteren Nachmittag traf dann eine Botschaft Chamberlains an Hitler ein, in der versichert wurde, daß die britische Regierung das deutsche Schriftstück mit der gebotenen Dringlichkeit studiere und mit ihrer Stellungnahme noch am 30. zu rechnen sei; Chamberlain fügte hinzu, daß die britische Regierung in Warschau energisch auf die Wichtigkeit der Vermeidung von Grenzzwischenfällen hinweise 576 . Hitler und Ribbentrop reagierten darauf nicht; sie hüllten sich auch am 30. August in Schweigen und gaben weder London noch gar Warschau gegenüber zu erkennen, daß sie - ob geduldig oder ungeduldig - auf einen polnischen Bevollmächtigten warteten, der in der Tat, wie vorherzusehen, nicht erschien.

Als Henderson, im Laufe des Abends mit den erforderlichen Instruktionen versehen, um Mitternacht von Ribbentrop empfangen wurde, stellte sich indes definitiv heraus, daß die Besorgnisse der Berliner Kriegspartei ganz unbegründet gewesen waren ${ }^{577}$. Die britische Regierung nahm die nach den Erfahrungen der letzten anderthalb Jahre einzig mögliche Haltung ein und ließ durch ihren Botschafter bestellen, sie „sei nicht in der Lage, der Polnischen Regierung zu empfehlen“, sofort einen bevollmächtigten Vertreter nach Berlin zu entsenden. Auf der Basis ihrer Erklärung vom 28. August, daß Warschaus Einverständnis mit dem direkten deutschpolnischen Gespräch bereits vorliege, schlug sie der Reichsregierung danach vor, ,auf normalem diplomatischem Wege, d.h. durch Überreichung ihrer Vorschläge an den Polnischen Botschafter, die Dinge ins Rollen zu

573 Halder, Kriegstagebuch, S. 42.

574 ADAP, D, 7, Nr. 411.

575 DBFP, 3, VII, Nr. 504, 520.

576 ADAP, D, 7, Nr. 450.

577 Ebenda, Nr. 461; DBFP, 3, VII, Nr. 570, 571, 574. 
bringen, um den Polnischen Botschafter in die Lage zu versetzen, im Einvernehmen mit seiner Regierung die Vorbereitungen für direkte deutschpolnische Verhandlungen zu treffen". Wenn die Reichsregierung, so hieß es mit einiger Zurückhaltung weiter, ihre Vorschläge „auch der Britischen Regierung zuleiten würde und diese der Ansicht wäre, daß die Vorschläge eine vernünftige Grundlage für eine Regelung der zur Erörterung stehenden Probleme bilden, so würde sie ihren Einfluß im Sinne einer Lösung in Warschau zur Geltung bringen". Damit war Hitler klar gesagt, daß er, sofern es ihm mit der Verständigung und der Rettung des Friedens ernst sei, dies zu beweisen habe, indem er Vernunft, Mäßigung und zivilisierte diplomatische Manieren an den Tag lege; ein Traktieren der Polen und mithin praktisch auch der Westmächte, das der Behandlung gleiche, wie sie im $\mathrm{Fe}-$ bruar und März 1938 Schuschnigg zuteil geworden sei, in München den Tschechen und den Westmächten, im Frühjahr 1939 dann Hacha, Urbsys und den Rumänen, in der polnischen Krise bislang sowohl Warschau wie London und Paris, ein solches Traktieren der Polen werde nicht länger toleriert und müsse zum Krieg führen. Anschließend fragte Henderson, ob die deutschen Vorschläge, die Hitler am 29. in Aussicht gestellt habe, schon ausgearbeitet seien und er sie gleich in Empfang nehmen könne.

Niemand in London ahnte, daß die ebenso verständliche wie richtige und korrekte britische Haltung Hitlers Taktik weit entgegenkam. Daß der polnische Bevollmächtigte ausgeblieben war und nun auch die Briten die Ansicht vertraten, für den deutsch-polnischen Dialog müsse der normale diplomatische Verbindungsapparat genügen, bot Hitler und Ribbentrop die rasch und freudig ergriffene Chance, den Vorgang als Warschauer Verweigerung direkter deutsch-polnischer Gespräche und als Scheitern der britischen Vermittlung, ja als Londoner Ablehnung der Vermittlerrolle zu behandeln und in solchem Sinne vor allem der deutschen Bevölkerung hinzustellen. Ribbentrop machte, offensichtlich von Hitler vorsorglich entsprechend instruiert, sofort den Anfang, indem er die deutschen Vorschläge, die für das Haldersche „Zerplatzen“ in der Tat bereits formuliert, nun aber für diesen Teil des Berliner diplomatischen Spiels überflüssig geworden waren, noch in der Unterredung mit Henderson zu einer Szene benützte, die in der Geschichte der europäischen Diplomatie beispiellos dasteht. Zwar zog er das Papier, auf dem die Vorschläge geschrieben standen, aus der Tasche und las dem britischen Botschafter die insgesamt sechzehn Punkte auch vor, wenngleich etwas schnell für Henderson, der in derart gespannten Augenblicken des Deutschen doch nicht mehr ganz mächtig sein konnte. Anschließend steckte er jedoch das Papier wieder ein, erklärte die Vorschläge, weil kein polnischer Unterhändler erschienen sei, für überholt und weigerte sich sogar, ein Exemplar des Dokuments dem Botschafter auszuhändigen. Noch schroffer lehnte er Hendersons Bitte ab, dann eben den polnischen Botschafter herbeizurufen und diesen über die sechzehn Punkte ins Bild zu setzen. Gleichwohl bestritt er aufs heftigste - und ganz 
unsinnigerweise - Hendersons zutreffende Bemerkung, Hitlers Note vom 29. August sei also doch ein Ultimatum gewesen.

Damals wie später ist oft die Meinung zu hören gewesen, der Ablauf der Dinge wäre anders geworden, hätte sich Ribbentrop in jener Nacht vom 30. auf den 31. August dazu verstanden, die deutschen Vorschläge dem britischen und dem polnischen Botschafter zu übergeben und damit offiziell ins diplomatische Geschäft einzuführen. Diese Meinung ist indes unhaltbar. Man darf nicht vergessen, daß die sechzehn Punkte lediglich den Anschein der Mäßigung erwecken sollten, in Wirklichkeit aber fürs „Zerplatzen“ konstruiert waren und ihren Zweck auch durchaus erfüllt hätten ${ }^{578}$. Zwar gingen die jetzt genannten deutschen Forderungen scheinbar hinter die Note vom 29. zurück, da nur die Annexion Danzigs direkt verlangt, für das Territorium des Korridors hingegen eine Volksabstimmung angeboten wurde. Bei genauerem Zusehen ist freilich zu entdecken, daß das deutsche Dokument der polnischen Regierung zumuten wollte, das gesamte Korridorgebiet ,in kürzester Frist“ - und das hieß mindestens zehn Monate vor der frühestens nach einem Jahr in Aussicht genommenen Abstimmung von polnischem Miliär, polnischer Polizei, ja jedem polnischen Beamten zu räumen. Damit nicht genug, sah Punkt 3 vor, alle nach dem 1. Januar 1918 dorthin zugewanderten und sogar alle nach diesem Datum dort geborenen „Polen, Kaschuben usw.“ von der Abstimmung auszuschließen, dafür jedoch sämtliche bis zum 1. Januar $1918 \mathrm{im}$ Korridor wohnhaften oder geborenen Deutschen für die Abstimmung zurückzuschleusen. Außerdem sollte die polnische Regierung dazu verpflichtet werden, innenpolitische Akte wie die Bodenreform für betroffene deutsche Grundbesitzer wieder aufzuheben, und zwar unter Zahlung einer Entschädigung; der zusätzlich erhobene Anspruch auf „vollständige Entschädigung“ für „sonstige Eingriffe in das wirtschaftliche Leben" bedrohte Warschau ferner mit einer unübersehbaren Flut gänzlich unkontrollierbarer finanzieller Forderungen des Reiches und einzelner Deutscher. Zur Krönung wurde Polen schließlich noch angesonnen, den im Lande lebenden Deutschen einen mit diversen Privilegien - z.B. Befreiung von der militärischen Dienstpflicht - verbundenen Sonderstatus einzuräumen. Keine polnische Regierung wäre in der Lage gewesen, einen derartigen Katalog als Verhandlungsgrundlage zu akzeptieren oder gar einfach anzunehmen. Keine britische und keine französische Regierung hätte unter diesen Umständen eine Möglichkeit gesehen, Warschau zu direkten Gesprächen mit Berlin zu raten oder gar zu drängen.

Gleichwohl hat auch das Verhalten der polnischen Regierung das Hitlersche Manöver etwas begünstigt. Gewiß war es nicht nur begreiflich, sondern auch geboten, daß Außenminister Beck, der einer unter normalen Bedingungen stattfindenden deutsch-polnischen Gesprächsrunde ja bereits zugestimmt hatte, nicht bereit war, selbst nach Berlin zu kommen oder ei- 
nen Vertreter als Bevollmächtigten dorthin zu schicken, nur um dann von Hitler, Ribbentrop und Göring "hachaisiert" zu werden. Hingegen muß es sicherlich als ungeschickt gelten, daß die Warschauer Regierung in ihrer Angst, womöglich doch noch auf die Straße nach einem neuen München gestoßen zu werden, Stunde um Stunde zögerte, ehe sie den britischen Gedanken aufgriff und Botschafter Lipski beauftragte, sich im Auswärtigen Amt zu melden 579 , und daß Lipski, als eine Unterredung mit Ribbentrop am späten Nachmittag des 31. August, um $18.30 \mathrm{Uhr}$, tatsächlich zustandekam, lediglich mitteilen durfte, seine Regierung erwäge die britischen Anregungen - hinsichtlich der Aufnahme direkter deutsch-polnischer Besprechungen auf dem normalen diplomatischen Wege - „im günstigen Sinne“ und werde London in wenigen Stunden formell antworten; die Frage, ob er schon zu Verhandlungen bevollmächtigt sei, mußte er verneinen 580 .

Indes boten die britische Haltung und das polnische Verhalten der Hitlerschen Taktik lediglich einige willkommene Handhaben. Fühlbarer Einfluß auf den Gang der Dinge kam ihnen nicht zu, und zwar nicht einmal in dem Sinne, daß es Hitler und Ribbentrop gelungen wäre, den eigenen Kriegswillen hinter den - teils unvermeidlichen, teils vermeidbaren Schönheitsfehlern der britisch-polnischen Politik zu verstecken. Es gab einfach keine Taktik, mit der ein so konsequenter und brutaler Wille zum Krieg hätte bemäntelt oder völlig getarnt werden können. In diesem letzten Stadium war dem Augenblick nicht auszuweichen, da mit irgendeiner Begründung der deutsch-polnische und der deutsch-britische Gesprächskontakt - einen deutsch-französischen hatte man ja gar nicht erst zugelassen - unterbrochen oder abgeblockt und jede weitere Verhandlung unmöglich gemacht werden mußte. Dabei konnte es nicht ausbleiben, daß der böse Wille deutlich hervortrat. Ob das geschah, indem man am 30. und 31 . einen polnischen Bevollmächtigten mit unerfüllbaren Forderungen konfrontierte oder indem man in der Nacht vom 30. zum 31. die deutsche Note als abgelehntes Ultimatum behandelte und eine polnische Verhandlungsverweigerung zu konstruieren suchte, war im Grunde gleichgültig. In jedem Falle handelte es sich um notwendigerweise durchsichtige Manöver, die den Drang zum Krieg und die Abwehr einer friedlichen Beilegung der Krise, statt beides zu kaschieren, nur um so schärfer konturierten. Derartige Gebrechen der deutschen Politik waren dann naturgemäß nicht dadurch $z u$ heilen, daß Hitler und Ribbentrop behaupteten, Polen und die Westmächte hätten, weil sie Deutschland eben vernichten wollten, ein maßvolles, ja großherziges letztes Angebot des „Führers“ sabotiert und zurückgewiesen. Vom Mangel an Maß und Großherzigkeit des Angebots ganz abgesehen, schaffte jene Behauptung ja die Tatsache nicht aus der Welt, daß weder Polen noch die Westmächte eine Offerte zurückzuweisen ver- 
mochten, die ihnen doch gar nicht übermittelt worden war. Die polnische Regierung erhielt die sechzehn Punkte nie, die Botschafter der Westmächte erhielten sie erst zu einem politisch nicht mehr relevanten Zeitpunkt, nämlich am späten Abend des 31. August, zwischen 21 und $22 \mathrm{Uhr}$, als der Angriffsbefehl an die deutsche Wehrmacht längst gegeben war; selbst Attolico bekam sie - wenn auch vom „Führer" persönlich - nur zwei Stunden früher ausgehändigt. An diesem Sachverhalt ändert sich auch dadurch nichts, daß Göring - vermutlich wiederum zu seiner persönlichen Salvierung - Birger Dahlerus benutzte, um die sechzehn Punkte im Laufe des 31. sowohl Henderson wie Lipski inoffiziell zur Kenntnis bringen zu lassen. Eine solche Information war keine diplomatische Demarche, mit der die Botschafter etwas hätten anfangen können ${ }^{581}$.

Hitler und Ribbentrop brachten für das diplomatisch-politische Hin und Her des 31. August ohnehin kein Interesse mehr auf; solche Vorgänge spielten sich schon unterhalb der Ebene ab, auf der ihr Geist arbeitete, Schlüsse zog, Entscheidungen traf. Um 5.15 Uhr morgens ging am 31. August Hendersons Bericht über seine mitternächtliche Unterredung mit Ribbentrop und über dessen Weigerung, die sechzehn Punkte aus der Hand zu geben, nach London ab, wo er im Foreign Office um 9.30 Uhr eintraf 582 . Zwischen der Absendung und der Ankunft des Telegramms, um 6.30 Uhr, hatte Hitler aber der deutschen Wehrmacht den Befehl zum Angriff auf Polen bereits erteilt ${ }^{583}$, und um $16.00 \mathrm{Uhr}$ - zweieinhalb Stunden vor der Frage Ribbentrops an Lipski nach seiner Verhandlungsvollmacht - folgte die Exekutiv-Order des OKW: Am 1. September 1939, $4.45 \mathrm{Uhr}$, hatten die deutschen Streitkräfte in Polen einzufallen. Und so geschah es denn auch, wobei Hitler, als er am Vormittag des 1 . September im Reichstag verkündete, seit $5.45 \mathrm{Uhr}$ - nicht einmal die Uhrzeit stimmte in der mit Lügen und Verdrehungen vollgestopften Rede - werde ,jetzt zurückgeschossen“, sich nur seltsam beiläufig auf die sechzehn Punkte und auf den tatsächlich exekutierten Überfall auf den Sender Gleiwitz berief; von letzterem machte auch die Propaganda der NS-Medien keinen intensiveren Gebrauch. Gegen die Unerbittlichkeit des Hitlerschen Kriegswillens und gegen die Unerbittlichkeit der davon nun gestarteten Militärmaschine waren politische und diplomatische Aktionen völlig bedeutungslos geworden. Der „Führer" selbst sah keinen Anlaß zu einem zweiten - und für sein Prestige sowieso zu gefährlichen - Anhaltebefehl: Der Aufmarsch war ja vollendet, die Armee stand wirklich stoßbereit. Nachdem Hitler ultimative britischfranzösische Forderungen nach Rücknahme der in Polen eingedrungenen Truppen ebenso unbeachtet gelassen hatte wie einen letzten Vermittlungsversuch Mussolinis, hielt er am 3. September überdies - und wie nicht an-

581 DBFP, 3, VII, Nr. 587, 589, 597; Lipski, Diplomat in Berlin, S. 573.

582 DBFP, 3, VII, Nr. 574.

583 Vormann, Der Feldzug 1939 in Polen, S. 46; Halder, Kriegstagebuch, S. 47. 
ders zu erwarten - auch die Kriegserklärungen Frankreichs und Großbritanniens in den Händen ${ }^{584}$. Sehenden Auges hatten die nationalsozialistischen Führer des Deutschen Reiches, weder Polen noch den westeuropäischen Demokratien eine Wahl lassend, tatsächlich den zweiten großen europäischen Krieg des Jahrhunderts vom Zaune gebrochen.

Zur Rekapitulation: Hitler hat dem UUberfall auf Polen das Etikett „Krieg um Lebensraum" erst aufgeklebt, nachdem er den Entschluß zum Angriff aus einem ganz anderen Grunde bereits gefaßt hatte. Jedoch ist unverkennbar, daß auch schon der Entschluß selbst gleichsam ein direkter Abkömmling ideologisch begründeter Expansions- und Kriegsplanung gewesen ist. Es ging dem „Führer" ja keineswegs um Ziele, die mit so vertrauten Begriffen der europäischen Machtpolitik wie „Hegemonie“ zu fassen wären. Erster und eigentlicher Zweck der Ausschaltung Polens war ja die Beseitigung einer potentiellen Gefahr im Rücken des von Hitler fest beschlossenen Westkriegs, der wiederum Rückenfreiheit für die kriegerische Raumpolitik im Osten schaffen sollte, und so läßt sich sagen, daß der Krieg gegen Polen letztlich ein von der Kernlehre nationalsozialistischer Ideologie verursachter und geforderter Krieg war. Er diente jenem Lebensraum-Imperialismus, der, wie in Erinnerung gerufen sei, mit den sozusagen normalen Imperialismen der neueren und neuesten europäischen Geschichte zwar sicherlich verwandt gewesen ist, jedoch ein Phänomen höchst eigener Prägung darstellte. Nicht nur Kategorien wie „Hegemonie“ und „Hegemonialkrieg" werden gegenüber diesem Phänomen unangemessen, es ging auch nicht um den Schutz oder die Erschließung von Handelswegen und Märkten, ebensowenig darum, durch Erfolge einer imperialen Politik die Herrschaft angefochtener und in ihrer Lebensform bedrohten Oberschichten zu stabilisieren; die Nationalsozialisten betrachteten ja die alten deutschen Eliten in Landwirtschaft und Industrie, in Bürokratie und Armee bestenfalls als nützliche Idioten, häufiger noch als bloß temporär zu benutzende Feinde. Erst recht stand ihr Imperialismus, wie kaum gesagt zu werden braucht, nicht im Dienste der missionarischen Ausbreitung reformerischer oder revolutionärer gesellschafts- und verfassungspolitischer Ideen mit universalem Anspruch, wie zeitweilig der französische, der amerikanische und der russische Imperialismus.

Auf epigonenhafte und dekadente Art süchtig nach historischer Größe des eigenen politischen Handelns und der eigenen Person, fühlten sich Hitler und die Kerngruppen der NS-Bewegung gewiß als Reichsgründer, doch schwebte ihnen ein Reich vor, das selbst der primitivsten positiven Züge ermangelte. Zwar sollte dieses Reich die Verwirklichung jener Gesellschaftsutopie bringen, die allen Angehörigen der deutschen Nation bzw. den Angehörigen der germanischen oder arischen Rasse die angeblich ge-

584 ADAP, D, 7, Nr. 513, 515, 560, 562, 563, 564; zu Mussolinis Vermittlungsvorschlag ebenda, Nr. 478, 535, 539, 541, 554, 565. 
sunde Existenz von Kriegern und größeren oder kleineren Grundbesitzern ermöglichte. Aber von der dubiosen Qualität solcher Existenz ganz abgesehen, waren ihre Segnungen per definitionem auf die sogenannten Arier beschränkt. Den anderen brachte das Reich der Nationalsozialisten, wenn es sich nach Westen oder Osten ausdehnte, nichts weiter als deutsche Herrschaft. Selbst das heißt noch zu günstig charakterisieren. Sicherlich waren die Nationalsozialisten bereit, Herrschaft an sich zu reißen und auszuüben, wenn sie das um militärischer, wirtschaftlicher und politischer Interessen willen für notwendig hielten. Doch handelte es sich bei ihnen im Grunde um widerwillige Herren. Mit Begriffen wie „Herrenvolk“ oder „Herrenrasse" meldeten sie wohl auch den Anspruch auf Herrschaft über fremde Völker und Rassen an, vor allem aber begründeten sie damit das Recht auf die Eroberung von Raum. Im März 1941 z.B. gab Hitler dem sogenannten Generalgouverneur Hans Frank den Befehl, das in Polen geschaffene Generalgouvernement nicht nur ,judenfrei“, sondern in einem etwas längeren Prozeß auch „polenfrei“ zu machen. Stetes Wachstum des Volks- und Rassenkörpers vor Augen, träumten Hitler und seine Gefolgsleute von einem Reich, das etwa im Jahre 2040 rund 250 Millionen Exemplaren der deutschen „Herrenrasse“ Platz bieten sollte ${ }^{585}$.

Mit anderen Worten: Im Zuge der Expansion des Deutschen Reiches mußte nationalsozialistischer Imperialismus, grundsätzlich gesehen, nicht Herrschaft bringen, sondern Vernichtung, jedenfalls da, wo er nicht auf germanische oder sogenannte artverwandte und mithin als einschmelzungsfähig geltende Völker stieß. In seiner nationalsozialistischen Entartung war also der deutsche Nationalismus, nachdem er die Fähigkeit zum Transport liberalisierender und demokratisierender Tendenzen ohnehin längst verloren hatte, am Ende auf den Hund des schieren Biologismus gekommen, und dieser biologistische Nationalismus gebar einen Imperialismus, der sich selbst nur noch als permanent fressende Wucherung an anderen Völkern und Staaten zu definieren vermochte. Daß die deutschen Armeen, als sie am 1. September 1939 um 4.45 Uhr die polnischen Grenzen überschritten, tatsächlich einer in solchem Sinne zu verstehenden Politik der Vernichtung Bahn brachen, sollte sich nicht erst im weiteren Verlauf des Krieges, sondern schon wenige Wochen nach den ersten Schüssen in der Dämmerung jenes Septembermorgens auf die schrecklichste Weise bewahrheiten.

585 L. Gruchmann, Der Zweite Weltkrieg. Kriegführung und Politik, in: Deutsche Geschichte seit dem Ersten Weltkrieg, Bd. II, S. 156. 